
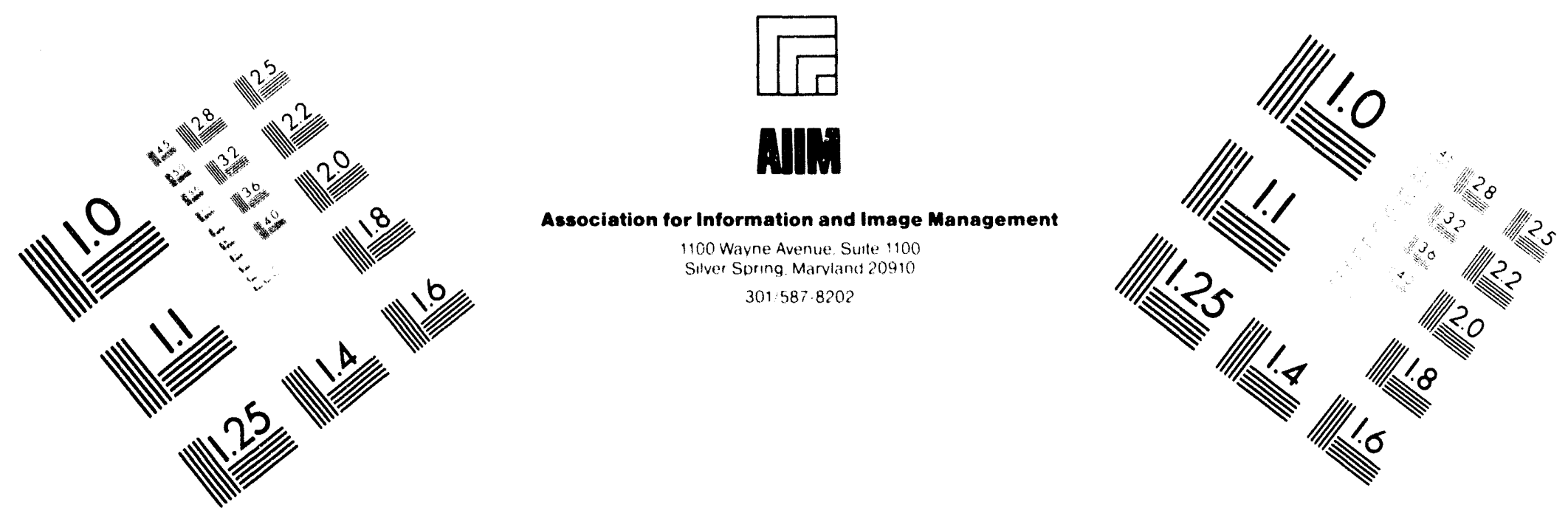

\title{
Centimeter
}

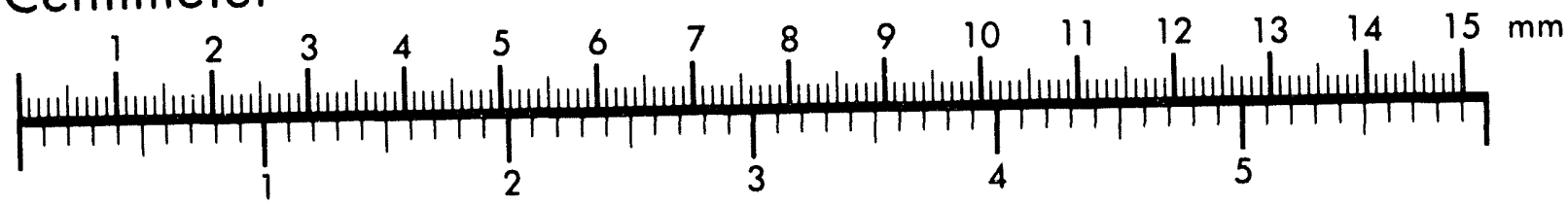
Inches
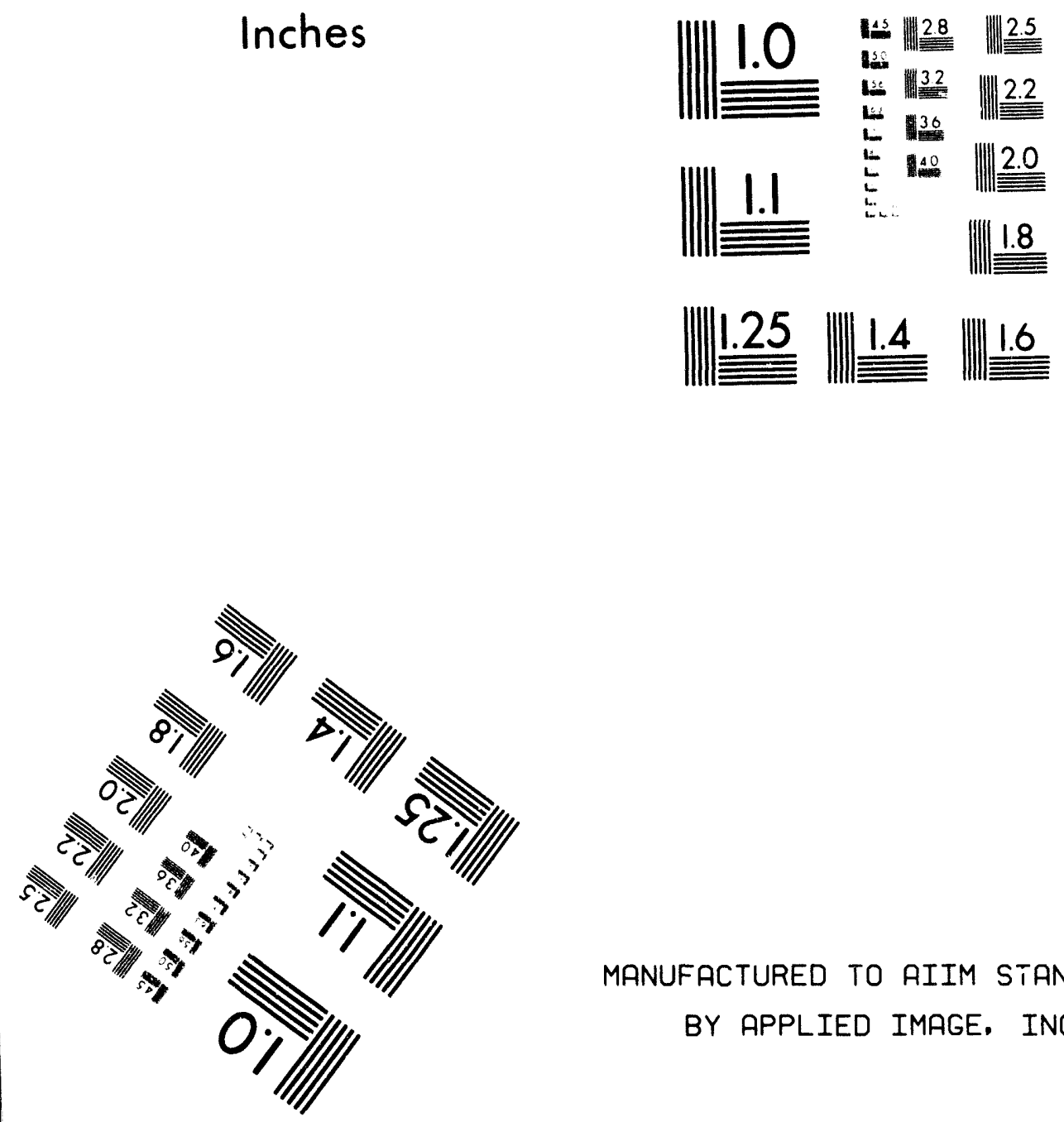

MANUFACTURED TO AIIM STANDARDS

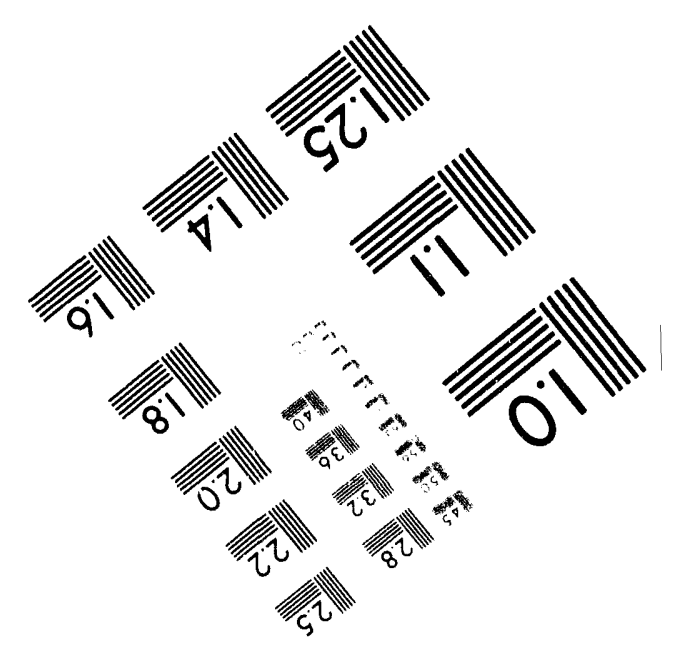



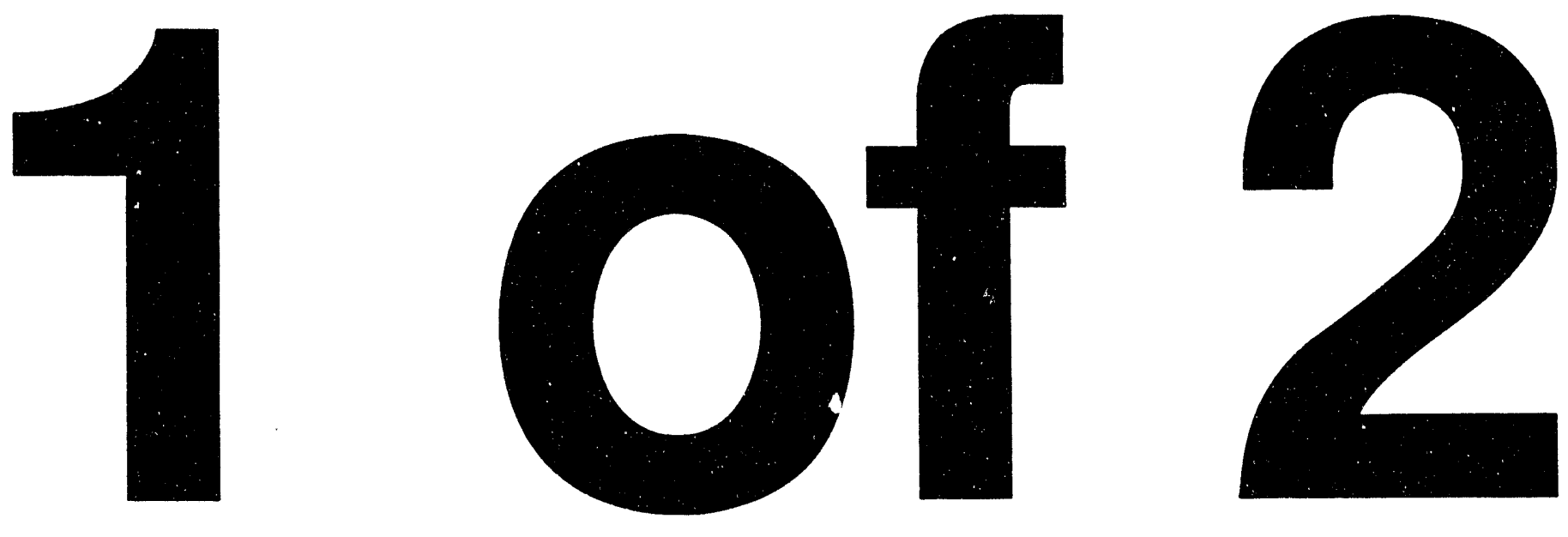


\section{Routine Environmental Audit of the Hanford Site Richland, Washington}

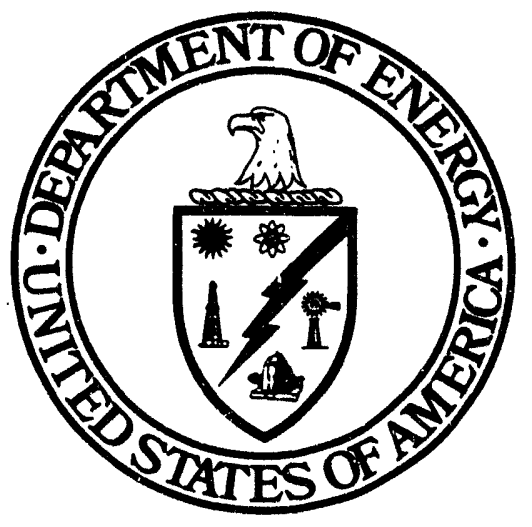

\section{U.S. Department of Energy Office of Environmental Audit Washington, DC 20585}

May 1994 
Page intentionally blank 
Page intentionally blank 


\author{
Preface \\ U.S. Department of Energy \\ Routine Environmental Audit \\ Conducted at \\ The Hanford Site \\ Richland, Washington
}

The Secretary of Energy's July 20, 1993, Environment, Safety, and Health Policy establishes daily excellence in the protection of the worker, the public, and the environment as the hallmark and highest priority of all DOE activities. That policy also calls for a proactive program of continuous improvement to move the Department beyond minimal cumpliance with standards. In furtherance of that policy, the Office of Environment, Safety and Health (EH) has established, as part of the internal oversight responsibilities within DOE, a program within the Office of Environmental Audit (EH-24) to conduct environmental assessments of DOE programs and operating facilities. The ultimate goal of this program is enhancement of environmental protection and minimization of risk to public health and the environment through systematic and periodic evaluations of the Department's environmental programs within line organizations.

Through its environmental evaluation program, which provides measurable goals with milestones, EH-24 is committed to helping establish the DOE as a model of responsible environmental stewardship. In addition, this program will serve to reinforce the Secretary's goal of building on the efforts currently ongoing to attain and maintain compliance in cooperation with the regulatory authorities and other affected stakeholders.

This document contains the findings identified during the Routine Environmental Audit of the Hanford Site, Richland, Washington, conducted May 2-13,1994. The audit included a review of all Hanford operations and facilities supporting DOE-sponsored activities. The audit's objective is to advise the Secretary of Energy, through the Assistant Secretary for Environment, Safety and Health, as to the adequacy of the environmental protection programs established at Hanford to ensure the protection of the environment, and compliance with Federal, State, and DOE requirements.

May 1994

Washington, DC 
Page intentionally blank 


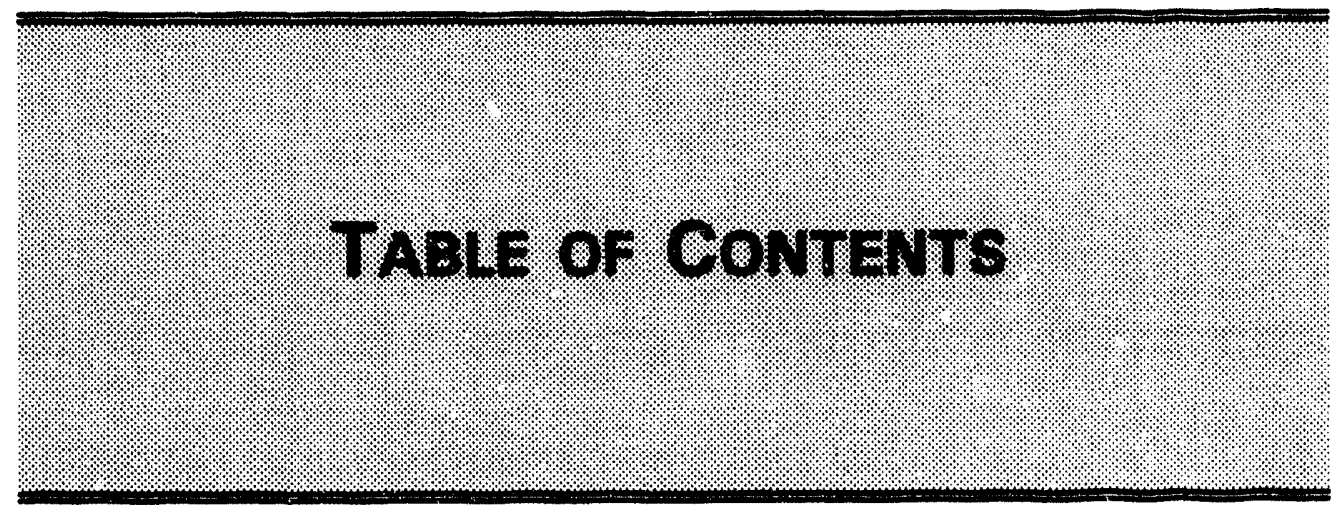


Page intentionally blank 
TABLE OF CONTENTS

PREFACE

EXECUTIVE SUMMARY

ES-1

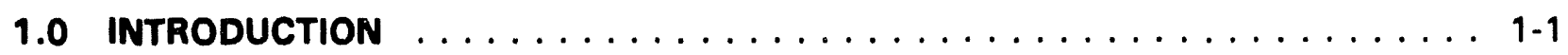

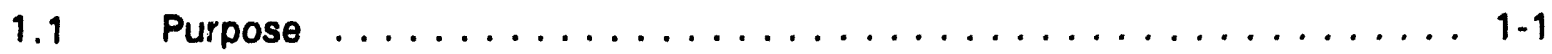

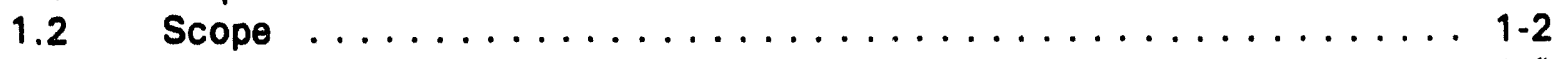

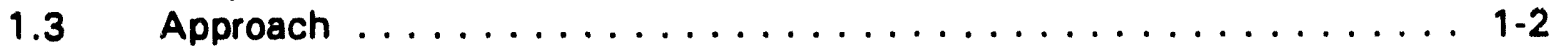

1.4 Background and Project Description . . . . . . . . . . . . . . 1-4

2.0 SUMMARY OF ROUTINE ENVIRONMENTAL AUDIT RESULTS $\ldots \ldots \ldots \ldots$

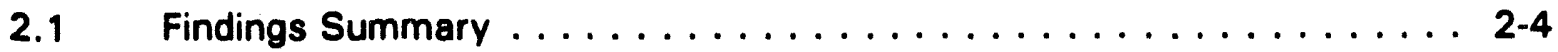

2.2 Key Findings ........................

3.0 ENVIRONMENTAL AUDIT OVERVIEWS AND FINDINGS $\ldots \ldots \ldots \ldots \ldots \ldots$

3.1 Organizational Structure (OS) $\ldots \ldots \ldots \ldots \ldots \ldots \ldots \ldots$

3.1.1 Overview ....................

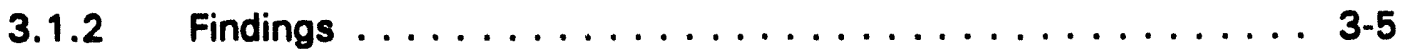

3.2 Environmental Commitment (EC) $\ldots \ldots \ldots \ldots \ldots \ldots \ldots \ldots \ldots$

3.2.1 Overview ...................... 3.13

3.2.2 Finding ........................ $3 . \ldots \ldots$

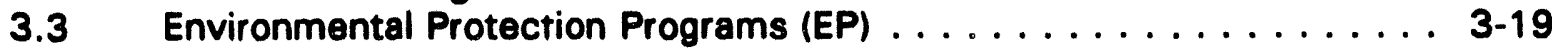

3.3.1 Overview ...................... 3-19

3.3.2 Finding . . . . . . . . . . . . . . . . . . 3-26

3.3.3 Technical Assessment . . . . . . . . . . . . . . . . 3-29

3.3.3.1 Groundwater/Surface Water Monitoring . . . . . 3-29

3.3.3.1.1 Overview . . . . . . . . . . 3-29

3.3.3.1.2 Findings . . . . . . . . . 3-35

3.4 Formality of Environmental Programis (FP) . . . . . . . . . . . 3-43

3.4.1 Overview ....................... 3.43

3.4.2 Finding . . . . . . . . . . . . . . . . . . 3-46

3.5 Internal and External Communication (IC) . . . . . . . . . . 3-49

3.5.1 Overview ....................... 3-49

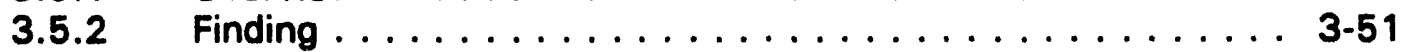

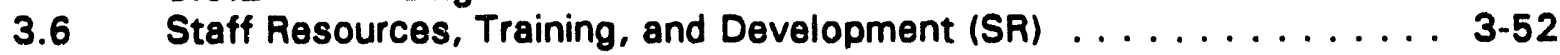

3.6.1 Overview ........................ 3.52

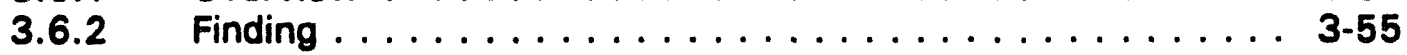

3.7 Program Evaluation, Reporting, and Corrective Action (PE . . . . . . 3-57

3.7.1 Overview ...................... 3-57

3.7.2 Finding ........................ 3-59

3.8 Environmental Planning and Risk Management (RM) . . . . . . . . . 3-62

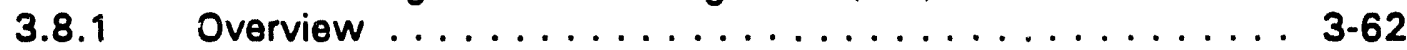

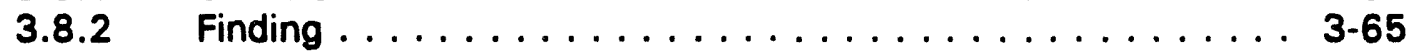




\section{LIST OF FIGURES}

Figure 1-1

Figure $1-2$

Figure 1-3

Regional Setting of Hanford $\ldots \ldots \ldots \ldots \ldots \ldots \ldots \ldots \ldots$ 1-5

Hanford Site Map . . . . . . . . . . . . . . . . . . . . . . 1-6

U.S. Department of Energy Richland Operations

Office Organizational Chart . . . . . . . . . . . . . . . . . 1-8

Figure 1-4

Westinghouse Hanford Company Organizational Chart . . . . . . . . . . 1-9

Figure 1-5

Pacific Northwest Laboratory Organizational Chart

$1-10$

\section{LIST OF TABLES}

Table 2-1 Routine Environmental Audit Team Findings $\ldots \ldots \ldots \ldots \ldots$

\section{LIST OF APPENDICES}

Appendix A Biographical Sketches of the Audit Team $\ldots \ldots \ldots \ldots \ldots \ldots \ldots$

Appendix $B$ Audit Plan ................................ B-1

Appendix C Site Documents Reviewed by the Audit Team . . . . . . . . . . . . C C-1

Appendix D Contacts and Interviews Conducted by the Audit Team . . . . . . . . . D-1

Appendix E Regulations, Requirements, and Guidelines

Used in Evaluating the Hanford Site . . . . . . . . . . . . . . . . E-1

Appendix $F \quad$ Glossary of Acronyms and Abbreviations $\ldots \ldots \ldots \ldots \ldots \ldots \ldots$ 


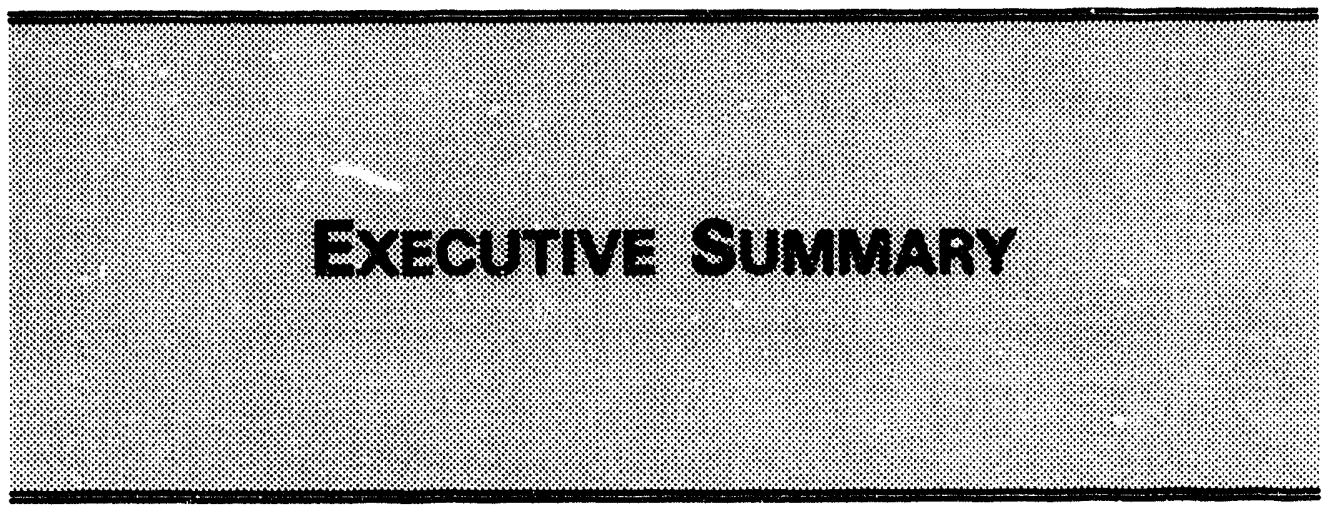


Page intentionally blank 


\section{EXECUTIVE SUMMARY}

This report documents the results of the routine environmental audit of the Hanford Site (Hanford), Richland, Washington. During this audit, the activities conducted by the audit team included reviews of internal documents and reports from previous audits and assessments; interviews with U.S. Department of Energy (DOE), State of Washington regulatory, and contractor personnel; and inspections and observations of selected facilities and operations. The onsite portion of the audit was conducted May 2-13, 1994, by the DOE Office of Environmental Audit (EH-24), located within the Office of Environment, Safety and Health (EH).

DOE 5482.1B, "Environment, Safety, and Health Appraisal Program," establishes the mission of EH-24 to provide comprehensive, independent oversight of Department-wide environmental programs on behalf of the Secretary of Energy. The ultimate goal of EH-24 is enhancement of environmental protection and minimization of risk to putlic health and the environment. EH-24 accomplishes its mission by conducting systematic and periodic evaluations of the Department's environmental programs within line organizations, and by using supplemental activities that strengthen self-assessment and oversight functions within program, field, and contractor organizations.

The audit evaluated the status of programs to ensure compliance with Federal, State, and local environmental laws and regulations; compliance with DOE Orders, guidance, and directives; and conformance with accepted industry practices and standards of performance. The audit also evaluated the status and adequacy of the management systems developed to address environmental requirements.

The audit's functional scope was comprehensive and included all areas of environmental managemunt and a programmatic evaluation of the groundwater and surface water monitoring programs. Although the audit was designed to be thorough and to consider a representative sample of Hanford's environmental activities and programs, it was not intended to be exhaustive in scope. Instead, it was meant to provide DOE organizations, including the Secretary, with an indication of the status of Hanford management's effectiveness in achieving its mission in an environmentally responsible manner.

In a precedent-setting move, EH-24 met with Richland Operations Office (RL), Westinghouse Hanford Company (WHC), and Pacific Northwest Laboratory (PNL) senior managernent approximately one month before the formal Hanford pre-audit site briefing. In an open forum, the Hanford managers were provided the opportunity to present their recommendations for management systems and programmatic areas of audit concentration in order to provide them with the optimum return for their investment of time and resources. This innovative technique resulted in the establishment of an atmosphere of mutual trust and respect which carried over into the actual audit. It reinforces EH-24's position that all audits it conducts are collaborative efforts, in which the audit team works together with the site to identify areas needing improvement. This process strives to take the site beyond mere environmental compliance, seeking to achieve the ultimate goal of environmental excellence.

The audit team identified 12 findings, of which 10 were in the environmental management systems area and 2 were related to groundwater monitoring. An evaluation of these findings resulted in the identification of two "key findings": 
Environmental Program Integration - There is inadequate integration and/or coordination of many environmental management activities among the contractors and RL.

Hanford has multiple contractors with their own functions and objectives. Crosscommunication between these activities usually is conducted on an informal basis, with inconsistent results. Formal integration plans generally are absent. For example: there is no sitewide environmental as low as reasonably achievable (ALARA) program, although pieces of one exist in various organizations; a wide variety of monitoring functions are conducted by many parties, often informally coordinated, but without a sitewide plan for coordination of these activities; and a variety of self-assessment and oversight activities are conducted and tracked in several systems without adequate coordination. These issues, among others, are being addressed by RL top management in the current reorganization pianning.

Program Oversight and Control - There is inadequate oversight and control of the Hanford environmental program by RL.

Primarily due to resource constraints and organizational issues, $R L$ is not adequately overseeing contractor environmental operations to ensure efficient pursuit of compliance with requirements and, ultimately, environmental excellence. RL is not providing sufficient guidance and direction, oversight, direct involvement in environmental issues, or self-assessment. The primary causes appear to be lack of staff resources and somewhat unclear roles and responsibilities. The former is being addressed with a significant infusion of full-time-equivalent (FTE) employees, and the latter with planned organizational changes.

While these issues present big challenges, they also provide excellent opportunities to make the changes that will make environmental excellence a reality. These issues are addressed in greater detail in Section 3.

The audit team identified the following strengths in Hanford's environmental management programs:

- Employee Concern Program - RL's Employee Concern Program addresses all concerns that are submitted. Concerns are directed to the highest level of management necessary in order to conduct an adequate investigation. This program has been used as a model for programs at several other DOE facilities including the Savannah River Plant, and the Albuquerque, Oak Ridge, and Nevada Operations Offices.

- External Communication - The external communication activities at Hanford are very impressive. Public interest groups have been kept informed about the remediation processes at Hanford through publications such as Hanford Today and through the use of videotapes addressing the remedial activities at Hanford as well as the natural resources and cultural resources heritage of the site.

- Waste Reduction and Recycling Initiatives - WHC, PNL and the Hanford Environmental Health Foundation exhibit a commitment to environmental protection demonstrated by their waste reduction and recycling programs. 
- Radioactive and Mixed Waste - Overall, the radioactive and mixed waste program at WHC is strong. The site has met the criteria for exclusion from the mixed waste moratorium, and currently is completing construction of the first DOE Resource Conservation and Recovery Act (RCRA-) compliant mixed waste disposal trench lequipped with liners, leachate collection, holding tanks, etc.). The solid waste management group actively audits generators against waste acceptance criteria.

- Environmental Remediation/Decontamination and Decommissioning (D\&D) Activity - The environmental remediation and D\&D programs appear to be well managed and proactive in stabilizing radiologically contaminated areas.

- Quality of WHC's Formal Documentation - WHC's goals to maintain an exceptionally high quality of formal documentation, both in procedures and quality assurance, was, in the estimation of the audit team, among the best in DOE complex.

- $\quad$ Quality Improvement Initiatives - PNL has initiated proactive quality assurance activities and the Process Quality Department has been working closely with project managers to initiate process improvement activities.

- Radiological Emergency Responsn - WHC has developed a model technical approach for radiological emergency response.

Overall, Hanford has been effective, to varying degrees, in addressing the myriad environmental issues and responsibilities it faces. This is a challenging period for Hanford, since it is transitioning from a defense program mission to one of environmental remediation. Although some deficiencies were observed by the audit team in environmental management and environmental compliance, the general consensus of the audit team was that top management of RL, WHC, and PNL have committed themselves and their organizations to resolving the organizational, management, and resource issues affecting the program. 
Page intentionally blank

ES-4 


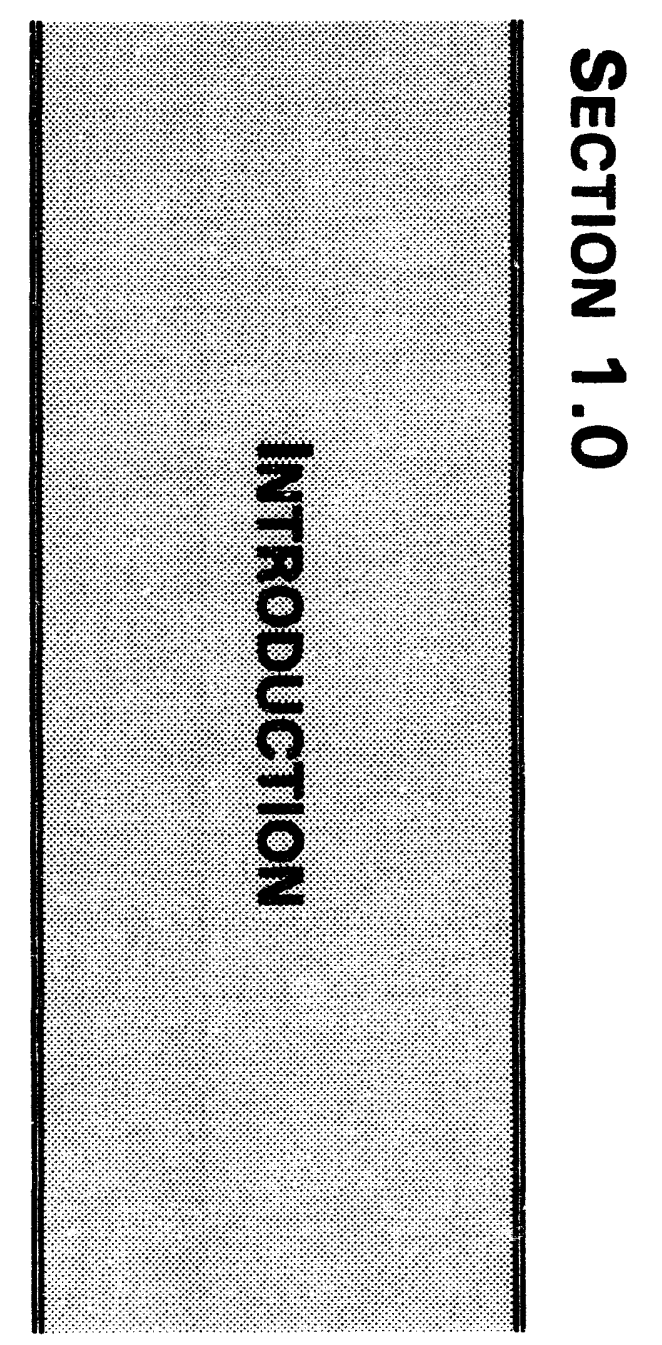


Page intentionally blank 


\section{0}

INTRODUCTION

This report documents the results of the routine environmental audit of the Hanford Site (Hanford), located near the Tri-Cities area of southeastern Washington State. The onsite portion of the audit was conducted May 2-13, 1994, by the DOE Office of Environmental Audit (EH-24).

DOE 5482.1B, "Environment, Safety, and Health Appraisal Program," establishes the mission of EH-24, which is to provide comprehensive, independent oversight of DOE complex-wide environmental programs on behalf of the Secretary of Energy. The ultimate goal of EH-24 is to enhance environmental protection and minimize risk to public health and the environment. EH-24 accomplishes its mission by conducting systematic and periodic evaluations of the Department's environmental programs within line organizations. The Department also uses supplemental activities to strengthen self-assessment and oversight functions within program, field, and contractor organizations.

These evaluations function as a vehicle to apprise the Secretary and program managers of the current status and vulnerabilities of Departmental environmental activities and environmental management systems. Several types of evaluations are conducted, including:

- comprehensive baseline environmental audits;

- routine environmental audits;

- environmental management assessments; and

- $\quad$ special issue reviews.

The purpose, scope, and approach of the routine environmental audit of Hanford are described below.

\section{$1.1 \quad$ PURPOSE}

The purpose of the routine environmental audit of Hanford was to provide the Secretary of Energy, through the Assistant Secretary for Environment, Safety and Health, with concise information pertaining to the following areas:

- The adequacy of environmental management programs and organizations;

- DOE vulnerabilities and liabilities associated with environmental management practices;

- Compliance with environmental laws and regulations, DOE Orders, and DOE environmental policies (as identified in Appendix E) that address environmental management programs;

- Adherence to best management (and accepted industry) practices pertaining to environmental management programs; 

the 1990 Tiger Team Assessment; and

Noteworthy environmental management practices.

The information gathered during this audit and embodied in this report will assist DOE in determining patterns and trends in environmental deficiencies and strengths. The Assistant Secretary for Environmental Management, the directors of the Offices of Energy Research and Laboratory Management, and DOE Richland Operations Office (RL), are expected to use this information to develop corrective actions; to identify root causes; to make appropriate modifications to specific programs to prevent recurrence; and to implement lessons-learned programs to ensure broad applications to other operations, programs, and facilities.

\subsection{SCOPE}

The scope of the audit included the eight environmental management disciplines described in Protocols for Conducting Environmental Management Assessments (DOE/EH-0326), and a programmatic assessment of the groundwater and surface water monitoring programs. The management disciplines were organizational structure (OS); environmental commitment (EC); environmental protection programs (EP); formality of environmental programs (FP); internal and external communication (IC); staff resources, training, and development (SR); program evaluation, reporting, and corrective action (PE); and environmental planning and risk management (RM).

Environmental management was evaluated within and among RL, Westinghouse Hanford Company (WHC), and Pacific Northwest Laboratory (PNL). In addition, a limited review of the environmental management programs of ICF Kaiser Hanford Company (ICF KH) and Hanford Environmental Health Foundation (HEHF) was conducted. One Hanford environmental program omitted from the scope of this audit was the Tank Waste Remediation System. This omission was due primarily to the significant involvement of EH-24 in the Hanford Tank Farm Mentoring Program.

\subsection{APPROACH}

The routine environmental audit was conducted in accordance with the DOE Environmental Audit Program Guidance (January 1994 Draft Final), Protocols for Conducting Environmental Management Assessments of DOE Organizations (DOE/EH-0326), and Performance Objectives and Criteria for Conducting DOE Environmental Audits (DOE/EH-0358). Accepted assessment techniques were followed.

The audit was conducted by a team of professionals managed by a DOE Headquarters Team Leader and Deputy Team Leader from EH-24, and staffed by technical and administrative support contractor personnel. The names, areas of responsibility, affiliations, and biographical sketches of the team members are provided in Appendix A. The audit included three phases: planning, conducting onsite activities, and reporting.

As part of the planning phase, a memorandum was sent to Hanford announcing the audit and requesting information about Hanford management systems and selected 
environmental programs. A pre-audit site visit was conducted April 7, 1994. The site's response to the information requested, combined with the pre-audit site visit information, formed the basis for the "Plan for the DOE Routine Environmental Audit of the Hanford Site" (see Appendix B), which included a preliminary schedule for onsite activities. The audit team modified the preliminary schedule during the onsite activities as more information was obtained and additional areas of interest were identified.

Onsite audit activities included interviews with RL personnel, contractor employees, and State regulators; document reviews (including previous audit and self-assessment reports); and observations of actual environmental management activities or operations. The audit team conducted daily debriefs that were attended by RL and contractor personnel. Using information from site observations, document reviews, and interviews, the audit team developed findings, as discussed in Sections 2.0 and 3.0 of this report. Lists of site documents reviewed and interviews performed are provided in Appendices $C$ and $D$, respectively.

Deficiencies identified by the audit team were categorized as findings. Findings are conditions that, in the judgment of the team, may not satisfy one or more of the following: environmental regulations; DOE Orders; Consent Agreements with regulatory agencies; environmental permit conditions; DOE or contractor environmental policies ar.d procedures; regulatory agency guidance; accepted industry practices or technical standards; DOE guidance; and/or best management practices.

Overviews and findings are detailed in Section $\mathbf{3 . 0}$ and are organized into the eight environmental management disciplines, as identified in Section 1.2 of the Introduction. The overview and findings that address groundwater and surface water monitoring are found in the environmental protection programs (EP) discipline. Each finding is organized into three sections: the performance objective, the finding statement, and a discussion of the facts and observations supporting the finding. The performance objectives specify the particular standards against which the finding is being evaluated. The findings are not arranged in order of relative significance.

When documenting environmental management and specific environmental compliance concerns in the report, the concern is called a "finding." No other terms are used. The bases for specific environmental compliance findings usually are non-compliance with a regulatory or agency-related requirement, and/or non-adherence to a good industrial practice. Such terms as "compliance findings" and "best management practice findings" usually are associated with these concerns. Further, these two terms are found in the context of environmental compliance audits, rather than environmental management assessments. On the other hand, the bases for environmental management findings usually are associated with voluntary standards that are designed to achieve environmental excellence, thus going beyond the minimum standard for environmental compliance.

Since the management findings usually are associated with management practices rather than environmental requirements, the use of the terms "compliance finding" or "best management practice" would serve only to diminish the importance of any management finding. Hence, when developing a corrective action plan with schedules and milestones, each management- related finding should be addressed as though it were at least as important, if not more important, than a specific compliance-related finding. This is because the management principles, when effectively developed and employed, can ensure 
that line organizations across entire facilities achieve sustained excellence in overall environmental performance.

\section{4}

\section{BACKGROUND AND PROJECT DESCRIPTION}

Hanford occupies 560 square miles of semi-arid desert in southeastern Washington State. This land area, with restricted public access, provides a buffer for the smaller areas used for operations, waste storage, and waste disposal. The Columbia River flows through the northern part of the site, and, turning south, it forms part of the eastern boundary. The Yakima River runs along part of the southern boundary and joins the Columbia River near the city of Richland. Adjoining areas to the west, north, and east are principally range and agricultural lands that include vineyards, orchards, and both dry and irrigated farms. Immediately southeast of the site, the cities of Richland, Kennewick, and Pasco (often called the Tri-Cities) comprise the nearest population center, with about 150,000 residents. Figure 1-1 shows the regional setting of Hanford. Figure 1-2 is the Hanford site map.

Hanford was chosen for the Manhattan Project in 1943 to produce plutonium for the world's first nuclear weapons. An important factor in the original selection of Hanford was the presence of the Columbia River, which could provide the large volumes of water needed to cool nuclear reactors. Although defense production has been a prime mission of Hanford for most of its existence, the mission has changed over the years. Today, there are virtually no production activities. The focus has been shifted to environmental cleanup and remediation; scientific and environmental research; development and application of radioactive and hazardous waste management technology; and the design, construction, and operation of major energy-related test and development facilities.

As a result of Hanford operations, the Columbia River is one of the most studied rivers in the world. Routine monitoring began in 1945, shortly after the start-up of the original production reactors. River water and sediments are collected from a number of locations and water from selected riverbank springs (seeps) is also sampled. Samples of various species of wildife (e.g., fish, clams, and waterfowl) are routinely collected. Local agricultural products that are irrigated with river water downstream of Hanford (e.g., alfalfa, wheat, apples, and cherries), and wine produced from locally grown grapes and milk from local dairy farms also are routinely sampled. Results of these sampling activities are summarized annually in the Annual Site Environmental Report.

In 1991, as a reflection of its changing mission, management responsibility for Hanford was transferred from the Office of Defense Programs (DP) to the Office of Environmental Restoration and Waste Management (EM). This office has undergone reorganization and is today the Office of Environmental Management, with Environmental Restoration and Waste Management being offices in the new organization. In addition, the Offices of Energy Research and Laboratory Management have management responsibility for PNL. Day-today oversight and program management of Hanford is performed by RL, which currently has a staff of 421 people.

In addition to the routine DOE contractor monitoring and surveillance programs, other nonDOE programs perform environmental surveillance at Hanford. Both the Washington public Power Supply System, which operates an electrical power generating reactor on land leased by the State from DOE, and U.S. Ecology, Inc., which operates a nuclear waste 


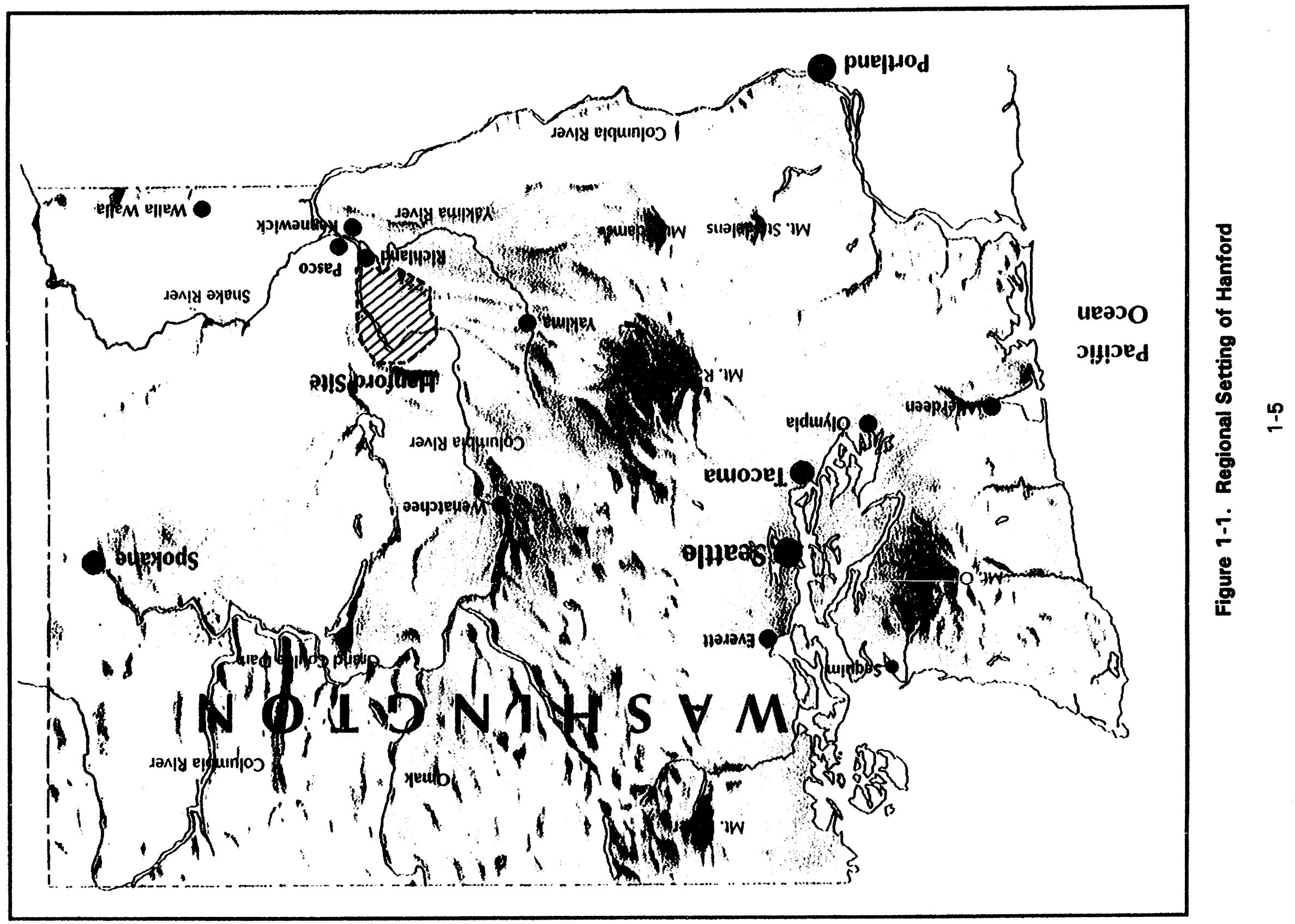




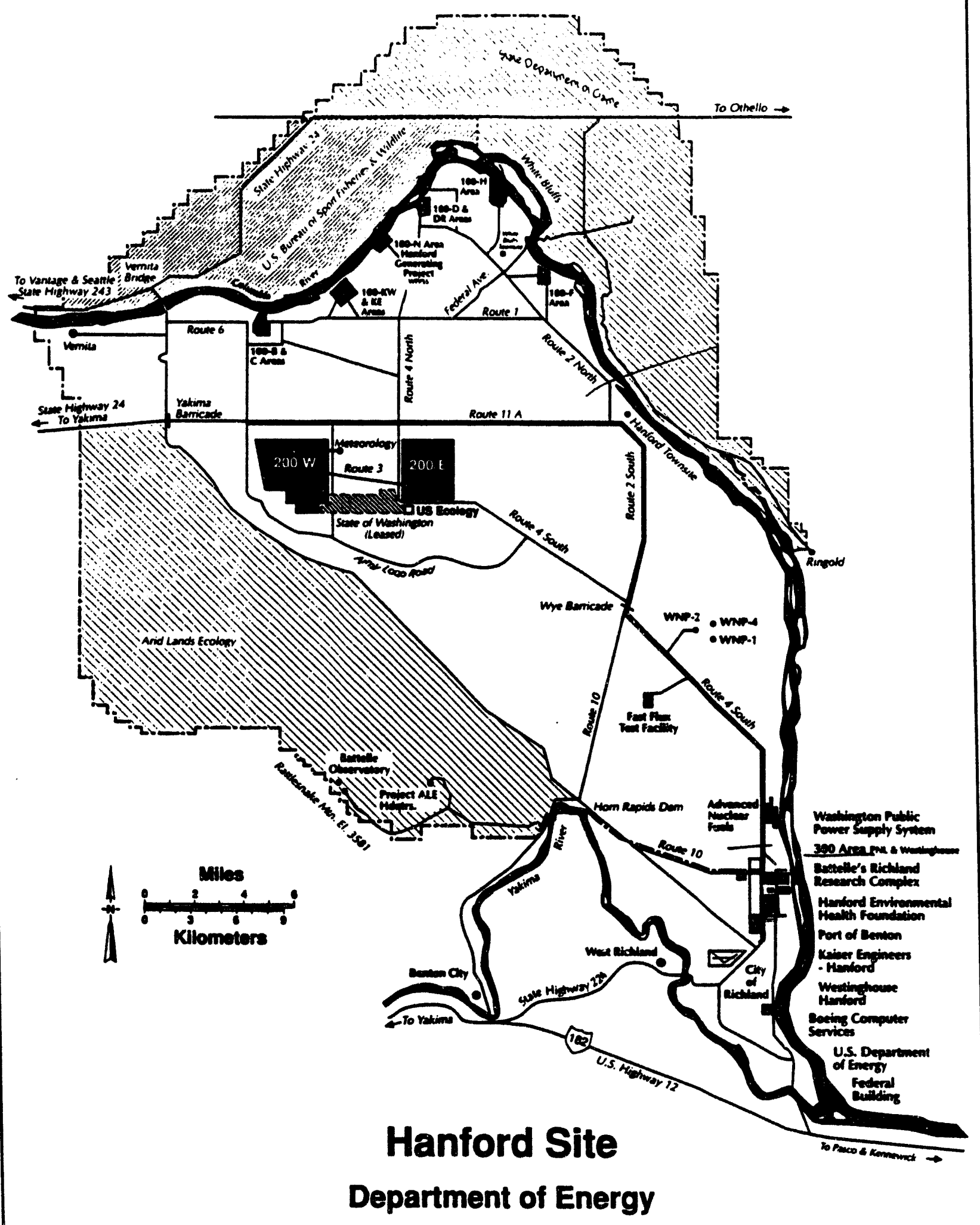

Figure 1-2. Hanford Site Map 
disposal site on land leased by the State from DOE, perform environmental surveillance to assure compliance with the U.S. Nuclear Regulatory Commission and Washington State Department of Health (WDOH) regulations. WDOH also performs an environmental monitoring and surveillance program at Hanford which includes collocated sampling, split sampling, and compliance sampling with both DOE and non-DOE programs.

The Hanford Site currently employs a total work force of approximately 18,000 people. The RL organization includes support and line organizations responsible for the oversight and management of the site contractors. WHC is the management and operating concractor for the site, and manages its own subcontractors, including ICF KH, a contractor that has assumed significant facility management and support roles in addition to its construction responsibility. WHC leads the site's environmental cleanup and environmental remediation activities under the Tri-Party Agreement between the Environmental Protection Agency, the Washington State Department of Ecology, and DOE. Battelle Memorial Institute operates PNL, a multi-program national laboratory and research and development center for the site. PNL's missions are to advance science and to rapidly develop and deploy technology. Hanford Environmental Health Foundation (HEHF) provides personnel health services in the fields of occupational medicine, behavioral sciences, and industrial hygiene for DOE and its Hanford contractors. Figures 1-3, 1-4, and 1-5 provide organizational charts for RL, WHC, and PNL, respectively. 


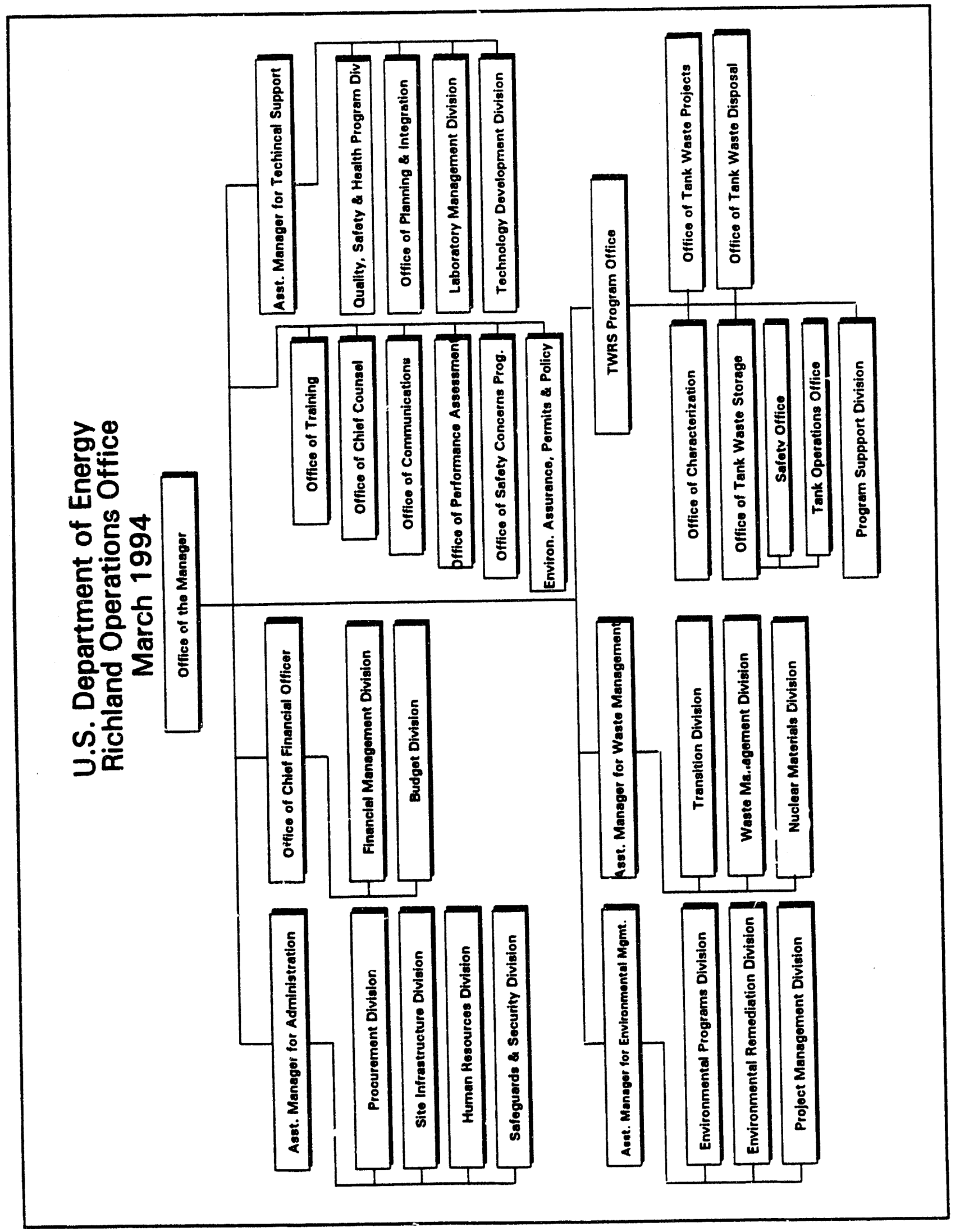

Figure 1-3. U.S. Department of Energy Richland Operations Office Organizational Chart 


\section{Westinghouse Hanford Company}

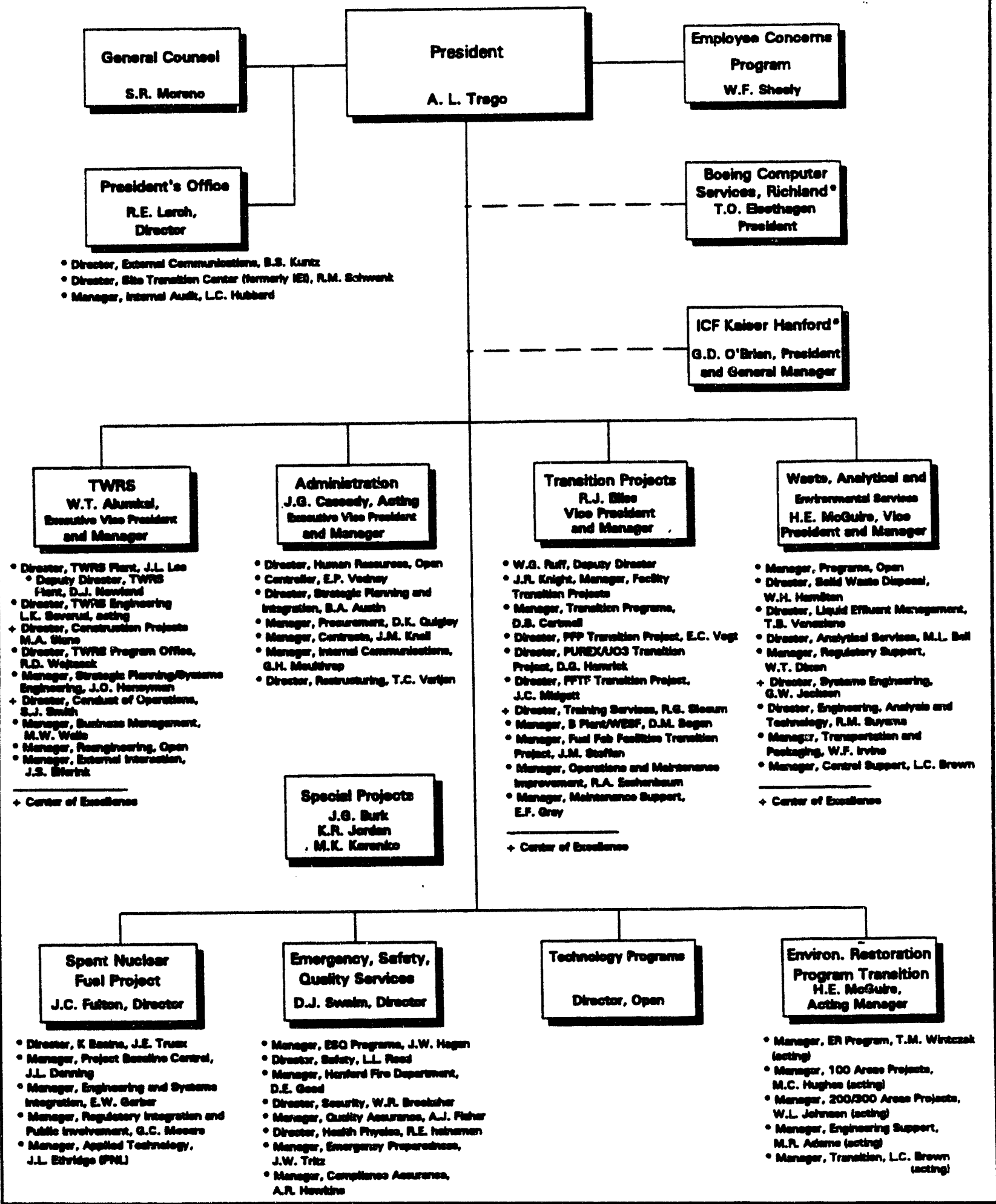

Figure 1-4. Westinghouse Hanford Company Organizational Chart 


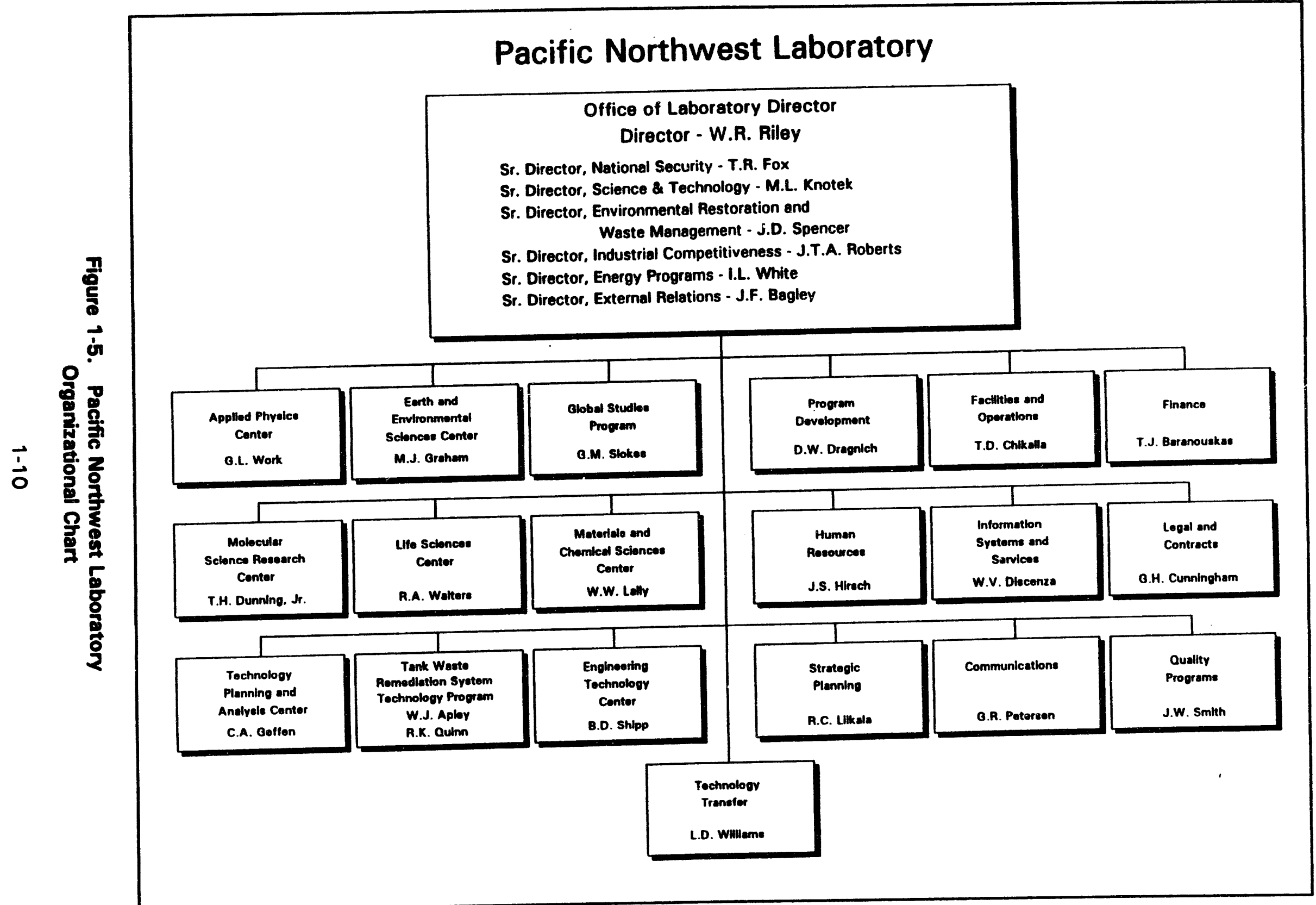




\section{Section 2.0}

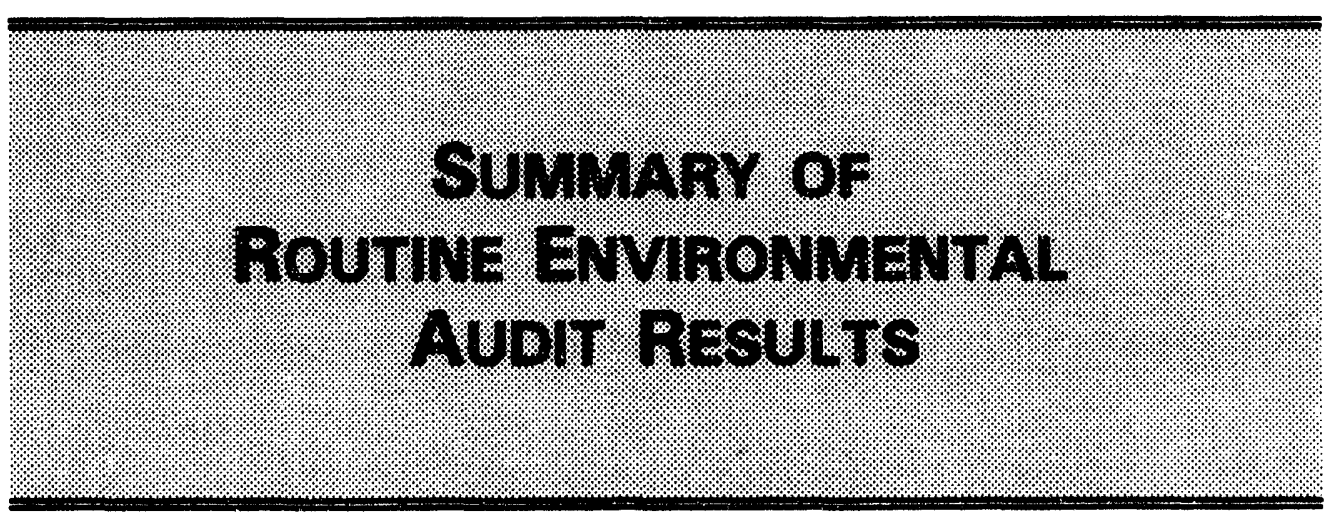


Page intentionally blank 
The following summarizes the results and conclusions of the routine environmental audit of the Hanford Site (Hanford) conducted May 2-13, 1994.

The focus of this audit was to have been a standard follow-on to the Environmental Survey (1988), the Tiger Team Assessment (1990), and the Environment, Safety and Health (ES\&H) Progress Assessment (1992). However, the transition from the Office of Defense Programs (DP) to the Office of Environmental Management (EM), with the accompanying change to the Hanford mission, made it more logical for this audit to consider the new mission in concert with the activities that occurred under the old mission. Relevant issues identified during the previous assessments were also considered. In addition, this audit emphasized the environmental management assessment approach developed by the Office of Environmental Audit (EH-24).

Overall, Hanford has been effective, to varying degrees, in addressing the myriad erivironmental issues and responsibilities facing them. Although this audit revealed some environmental management and compliance deficiencies, the audit team observed extensive effort at all levels toward resolving the organizational, management, and resource issues affecting the program.

During the audit, 12 findings were identified, 10 of which were in management systems disciplines. Two were in the groundwater monitoring technical discipline. The finding numbers and titles are presented in Table 2-1.

The audit team identified a number of strengths in the environmental program at Hanford. The following areas represent pockets of excellence within the overall program.

- Employee Concern Program - The Employee Concern Program addresses all concerns that are submitted. Concerns are directed to the highest level of management necessary to adequately investigate the issue. The Hanford Environmental Concern Program has been used as the model for programs at a number of DOE sites (e.g., the Savannah River Plant and the Albuquerque, Oak Ridge, and Nevada Operations Offices).

- External Communication - Hanford has undertaken a number of initiatives in the area of external communication, including the production of three videotapes relevant to the relationship between the site and the surrounding communities. The latest, relating to Native American heritage, was reviewed by the local tribes during production. Pacific Northwest Laboratory (PNL) has been providing a large amount of site information to school teachers throughout the state, and is currently developing a teaching guide to accompany the videos.

The Public Outreach Program, including such publications as Hanford Today. has been successful to the extent that several of the public interest groups have opted not to request hearings on recent Environmental Impact Statements. When hearings are held, they are now are participative rather than unidirectional. The Hanford communications organizations continue to seek innovative ways to publicize Hanford activities. The Washington State 
Table 2-1

ROUTINE ENVIRONMENTAL AUDIT TEAM FINDINGS

\begin{tabular}{|c|c|c|}
\hline 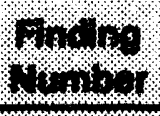 & The of Finting & Pape \\
\hline \multicolumn{3}{|c|}{ 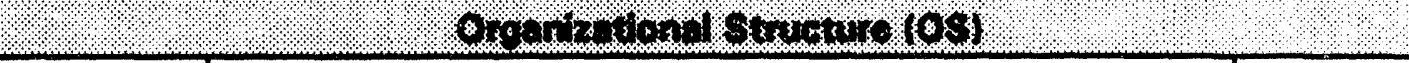 } \\
\hline OS-1 & $\begin{array}{l}\text { RL Organizational Structure and Roles and } \\
\text { Responsibilities }\end{array}$ & 3-5 \\
\hline $0 S-2$ & PNL Analytical Support Services Project & 3-8 \\
\hline OS-3 & $\begin{array}{l}\text { Integration of Environmental Protection Programs and } \\
\text { Activities }\end{array}$ & 3-11 \\
\hline \multicolumn{3}{|c|}{ 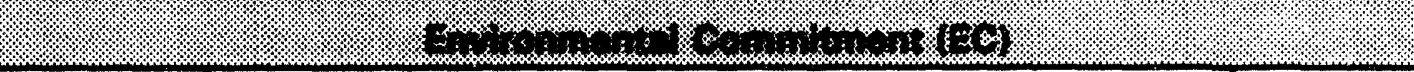 } \\
\hline EC-1 & Environmental Commitment & 3-16 \\
\hline \multicolumn{3}{|c|}{ 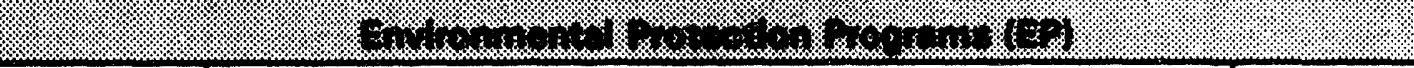 } \\
\hline EP-1 & Environmental ALARA Program & 3-26 \\
\hline EP-2 & Sitewide Groundwater Monitoring Program & 3-35 \\
\hline EP-3 & Groundwater Protection Management Program & 3.39 \\
\hline \multicolumn{3}{|c|}{ 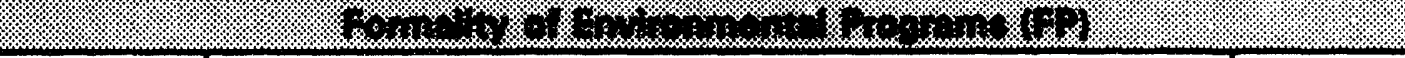 } \\
\hline FP-1 & Formality of Oversight Activities & $3-46$ \\
\hline \multicolumn{3}{|c|}{ (2) } \\
\hline IC-1 & Channels of Internal Communication & 3-51 \\
\hline \multicolumn{3}{|c|}{ 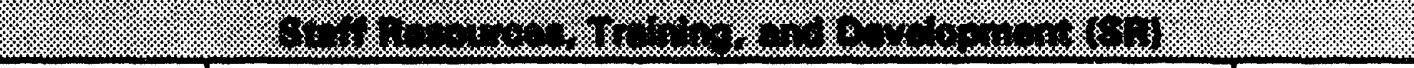 } \\
\hline SR-1 & RL Environmental Staff Resources & $3-55$ \\
\hline \multicolumn{3}{|c|}{ 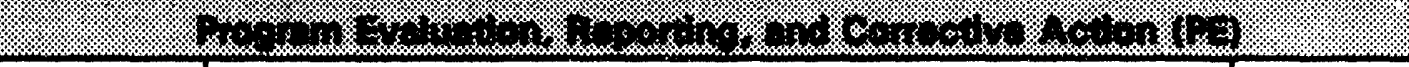 } \\
\hline PE-1 & Hanford Self-Assessment Program & $3-59$ \\
\hline \multicolumn{3}{|c|}{ 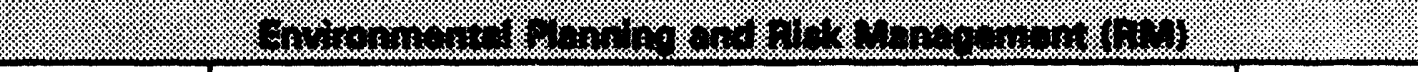 } \\
\hline RM-1 & Classification of Mixed Waste & $3-65$ \\
\hline
\end{tabular}


Department of Ecology (WDOE) also has lauded an overall opening-up and sharing of information by the site.

Waste Reduction and Recycling Initiatives - WHC has prevented 530,000 liters of liquid chemicals and 120,000 kilograms of solid chemicals from becoming waste. In addition, WHC recycles cardboard, office paper, scrap metals, antifreeze, gel cell, lead acid batteries, etc. Hanford Environmental Health Foundation (HEHF) has reduced ozone-depleting chemical purchases by two-thirds ( 35 kilograms per year to 10 kilograms per year) through redistillation. The PNL Poilution Prevention Program recycles unopened and opened chemicals to other laboratory centers within PNL, thus reducing chemical purchases and disposal. Similar programs are being initiated in other areas at the site.

- Radioactive and Mixed Waste - Overall, the radioactive and mixed waste program at Westinghouse Hanford Company (WHC) is strong. The site has met the criteria for exclusion from the mixed waste moratorium, and currently is completing construction of the first DOE Resource Conservation and Recovery Act (RCRA-) compliant mixed waste disposal trench (equipped with liners, leachate collection, holding tanks, etc.). The solid waste management group actively audits generators against waste acceptance criteria.

Environmental Remediation/Decontamination and Decommissioning (D\&D) Activity - The environmental remediation and D\&D programs appear to be proactive with regard to stabilization of radiologically contaminated areas (e.g., cribs, ponds, and inactive waste sites).

- Quality of WHC's Formal Documentation - The quality of the formal documentation of environmental programs within WHC, in terms of both procedures and quality assurance, was deemed by the audit team to be among the best in the DOE complex.

- Quality Improvement Initiatives - PNL has initiated proactive quality assurance activities and the Process Quality Department has been working closely with project managers to initiate process improvement activities. For example, in the Groundwater Surveillance Project, the project manager and the Process Quality Department have started efforts to develop streamlined, cost-effective data management processes.

Radiological Emergency Responses - WHC has developed a "model" approach for radiological emergency response. The approach involves a hazard assessment of each facility with a source term inventory determination, accident scenario development, offsite dose calculation for worst-case releases, and plotting of those doses versus distance for emergency zone delineation and protective action guide response. The results of these efforts are summarized by facility and printed on laminated tabletop cards for first responders. Emergency response authority is well defined, and facilities and support equipment are provided. Tabletop scenarios are drilled monthly and field exercises are drilled quarterly. This 
emergency response plan has been shared with other DOE facilities (e.g., Fernald Environmental Management Project and the Savannah River Plant).

\section{$2.1 \quad$ FINDINGS SUMMARY}

The following paragraphs briefly describe the findings in management systems and the technical discipline discussed in the Hanford Site Routine Environmental Audit Report. Full details for each discipline are found in the overviews and findings in Section 3 of this report.

Oraanization Structure (OS). There were three findings in this portion of the audit. The first pertains to unclear organizational roles, responsibilities, and authority at Hanford; the second relates to difficulties in resolving routine data validation issues in the Hanford monitoring programs as a result of organizational issues within the PNL Analytical Support Services Project; and the third relates to insufficient integration of environmental programs and activities. The overview of this discipline is found in Section 3.1.1.

Environmental Commitment (EC). There was one finding in this portion of the audit, pertaining to top management's not having presented definitive indicators of a full commitment to environmental excellence. The overview of this discipline is found in Section 3.2.1.

Environmental Protection Proarams (EP). There was one finding identified in this portion of the audit, relating to the lack of a formal environmental as low as reasonably achievable (ALARA) program for comprehensive evaluations of Hanford activities and facilities, as required by DOE 5400.5. Parts of such a program exist within the various organizations at the site, but they have not been integrated into a complete program. The overview of this discipline is found in Section 3.3.1.

Groundwater/Surface Water Menitering. There were two findings in this portion of the audit. The first relates to the incomplete integration of the multiple groundwater monitoring programs at Hanford; the second pertains to the fact that some elements of the Hanford Groundwater Protection Management Program have not been fully implemented. Improvements in these areas have been noted since the May 1992 Progress Assessment, but the deficiencies have not yet been fully corrected. The overview of this discipline is found in Section 3.3.3.1.1.

Formality of Environmental Programs (FP). There was one finding in this portion of the audit. While overall formality of environmental programs at Hanford was deemed adequate, oversight was not sufficiently formal and consistent. This includes policies and procedures, findings and regulatory tracking, and field surveillance and documentation. The overview of this discipline is found in Section 3.4.1.

Internal and External Communication (IC). There was one finding in this portion of the audit, relating to deficiencies in internal communication which contribute to problems with required date reporting and communication of program rationale/strategy. There were no findings relating to external communication. The overview of this discipline is found in Section 3.5.1. 
Staff Resources. Training, and Development (SR). There was one finding identified in this portion of the audit, relating to the limitations placed on Richland Operations Office's (RL) oversight of Hanford sitewide environmental management by limited technical staff resources. A carefully placed infusion of new personnel authorized for RL is expected to provide some relief for this problem. The overview of this discipline is found in Section 3.6.1.

Program Evaluation, Reporting, and Corrective Action (PE). There was one finding identified in this portion of the audit, relating to the lack of a comprehensive, integrated self-assessment program. Such a program must involve such elements as program charters and implementation plans, comprehensive scope, performance objectives and criteria, and schedules. The program must include all levels of organization, avoid duplication and gaps, and promote a culture of accountability; it must ensure timely implementation of corrective action. The overview of this discipline is found in Section 3.7.1.

Environmental Planning and Risk Management (RM). There was one finding identified in this portion of the audit, pertaining to management of certain hazardous materials that are radioactively contaminated. The issues cited indicate that risk management is not uniformly applied. The overview of this discipline is found in Section 3.8.1.

KEY FINDINGS

A key finding is a group of observations relating to a single issue which, in the judgment of the audit team, is essential to understandirg the nature and scope of the environmental management deficiencies of the facility audited. The key findings are:

- Environmental Program Integration - There is inadequate integration and/or coordination of many environmental management activities among the contractors and RL.

Hanford has multiple contractors, each with its own functions and objectives. Cross-communication between these activities usually is conducted on an informal basis, with inconsistent results. Formal integration plans are generally absent. For example: There is no sitewide environmental ALARA program, although pieces of one exist in various organizations; a wide variety of monitoring functions are conducted by many parties, often informally coordinated, but without a sitewide plan; and a variety of self-assessment and oversight activities are conducted and tracked in several systems without adequate coordination. These issues, among others, are being addressed by top management in the current reorganization planning.

- Program Oversight and Control - There is inadequate oversight and control of the Hanford environmental program by RL.

Primarily due to resource constraints and organizational issues, RL is not adequately overseeing contractor environmental operations to assure efficient pursuit of compliance with requirements and, ultimately, environmental excellence. RL is not providing sufficient guidance and direction, oversight, direct involvement in environmental issues, or self-assessment. The primary causes appear to be lack of 
staff resources and somewhat unclear roles and responsibilities. The former is being addressed with a significant infusion of full-time-equivalent employees, and the latter is being dealt with via planned organizational changes.

The individual findings in Chapter 3 contain much more detail on these issues. While these areas present a big challenge, they also provide an excellent opportunity to make the changes that will make environmental excellence a reality. 


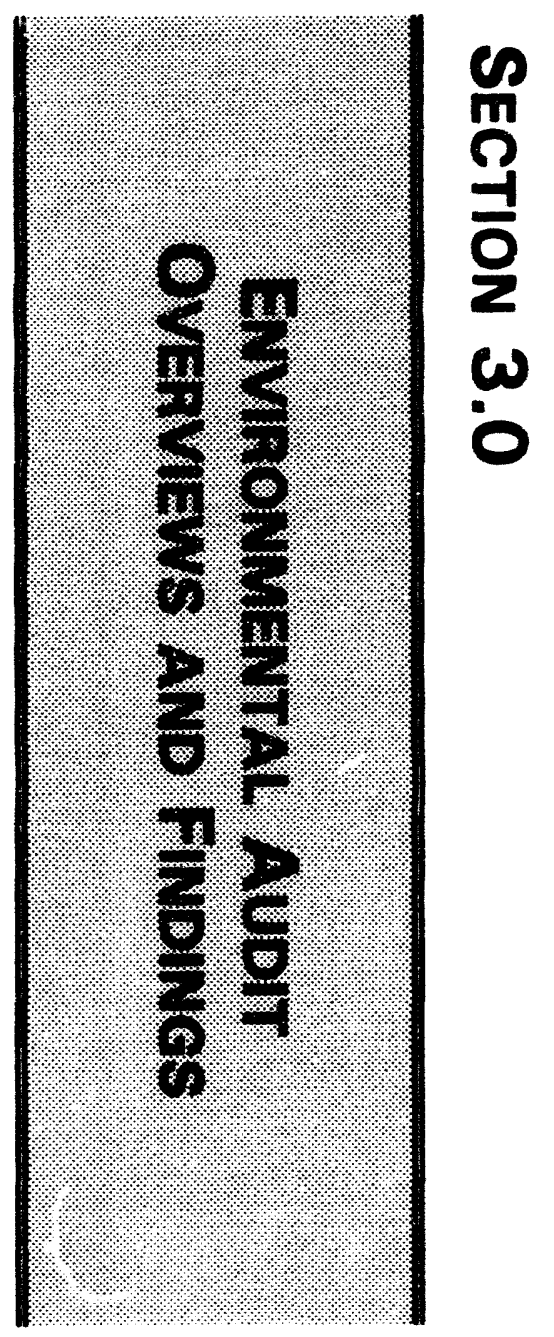


Page intentionally blank 
The audit findings are presented in the following pages and are not necessarily in order of importance. They are grouped by area of investigation, as listed in the Protocols for Conducting Environmental Management Assessments (DOE/EH-0326). This set of protocols is one of the primary tools used by the Office of Environmental Audit (EH-24) team to conduct this audit. In addition to these protocols, the technical specialists used the DOE Environmental Audit Program Guidance (January 1994 Draft Final) and Performance Objectives and Criteria for Conducting DOE Envirenmental Audits (DOE/EH-0358) to conduct the audit. Each area of investigation is introduced by an overview that describes (1) the approach taken by the management or technical specialist in conducting that portion of the audit; (2) Hanford programs and activities related to the area of investigation; (3) characterization of the strengths and weaknesses of Hanford's environmental management activities; and (4) a brief summary of the findings. Each finding is organized into three sections: the performance objectives, the finding statement, and a discussion of the details of the finding. The performance objectives section specifies the particular practices or standards against which the finding is being evaluated. In many cases, where the phrase "best management practices" appears in the performance objective, there are no specific regulatory or DOE references cited. Where this occurs, the best management practices are often based upon the protocols described above. The finding statement provides a concise description of an issue requiring resolution. The discussion section details the facts and observations supporting the finding.

Within each finding, references to other findings, interviews, and documents are presented parenthetically. An example of a referenced finding is: "(see Finding EP-1)," in which EP stands for "Environmental Protection Programs," and " 1 " is the finding number. The abbreviations used to identify findings are as follows:

$\begin{array}{ll}\text { OS } & \text { Organizational Structure } \\ \text { EC } & \text { Environmental Commitment } \\ \text { EP } & \text { Environmental Protection Programs } \\ \text { FP } & \text { Formality of Environmental Programs } \\ \text { IC } & \text { Internal and External Communication } \\ \text { SR } & \text { Staff Resources, Training, and Development } \\ \text { PE } & \text { Program Evaluation, Reporting, and Corrective Action } \\ \text { RM } & \text { Environmental Planning and Risk Management }\end{array}$

These abbreviations are used rather than the more conventional annotation for environmental management findings (i.e., EM-1) so that the reader can more easily determine the specific areas of investigation from which the finding was derived. The groundwater/surface water monitoring portion of the audit is reported in the environmental protection programs subsection of the report.

Some audit team specialists covered more than one of the areas listed above. As such, interviews and document reviews quite often were completed with multiple areas of responsibility in mind. In order to reduce unnecessary duplication when referencing interviews and documents, they are identified as follows. An example of a referenced interview is $(1-A-1)$ where " 1 " denotes an interview, "A" denotes an individual audit team member, and " 1 " is the assigned sequential interview number. Documents referenced for this audit are designated first by the letter " $D$ " for document, followed by a letter 
designation for each specialist as described below, followed by a sequential number (e.g., $D-A-1)$. The list of documents reviewed and interviews conducted are presented in Appendices $C$ and $D$ respectively.

Designator

Letter
A
B
C
D
E
F
Stow Walker
David J. Allard
Edward F. Maher
Mark O. Heuberger
James C. Melloni, Jr.
Joseph Lischinsky

Specialist 


\subsubsection{Overview}

The purpose of the organizational structure portion of the routine environmental audit was to evaluate whether Hanford's environmental management organization is consistent with the overall organizational structure; whether roles and responsibilities are well defined, clearly communicated and understood, and supported by appropriate management systems and documentation; and whether a group independent of line management is responsible for the policy and standards development and oversight functions. The regulations, requirements, and guidelines used to eV 'uate the site are shown in Appendix $E$.

The general approach to this portion of the audit included a review of background documents provided by Hanford and onsite interviews with key personnel. Documents reviewed included organizational charts, organizational unit descriptions, position descriptions, and a variety of other documents that describe the current organizational structure and roles at the Richland Operations Office (RL), Westinghouse Hanford Company (WHC), Pacific Northwest Laboratory (PNL), and ICF Kaiser Hanford Company (ICF KH).

Interviews were conducted with selected managers and staff of several RL support and line offices, divisions, and branches, including RL Office of the Manager; Office of the Deputy Manager; Office of Environmental Assurance, Permits and Policy (RL-EAP); Office of Chief Counsel; Office of Chief Financial Officer; Office of the Assistant Manager for Technical Support; and the Office of the Assistant Manager for Environmental Management. Interviews also were conducted with individuals from WHC, PNL, and ICF KH organizations with relevant environmental planning, implementation, and oversight roles, responsibilities, and authority.

At Hanford, the RL manager, with assistance from the deputy manager, has primary responsibility and authority for overall line management and operations. The RL manager reports to the Assistant Secretary for Environmental Management at DOE Headquarters (DOE HQ). The RL Assistant Managers report to the RL Mana\&ar, as well as to their respective Environmental Management, Energy Research, and Laboratory Management organizational counterparts at DOE HO. The RL organization includes support and line organizations responsible for the oversight and management of the site contractors. WHC is the management and operating contractor for the site, and manages its own subcontractors. One such contractor, ICF KH, has assumed significant facility management and support roles in addition to its construction responsibility. The site subcontractors to WHC report directly to WHC, which in turn reports directly to RL. Each WHC manager has an identified RL contact for management and reporting activities.

RL roles, responsibilities, and authority for environmental management generally are clear, but in some cases involve matrix relationships between support and line organizations. Specific roles, responsibilities, and authority then are less clear or inconsistently recognized by all parties. There has been no comprehensive review of mission statements developed by individual RL organizations to ensure congruence, clarity, and adequate formality. In addition, DOE HO maintains a high level of involvement in certain Hanford decisions, and there is uncertainty about roles, responsibilities, and authority between RL management and DOE HQ. 
The organizational structure of environmental management functions among contractors and subcontractors is characterized by generally clearer lines of authority. WHC subcontractors are responsible for conducting their environmental management activities, and reporting their performance to WHC, which in turn reports to RL. PNL, an RL contractor, is responsible for its own environmental management programs, and reports directly to RL.

The roles, responsibilities, and authority of the compliance function in RL's Regulatory Policy, Planning, and Analysis staff within the Office of Environmental Assurance, Permits and Policy is of particular concern. Although the RL regulatory compliance specialists are assigned to this office, managers in RL line organizations have the final decision-making authority for projects. Tension exists between those who are focusing on demonstrating tangible progress in the site's mission and those who are knowledgeable about potential and real legal complications posed by any proposed plan of action. This is a result of the high environmental compliance profile of Hanford operations, the complicated nature of problems on the site, and the need for the site to demonstrate cost-effective success of operations. RL must increase its effort to ensure that the environmental compliance assurance and project management functions of its organization are adequately staffed and effectively integrated to produce the most informed level of project management decisionmaking possible. The events surrounding the delay in the disclosure to the Washington State Department of Ecology (WDOE) of the presence of mixed waste in PNL's 324 Bldg. B-Cell illustrate the management challenges and regulatory risks involved.

Hanford's organizational structure, including roles, responsibilities, and authority, is changing. The lack of clarity within RL in part reflects the overall change in site mission from defense programs to environmental remediation. The need for additional clarity in RL roles, responsibilities, and authority had been identified prior to this audit, most recently during the Stand-Down conducted by RL in January 1994. "Undefined mission, roles, and responsibilities, accountabilities, authorities, etc." was specified as one of the major obstacles to improved performance at Hanford, and is one of the four areas selected by RL top management for followup analysis and corrective action. In addition to the RL reorganization now being formulated by RL top management to reflect a sitewide project management orientation, there are several other ongoing efforts at Hanford designed to introduce and measure process improvements. These activities will result in further clarification of Hanford management's organizational roles, responsibilities, and authority.

It is also important to note that Bechtel Hanford, Inc. (BHI) will assume WHC's current Hanford cleanup responsibilities as the site's first Environmental Restoration Contractor on July 1, 1994. Although the exact details of the BHI organization have not yet been determined, it will reinforce the RL reorientation towards integrated, sitewide project management.

There are three findings in the area of organizational structure. The first pertains to the lack of clarity in RL's organizational roles, responsibilities, and authority; the second pertains to specific organizational problems involving the PNL Analytical Support Services Project and the PNL Laboratory Subcontracting Department, which effectively prevent routine resolution of data validity issues in Hanford environmental monitoring programs; and the third is related to a lack of integration of environmental programs and activities. 


\subsubsection{Findings}

OS-1: RL Organizational Structure and Roles and Responsibilities

Performance Objective: DOE 5400.1, "General Environmental Protection Program," requires that DOE organizations develop management plans that clearly define the roles and responsibilities for environmental management activities.

DOE 5480.19, "Conduct of Operations Requirements For DOE Facilities," states that clear lines of authority and responsibility for operations should be established.

DOE 4700.1, "Project Management System," establishes guidelines for project management systems that entail the establishment of clear lines of authority and other bases for managing programs.

DOE 5700.6C, "Quality Assurance," requires that roles, responsibilities, and authority should be well conceived, well defined, clearly communicated, and understood by all personnel.

Best management practices suggest that the structure of the organization should be such that environmental management functions are congruent and effectively integrated with other functions and processes. Roles, responsibilities, and authority should be well defined and clearly communicated to effectively manage environmental issues. Authority should be delegated to organizational levels that can ensure the effective implementation of environmental programs.

Finding: The overall RL organizational structure is not uniformly supported by clear roles, responsibilities, and lines of authority to ensure efficient and effective decision-making and implementation of environmental programs at Hanford.

Discussion: Sitewide organizational adherence to agreed-upon roles and responsibilities is particularly important at Hanford. The complexity and number of problems at this location require informed and well-defined interactions between $\mathrm{RL}$ and DOE HQ organizations that include Environmental Management, Energy Research, and Laboratory Management. In addition, there must be an effective matrix of relationships between RL line orjanizations that are responsible for project management, and RL support organizations that have specific knowledge and experience necessary for successful project planning and implementetion. The requirement for a clear framework of explicit roles, responsibilities, and authority is underscored by the current DOE HQ, RL, and Tri-Party Agreement emphasis on achieving significant new economies in Hanford operations and on demonstrating competence and environmental excellence to regulators and the public.

Although the organization generally is adequately structured to support Hanford operations, this audit has identified areas where further definition is required. RL management recognizes that its current system of roles, responsibilities, and authority, which governs interaction among DOE HQ, RL, and contractors, must reflect the overall transition now under way at Hanford from a defense program mission to one of environmental remediation. Although the organizational reform process is under way, results have not yet been fully developed. The current organization reflects Hanford's environmental mission, to a certain extent, through changes in division names and mission descriptions; however, 
it does not explicitly reflect the new integrated, sitewide, project orientation embraced by RL management. Individual RL organizational roles, responsibilities, and authority, including individual division and branch mission statements recently created as part of the Training Development Program retreats conducted by the Oak Ridge Institute for Science and Education, have not yet been subjected to a comprehensive review by senior management to ensure overall consistency $(1-A-5, I-A-16$, and $I-A-20)$.

Of particular concern is the need for increased understanding and agreement on the appropriate roles of RL support organizations in $R L$ and contractor project management decisions with respect to regulatory compliance. The mission statement of the Office of Environmental Assurance, Permits and Policy (RL-EAP) includes the following compliance and permitting responsibilities to:

- ensure that all Hanford activities are conducted in an environmentally compliant manner;

- support all Hanford environmental permitting operations;

- establish permitting procedures and protocol;

- provide regulatory interpretation, general guidance, and assistance to RL divisions, RL project offices, and site contractors in obtaining all environmental permits consistent with requirements set forth in DOE Orders and Federal, State, and local laws and regulations; and

- serve as the RL focal point for interactions with the regulatory agencies for negotiating the conditions and issuance of environmental permits (D-A-37).

Nevertheless, as part of the customary project planning and management process, $\mathrm{RL}$ and contractor line organizations perform internally activities that are part of the mission of RL-EAP. At times, these activities place the line organizations and RL-EAP in conflict. For example, there have been recent instances when RL line organizations have chosen to:

- develop regulatory positions internally without consulting RL-EAP;

- support regulatory interpretations contrary to those of RL-EAP; and/or

- initiate discussions/negotiations with regulators independent of RL-EAP (1-A-18).

Events surrounding the delay in the disclosure to the Washington State Department of Ecology (WDOE) of the presence of mixed waste in PNL's 324 Bldg. B-Cell illustrates the management challenges and regulatory risks involved in the practices listed above. Without proper recognition of the organizational roles and responsibilities of RL-EAP, Hanford will experience difficulties in the planning and integration of environmental compliance issues with line organization management.

The problem of inconsistent reliance on RL-EAP for regulatory guidance is exacerbated by inadequate staffing in RL-EAP. This shortage of personnel limits the office's ability to track all projects and issues and address all inquiries from RL line organizations and contractors 
in a timely manner. Although RL-EAP will receive 9 of the 12 additional full-time-equivalent employees that it requested during the recent Office of Environmental Management bid process, these additions will be allocated broadly across the office's many responsibilities, including management of the Tri-Party Agreement. As a result, RL-EAP indicated that the increased staff will not be sufficient to proactively manage all of Hanford's compliance issues (1-A-24) (see Finding SR-1).

Another area of concern relates to the lack of comprehensive management of selfassessment activities conducted throughout Hanford. Self-assessment activities at the site currently are performed under multiple programs by multiple organizations, including groups within RL, WHC, and PNL. There is no RL management system specifically charged with integrating the results of these separate programs into a meaningful and useful summary of sitewide self-assessment that would enable RL to fulfill its reporting responsibilities, evaluate the performance of individual organizations and contractors, and more clearly assess environmental risks throughout the site (see Finding PE-1).

It is important to note that the lack of clarity in organizational roles, responsibilities, and authority was explicitly recognized by $R L$ and its contractors during the three-day StandDown in January 1994 (D-A-21). This issue was identified by RL management to be one of four major obstacles to be addressed by the RL Post Stand-Down Action Plan. At a recent Leadership Team meeting of RL senior managers, approval was given to initiate implementation of the Action Plan (1-A-22). This work, along with the ongoing reorganization being conducted by the manager, deputy manager, and other senior managers, is designed to address the issues raised by this finding (I-A-16). 
OS-2: $\quad$ PNL Analytical Support Services Project

Performance Objective: DOE 5400.1, "General Environment Protection Program," requires that DOE organizations develop management plans that clearly define the roles and responsibilities for environmental management activities.

DOE 5480.19, "Conduct of Operations Requirements for DOE Facilities," states that clear lines of authority and responsibility for operations should be established.

DOE 4700.1, "Project Management System," establishes guidelines for project management systems that entail establishment of clear lines of authority and other bases for managing programs.

DOE 5700.6C, "Quality Assurance," requires that roles, responsibilities, and authority be well conceived, well defined, clearly communicated, and understood by all personnel.

Best management practices suggest that the structure of the organization should be such that environmental management functions are congruent and effectively integrated with other functions and processes. Roles, responsibilities, and authority should be well defined and clearly communicated to effectively manage environmental issues. Authority should be delegated to organizational levels that can ensure the effective implementation of environmental programs.

Finding: The roles, responsibilities, and authority of the management system used by the PNL Analytical Support Services Project (ASSP) impede the efficient and effective implementation of environmental monitoring programs at Hanford.

Discusaion: The need for an effective and efficient management system for environmental monit ring sample analysis is grounded in the fundamental requirement that Hanford opera. ns demonstrate competence and environmental excellence, as well as by the curreni DOE HQ, RL, and Tri-Party Agreement (TPA) emphasis on achieving significant new budget savings.

ASSP manages the analysis by subcontract laboratories of samples for most non-CERCLA sitewide environmental monitoring activities. These analytical activities are conducted for many Hanford "customer" organizations, including RL, WHC, PNL, and Hanford Environmental Health Foundation (HEHF), and consist of soil, solid and liquid wastes, groundwater, surface water, air, and bioassay analyses.

A significant barrier to the resolution of potential environmental monitoring discrepancies involves requirements imposed by the PNL Laboratory Subcontracting Department. That department has established a requirement that its subcontracting representative act as the single point of contact with subcontract laboratories. Inspections of these laboratories, however, are performed by ASSP quality assurance representatives and ASSP technical task leaders without the presence of the subcontracting representative. In addition, the PNL Laboratory Subcontracting Department requires that its representative, who does not have relevant technical qualifications, determine whether there is adequate justification for discussing the data discrepancy with the laboratory in question. The threshold requirement for such a discussion between the environmental monitoring technical managers and the laboratory is whether those requesting clarification of the data have developed formal and 
conclusive proof that the potential discrepancy is not the result of any sampling procedures or practices by the Hanford "customer" organization (I-C-15, 16, 19, and 24).

The PNL Laboratory Subcontracting Office controls were instituted following a lawsuit several years ago involving a former subcontract laboratory. Now, however, those controls create unnecessary and highly disruptive barriers to effective management of sample data discrepancies. The requirements do not represent best management practices for the routine resolution of potential inconsistencies in analytical data.

The PNL Laboratory Subcontracting Office communication limitations have had a noticeably negative impact on Hanford environmental programs (I-C-15). The degree of difficulty involved in meeting the requirements for a discussion with the laboratory is substantial, especially with respect to providing formal and conclusive sample quality assurances. Laboratory inspections, which are conducted in lieu of routine discussions of suspected discrepancies, are unsatisfactory for addressing the questions surrounding the analysis of a specific sample at a particular time, and have not produced useful resolution of data validity concerns. Taken together, these restrictions effectively prevent the resolution of many questions involving suspect sample data quality from environmental monitoring activities sitewide.

For example, a sudden and substantial increase in tritium concentrations in air, which occurred at the site during the first 6 months of 1992, was investigated only as part of a subcontract analytical laboratory inspection. A brainstorming meeting between ASSP staff, environmental monitoring technical managers, and subcontract laboratory personnel was eventually held, following the laboratory inspection, to attempt to trace the problem; however, it was late in coming and could not be considered a proper substitute for an ongoing dialogue between data gatherers, managers, users, and the analytical laboratory. The brainstorming meeting was an exception to standard procedures, rather than a recognition of the need for routine, direct, easily organized interaction among the parties involved. In this case, the elevated tritium levels were presented in the 1992 Hanford Site Environmental Report, but could only be reported as "suspect." The actual source of high sample readings could not be identified through laboratory inspection (D-A-64).

The PNL manager of the ASSP is supported by four technical task leaders responsible for interfacing with Hanford customer organizations and the PNL subcontract and quality assurance organizations. These task leaders also manage and participate in the interaction between these laboratories and those within Hanford who must interpret the results and use them to make project decisions. Three of the four technical task leaders are assigned to managers in research and development groups elsewhere in the PNL organization, and do not report directly to the manager of the PNL Office of Health and Environment, the line organization responsible for ASSP activities. Under this arrangement, the primary responsibilities of these three individuals are to other offices, and they devote less than 30 percent of their time to the ASSP (I-C-10 and I-C-24).

The indirect reporting relationship between the PNL ASSP manager and three of the technical task leaders represents an inadequate level of management control of ASSP. The ASSP manager should have direct management control of project staff responsible for the interaction between Hanford and its contractors on issues of aata validity. This issue was recognized and addressed with respect to the fourth technical task leader, who has been assigned to report directly to PNL's Office of Health and Environment. Nevertheless, the 
balance of the technical task leader responsibilities remain unconsolidated among the three part-time positions who report indirectly to the ASSP manager (I-C-10 and I-C-15).

These concerns about the efficiency and effectiveness of the PNL ASSP have been raised with PNL senior management (I-C-10 and I-C-27), but no action has been taken to:

- Enable ASSP personnel to resolve data validity issues with the contractor without: (1) the presence of PNL Laboratory Subcontracting Department staff; and (2) prior irrefutable proof that the cause for the sample data validity concerns is not attributable to sampling activities.

- Train ASSP staff and other appropriate Hanford personnel in contact with laboratory contractors to be skilled in dealing with the issues which resulted in the current high level of PNL Laboratory Subcontracting Department oversight.

- Consolidate the three part-time technical task leader responsibilities into one position that would report directly to PNL's Office of Health and Environment. 


\section{OS-3: Integration of Environmental Protection Programs and Activities}

Performance Objective: DOE 5400.1, "General Environmental Protection Program," requires that DOE facilities design and implement a comprehensive environmental protection program. Best management practices suggest that all of a facility's environmental activities be performed within a clearly defined and communicated structure of environmental programs, projects, and activities, which guarantees that all such activities are performed in a manner that ensures effective performance through the integrated development of goals and objectives and consistency of missions, procedures, and performance.

Finding: Some elements of Hanford's environmental programs do not provide an integrated framework for coordination of program requirements, regulatory requirements, and similar environmental activities among the multiple site contractors.

Discussion: DOE 5400.1, "General Environmental Protection Program," requires each DOE facility to design and implement a comprehensive sitewide environmental protection program. These programs may vary among contractors, depending on their missions and specific operations. Both WHC and PNL have comprehensive programs and procedures for their respective operations, and these programs and procedures appear to be reviewed and updated on a regular basis. The baseline standards and policies of these contractors' programs, however, are not integrated on a sitewide basis to facilitate management control and oversight. This function is not contained in the roles, responsibilities, and authorities of the RL organizations charged with oversight and reporting responsibilities related to these programs.

Examples of activities that support the need for such programmatic integration include the following:

- RL's Hanford Site Waste Minimization Coordinator voluntarily transmits semiannual waste minimization reports to the Washington State Department of Ecology (WDOE). The information included in these reports is a result of consolidation of the various site contractors' semiannual waste minimization reports by WHC for RL. WHC, PNL, ICF Kaiser Hanford Company (ICF KH), and the Hanford Environmental Health Foundation (HEHF), however, each maintain separate Pollution Prevention Awareness Programs (PPAPs) as well as stand-alone procedures.

- Groundwater monitoring activities at Hanford currently are performed under multiple programs by multiple organizations, including organizations within WHC, PNL, ICF KH, HEHF, and the U.S. Army Corps of Engineers (USACE). under the oversight of multiple organizations at RL. These programs are not integrated to facilitate sitewide management and coordination (see Finding EP-3).

- In February 1993, RL contacted the chief executive officers of the four principal contractors at Hanford and requested their assistance in establishing the Hanford Training Council. The Council's charter suggests that it "operate as a steering group and actively participate in the overall planning of training programs at Hanford" (D-F-73). RL's goals for the 
Council included such items as development of a comprehensive, integrated effort to meet new training requirements; elimination of redundant training; implementation of changes to make training at Hanford effective, adaptable, and coordinated; and establishment of other task forces in areas such as needs assessment and training evaluation.

Through the combined efforts of the respective site training organizations and the Quality Training Resource Center, many of these activities have been initiated and the integration of several training courses has occurred. However, many environmental training activities at the site remain unintegrated. Training organizations exist within RL, WHC, and PNL, with both WHC and PNL providing environmental training to their respective staff in health physics, radiation protection technician training, and pollution prevention training. Resources are duplicated in the areas of instructional design, technical writing, and desk-top publishing, and may present an opportunity for consolidation. Although these support activities are available through the Quality Training and Resource Center, the Center is noi utilized as a sitewide resource in these areas (I-F-28 and I-F-29). Finally, the level of support provided to environmental trainers (i.e., lack of "train the trainer" education) and the quality of training materials is not consistent across all organizations conducting environmental training at Hanford II-F-12, 13, 23, 28, and 29). RL's Office of Training \& Education identified deficiencies in the "train the trainer" programs during a November 1993 assessment of the WHC Instructor Qualification program and directed WHC to implement corrective action.

Integration of sitewide environmental programs and oversight responsibilities is essential to limit duplication of efforts, ensure the establishment of a fully compliant program, and ensure efficient and cost-effective management of the site environmental program. 


\subsubsection{Oveniew}

The environmental commitment portion of the routine environmental audit was conducted to assess Hanford's overall awareness of relevant environmental issues and its commitment to environmental excellence. More specifically, the review included an assessment of Hanford's environmental policy, senior management's support of and involvement in environmental issues, the extent to which all employees take personal responsibility for the potential environmental impacts of their activities and decisions, and Hanford's overall commitment to environmental excellence. The regulations, requirements, and guidelines used to evaluate the site are shown in Appendix E.

The focus was to review senior management's support of environmental issues, and the degree to which individuals in Hanford's organizations are aware of and take responsibility for potential environmental impacts, and seek to eliminate those impacts in their activities.

The approach involved a review of DOE Orders and background documents from Hanford prior to visiting the site. Documents reviewed included Hanford publications for employees and other interested parties, job descriptions, environmental mission statements, policies and procedures, and other documents. Additional documentation was reviewed onsite as provided by the Hanford staff.

Based on this information, interviews were scheduled for the site visit. Supplementary interviews were added as concerns and issues were investigated. Interviews were conducted with the RL Manager and Deputy Manager; the Offices of the Chief Financial Officer and Chief Counsel; the Office of Environmental Assurance, Permits and Policy; and the Offices of the Assistant Managers for Technical Support and Environmental Management. Interviews also were conducted with management and staff at WHC, PNL, and ICF Kaiser Hanford Company (ICF KH). Input from all members of the audit team were included in this portion of the audit.

Hanford is now in transition from a defense program mission to one of environmental remediation, and has indicated dedication to environmental excellence. Given the complexity and magnitude of environmental problems and risks, RL and contractor responsibilities and reporting relationships, and issues of public interest, Hanford represents a formidable set of management obstacles. Within this challenging context, top management at RL, WHC and PNL have publicly committed the organization to attaining environmental excellence. Examples of this environmental commitment include the following:

- The Hanford Strategic Plan states its vision as "(o)perational excellence in all that we do", and the Environmental Protection Implementation Plan (EPIP) states "The new mission is to transform the Hanford Site into the nation's model for...(e)xcellence in environmental and waste management."

- Top and middle management at Hanford generally are familiar with the EPIP, which establishes the sitewide environmental plan and broadly outlines environmental roles and responsibilities. 
While staffing is not yet adequate, there has been a substantial overall commitment of staff resources to environmental support activities for Hanford, including areas such as RL's Environmental Assurance, Permits and Policy; Office of Performance Assessment; and Quality, Safety, and Health Programs Division; and WHC's Office of Regulatory Support.

Managers and staff throughout the organization generally recognize the environmental aspects of their job, and execute those duties professionally.

- There is a general sense of dedication to environmental protection and compliance by both top and line management.

- Hanford RL and contractor organizations have formed several Norking groups, including the Environmental Issues Roundtable, the Central Environmental Committee, and the ICF KH Environmental Committee, to support analysis and increased awareness of environmental requirements and issues.

RL has developed and implemented a highly successful Employee Concern Program, which was designed to encourage all Hanford employees to identify and report potential problems at the site.

RL management has explicitly recognized the need to approach its environmental mission through an integrated project management orientation with sitewide priorities and planning processes.

Reorganization and process improvement efforts designed to assist Hanford in its pursuit of operational and environmental excellence are under way.

RL senior management at Hanford demonstrates an understanding of environmental protection and regulatory compliance, but has not differentiated environmental excellence from a culture of compliance. Despite the positive efforts of some groups within contractor organizations, interviews with senior management and line employees indicate that, overall, the Hanford organizational culture generally considers environmental excellence to be the meeting of compliance requirements, typified by the Tri-Party Agreement (TPA) milestones. As a measure of the degree of overall organizational commitment, Hanford personnel interviewed during this audit view endorsements of environmental excellence as obligatory, but not particularly motivational.

Moreover, RL top management has not demonstrated commitment to environmental excellence through a level of personal involvement that is visible to the vast majority of the Hanford organization. This personal involvement would communicate a coherent, practical vision of environmental excellence at Hanford, and would include visible actions taken by senior and top management in RL as well as contractor organizations.

There are some indications that RL top management is determined to take a more aggressive leadership role in improving environmental performance. Two of the most prominent of these actions are: 
- The appointment of a permanent deputy manager to effect greater cooperation of RL senior management in the adoption of a project-oriented, integrated sitewide approach to the Hanford mission; and

- The creation this year of an integrated Hanford budget request to DOE Headquarters (DOE HQ) that focuses planning on specific projects and sitewide priorities. Critical DOE HO support for this innovative budget planning effort is provided by the DOE Assistant Secretary for Environmental Management.

RL's effort to address the issue of reprogramming delays also is supportive of the site's commitment to environmental excellence. The ability to obtain timely budget reprogramming to respond to unexpected changes in environmental priorities is critical to Hanford's environmental performance. Swift action by DOE HQ and Congress on reprogramming requests is needed to provide Hanford with the flexibility to reallocate resources effectively and efficiently. RL has been unable to obtain timely approvals of reprogramming submittals in the current fiscal year and in previous years and, therefore, has been unable to respond appropriately to unexpected and evolving developments. Management has been frustrated by this restriction, and now is working in conjunction with representatives of DOE HQ and Congress to develop an expedited reprogramming process.

Based on the documents reviewed and interviews conducted, Hanford appears to demonstrate an overall goal of environmental compliance and excellence. The Hanford program, however, lacks several specific characteristics of a strong organizational commitment to environmental excellence. As a result, there is one finding. 


\subsubsection{Finding}

\section{EC-1: Environmental Commitment}

Performance Objective: Consistent with the guidance given by DOE, including Secretary O'Leary's Environment, Safety, and Health Policy, it is the goal of all DOE facilities to demonstrate a commitment to environmental excellence in all aspects of their operations. Best management practices suggest that this commitment to environmental excellence should be supported by all aspects of an environmental program. This includes comprehensive, formal environmental protection programs and procedures as well as an organizational structure that effectively coordinates environmental professionals within the organization and integrates environmental activities into the overall site operations.

Finding: Top management within RL, WHC, and PNL have publicly committed their organizations to attaining environmental excellence at Hanford, but specific definitive indicators of a full commitment to environmental excellence are not evident.

Discusaion: Hanford top management has stated its goal that the site become "the DOE Model for Environmental Restoration" through "operational excellence" (D-F-42). A central requirement for this objective is commitment to environmental excellence. Although the elements cited in the Overview demonstrate environmental commitinent, certain key elements characteristic of this commitment are not evident at Hanford. Hanford cannot demonstrate full commitment to environmental excellence because of the following deficiencies:

- RL top management has not demonstrated a commitment to overall environmental excellence through a level of personal involvement that is visible to the organization.

- RL senior management has not communicated practical guidance to pursue environmental excellence at Hanford.

- RL and PNL managers have not demonstrated commitment to environmental excellence through clear statements and actions on certain particularly difficult issues of environmental compliance.

- Proceedings of weekly RL Senior Management Leadership Team meetings are not formally recorded to document management's consideration of environmental issues and problems, as well as commitments to those actions necessary to pursue environmental excellence at Hanford.

- RL top and senior management has not created a culturs of teamwork conducive to achieving environmental excellence.

RL top management has not demonstrated commitment to environmental excellence through a level of personal involvement that is visible to the vast majority of the organization. Several interviewees could not identify clear, convincing evidence of RL top management's personal involvement in demonstrating commitment to environmental excellence, and indicated that they view statements concerning environmental excellence in Hanford documents to be obligatory, but not particularly motivational (I-A-1, 4, 5, 11 , 
$18,20,25$, and 26). An additional indicator of a lack of visible top and senior management commitment on this issue is indicated by the January 1994 Stand-Down finding that identified a "lack of upper management leadership and consistency" (D-A-21).

Furthermore, rather than viewing the term "environmental excellence" to mean "beyond compliance," several individuals interviewed indicated that environmental excellence is generally construed by Hanford personnel to be satisfaction of compliance requirements as typified by the meeting of the Tri-Party Agreement milestones (1-A-1 through 5, 8, 9, 11 , and 25). Although there are documents describing Hanford environmental programs and the overall goal of excellence, RL has not produced an explicit roadmap to environmental excellence at Hanford. No RL document or other type of presentation exists that specifically defines environmental excellence as it applies to Hanford, that recognizes RL and contractor programs that reflect this standard, and that assists employees in understanding how to implement the concept within the context of their individual job responsibilities.

RL and PNL managers have not been overly proactive in demonstrating a commitment to excellence through timely, clear statements and actions on particularly difficult compliance issues. This is indicated by the delay in RL's disclosure to State regulators of the presence of mixed waste in PNL's 324 Bldg. B-Cell (I-A-11 and I-A-18). Regulators were notified of the presence of the radioactive component of the waste in a timely manner; however, it appears that the presence of hazardous waste within the B-Cell had been recognized for more than 2 years before regulators were informed of its existence. It should be noted that even though regulators received this notification after significant delay, they felt that the material was being managed in a responsible manner, given the complex and difficult management issues and risks associated with the cleanout of the contamination.

Discovery of the hazardous constituents has not impeded cleanup activities to mitigate the radiological safety hazard.

It should be noted that WDOE has been notified of high-level mixed waste at several other Hanford locations. Because of the regulatory and technical problems of mixed waste management, including the absence of any licensed/permitted disposal facilities, WDOE has made mixed waste a lower regulatory priority at the site. WDOE has been made aware of other mixed waste locations on the site as they have become known. By contrast, because of the financial and operational concerns surrounding disclosure of high-level mixed waste in the 324 Bldg. B-Cell in particular, there was a substantial delay in the acknowledgement of the hazardous waste component of the material at this location.

No formal written records are kept of weekly RL Senior Management Leadership Team meetings. This practice prevents the institutional documentation and tracking of senior management's environmental discussions and decisions over time, and makes it extremely difficult to gauge whether organizational commitment to environmental excellence was evident during these meetings.

The lack of senior management's demonstrated commitment to teamwork for environmental management, an important element of organizational commitment to environmental excellence, was reported by many individuals interviewed. This reluctance by senior management to work collectively toward an integrated approach to the site was attributed in part to a lack of top management leadership, and to individual senior managers' concerns about protecting their own organizations' budgets and areas of 
control. Interviewees expressed belief that the basis for this culture among senior management relates to the traditional DOE Headquarters funding mechanism, which funds sites through separate programmatic budgets rather than integrated planning explicitly related to site projects and priorities. 


\subsubsection{Overview}

The purpose of the environmental protection programs portion of the audit was to evaluate the extent to which Hanford has developed and implemented specific environmental protection programs and plans directed by Federal and State regulations, DOE Orders, the Tri-Party Agreement (TPA), and best management practices. Appendix $E$ lists the regulations, requirements, and guidelines used in the audit.

Because of the scope and size of Hanford, environmental programs were reviewed from a broad programmatic perspective to determine the general quality of programs, whether basic program elements exist, and the overall effectiveness of those programs. Specific environmental protection programs that were evaluated, on a sample basis, during this audit include: air emissions monitoring pursuant to the 1990 amendments to the Clean Air Act; surface water protection including source identification, spill prevention control, and reporting; envircnmental remediation programs under the Comprehensive Environmental Response, Compensation, and Liability ACt (CERCLA); groundwater protection programs including those under the Resource Conservation and Recovery Act (RCRA); operational, and sitewide environmental monitoring and surveillance plans and programs required by DOE Orders; the National Environmental Policy ACt (NEPA); and the management of solid, hazardous, radioactive, and mixed wastes including source identification, characterization, training, minimization, contingency planning, recordkeeping, and storage and disposal practices.

Formal environmental protection programs and/or plans required by DOE Orders, Federal or regulatory statutes, and the TPA that were evaluated include the site's: Environmental Protection Implementation Plan (EPIP); Long-Range and 5-Year Environmental Protection plans; Groundwater Protection Management Program; Waste Minimization, Pollution Prevention Awareness, and Recycling Programs; NEPA Implementation Program; Environmental Monitoring and Surveillance Plans; Emergency Preparedness Program and Response Plans; and Quality Assurance Program.

Specific program elements considered in this review include identification of applicable regulatory requirements, assignment of program responsibilities, identification of and monitoring systems for emission sources, training requirements, notification and reporting to regulatory agencies, and program evaluation and oversight.

The general approach to this portion of the audit was to review DOE Orders and regulatory requirements, as well as background documents provided by $\mathrm{RL}$, WHC, and PNL prior to the onsite portion of the audit. Onsite activities focused on interviewing key management personnel within WHC's Waste, Analytical \& Environmental Services and Emergency Safety, Quality Services; PNL's Office of Health and Environment, and Facilities and Operations; the Hanford Environmental Health Foundation's (HEHF) Health Services Division; and RL. This portion of the audit relied on input from all members of the audit team.

Hanford's environmental protection programs are executed by the site's three principal contractors, WHC, PNL, and HEHF, and their respective subcontractors. ICF Kaiser Hanford Company's (ICF KH) programs were not evaluated during this audit. Each 
contractor's roles and responsibilities are detailed in the RL EPIP. WHC manages most of the environmental protection programs supporting the site, including: environmental remediation, environmental compliance, pollution prevention, waste management, emergency preparedness, near-field operational monitoring, effluent monitoring, and most other related site support. PNL's primary mission is multidisciplined research and development (R\&D), including restoration and waste management R\&D. PNL also executes environmental protection programs in direct support of its laboratory $R \& D$ programs in the 300 Area and supports WHC as a subcontractor for RCRA and operational groundwater/surface water monitoring. PNL also manages the sitewide Environmental Monitoring and Surveillance Program. HEHF is responsible for the non-radiological analytical program supporting WHC's potable water supply programs; PNL is responsible for radiological analytes under the Safe Drinking Water Act (SDWA).

The site's extensive sampling activities include collection of liquid and airborne effluent samples to determine radioactive material releases; direct radiation measurement; measurement of meteorological parameters for modeling potential releases; collection and analysis of various environmental media; and ecosystem and foodstuff sampling for assessment of Hanford's operational impacts. These environmental protection programs, as well as groundwater and surface water programs conducted by WHC and PNL, are discussed below.

- Environmental Monitorina Plan - On November 9, 1991, RL issued an Environmental Monitoring Plan (EMP) for Hanford. The plan is adequate in its general description of sitewide environmental monitoring and surveillance activities. Actual activities of PNL and WHC are quite comprehensive with respect to surveillance and characterization of radiological conditions onsite and offsite. WHC is responsible for operational environmental surveiliance and effluent operational monitoring around facilities ("near-field"); PNL implements "far field" surveillance. Hanford operations and activities are monitored for potential impact on air, land, biota, and water resources. Public dose estimates are calculated using the PNL computer code (GENII) for all environmental pathways; the EPA method (CAPB8) is used for the air pathway analysis required for National Emission Standards for Hazardous Air Pollutants (NESHAPs). Effluent and ambient monitoring data are used to calculate these doses. Direct radiation is measured via passive thermoluminescent dosimeters and portable radiation survey instrumentation. Results of these environmental monitoring and surveillance activities are published in the Annual Site Environmental Report. The only EMP deficiency noted was the lack of documented rationale and design criteria for sampling locations and frequency (see Finding FP-1). It should be noted that the EMP is due for revision this year, and site personnel responsible for the update indicated concern regarding their ability to meet this deadline.

- Airborne and Liquid Effluent Monitoring Plans - Effluent monitoring, as required by DOE 5400.1 , is conducted to demonstrate compliance with applicable Federal, State, and local regulations. WHC conducts extensive operational airborne and liquid effluent monitoring at Hanford facilities according to specific Facility Effluent Monitoring Plans (FEMPs). Under the Federal Facilities Compliance Agreement (FFCA), monitoring equipment associated with Hanford's designated major stacks will be upgraded to meet 
EPA requirements. Additionally, liquid effluents discharged to soil will be phased out according to the TPA Milestone schedule. With the shutdown of most production operations, and mission transition from defense programs to environmental remediation, both airborne and liquid effluents have decreased. A review of the effluent monitoring programs and plans indicates WHC has well-documented FEMPs, and recently performed a thorough selfassessment against the DOE Regulatory Guide DOE/EH-0173T. Most action items identified during the self-assessment have been corrected.

Groundwater Protection Management Program Plan - Hanford's Groundwater Protection Management Program Plan (GPMPP), along with subordinate planning documents, is prepared by RL to fulfill planning requirements for groundwater protection activities required under DOE 5400.1. The GPMPP states that many of the elements required for the Groundwater Protection Management Program (GPMP) are covered by existing programs at Hanford. The purposes of the GPMP, the Plan says, are to provide a framework for coordination of existing groundwater protection activities and to provide the general scope, philosophy, and strategies for groundwater protection and management. The current draft of the GPMPP was published in November 1993 and currently is under revision (1-D-9 and (-D-25). Groundwater monitoring activities at Hanford currently include:
- The Groundwater Surveillance Program;
- The RCRA Groundwater Monitoring Program;
- The Operational Groundwater Monitoring Program;
- CERCLA-related monitoring;
- Washington State 216 Permit-related monitoring (Washington State Liquid Effluent Consent Order (WSLECO)); and
- Washington State underground storage tank (UST) monitoring.

In general, the individual groundwater monitoring programs are formally implemented through planning documents and procedures, are technically comprehensive, and have met the requirements and milestones established by the various regulatory drivers. Hanford has an extensive monitoring well network, well-planned and implemented surveillance programs, and technically competent staff in each of the programs. However, no single organization has formal authority or responsibility for a sitewide groundwater monitoring program or a sitewide GPMP, and there are a number of issues in the implementation of groundwater monitoring programs by multiple organizations (see Finding EP-2). Additionally, elements of the Hanford GPMP have not been fully implemented (see Finding EP-3).

Meteorological Monitoring Plan - The Meteorological Monitoring Plan (MMP) is contained within the Hanford EMP. It is designed to meet the requirements of DOE 5400.1 and regulatory guide DOE/EH-0173T. Meteorological monitoring at Hanford is site-specific and has been developed to provide information and data for assessment of impacts of planned and unplanned releases of radionuclides. A network of 26 monitoring stations has been located onsite and nearby offsite to characterize the meteorological conditions of wind speed, direction, etc., taking into account the influence of 
a varied topography throughout the site. PNL craft personnel maintain the equipment and calibration is traceable through WHC to the National Institute of Standards and Technology. Sensor data acquisition is via signal interface and telemetry. A meteorological forecaster reviews the data every hour. The MMP appears adequate in providing valid data for input to atmospheric transport and diffusion models for onsite and offsite dose calculations.

Environmental As Low As Reasenably Achievable (ALARA) Program - A program for implementing the ALARA process, which is required by DOE 5400.5, "Environmental ALARA Program," has not been implemented at Hanford (see Finding EP-1). Such a program would allow the evaluation of existing and proposed facilities and activities to be reviewed with respect to factors that may affect offsite radiation dose. Judgments would be made based on a logical, step-by-step process considering societal, technological, economic, and other public policy factors.

Decontamination and Decommissioning Program - Decontamination and decommissioning (D\&D) policies and guidelines for the management of contaminated facilities are established in DOE 5820.2A. There are approximately 4,000 acres of surface and underground soil contamination areas, hundreds of contaminated facilities, and millions of gallons of highlevel liquid waste in the tank farms. These facilities currently are being placed in a safe storage condition, with appropriate surveillance and maintenance. Inactive waste sites are to be remediated. Hanford is under a Federal Facility Agreement and Consent Order between the Washington State Department of Ecology (WDOE), EPA, and DOE to meet specific milestones for site remediation. A review of a sample of $D \& D$ plans and recent soil contamination stabilization projects indicates Hanford is being proactive in D\&D program management.

Waste Minimization and Pollution Prevention Awareness Proarams Hanford has three separate, nonintegrated pollution prevention awareness and waste minimization programs corresponding to WHC, PNL, and HEHF activities. Each program is well developed with respect to documentation and guidance, but the extent of implementation is highly variable within and among the three organizations. RL developed a sitewide implementing guidance (DOE/RL-91-31) in May 1991 that directs each of Hanford's contractors to develop and maintain pollution prevention (PP) and waste minimization (WM) programs that address source reduction, material substitution, and recycling. Each of the contractor programs appear to meet the requirements of DOE 5400.1 and 5820.2A.

- WHC's program seems to be the most advanced, in that each waste generation function has developed a relatively comprehensive program with a high level of documentation. WHC's program places considerable emphasis on inventory management and operational changes that will meet pollution prevention objectives in the acquisition phases of hazardous and radiological materials. WHC has a comprehensive recycling program that includes hazardous and non- 
hazardous chemicals, batteries, anti-freeze, scrap metal, cardboard, and office paper.

- PNL's PP program has similar emphasis on reducing the purchases of hazardous and radioactive materials, but also includes an innovative feature of recycling hazardous and radioactive materials within the laboratory centers. This currently is being conducted informally, and consists of reviewing PNL's research protocols to find opportunities to reissue unopened chemical reagents to other research centers, so as to reduce the volume of virgin reagents that become waste at the termination of a research project.

- HEHF also has made significant inroads in the WM program, its most noteworthy accomplishment being the reduction of its ozone depleting chemical (ODC) purchases in calendar year 1993 from 35 kilograms to 10 kilograms by redistillation of ODCs. In general, HEHF was the only contractor that was able to report on its reduction of ODC usage, despite the Presidential Memorandum requesting milestone reporting and established goals.

The overall site program for ODC use reduction is weak, and a start-up program has not reached full potential. Aside from HEHF's ODC reduction data, most of the site's PP and WM programs are not routinely capturing and trending their ODC or hazardous/radioactive waste reduction/minimization progress, except to produce the Annual Waste Minimization Report (Volume V Supplement to the Hanford Site Annual Dangerous Waste Report, DOE/RL-94-10). Although not a finding, the audit team members concluded that there should be more emphasis on trending this information to provide line managers with feedback as to the efficacy of their efforts.

The weakest portion of the site's PP program is nonhazardous solid waste recycling. Bond paper, newspaper, toner cartridges, and aluminum recycling programs have been implemented; the programs, however, are not being implemented consistently sitewide. Some offices and complexes are recycling these materials at a high capture rate, but many areas are placing little effort on recycling. The reasons for these differences are not clear. Although this does not merit an audit finding, it does represent a part of the PP Awareness Program that could use more emphasis.

Hazardous, Radioactive, and Mixed Waste Management - In accordance with DOE 5820.2A, radioactive and mixed waste must be managed in a manner that ensures protection of the health and safety of the public, workers, and environment. Similarly, FFCA directs all agents of the Federal government to follow the provisions of RCRA, as any other non-Federal agency must. Furthermore, CERCLA requires that Hanford establish a program to ensure that sites contaminated by hazardous and radioactive substances are remediated. Preliminary assessments indicate that more than 1,000 individual waste sites require further evaluation for environmental impact. RCRA, as implemented by the TPA, establishes regulatory standards for the generation, storage, treatment, transportation, and disposal of 
hazardous and mixed wastes. There are 50 or more less-than-90-day accumulation units at Hanford, and there are more than 60 treatment, storage, and disposal (TSD) units that are under interim status. When the Hanford RCRA Permit becomes final and in effect (expected mid-August 1994), it is anticipated that five of the interim-status TSD units will be subject to final status standards. Approximately half of the TSD units are scheduled to be closed. Eventually, all of the TSD units could be covered by the RCRA permit. The RCRA Permit Implementation Plan currently is under development, and will be available prior to issuance of the Henford facility RCRA permit. Overall, WHC and PNL appear to be managing their respective waste quite well and have adequate documentation and program formalization. The site is constructing new waste facilities for the storage and evaluation of mixed and transuranic wastes. RCRA milestones for the TPA recently have been renegotiated, but most milestones are being met on schedule. Furthermore, in 1993, the mixed waste shipping moratorium was lifted for the WHC waste centers; PNL's waste centers are still under the moratorium, but have made application for relief, which is expected by mid1994. Despite these accomplishments, the audit team does have concerns about the management of high-level mixed wastes stored at 324 Bldg. B-Cell (radiologically contaminated heavy metals), and the 2727-WA Bldg. (radiologically contaminated sodium) (see Finding RM-1).

NEPA Compliance - RL's NEPA compliance officer is assigned the responsibility of ensuring that NEPA guidance and procedures are available to the site's contractors and that the appropriate level of NEPA documentation and consideration is given to Hanford projects and activities that could have a potential impact on the environment. In February 1990, Secretary of Energy Notice (SEN) $15-90$ revised guidance on preparing NEPA documentation and raised the consideration threshold for use of the categorical exclusion. This SEN effectively made the existing RL Implementing Directive obsolete for the preparation of NEPA documents. Since then, although SEN 15-90 has been rescinded, RL's NEPA compliance officer has relied on draft RL guidance that is updated and informally distributed upon request to the site's NEPA document preparers. There are 12 environmental assessments in progress and approximately 60 categorical exclusion actions pending or in progress. The NEPA compliance officer has developed a good tracking system that displays the current status of each action, and the tracking system has been formalized in PNL-6955, "Hanford Site Implementation of the National Environmental Policy Act: Activities Tracking"; however, draft NEPA guidance instructions have not been formalized or approved (see Finding FP-1).

- Emeraency Preparedness and Planning - Hanford has an excellent Emergency Preparedness Office, managed by WHC. The organization provides support services, training, and large accident/incident response to the entire site. The capabilities meet CERCLA and RCRA requirements to develop and implement emergency response plans for large chemical/radiological spills. The office also provides guidance to a sitewide network of Building Emergency Directors (BEDs), who are responsible for developing emergency preparedness plans for the 33 major facilities with 
associated facility boundaries, which usually consist of one or more buildings or facilities that may store hazardous materials. The BEDs' Building Emergency Plan (BEP) covers contingency plans and actions for all types of emergencies from fire evacuation to a major chemical spill that endangers onsite and offsite areas. The BEP includes the Spill Prevention, Control, and Countermeasure Plan for each zone that used, stored, or treated hazardous, noxious or radioactive materials. The Emergency Preparedness Office not only provides assistance in developing the BEPs, but also plans, arranges, schedules, and evaluates accident drills and exercises designed to test the BEP's effectiveness and implementation. A total of 20 large-scale (field or tabletop) exercises were scheduled for fiscal year 1994, with each exercise followed with a lessons-learned debriefing and report. The audit team conducted a no-notice assessment of four randomly selected BEPs for content, applicability, and quality. Three of the four BEPs reviewed met or exceeded the requirements of DOE 5400.1. The fourth BEP was unavailable for review because the BED could not be contacted. The team's overall assessment of the site's emergency preparedness activities was very positive. Emergency planning is the "example" program for integrating environmental programs sitewide. As of May 1, 1994, emergency planning and accident response procedures have been integrated among all site contractors, and the site now operates and responds from a single EMP and associated quality assurance program.

The audit team found that Hanford had developed and implemented most of the elements that constitute a comprehensive environmental protection program for radiological and nonradiological agents. Most required program plans and implementation plans required by DOE 5400.1 have been developed and implemented. The only exception noted was the Environmental ALARA Program. All required permits and notifications are in place for current operations, and they are updated and renewed in a timely manner. Hanford does not have any outstanding Notices of Violation from Federal, State, or local environmental organizations despite a great deal of scrutiny.

The audit team identified three findings in this section of the audit, relating to the Environmental ALARA Program, the Groundwater Monitoring Program, and the Groundwater Protection Management Program. 


\subsubsection{Finding}

\section{EP-1 Environmental ALARA Program}

Performance Objective: DOE 5400.5, "Radiation Protection of the Public and Environment," Chapter II, Section 2, on the as low as reasonably achievable (ALARA) process states "Field Elements shall develop a program and shall require contractors to implement the ALARA process for all DOE activities and facilities that cause public doses."

Finding: RL, PNL, and WHC have not implemented an environmental ALARA program for comprehensive evaluations of Hanford activitios and facilities as required by DOE 5400.5.

Discuseion: The Secretary of Energy signed a policy statement June 8, 1993, that formally expresses the Department's fundamental policies and objectives on radiological health and safety (FR 33804, Vol. 58, No. 117). This notice of policy states "The Department shall ensure that radiation exposure to its workers and the public and releases of radioactivity to the environment are maintained below regulatory limits and deliberate efforts are taken to further reduce exposures and releases in accordance with a process that seeks to make any such exposures or releases as low as reasonably achievable". The policy further states "Radiological operations and activities shall be preplanned to allow for the effective implementation of dose and contamination reduction and control measures."

DOE 5400.5, Chapter II, Section 2.a, notes that ALARA requires a judgment of what is reasonably achievable, and that factors relating to technology, cost, and societal and public policy must be considered in evaluations. The factors to be considered, at a minimum, shall include the following:

- Maximum dose to members of the public;

- Collective dose to the population;

- Alternative processes (i.e., treatment of effluents, operations, or controls):

- Doses for each alternative process;

- Cost for each technological alternative; and

- Examination of the changes in cost alternatives (e.g., doses from various pathways).

"DOE Guidance on the Procedures in Applying the ALARA Process for Compliance with DOE 5400.5" (March 8, 1991), provides interim guidance for the implementation of the ALARA process to protect the public and environment. This guidance directs the implementation of an approved ALARA program, with a review and update every 3 years. The program is to be described in the Environmental Protection Implementation Plan and a separate ALARA plan. Proposed codification of DOE 5400.5 as 10 CFR Part 834 (FR 16268, Vol. 58, No. 56) further supports the suggested guidance of a step-by-step, logical procedure for environmental ALARA judgments, and may be used as a guide in preparing the environmental ALARA plan. 
The facilities and operations at Hanford have the potential to cause public doses resulting from airborne and liquid effluents and direct radiation exposure. With the shutdown of facilities and transition in mission from defense programs to environmental remediation, the magnitude of these releases and doses has been measurably reduced (D-B-2, 61, 68, and 70). This is especially true for routine facility effluents. It is important to note that the calculated dose to the hypothetical maximally exposed individual from Hanford operations is well below regulatory limits. Nonetheless, considering the volume of high-level radioactive waste requiring processing, the number of plutonium production reactors and other facilities requiring decontamination and decommissioning, and the approximately 4,000 acres of outdoor posted surface and underground radiological soil contamination, the potential for offsite dose to the public and further contamination of the environment will need to be evaluated critically for the foreseeable future.

Hanford contractors have in place extensive facility and site radiological environmental monitoring and surveillance programs (D-B-4, 19, 27, 39, 43, and 64). Within the individual facility effluent monitoring plans, administrative control values have been imposed to limit the release of radionuclides based upon ALARA goals for protection of the public (D-B-52; I-B-13). Additionally, both WHC and PNL have occupational ALARA programs designed to reduce worker exposure (D-B-80 and D-B-81; $1-B-14)$. Further, WHC in the past several years has made notable progress in the stabilization of radiological outdoor surface contamination (D-B-1 1; $1-B-25$ and $1-B-26)$. The Hanford Site Surface Soil Radioactive Contamination Control Plan was developed in response to a finding identified by the Tiger Team (D-B-11). This plan is implemented by the Radiation Area Remediation Action activity, the primary objective of which is to conduct surveillance, maintenance, decontamination, and/or internal stabilization of Hanford's inactive burial grounds, cribs, ponds, trenches, and unplanned release sites. This has well-documented ties to the WHC Occupational ALARA Program for these activities (D-B-82; 1-B-25). Hanford, however, lacks a fully contractor-integrated environmental ALARA program with an auditable process for evaluating offsite dose to the public, environmental release of radioactivity, and defined tools for implementation (D-B-53; I-B-2, 4, 6, 8, 14, 15, 17, and 26). Specific issues related to development and implementation of the environmental ALARA program and plans required by DOE $\mathbf{5 4 0 0 . 5}$ are summarized below:

- RL, WHC, and PNL have not implemented an environmental ALARA program with management policy, statement of commitment to the ALARA philosophy, organizational responsibility, authority and structure for implementation, evaluation of site operations to identify activities responsible for release of and public exposure to radioactive materials, and an overall procedure to be used to analyze existing and proposed operations and activities to determine if impact is ALARA (D-B-53; I-B-4, 6, 8, and 14).

- $\quad$ RL, WHC, and PNL have not implemented an ALARA plan with identified general areas to be considered in making environmental ALARA decisions (i.e., societal, technological, economic, public policy, etc.), a checklist of evaluation factors (i.e., maximum individual and collective dose, alternative processes, cost of each, change impact, worker dose, non-radiological impact, etc.), staff training requirements, and required records (D-B-53; I-B-4, 6,8 , and 14). 
- In the near future, environmental remediation activities currently performed by WHC will be transferred to Bechtel Hanford, Inc. (BHI). RL has not documented in the current Environmental Protection Implementation Plan how the environmental ALARA program and plan will be integrated among BHI, WHC, PNL, and ICF Kaiser Hanford Company operations and activities (D-B-53). Lastly, the basis for quantitative versus qualitative environmental ALARA judgments, commensurate with the magnitude of potential doses and costs, has not been documented.

During the course of the audit, the team did note various elements of an environmental ALARA program throughout RL, WHC, and PNL's environmental programs and plans. Additionally, PNL has proposed an Integrated Risk Assessment Program to provide health and ecological risk assessments for Hanford's various remediation activities. It appears that RL and its contractors have not implemented an environmental ALARA program because they have not assessed the relative degree of risk involved in not having such a program. This issue was identified in the 1990 Tiger Team Assessment Report (RAD/CF-5), but to date has not been addressed by RL or its contractors. RL did receive the March 8, 1991, Environmental ALARA Interim Guidence and PNL, WHC, and RL provided comments to DOE HQ Office of Environmental Guidance (D-B-118). 


\subsubsection{Technical Assessment}

This section provides an overview of two environmental and technical programs and reports the findings of the technical specialist. The groundwater and surface water monitoring programs were selected for evaluation based upon input provided by the site. The specialist evaluated objective evidence to confirm that applicable elements of the programs had been developed, documented, and effectively implemented in accordance with specific environment, safety, and health requirements. He also assisted in the environmental management audit and provided evidence to support the conclusions of the management specialists.

\subsubsection{Groundwater/Surface Water Monitoring}

\subsection{Oyeniew}

The purpose of the environmental monitoring portion of the routine environmental audit was to evaluate the groundwater monitoring and surface water monitoring programs at Hanford. The audit was intended to evaluate the monitoring programs in terms of compliance with applicable DOE Orders, regulations, and guidelines, as well as to evaluate the monitoring programs against the management systems protocols addressed in other portions of the audit. The specific regulations, requirements, and guidelines used to evaluate the site are shown in Appendix E.

Specifically, the audit focused on the following areas:

- Coordination and integration of groundwater and surface water monitoring activities under Resource Conservation and Recovery Act (RCRA): Comprehensive Environmental Response, Compensation, and Liability Act (CERCLA); 216 Permit (Washington State Liquid Effluent Consent Order (WSLECO)); and Underground Storage Tank (UST), Operational, and Surveillance programs.

- Consistency and integration of sampling procedures, quality control procedures, data management, and reporting among monitoring programs and contractors including WHC, PNL, and ICF Kaiser Hanford Company ICF $\mathrm{KH})$.

- Milestones under the Hanford Federal Facility Agreement and Consent Order (Tri-Party Agreement (TPA)).

- WSLECO requirements for geohydrologic evaluation and sampling plans for liquid effluent discharge sites.

- Sitewide program for construction, maintenance, and abandonment of monitoring wells.

- Handling, transfer, and management of sitewide monitoring data.

- Permit status, monitoring requirements, and reporting under the National Pollutant Discharge Elimination System (NPDES). 
The audit included a review of DOE Orders, environmental regulatory requirements, and background documents provided by Hanford prior to the audit team's arrival onsite. Onsite activities included additional document review; interviews with management and staff within RL, WHC, PNL, the U.S. Army Corps of Engineers (USACE), and Washington State Department of Ecology (WDOE); and observation of a groundwater sampling event. This portion of the audit also involved coordination with the other members of the audit team, particularly the Environmental Protection Programs specialists.

Since the 1990 Tiger Team Assessment and the 1992 Progress Assessment, Hanford has made considerable progress in the implementation of formal groundwater and surface water monitoring programs and completion of planning and reporting documents to meet DOE 5400.1 requirements and regulatory consent orders. The audit team generally was impressed with the formality of monitoring plans and procedures, the establishment of informal communication systems between program organizations, and the development of cooperative working relationships with the regulatory agencies overseeing the monitoring programs. Some program elements, however, have not been fully implemented.

\section{Groundwater Monitoring Programs}

Groundwater monitoring activities at Hanford currentiy include: (1) the Groundwater Surveillance Program; (2) the RCRA Groundwater Monitoring Program; (3) the Operational Groundwater Monitoring Program; (4) CERCLA-related monitoring; (5) Washington State 216 Permit-related monitoring under WSLECO; and (6) Washington State UST monitoring.

The Groundwater Surveillance Project provides sitewide surveillance to meet the requirements of DOE 5400.1. PNL is responsible for this program under the oversight of the RL Quality, Safety, and Health Programs Division (RL-OSH). Sampling for this program is performed by the PNL Field Sampling and Analysis Group.

The RCRA Groundwater Monitoring Program provides permit-related monitoring of RCRAregulated facilities. The RCRA monitoring requirements are covered under the TPA. The draft sitewide RCRA Permit, anticipated to be approved in July 1994, will provide additional monitoring requirements.

The Operational Groundwater Monitoring Program primarily provides "near-field" monitoring adjacent to facilities with liquid waste disposal systems. Both the RCRA and Operational Groundwater Monitoring programs are under the auspices of WHC's RCRA and Operational Monitoring Program and the WHC Geohydrologic Support Group, with oversight from the RL Waste Management Division. Sampling is done primarily by PNL's Field Sampling and Analysis Group.

CERCLA-related groundwater monitoring is performed in accordance with site-specific work plans for individual operable units under the requirements of the TPA. This program is primarily managed by WHC's Environmental Remediation Division under the oversight of the RL Environmental Remediation Division (RL-ERD); howevar, some operable units are managed by the USACE as a contractor to RL-ERD. Technical support and sampling is performed by WHC's Geohydrologic Support Group, WHC's Industrial Health Physics, PNL's Field Sampling and Analysis Group, and the USACE. Groundwater monitoring related to WSLECO and the UST Program is managed by WHC's Waste, Analytical and 
Environmental Services within the Operational Monitoring Program, and monitoring related to the UST Program is implemented by both WHC and ICF KH.

In general, the individual groundwater monitoring programs are formally implemented through planning documents and procedures, are technically comprehensive, and have met the requirements and milestones established by the various regulatory consent orders, agreements, and permits.

Strengths noted in the programs include the following:

- Hanfred has developed an extensive monitoring-well network to address requirements under DOE 5400.1, RCRA, and CERCLA.

- Monitoring milestones required under the TPA have been met to date. However, it should be noted that a number of milestones have been deleted, extended, or renegotiated. For example, RL has successfully negotiated a reduction in the number of new RCRA wells required for installation annually.

- Sampling programs are formally implemented through plans and procedures. Several commendable sampling practices were noted in the Groundwater Surveillance Program, including written work sheets for the sampling crews that specify purging requirements and sampling requirements; a master list of wells which documents purge water disposal requirements; and use of Electrical Well Power System Monitors to ensure that well pumping systems are electronically sound prior to initiation of pumping.

- Progress has been made toward establishing coordination between the individual monitoring programs through informal communication, meetings, and working groups. For example, a Will Administration Team has been established to coordinate sitewide well inventory, numbering, and maintenance issues, and sampling integration meetings have been initiated to coordinate sampling between PNL and WHC (I-D-7, I-D-11, and I-D-26).

- Co-sampling programs with the Washington State Department of Health (WDOH) and WDOE have been effective and cooperative (I-D-2 and I-D-19).

Several weaknesses also were identified in the programs. No single organization has formal authority or responsibility for a sitewide groundwater monitoring program. There are a number of issues related to the implementation and integration of groundwater monitoring programs by multiple organizations (see Finding EP-3). Additionally, elements of the Hanford Groundwater Protection Management Program have not been fully implemented (see Finding EP-4). One additional weakness that was not identified in a finding is the lack of deeper wells in the unconfined aquifer to: (1) provide complete characterization of groundwater contamination in the lower portion of the unconfined aquifer-particularly in areas where denser-than-water contaminants such as chlorinated solvents are present (e.g., 200 Area and 300 Area) and at depth could occur as dense non-aqueous phase liquids; and (2) account for falling water tables as a result of cessation of liquid effluent discharges. Both issues were identified in the 1990 Tiger Team report and have not been fully addressed. It should be noted that work has been initiated by PNL on a study to determine the impact of declining water levels on groundwater monitoring networks. 
Potential barriers cited as contributing to the difficulty in integration among monitoring programs are: (1) the lack of incentive for accountability to and ownership of the site mission as opposed to a program mission; and (2) the perception of negative effects of integration (i.e., loss of project/program control and reduction of program authority and responsibility) (I-D-26). Additional barriers include organizational separation of oversight functions at RL, organizational separation of funding sources, and the separate internal corporate procedural requirements of individual subcontractors.

RL has not fully incorporated lessons learned from past audits, progress assessments, and GAO Reports into improvements of the groundwater monitoring program management. Previous audits have cited lack of coordination of monitoring programs as a deficiency. Additionally, the March 1993 GAO Report RCED-93-71, "Hanford's Well-Drilling Costs Can Be Reduced," stated that the current management structure, lacking a central organization with responsibility for all well drilling, has resulted in increased well-drilling costs at Hanford (D-D-24). The report also cited a value engineering study's recommendations to reduce the number of offices with well-drilling roles and noted that precodents have been established for the establishment of a single project management entity for programs with more than one funding source (D-D-24). These observations and recommendations also are appropriate for the groundwater monitoring programs.

\section{Surface Water Monitoring Programs}

Surface water monitoring conducted at the site under the Surface Water Surveillance Task within the Surface Environmental Surveillance Project includes monitoring of the Columbia River, groundwater spring discharges along the river bank, ponds located onsite, offsite water systems located east of and across the Columbia River from Hanford, and an irrigation canal supplied by the Columbia River downstream from Hanford. The Surface Water Surveillance Project is conducted as a component of the Surface Surveillance Project by PNL under the oversight of RL-OSH.

Surface water monitoring also is conducted as a component of the Near-Field Operational Environmental Monitoring Program by the WHC Environmental Engineering Studies function under the technical oversight of RL-OSH and the programmatic oversight of the Waste Management Division. This program includes ponds and ditches adjacent to facilities as well as groundwater seeps along the Columbia River in the 100-N Area.

Routine monitoring of liquid effluent discharges is coordinated and reported by Regulatory Support within WHC's Waste, Analytical and Environmental Services under the oversight of the RL Office of Environmental Assurance, Permits and Policy. This program currently includes 10 liquid discharge points, reduced from an original 33 points as part of liquid effluent cessation required under WSLECO and the TPA.

Monitoring also is performed at NPDES-permitted outfalls. NPDES Permit No. WA-000374-3, issued to RL by EPA Region 10, specifies discharge points, effluent limitations, and monitoring requirements for nonradioactive discharges to the Columbia River from eight outfalls. The current NPDES permit, issued in 1985, has expired. An application for a new permit was submitted by RL in 1991 in accordance with the schedule required by EPA, but has not yet been approved. $R L$ currently is monitoring the outfalls under the conditions of the original permit until the new permit is issued. Monitoring and reporting is performed for seven of these outfalls by WHC and for one outfall by PNL. 
Lastly, characterization of groundwater seeps to the Columbia River is performed as a component of certain operable unit remedial investigations by WHC's Environmental Remediation Division as part of CERCLA-related activities under the TPA.

The following strengths were noted in the surface water programs:

- A series of technical reports have been prepared by PNL and WHC, as part of the Surveillance and CERCLA Programs, to compile and evaluate historic and current monitoring data for the Columbia River. These reports have included trending of data over time, trending of data versus river flow conditions, and establishing site-related contributions versus offsite derived contributions of analytes detected in the river.

- The surface water surveillance program has expanded the analytes to include those covered under the RCRA facility monitoring requirements for determining potential and future impacts from these facilities, although inclusion of these analytes in the surface water monitoring has not been specifically required by the TPA.

- The surveillance program has included an analysis of groundwater seepage rates and contaminant concentrations under various river stage conditions in order to determine the most representative sampling conditions and to determine the useability of seep data.

- The WHC Environmental Engineering Studies organization conducted a pointby-point justification of the rationale for surface water sampling points as part of self-assessment response actions, to minimize redundancy with other programs (I-D-10).

There also were several weaknesses noted in the surface water programs. Several of these weaknesses were identified in findings that were included in other sections of this audit report:

- Formal comparison of surface water data collected in the individual surface water programs is incomplete. For example, surface water data collected as part of the Surveillance Program are not formally compared with data for adjacent locations from the Operational Program. Additionally, the Liquid Effluent Monitoring Program and Operational Environmental Monitoring Program (OEM) collect samples in close proximity; however, data are reported in separate reports and there is no report containirg a comprehensive comparison of these data (I-D-10 and I-D-16). This is a minor weakness considering the required elimination of effluent discharges to the ground in 1995.

- Some inefficiency is created by three different programs having responsibility for monitoring of onsite ponds and springs; however, there is currently very little redundancy between these programs (I-D-10, I-D-18, and I-D-22).

- Formal procedures for seep sampling are not in place (I-D-18 and I-D-22). This is an internal milestone in PNL's Contractor Work Plan for the Surface 
Water Surveillance Project under the Public Safety and Resource Protection Program and is currently behind schedule (D-D-21) (see Finding FP-1).

- Surface water sampling for the OEM is performed by the WHC Site Surveillance Health Physics Group in support of the OEM under the direction of WHC Environmental Engineering Studies. Until recently the Health Physics group used informal "desktop procedures." Formal procedures recently have been developed but are still in draft form (D-D-22; I-B-14 and I-D-10) (see Finding FP-1).

No findings specific to the Surface Water Monitoring Program were developed during the audit.

Two findings specific to groundwater monitoring, related to the Sitewide Groundwater Monitoring Program and the Groundwater Protection Management Program, were identified in the environmental monitoring portion of the audit. 


\subsection{Findings}

\section{EP-2: $\quad$ Sitewide Groundwater Monitoring Program}

Performance Objective: DOE 5400.1. "General Environmental Protection Program," Chapter IV, Section 9.b., specifies requirements for a Groundwater Monitoring Program. DOE 5400.1 also states "It is DOE's policy that efforts to meet environmental obligations be carried out consistently across all operations and among all field organizations and programs." Section 4.d also states "Monitoring networks should be operated and maintained in a uniform manner, i.e., through established procedures that allow comparative evaluations of data from monitoring sites."

DOE 5480.19, "Conduct of Operations Requirements for DOE Facilities," states that it is DOE policy to conduct its operations with a consistent and auditable set of requirements, standards, and responsibilities.

DOE 4700.1, "Project Management System," states that costly, complex, and long-running multimillion-dollar efforts should be managed as a project and establishes objectives to: provide a disciplined, systematic, and coordinated approach to project management; and centralize authority for project approval and allocation of resources.

The Hanford Federal Facility Agreement and Consent Order (Tri-Party Agreement (TPA)) specifies requirements and milestones for groundwater monitoring and related activities at Hanford under the Resource Conservation and Recovery Act (RCRA), the Comprehensive Environmental Response, Compensation, and Liability Act (CERCLA), and other programs. Groundwater monitoring requirements also are specified in the Washington State Liquid Effluent Consent Order (WSLECO).

The Groundwater Protection Management Program Plan (GPMPP) states that one of its primary purposes is to provide a framework for coordination of existing groundwater protection activities. The GPMPP also states "A common approach or process should be used regardless of the specific groundwater-related regulation or requirement."

Finding: The multiple groundwater monitoring programs at Hanford are not fully integrated into a sitewide monitoring program.

Discussion: Groundwater monitoring activities at Hanford now are being performed under multiple programs by multiple organizations, including groups within WHC, PNL, ICF Kaiser Hanford Company (ICF KH), Hanford Environmental Health Foundation (HEHF), and the U.S. Army Corps of Engineers (USACE). The various program responsibilities are discussed in the overview. These programs also are under the oversight of multiple organizations at RL, including the Waste Management Division, the Environmental Remediation Division, and the Quality, Safety, and Health Programs Division. No single organization has formal authority or responsibility for a sitewide groundwater monitoring program.

RL, WHC, PNL, USACE, and Washington State Department of Ecology (WDOE) personnel cited the lack of a formal sitewide groundwater monitoring program and indicated problems in the implementation and integration of groundwater monitoring programs by multiple organizations. These problems included inefficiencies and redundancies in sarnpling and 
reporting, potential conflicts between CERCLA remediation and RCRA compliance, lack of a cohesive long-term groundwater plan and strategy in the Groundwater Protection Management Program, and barriers to conflict resolution (I-D-1 through 3, 5, 8, 19, and 25). The site has made notable progress during the past 2 years in coordinating multiple programs to reduce duplication and conflicts, and there are a number of informal coordination mechanisms in place, as discussed in the Overview. Still, these mechanisms do not establish a formal sitewide program and do not ensure consistency and integration among all programs. These issues may be compounded in light of anticipated organizational changes, including the addition of a new contractor-Bechtel Hanford, Inc. - who also will have groundwater monitoring responsibilities for the environmental remediation program.

Specific issues related to the lack of an integrated sitewide groundwater monitoring program include the following:

- The Memorandum of Understanding for implementation of the Hanford Environmental Management Program has not been updated since 1987 and does not reflect the current Environmental Monitoring Plan and Environmental Protection Implementation Plan (D-D-17; I-D-5 and I-D-10). In addition, there are some inaccuracies in the current Memorandum of Understanding (I-D-5). For example, responsibilities for geologic logging and hydrologic testing are assigned solely to PNL, but these activities are performed by both PNL and WHC.

Two examples of potential or perceived redundancies as a result of separation of groundwater programs were identified during the audit: (1) completion of sitewide water table measurements by both PNL and WHC (I-D-5, I-D-6, and I-D-11); and (2) completion of separate sitewide groundwater models by PNL and WHC (I-D-5, I-D-6, and I-D-11). Section 8.0 of the GPMPP specifies that WHC is responsible for conducting sitewide conceptual/numerical modeling. It should be noted that these activities may only be perceived as redundancies, since PNL has indicated that there are technical bases for these overlaps.

There has not been clear and consistent justification of the monitoring wells owned and sampled by the separate programs. For example, individuals at RL, WDOE, and PNL indicated a lack of justification for continued and increased monitoring as part of the Operational Groundwater Monitoring Program (I-D-5, I-D-18, and I-D-19).

The Hanford Site Groundwater Monitoring Report for 1992 states "The operational monitoring program was significantly redesigned in 1989 to reflect the diminishing importance of site production facilities" (D-D-9). The GPMPP also suggests a reduction in operational groundwater monitoring as "Operational monitoring activities diminish in response to cleanup milestones and schedules for elimination of liquid waste streams" (D-D-3). There has been, however, an increase in the number of wells sampled in the Operational Groundwater Monitoring Program. Fifty-seven wells in the operational network were sampled in 1992 (D-D-9). Current estimates of the 
number of wells included for 1994 range from 130 to 169 (D-D-18 and D-D-25; (-D-5).

- The purpose, rationale, and long-term strategy for the collective programs is not clearly established and communicated.

For example, the GPMPP states "The operational monitoring program serves as the mechanism for the integrating and reporting of groundwater-related activities originating with other programs" (RCRA, CERCLA, WSLECO, etc.) at Hanford (D-D-3). The GPMPP also states that the Groundwater Surveillance Program is "an integrated assessment of the impact of site operation on the groundwater system."

Both the public and the regulators have expressed concern that there is no single entity at Hanford that is responsible for groundwater issues and strategy (I-D-19 and I-D-25).

The groundwater monitoring programs have not fully integrated sampling efforts to identify joint sampling opportunities in order to reduce costs and to minimize purge water and investigation-derived wastes (I-D-18, I-D-19, and I-D-25). It should be noted that significant progress has been made in the coordination of sampling through the development of integrated schedules and informal coordination meetings (I-D-5, I-D-11, and 1-D-24). However, there are additional well locations where RCRA/Operational and CERCLA programs, and CERCLA and Surveillance programs could share samples rather than collecting samples during separate events (I-D-19 and I-D-25).

Groundwater monitoring conducted under WSLECO and Underground Storage Tank (UST) programs do not appear to be well-integrated into the sitewide groundwater monitoring programs. These monitoring activities are not specifically discussed in the 1992 Annual Site Environmental Report or the Hanford Site Groundwater Monitoring Report for 1992. Ongoing groundwater monitoring activities associated with UST investigations are conducted by both WHC and ICF KH (I-D-29). The individuals and organizations responsible for oversight of these activities are not clearly defined. Also, the RL and contractor staff responsible for oversight and management of the Surveillance and RCRA/Operational Monitoring Programs were not fully aware of the status of WSLECO and UST-related monitoring programs or the organizations responsible for implementing these programs $(1-D-1,5,9$, and 11$)$.

Two potential barriers cited as contributing to the difficulty in integration among programs are (1) the lack of incentive for accountability to and ownership of the site mission as opposed to the program mission; and (2) the perception of negative effects of integration (i.e., loss of project/program control and reduction of program authority and responsibility) (I-D-26). Additional barriers include organizational separation of oversight functions at RL, organizational separation of DOE Headquarters funding sources, and the separate internal corporate procedural requirements of individual subcontractors. 
RL has not fully incorporated lessons learned from past audits, the 1992 Hanford Progress Assessment, and GAO Reports into improvements of the groundwater monitoring program management. Previous audits have cited lack of coordination of monitoring programs as a deficiency. Additionally, the March 1993 GAO Report RCED-93-71, "Hanford's WellDrilling Costs Can Be Reduced," stated that the current management structure, lacking a central organization with responsibility for all well drilling, has increased Hanford's welldrilling costs (D-D-24). The report also cited a previous value engineering study's recommendations to reduce the number of offices with well-drilling roles and noted that precedents have been established for the creation of a single project and management entity for programs with more than one funding source.

This issue also was partially identified in the May 1992 Hanford Progress Assessment (E/C-3 and E/C-4), and a number of the specific deficiencies cited in the Progress Assessment have not been fully corrected. These issues include the lack of an Office of Groundwater Protection Management, sitewide procedures, and a sitewide well inventory and abandonment plan. 


\section{EP-3: Groundwater Protection Management Program}

Performance Objective: DOE 5400.1, "General Environmental Protection Program," Chapter III, Section 4.A, requires a Groundwater Protection Management Program (GPMP) and a Groundwater Protection Management Program Plan (GPMPP). Among the specific activities to be included in the program are: "documentation of the groundwater regime with respect to quantity and quality"; "design and implementation of a groundwater monitoring program to support resource management . . ."; and "a management program for groundwater protection and remediation."

DOE 5400.1 also establishes DOE policy to "anticipate and address potential environmental problems before they pose a threat to the quality of the environment of of the public wolfare."

Revised Code of Washington (RCW) 90.44, "Regulation of Public Ground Water," states that groundwater management programs shall include identification of water resources, projection of water supply needs, identification of water resource management policies, and identification of land use and other activities that may impact the quality and efficient use of water.

Washington Administrative Code (WAC) 173-160, "Minimum Standards for Construction and Maintenance of Wells," sets standards for well drilling, construction, maintenance, and decommissioning and abandonment. WAC 173-160-415 states "Any well which is unusable or whose use has been permanently discontinued . . . shall be abandoned."

The Hanford GPMPP states that the strategy for well-remediation and decommissioning activities is provided in the Hanford Well Remediation and Decommissioning Plan.

The GPMPP states in Section 3.0, "General Program Objectives," that one of the sitespecific objectives for groundwater protection is to "manage groundwater (recharge and withdrawal) to minimize adverse impacts of existing contamination." Section 4.1, "General Policy and Strategy," includes the site-specific strategy element: "Control artificial recharge and groundwater withdrawals to minimize the movement of contaminant plumes."

Finding: Elements of the Hanford GPMP have not been fully implemented.

Discuscion: The Hanford GPMPP is prepared by $R L$, along with subordinate planning documents, to fulfill planning requirements for groundwater protection activities required under DOE 5400.1. The GPMPP states that many of the elements required for the GPMP are covered by existing programs at Hanford, and that the purposes of the GPMPP are to provide a framework for coordination of existing groundwater protection activities and to provide the general scope, philosophy, and strategies for groundwater protection and management.

The current draft of the GPMPP was published in November 1993 and currently is under revision (I-D-9 and I-D-25). Additionally, Tri-Party Agreement (TPA) Milestone M-13-81 requires submittal of a work plan on the Hanford Groundwater Remediation Strategy to EPA and the Washington State Department of Ecology (WDOE) by August 31, 1994, and submittal of a work plan on the Hanford GPMP to EPA and WDOE by October 31, 1994. 
Work has been initiated on these documents (I-D-1, 1-D-9, and I-D-25); however, it was not within the scope of this audit to review these documents in preparation.

Several elements of the GPMP have not been fully implemented in the existing programs at the site or are missing in the current GPMPP. Specific examples of deficiencies include the following:

- The GPMPP does not adequately address existing groundwater resources and uses, future resource needs, or water resource management policies. For example:

- There is no discussion of existing groundwater withdrawal by the 400 Area drinking water supply or the North Richland Wells, existing discharges to groundwater, or the relationship between these activities and potential impacts from site activities. There also is no discussion of strategies regarding future groundwater withdrawals and discharges other than cessation of current liquid waste discharges. The current document focuses on monitoring and remediation activities, but does not address groundwater and wellhead protection strategies. Section 4.4, "Groundwater Protection and Monitoring," discusses the Columbia River as the eventual discharge point for contaminant plumes, but does not discuss the supply wells as potential receptors (D-D-3).

- Current interpretations of groundwater flow indicate that several factors may be limiting the migration of the 200-E Area tritium plume toward the North Richland Wells. These include recharge from irrigation in the western North Richland Area, contributing to eastward flow toward the river; and groundwater mounding at the North Richland recharge basins, which serves as a hydraulic barrier limiting southward flow of groundwater from the site (D-D-9; I-D-18). The GPMPP does not address the significance of these practices or implications of future changes in recharge and withdrawal practices. A long-term groundwater protection strategy must include consideration of these recharge and withdrawal practices and the relationship between these activities and potential impacts from site activities.

- A sitewide program to inventory, remediate, maintain, and abandon wells in accordance with the Washington State Code and the anticipated Draft Hanford Facility Resource Conservation and Recovery Act (RCRA) Permit has not been fully implemented (I-D-1, 5, 24, and 28). For example:

- The Washington State Code specifies requirements for abandonment/closure of unused and unsuitable wells; however, there is no schedule specified. The Draft Hanford Facility RCRA Permit specifies a specific schedule for well abandonment (I-D-1 and I-D-24). There have been approximately 4,400 known wells drilled at Hanford, approximately 3,300 of which still exist (D-D-20). Reports of the number of wells currently in use vary from approximately 1,200 to 
2,400 (D-D-6 and D-D-20); therefore, approximately 900 to 2,200 wells may require abandonment. Some of the "in use" wells may require rehabilitation to meet current standards, or, alternatively, be sbandoned.

- Current funding and planning is limited to several specific decommissioning projects: 48 wells in the North Slope and Arid Lands Ecology areas for the environmental remediation program under a TPA milestone, and 53 new shallow vadose zone borings being installed and abandoned in the 200-W Area under the RCRA program (I-D-5 and I-D-24). Although a formal program has been established by WHC for well abandonment, this program is limited in scope, as noted above, and there is no funding or schedule for sitewide abandonment of wells to fully meet the requirements of WAC 173-160 (I-D-1, I-D-24, and I-D-28).

- There is no single point of contact at RL for oversight of sitewide well maintenance and decommissioning activities, and there has been inconsistent oversight of this program by RL (1-D-24). According to one RL staff member, the program has been viewed as a low-priority action because of the lack of an "imminent regulatory driver" (I-D-1).

This deficiency also was identified in the 1992 Progress Assessment Concern Number E/C-3. Significant progress has been made on several actions subsequent to the Progress Assessment: (1) a sitewide database of well ownership, the Hanford Wells Database System, is under development; (2) the Henford Well Remediation and Decommissioning Plan was issued by WHC in fiscal year 1993; and (3) specifications Ell 6.10, "Abandoning/ Decommissioning Groundwater Wells," and Ell 8.3, "Remediation of Groundwater Wells," were issued in fiscal year 1992 and revised in fiscal year 1993. WHC's Subsurface Investigation Services has been given authority by RL, and has established Ell procedures, to issue start cards for all well construction and decommissioning and meeting reporting requirements under WAC 173-160. There is not yet a formal system in place to ensure that all non-WHC activities are captured by these processes, although it is currently happening in practice (1-D-5 and I-D-24). For example, the PNL Statement of Work for Well Rehabilitation fiscal year 1994 specifies work to be done under the direction of PNL, but does not specify any coordination with WHC's Subsurface Investigation Services and does not reference the Ell Procedures (D-D-23; I-D-28).

- There currently is no program for routine or systematic characterization and maintenance of sitewide wells (1-D-24). PNL performs routine maintenance of wells under ownership of the groundwater surveillance program; however, WHC does not currently perform routine maintenance of wells (I-D-24 and I-D-28). It should be noted that the 1991 Hanford Environmental Monitoring Plan, Section II.B, "Operational Environmental Maint anance," states 
"Groundwater monitoring wells require periodic maintenance to ensure that the well is providing representative samples" and that wells used for the operational monitoring program are scheduled for routine inspection and maintenance every 3 to 5 years (D-D-27).

WHC's Subsurface Investigation services conducts field characterization of wells, fitness-for-use evaluations, and wellmaintenance activities. However, these activities are performed only on an as-needed basis for specific wells being considered for inclusion in individual programs. 


\subsubsection{Oveniew}

The purpose of the formality of environmental programs portion of the routine environmental audit is to assess whether environmental protection activities at the site are being conducted in accordance with formal programs supported by documentation, inspections, and procedures. DOE 5480.19, "Conduct of Operations Requirements for DOE Facilities," and DOE 5700.6C, "Quality Assurance," provide requirements and guidelines for the development of directives, plans, and procedures relating to the conduct of operations. These orders state that DOE policy requires facilities to put procedures in place to control the conduct of their operations, and that these operations be managed with a consistent and auditable set of requirements. Appendix $E$ lists the regulations, requirements, and guidelines used to evaluate the site.

This portion of the audit focused specifically on the following areas:

- Regulatory Tracking and Translation - systems to transmit, track, and interpret environmental regulations and DOE Orders and incorporate them into policies, standarts, and procedures.

- Procedures - mechanisms by which environmental programs and procedures are developed and effectively implemented throughout the organization.

- Routine Facility Surveillance Inspections - systems to conduct routine inspections to ensure site compliance with applicable environmental requirements, and to identify and correct potential problems.

- Recordkeeping and Reporting - systems to maintain and retain records, and to ensure timely completion of environmental regulatory and management reporting requirements.

The general approach to this portion of the audit was to review before arriving onsite: DOE Orders, environmental regulatory requirements, and formal site documentation describing the implementation procedures, conduct of operations, and quality assurance programs.

Onsite activities included additional document review and interviews with management personnel of RL's Quality, Safety, \& Health Programs Division (RL-OSH), Laboratory Management Division, Environmental Remediation Division, and Waste Management Division; WHC's Waste, Analytical and Environmental Services and Emergency, Safety, Quality Services; Hanford Environmental Health Foundation's (HEHF) Health Services Division; and PNL's Office of Health and Environment, Facilities and Operations Division, and Earth and Environmental Sciences Center. This portion of the audit relied on input from all members of the audit team.

\section{Requlatory Trackino and Translation}

Regulatory tracking within RL relies heavily on WHC's Regulatory Support organization within Waste, Analytical and Environmental Services. WHC notifies RL of impending 
changes in Federal and State regulations; RL, in turn, transmits requests for review, comment, or implementation to site contractors. PNL also relies upon WHC's regulatory tracking activities and has no internal, formal review procedures or regulatory tracking systems of its own, aside from customer-directed changes. Although WHC essentially is performing regulatory review sitewide, it has not been formally assigned this task by RL.

\section{Procedures}

The procedures used to implement the site's environmental programs are not integrated, and vary according to contractor. Each contractor assessed, however, had comprehensive procedures for most of its respective operations, and it appeared that procedures were reviewed and updated regularly. RL has been attempting to integrate sitewide environmental programs (e.g., emergency preparedness contingency planning), but most programs currently are conducted according to the respective contractor's own set of procedures. A prime example of this is the Pollution Prevention Awareness Program (PPAP) (see Finding OS-3). WHC, PNL, and HEHF maintain detailed procedures describing their respective PPAPs. Each is separate from the others, but there is some attempt to cross-feed technical information, particularly from WHC to the other contractors. WHC compiles and formats site contractors' waste minimization progress report data for RL into a single report for the Washington State Department of Ecology (WDOE). WHC has developed an excellent, comprehensive draft guide for its waste generators that describes how to prepare and maintain a facility-specific waste minimization plan.

For the most part, WHC's and PNL's procedures are updated as necessary (i.e., driven by customer noeds and regulatory changes), or at least annually, as described by the respective Quality Assurance Program section governing procedural reviews. Training requirements prescribed under the Quality Assurance Programs are well-documented, frequently updated, and accomplished by all three major site contractors. The training resources and training databases, however, are not centralized or integrated (see Finding EP-2).

\section{Routine Facility Inspections}

The responsibility for environmental programs is shared by several site contractors and their subcontractors. RL has the contractor oversight role for ensuring that these environmental programs are being implemented according to DOE Orders and policies, and that site activities are in compliance with all applicable regulations. Within RL. contractor oversight is provided by the Assistant Manager for Environmental Management, Assistant Manager for Technical Support, Assistant Manager for Waste Management, and the Tank Waste Mediation System Program Office. Independent oversight of contractor programs also is performed by RL's Office of Performance Assessment, and Office of Environmental Assurance, Permits and Policy (RL-EAP). Of these oversight roles, the one performed by RL's Office of Performance Assessment is by far the most proceduralized and formalized. Oversight by other RL offices consists of milestone document review and field surveillances. Because of staffing limitations, many RL managers interviewed rely heavily on document review and limit the number, extent, and rigor of field surveillances.

Contractor self-assessments are required under RL Implementing Directive 1000.1, "SelfAssessment." For the most part, the most effective oversight programs are being performed by the contractors' respective staff organizations (i.e., PNL's Facilities and 
Operations and WHC's Emergency, Safety, Quality Services). Self-assessments by line managers are not as well-developed, extensively implemented, or effective as intended by RL Implementing Directive 1000.1. The audit team reviewed the contractor selfassessment programs which varied from very good to very basic.

\section{Recordkeeping and Reporting}

The findings and interest item tracking systems within Hanford are varied and not integrated. RL-QSH relies upon a subcontractor-MACTEC-to provide the quarterly Central Information Control System (CICS) report. The CICS is an informational tracking system that includes a detailed accounting of open inspection items and findings that are either open, delinquent, in progress, or pending verification prior to closure. Each item in CICS is ranked according to its Priority Planning Grid value, which reflects the risk of occurrence and severity of outcome. Whereas CICS provides very valuable tracking information that allows RL-OSH to summarize all ongoing corrective actions, CICS is not used by many other RL managers, nor does it contain sitewide information (i.e., items identified and being tracked by contractors). WHC tracks its environmental findings and interest items using the Quality, Environmental, and Safety Tracking System (QUEST) relational database, which is maintained by corrective action data systems of WHC's Emergency, Safety, Quality Services. QUEST also uses the same Priority Planning Grid value system as CICS, but does not contain the same information about findings tracked by RL, PNL, or the site's other contractors and subcontractors. The PNL database tracking system, Compliance Action Tracking System (CATS), contains only the items pertaining to PNL's 300 Area, but none of WHC's items, even if they have some bearing on or relationship to PNL's activities. Weekly CATS updates are provided to the director of RL's Laboratory Management Division.

RL-EAP is responsible for regulatory reporting under the National Emission Standards for Hazardous Air Pollutants (NESHAPs) and National Pollutant Discharge Elimination System (NPDES). These reports are forwarded to EPA Region $X$; the radiological NESHAPs data also are reported to the Washington State Department of Health (WDOH) under a separate State regulatory agreement for monitoring radiological air emissions. Reports made under the Safe Drinking Weter Act (SDWA) are reported through RL-EAP to WDOH, which has primacy for the SDWA. RL was in full compliance with these environmental requirements and was meeting report milestones ahead of schedule.

The audit team concluded that the documentation reviewed indicated that site contractors had, for the most part, adequate formality in their environmental programs. Of particular note were the WHC goals to maintain an exceptionally high quality of formal documentation, both in procedures and quality assurance, that was among the best in DOE. Despite the overall high quality of formality, the audit team identified one finding associated with formality relating primarily to oversight functions and self-assessment programs. 


\subsubsection{Finding}

\section{FP-1: $\quad$ Formality of Oversight Activities}

Performance Objective: DOE 5480.19, "Conduct of Operations Requirements for DOE Facilities," provides requirements and guidelines for the development of directives, plans, and procedures relating to the conduct of operations. This Order states that DOE policy requires that the conduct of operations at DOE facilities be managed with a consistent and auditable set of requirements, standards, and responsibilities. The policy statement also addresses the use of procedures to control conduct of operations, review of programs, and assessment of program effectiveness.

Finding: Oversight, findings and regulatory tracking, and field surveillance activities are not being conducted with sufficient formality or consistency.

Discuseion: Best management practices dictate that formal systems and procedures should be in place to manage day-to-day environmental protection activities to ensure environmental compliance. This includes systems to track and understand regulatory requirements, procedures for implementation of policies and programs, routine inspections and field surveillances, and systems for recordkeeping and reporting. Specifically, the following Hanford programs and elements lack formality:

- Formal schedules and criteria have not been developed and issued for field surveillance of contractor environmental programs and documentation review (1-C-2, 7, 18, 21, and 22). Limited staff and competing requirements were cited most frequently by interviewees as reasons why formal schedules had not been developed or followed. For example, the RL project manager for Area 100 has oversight responsibilities for 373 separate hazardous waste sites. Other RL managers with oversight responsibilities have comparable workloads. Scheduling this number of site visits, in addition to the much larger task of performing field survaillance on each, appears to be an intractable problem (1-C-1).

- Results of RL field surveillances often are inadequately documented; consequently, findings obtained during these surveillances are not consistently entered into any of the Hanford internal tracking system databases (1-C-1, 2, 18, and 21).

The site operates at least three separate, contractor-developed tracking systems; RL managers appear to borrow from all three, depending on the specific area of oversight. For example, managers in RL's Laboratory Management Division use PNL's Compliance Action Tracking System (CATS) or their own personal tracking system, whereas those RL managers with oversight responsibilities for WHC's programs use the Quality, Environmental, and Safety Tracking System (QUEST) (1-C-28). RL managers in the Quality, Safety, and Health Programs Division maintain a separate tracking system called the Central Information Control System (CICS) (I-E-1). There is an effort now under way to consolidate findings and interest-item tracking for all Hanford organizations in a second-generation version of QUEST. 
There are inconsistencies in the content, frequency, and rigor of field surveillances; in one case, mostly because of staffing shortages, a responsible RL manager has not conducted field surveillance in more than 2 years. In lieu of field surveillances, RL managers have relied upon regulatory milestone completion reports as the principal evaluation tool for contractor performance (1-C-2 and $1-C-18)$.

There appears to be no formalized procedure to close verified Tiger Team findings and observations from the site's tracking database(s). Currently, 65 corrective actions resulting from the 1990 Tiger Team Assessment have been completed in the CICS, but they await verification because RL managers either do not believe they have the authority to close the finding or have not received verification evidence from the contractor(s) (I-C-18 and I-E-1). There are an additional 38 delinquent corrective actions for which completion date projections are lacking or have not been aggressively pursued. Followup requests for status on these open items do not appear to occur with any consistency or periodic frequency until a particular finding becomes highly visible to regulators. Consequently, finding closure tends to be reactive, rather than proactive.

RL does not have regulatory tracking procedures in place and must rely upon WHC's Regulatory Support organization for this service. Although WHC essentially is performing regulatory review sitewide, it has not been formally assigned this task by RL (I-C-18, I-C-28, and I-E-1).

Procedures and guidance on National Environmental Policy Act (NEPA) document preparation (RL 5440.1B) have not been approved and republished following the Secretary of Energy's Notice, SEN 15-90, issued in February 1990. Draft NEPA guidance documents have been issued periodically by RL on an as-needed basis; however, formal procedures have yet to be approved by RL senior staff (1-C-29).

- The Memorandum of Understanding for Implementation of the Hanford Environmental Management Program, which was supplemented in 1989 with a Memorandum of Understanding covering the PNL and WHC surface environmental monitoring programs, does not reflect the current Environmental Monitoring Plan (EMP) and Environmental Protection Implementation Plan (D-D-17; I-D-5 and I-D-10) (see Finding EP-3).

WHC performs routine compliance assessments of effluent monitoring stations and has a written checklist and schedule (I-D-16). The schedule is not up to date; it includes 15 liquid effluent stations, although the number of stations has been reduced to 10 as part of the cessation of effluents under the Tri-Party Agreement (I-D-16).

Formal procedures for seep sampling along the Columbia River are not in place (I-D-18 and I-D-22). This internal milestone in PNL's Contractor Work Plan for the Surface Water Surveillance Project, under the Public Safety and Resource Protection Program, currently is behind schedule (D-D-21). 
Surface water sampling for the Operational Environmental Monitoring Program (OEM) is performed by the WHC Site Surveillance Health Physics Group in support of the OEM, under the direction of WHC Environmental Engineering Studies. For approximately 10 months, the Health Physics group has been using informal "desktop procedures." Formal procedures recently have been developed but currently are in draft form and are expected to be approved and released by May 14, 1994 (D-D-22; I-B-14 and I-D-10).

An EMP is required by DOE 5400.1 for all DOE sites and facilities that use, generate, release, or manage hazardous materials. The EMP must consider the rationale and design criteria for the monitoring program, extent and frequency of measurements, procedures for laboratory analysis, quality assurance requirements, etc. To a great extent, the design bases for Hanford's environmental surveillance activities are not formally documented. Instead of specific rationale, the EMP references generic criteria from the DOE Regulatory Guide (DOE/EH-0173T). The EMP documents current monitoring and surveillance activities, and notes GENII computer code pathway analysis, but does not formally document design rationale and criteria for locating monitors and frequency of measurements (D-B-64; I-B-2, (-B-4, and $(-B-8)$.

DOE 5400.1 requires a formal quality assurance program covering each element of environmental monitoring and surveillance programs commensurate with its nature and complexity. One of PNL's quality assurance programs, dated June 1992, is for facility effluent monitoring; this plan, however, has not been formally approved, signed, and implemented (D-B-98; 1-B-5 and I-B-7).

DOE realizes that the level of oversighx must be determined on a case-by-case basis; RL's Self-Assessment Guidance Document, RL Implementing Directive 1000.1, suggests, however, that the rationale for the extent and frequency of oversight activities should be documented along with the results of the oversight activities. Considering the size of the environmental monitoring mission at Hanford and the enormous task of oversight, the best way to ensure that all contractor activities are receiving the appropriate level of oversight would be to formalize the procedures and processes to achieve this objective.

In summary, the audit team concluded that competent oversight is being performed in many areas, but a higher level of formality is required in the above areas to ensure that all areas are receiving the requisite oversight and assurance of continued compliance. 


\subsubsection{Overview}

The internal and external communication portion of the audit was conducted to evaluate the effectiveness of the communication systems, both internal and external, at Hanford. The review of these systems was designed to determine whether formal and informal channels of communication are effectively used to emphasize management commitment to environmental protection; to promote awareness and support of environmental policies and programs throughout the organization; and to share information with external organizations such as regulatory agencies, environmental groups, and the community. The specific regulations, requirements, and guidelines used to evaluate the site are shown in Appendix E.

Elements of internal communication evaluated during the audit included regular, formal processes such as staff meetings, management reporting, routing of key documents, distribution of employee newsletters, memoranda from senior management, and informal processes such as telephone calls and informal meetings. Common perceptions of information distribution and communication effectiveness also were considered. External communication efforts that were reviewed included interfaces with regulatory and external oversight groups, and community outreach programs.

The general approach to this portion of the audit was to review DOE Orders and other background documents received from Hanford prior to the onsite portion of the audit. Onsite activities included interviews with RL, WHC, and PNL personnel who participate in the exchange of environmental information, both internally and externally; and a review of written communication programs, policies, and other documents pertaining to environmental information exchange. This portion of the audit relied on input from all members of the audit team.

Interviews were held with RL, WHC, and PNL managers and staff, including the environmental program line organizations. Special attention was focused on the RL, WHC. and PNL communications offices, as well as RL's Employee Concern Program. Interviews were conducted with staff from the Washington State Department of Ecology (WDOE), one member of the Tri-Party Agreement (TPA).

Communication-related plans and documents reviewed included the Hanford Environmental Publications List; public outreach presentations/activities; the Employee Concern Program; presentation materials from management, staff, and public briefings; various Hanford press releases and environmental news releases and promotional literature. In addition, a videotape on the Hanford cultural heritage was viewed. This tape featured members of the local Native American tribes and was reviewed for accuracy by members of the tribes prior to distribution.

In reviewing internal communication, the team found that communication vertically within the program organizations was strong. Many instances of good lateral communication, the sharing of environmental information among line organizations and with support organizations, were observed. The Hanford Central Environmental Committee holds monthly executive and full-committee meetings. There are some areas at Hanford in which lateral communication needs development. Situations were found in which poor internal 
communication resulted in substantial delays in the reporting of environmental data. Of equal concern were areas of overlap and duplication, when communication among organizations could have resulted in coordination of effort (see Finding EP-2). These weaknesses in internal communication were characteristic of RL, WHC, and PNL.

RL has a well-implemented Employee Concern Program, which it has integrated throughout the site. This program has served as the model at other locations throughout the DOE complex. It investigates to closure all concerns filed, and accesses the highest level of management necessary to effect resolution. Anonymity, when requested, is maintained; investigations are timely and thorough; and results are reported in writing. Employee acceptance is high, and managers have been known to utilize the program. Although it is intended for employee use, concerns from local citizens received through the hotline have been investigated.

Hanford is among the most scrutinized sites in the DOE complex. Each year, Hanford hosts approximately 1,000 audits, assessments, site tours and visits from DOE, EPA, the State of Washington, local government, and a variety of public interest and oversight groups. Hanford has a well-integrated communications program that utilizes the talents of the RL, WHC, and PNL communications offices. Along with the public meetings, informational literature, and press releases, Hanford has implemented a variety of innovative programs to strengthen public outreach. Among these programs is the Community-Operated Environmental Surveillance Program, which uses local schoolteachers to conduct environmental air sampling. A series of videotapes on Hanford's cultural and ecological background has been produced and distributed to teachers throughout the Northwest. Hanford currently is developing a teaching guide to accompany the tapes. The public outreach activities have been so successful that some of the outlying public interest groups have allowed Hanford to eliminate several regional public meetings.

Hanford communicates frequently with regulators concerning environmental issues at the site. There are monthly Technical Review Meetings between the Washington State Department of Health (WDOH); RL Office of Environmental Assurance, Permits, and Policy (RL-EAP); WHC; and PNL. Quarterly Executive Management Meetings are held between WDOE, WHC Regulatory Support, and RL-EAP. Hanford has developed a protocol for interfacing with regulators. Despite generally strong communication with the regulators, WDOE members have expressed difficulty in assessing validated environmental analysis data within the time frame set forth in the TPA. Additionally, some individuals from WDOE have experienced difficulty in determining whom to contact regarding regulatory issues.

One finding was identified regarding lateral lines of internal communication. 


\subsubsection{Finding}

IC-1: Channels of Internal Communication

Performance Objective: Best management practices suggest that formal and informal channels of internal communication be established to ensure that environmental information is communicated throughout the organization (top-down, bottom-up, and lateral). Such channels of communication should foster cooperation and serve to minimize redundancy and duplication of effort.

Finding: Internal communication issues within Hanford's environmental programs have impacted data management and reporting, and the communication of program rationale/strategy.

Discuscion: The Hanford organization is structured along program lines. Line organizations within the four major programs, Environmental Remediation, Waste Management, Tank Waste Remediation, and Research and Development, tend to interact and exchange environmental information efficiently, from the top down and the bottom up.

Effective lateral communication between and among program lines, however, does not always occur at Hanford. Organizations in one program line often are unfamiliar with actions and requirements of other program lines. This lack of internal communication has resulted in areas of real or perceived duplication of effort and delays or conflicts in objectives. Specific weaknesses noted in internal communication include the following:

- A major disagreement between the WHC Waste Management and WHC Environmental Remediation Programs concerning the validation of environmental data required resolution by the DOE Office of Environmental Management. This dispute delayed the reporting of Environmental Remediation Program data for more than 1 year (I-C-1, 12, 17 and 22).

- A PNL contractual requirement that all communication with contract analytical laboratories go through PNL's Laboratory Subcontracting Department creates the potential for adding delays in reporting analytical data (see Finding OS-2).

- Two examples of potential or perceived redundancy resulting, in part, from poor communications among groundwater programs were identified during the audit: completion of sitewide water table measurements by both PNL and WHC, and completion of separate sitewide groundwater models by PNL and WHC (see Finding EP-2).

- The purpose, rationale, and long-term strategy for the Hanford collective groundwater programs are not clearly established and communicated among programs (see Finding EP-2).

If Hanford is to achieve its goal of environmental excellence, communication among programs, projects, and offices must occur freely and openly. Good internal communication is crucial to effective environmental monitoring and timely reporting of analytical results. 
The purpose of the staff resources, training, and development portion of the audit was to ensure that the level of staff resources is sufficient and is utilized effectively to develop and implement the organization's environmental protection programs; that a formal program is in place to ensure that all personnel have received environmental protection training appropriate for their job responsibilities; and that the organization provides staff development and career advancement opportunities for environmental staff. The specific regulations, requirements, and guidelines used in the ev aluation of the site are listed in Appendix E.

The general approach to this portion of the audit was to review DOE Orders and Hanford documents pertaining to staff resources, training, and development, prior to the onsite portion of the audit. Specifically, these documents included position descriptions, performance evaluation forms, training material, training records, and relevant procedures. Onsite activities included interviews with relevant administrative departments (human resources, training, and budget) within $R L, W H C$, and PNL, as well as staff representing various Hanford environmental programs.

It is critical that RL assures DOE Headquarters (DOE HQ) that Hanford has appropriate environmental protection. Oversight of the environmental activities should be consistent and comprehensive. The RL oversight demands will continue to increase as the transition from a defense programs mission to an environmental management mission continues, during the implementation of the Environmental Restoration Contract, and during the decontamination and decommissioning and remediation activities.

Through the Environmental Management bid process, an additional 158 full-time-equivalent (FTE) employees were approved for RL. The additional FTEs (roughly 70 percent are in technical areas), although less than the 200 requested during the bid process, should help to correct many of the environmental oversight concerns noted by the audit team (see Finding SR-1). There is, however, a need to ensure that the Hanford operation is moving forward in its goal of environmental excellence and that compliance is not the only benchmark of environmental protection. As regulations and programs change and/or accelerate at Hanford, additional oversight and reporting to DOE and the regulatory agencies will place added burden on RL. RL serior management has indicated its intention to carefully assign each FTE to fulfill priority environmental needs. The audit team viewed this as crucial to the pursuit of environmental excellence.

The technical experience and managerial backgrounds of key environmental staff were appropriate for their responsibilities. The staff interviewed within RL, WHC, and PNL were well qualified, both on technical and management issues.

A review of formal job descriptions indicated inconsistency in format among contractors. As a result of the recient organizational changes within RL, WHC, and PNL, many roles and responsibilities are in state of transition.

One element of the performance review criteria is recognition of an individual's environmental performance; however, environmental performance goals do not appear 
consistently as a line item in the individual's development plan. Pi Jtection of the workforce is amphasized in individual development plans by attention to safety; while health and safety justifiably are priorities, equal emphasis on environmental issues is essential to support the continued drive for environmental excellence.

Both WHC and PNL have recognition and incentive systems which include good environmental performance as part of their respective award programs. RL utilizes a group bonus program based on predetermined initiatives in place of individual performance awards or quality step increases. Additionally, RL has implemented a "Safe Buck" award program to recognize associates demonstrating preferred safety behaviors. Again, while attention to safety is a justifiable priority, equal emphasis on environmental issues is essential.

Hanford has a broadly based training capability, with training activities carried out by the RL Office of Training and Education, the WHC-managed International Environmental Institute and Quality Training and Resource Center, and the PNL Laboratory Safety Education Group. RL, WHC, and PNL have well-documented training course catalogs and descriptions, as well as training matrices that incorporate required environmental training. Input to these plans and matrices typically has been from the division level, where specific regulatory-driven environmental training requirements are vested. WHC, PNL, and the Quality Training and Resource Center each maintains its own training management information system. RL's Office of Training and Education is responsible for the RL employee training records, scheduling, and registration; it utilizes a separate WHC group to manage this system as a general support services contractor. There is some redundancy in the management of training information and in training programs offered by the various site contractors. This was a finding in the May 1992 Progress Assessment conducted at Hanford and is discussed in greater detail in the Organizational Structure section of this report. The lack of integration results mainly in an inefficient use of resources, particularly from an administrative perspective; however, consistency in the level of support provided to all environmental trainers (i.e., lack of "train the trainer" education) and training materials used across the site should be reevaluated (see Finding OS-3).

The respective training organizations provide oversight to monitor the effectiveness of the training programs. These oversight activities include participant evaluation, instructor evaluation, and course and instructor certification. The quality of training and the qualifications of instructors (the majority of whom are subject matters experts) are reviewed by the respective training personnel within RL, WHC, PNL, and the Quality Training and Resource Center.

General training is given to all new employees, visitors, and subcontractors by each contractor. The environmental portion of this training involves a written test after review of a video presentation and written material. The content is adequate for a basic understanding of environmental protection.

As a result of the nature of the program focus at Hanford, staff development opportunities for environmental professionals are abundant. Recent organizational changes have provided opportunities for environmental staff to receive promotions, and opportunities for further growth exist within both WHC and PNL. In addition, both WHC and PNL provide managerial and professional training for those staff needing to expand their existing skills. 
In the staff resources, training, and development portion of the audit, one finding was identified relating to RL environmental oversight staff resources. In addition, the Organizational Structure section of this report addresses a concern that is related to the integration of sitewide environmental training. 


\subsubsection{Finding}

\section{SR-1: $\quad$ RL Environmental Staff Resources}

Performance Objective: Best management practices suggest that an organization responsible for oversight and assessment of environmental management have adequate staff resources to accomplish its mission.

Finding: RL oversight of Hanford sitewide environmental management is restricted in its scope by limited technical staff resources.

Discussion: The responsibility for environmental compliance activities is spread across several organizations at Hanford. RL is responsible for providing oversight to ensure that environmental policies are properly implemented by site contractors, and to ensure that Henford is in compliance with all appropriate government regulations (I-F-1, I-F-4, and I-F-14). Within RL, line oversight of environmental responsibilities is performed through the Assistant Manager for Environmental Management, the Assistant Manager for Technical Support, the Assistant Manager for Waste Management, and the Tank Waste Remediation System Program Office. Independent oversight of the environmental programs of the contractors and RL is provided by RL's Office of Performance Assessment. The Office of Performance Assessment is responsible for the performance of formal surveillance-type oversight of contractor environmental programs and activities. RL line managers, with support from RL's Office of Environmental Assurance, Permits, and Policy (RL-EAP) and RL's Quality, Safety, and Health Programs Division, perform other oversight activities such as document review, self-assessment, and environmental program guidance and direction.

The following are examples of unsupported or undersupported oversight activities identified by the audit team:

- The review process for tracking impending and new regulations is conducted by WHC for RL-EAP mainly because of current staffing levels (I-F-14). This review process has not been formally assigned or implemented throughout RL (see Finding FP-1).

There is significant reliance upon overtime in the Environmental Remediation Division (RL-ERD), with an average work week totalling 50-60 hours (I-F-4). Limited staffing within this branch, which oversees environmental remediation projects, has resulted in 373 environmental remediation sites being assigned to one manager (I-C-1). Additionally, some RL oversight activities rely too heavily on milestone completion reports in lieu of field surveillance. Some activities have not experienced a field surveillance in 2 years (I-C-18 and I-C-22).

RL does not have sufficient staff to properly review documents prior to their submittal to regulatory agencies. For example, an RL-ERD-proposed plan was prepared by WHC, at the request of RL, for submission to EPA. WHC followed a standard protocol for preparation of the plan and was unaware that the plan contained several statements which contradicted previous agreements between RL and EPA. The level of review by RL prior to 
submission did not identify these contradictions; however, EPA's review did (I-F-4).

- The fiscal year 1994 Work Requirements for RL's Regulatory Policy, Planning, and Aralysis Branch identified nine reports mandated by Federal and State regulations which are submitted one or more times per year, on dates established by the regulators. Also, the Hanford Environmental Management Plan program manager must certify that the information contained in the reports is true, accurate, and correct under penalty of law (D-F-20). The Regulatory Policy, Planning, and Analysis Branch is responsible for obtaining certifications from appropriate management for the contractor and for ensuring that RL organizations have input into the various reports. Because the number of reports, as well as input into the reports, continues to increase each year, the amount of time needed for the Regulatory, Policy, and Planning Branch to complete the review and certification process exceeds existing staff resources (D-F-20; I-F-14). Consequently, the Regulatory, Policy, and Planning staff has been unable to fully coordinate the activities as in the past, and has functioned only as the RL point of contact for final compilation and submittal of the reports to the regulatory agencies. As a result, RL line organizations have assumed responsibility for conducting the accuracy review of those portions of each report that pertain to their function, and for conducting the review and certification prior to submittal to the Hanford Environmental Management Plan program manager for signature (I-F-14).

It is critical for RL to provide DOE Headquarters (DOE HQ) with assurance that Hanford has appropriate environmental protection. Oversight of the environmental activities should be consistent and comprehensive. The RL oversight demands will continue to increase as the transition from a defense programs mission to an environmental management mission continues, during the assimilation of the Environmental Restoration Contractor, and during the decontamination and decommissioning and remediation activities.

During the Environmental Management bid process, an additional 200 full-time-equivalent (FTE) employees were requested; an additional 158 FTEs were approved (I-F-26). These additional FTEs (roughly 70 percent are in technical areas), even though less than the 200 requested in the bid process, should help correct many of the environmental oversight concerns noted by the audit team (I-F-7). There is a need, however, to ensure that the Hanford operation is moving forward in its goal of environmental excellence and that compliance is not the only benchmark of environmental protection. As regulations and programs chanfe and/or accelerate at Hanford, additional oversight and reporting to DOE and the regulatory agencies will place additional burdens on RL. Appropriate resources must be allocated to meet environmental responsibilities. The RL environmental staffing levels cannot be considered sufficient until the additional planned positions are filled and roles and responsibilities are clearly defined. RL senior management has indicated its intention to carefully assign each FTE to fulfill priority environmental needs (I-F-26). The audit team views this as crucial to the pursuit of environmental excellence. 


\subsubsection{Qverview}

The purpose of the program evaluation, reporting, and corrective action portion of the Hanford audit was to evaluate programs that assess the design adequacy and implementation effectiveness of environmental protection systems, as well as the reporting and followup activities associated with these programs. The regulations, requirements, and guidelines used in the audit are listed in Appendix $E$.

The self-assessment and appraisal activities of RL, WHC, PNL, and the departments within the line organizations were assessed. The key elements reviewed were the design and formality of self-assessment and appraisal programs; program implementation; followup activities including trend analysis, root cause analysis, and corrective action systems; continuous improvement actions based on lessons learned; and selection of qualified staff to conduct evaluation activities.

The general approach to assessing this environmental management area was to conduct interviews of line management and support organization personnel who are responsible for evaluation of environmental programs. Documents were reviewed that relate to the various levels of self-sssessment and appraisal including plans, procedures, and documentation of the evaluation and followup activities.

At Hanford, the RL, WHC, and PNL organizations conduct environmental program evaluations. The comprehensiveness of the evaluations varies among the three organizations.

RL conducts a number of program evaluation activities that DOE guidance considers to be self-assessment activities. To date, these evaluations have not been conducted with the benefit of a comprehensive self-assessment program. RL personnel realize that additional formality and integration of the programs will be necessary in order to achieve continuous improvement and total quality. RL's program evaluation activities have focused primarily on the performance of formal oversight audits, assessments, inspections, and investigations. The personnel conducting these activities appear to be well-qualified to assess environmental programs. The results of RL oversight audits, assessments, surveillances, and inspections are recorded in the RL Central Information Control System (CICS). The RL internal self-assessment report was generated using the results recorded in the CICS. With the exception of two RL organizations, line organizations at RL did not perform individual self-assessments. Oversight by RL environmental program management was found to be inadequate in some areas. One program area has not been assessed in more than 2 years (see SR-1).

WHC has established a self-assessment program that includes self-assessments performed by individual line organizations. WHC personnel responsible for self-assessments report high variability of the self-assessment quality among the organizations. Some projects, such as Operational Environmental Monitoring and Effluent Emissions Monitoring, performed thorough self-assessments, while other organizations' self-assessments lacked detail. WHC currently is developing a program to train organizations to conduct thorough self-assessments. Additionally, WHC performs oversight audits, assessments, 

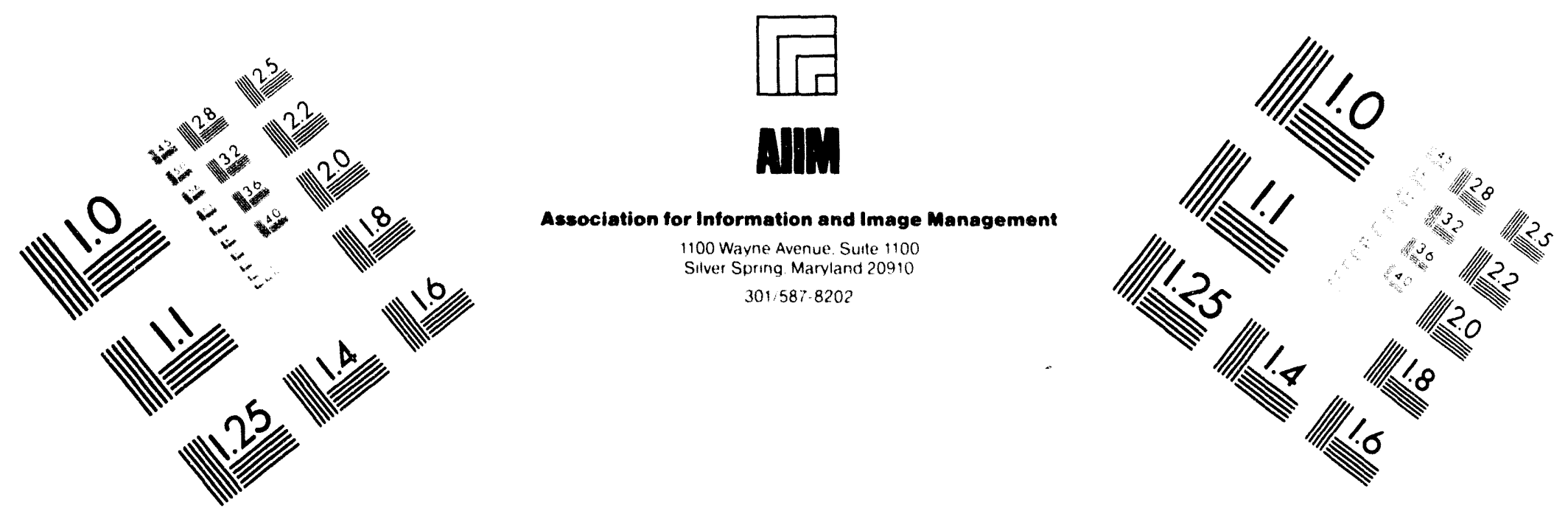

\section{Centimeter}

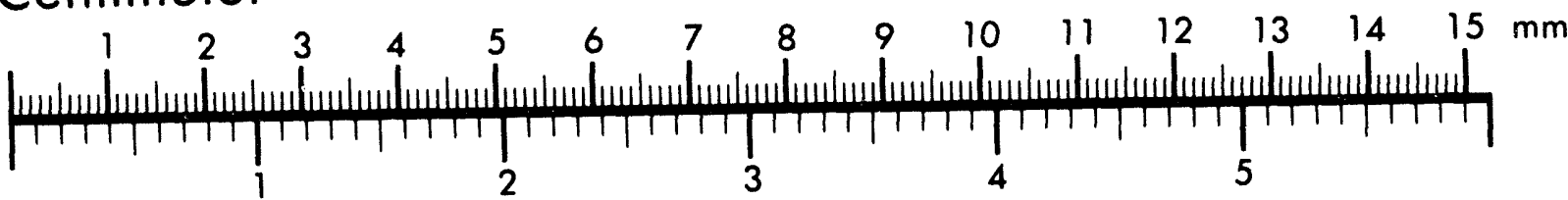
Inches
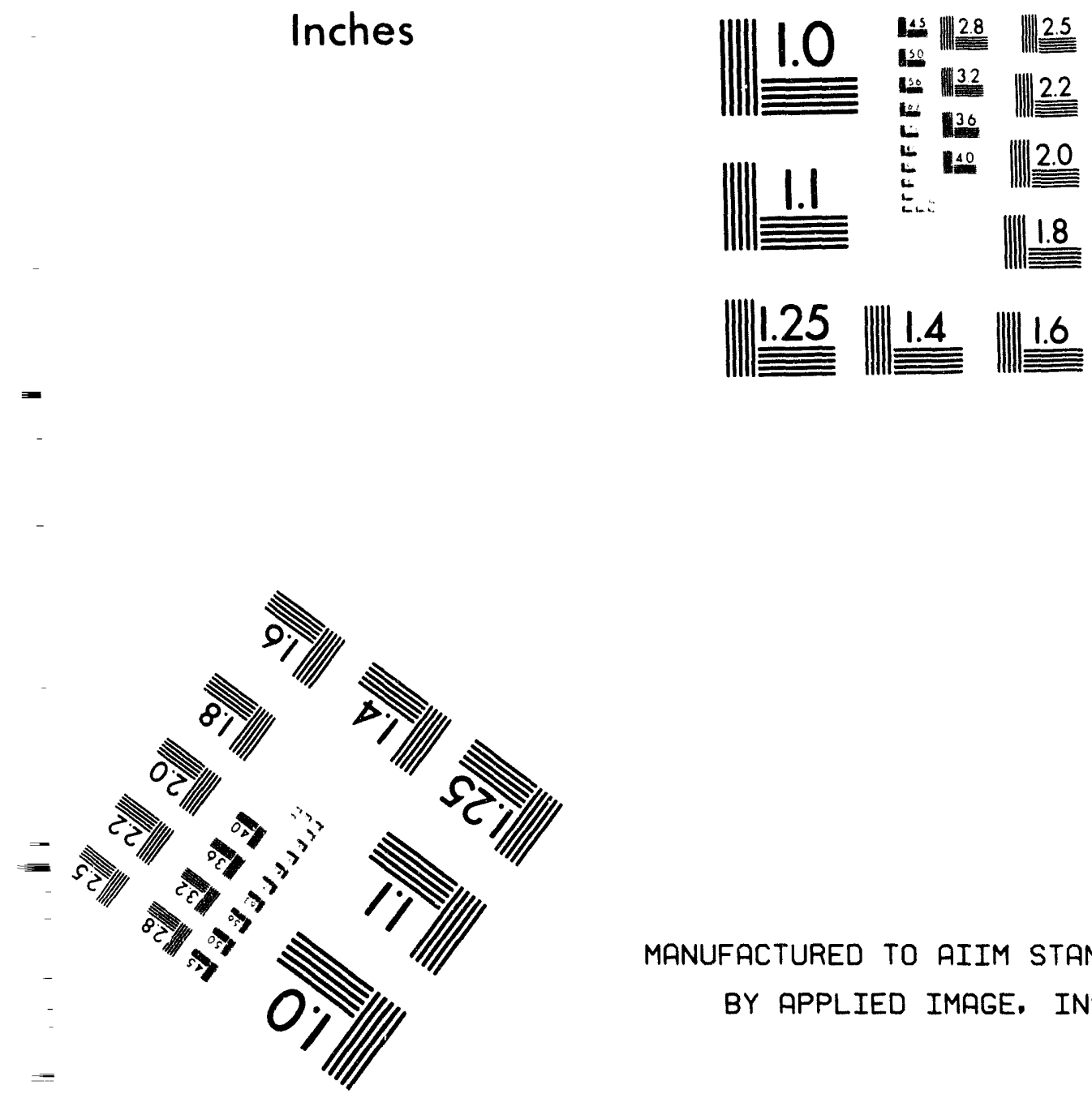

MANUFACTURED TO AIIM STANDARDS BY APPLIED IMAGE. INC.

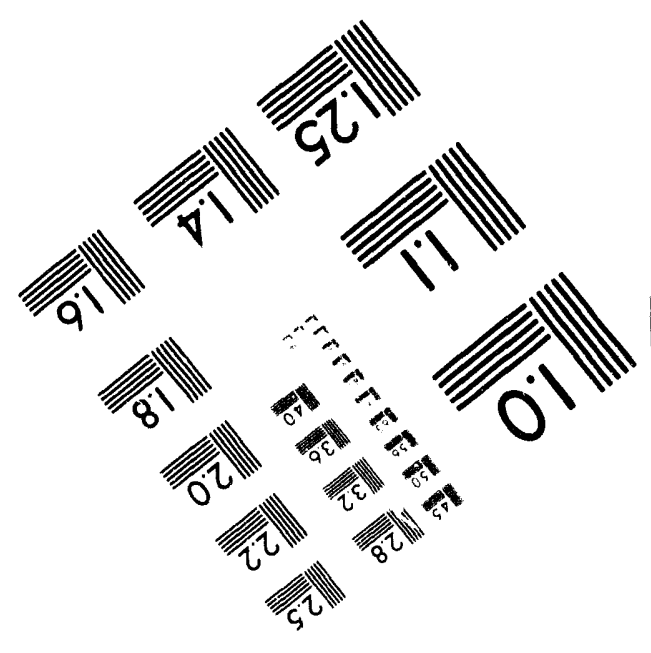



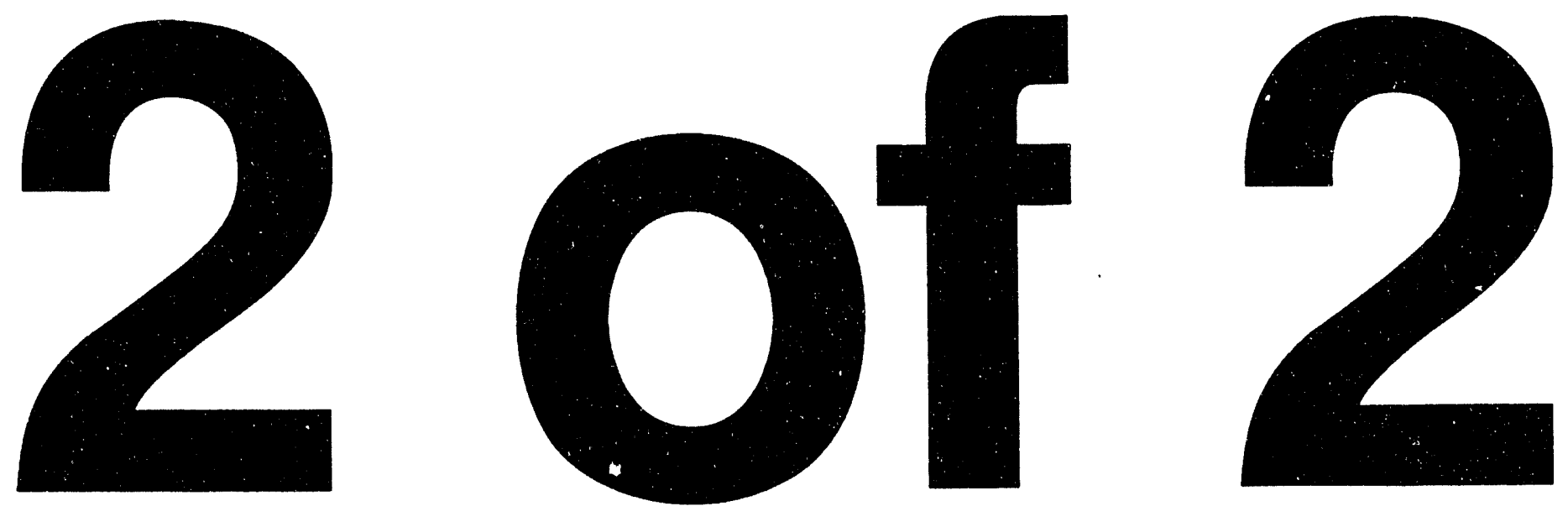
surveillances, and inspections. The results of these assessment activities are stored in the Quality, Environmental, and Safety Tracking System (QUEST).

PNL performed a conduct-of-operations self-assessment of its environmental program areas, using a dedicated task team; line personnel did not perform individual self-

assessment. Results of PNL assessment and oversight activities are maintained in the PNL database.

Significant contractor findings from the individual tracking systems, CICS, QUEST, and the PNL database, are consolidated in the Hanford Self-Assessment DataBase (HSADB). The HSADB is an RL database which collects significant contractor deficiencies and has the ability to sort the deficiencies by the responsible RL organization. Quarterly reports are provided to responsible RL line organizations so that they are aware of contractor-tracked deficiencies in their projects and programs. This information is considered input for RL line organization self-assessments. There is no sitewide, centralized corrective action tracking system.

The current corrective action management system does not ensure that corrective action is completed in a timely manner. A number of actions from the 1990 Tiger Team Assessment were found to be delinquent. An even greater number were awaiting verification of completion prior to closeout, even though RL holds closeout authority. Issues from the 1987 Environmental Survey are still awaiting closeout verification from the DOE Office of Environment, Safety and Health. WHC has tasked specific individuals to expedite assessment closure activities. Such action is worthy of mention, but would be unnecessary if the corrective action management systems worked effectively and management of all organizations assumed responsibility for closure.

One finding was identified in the program evaluation, reporting, and corrective action portion of the audit. The finding was related to the comprehensiveness of the Hanford Self-Assessment Program. 


\subsubsection{Finding}

PE-1: Hanford Self-Assessment Program

Performance Objective: DOE 5480.19, "Conduct of Operations Requirements for DOE Facilities," DOE 5480.1B, "ES\&H Program for DOE Operations," and DOE 5482.1B, "ES\&H Appraisal Program," establish requirements for self-assessment and appraisal programs at all levels of the organization.

On July 31, 1990, the Secretary of Energy issued the "Guidance on Environment, Safety, and Health (ES\&H) Self-Assessment" which states that self-assessment programs should contain a "line management-fostered atmosphere of continual self-evaluation and quality improvement in ES\&H at all levels, especially the operating level."

In December 1992, the DOE Office of Special Projects (E.4-5) issued the "Self-Assessment Guidance Document," which was designed to "promote consistency among selfassessment programs across the Department." The guidance states that the organization should have self-assessm. ant and oversight programs in place to effectively evaluate environmental protection activities, anticipate and report environmental concerns, and implement corrective actions.

On January 25, 1993, the Assistant Secretary for Environmental Restoration and Waste Management issued the "Office of Environmental Restoration and Waste Management (EM) Self-Assessment Management Plan." In the issuing memorandum, it states "the ultimate objective of self-assessment is for each employee of a [sic] EM assessable unit (facility. activity, or program) to be responsible for continuously evaluating his/her work effectiveness."

Best management practices suggest that self-assessment is a continual line management activity that acquires, assimilates, documents, and reports through all levels of an organization the effectiveness, adequacy, efficiency, and economy of its activities. Selfassessment should establish a culture of accountability and continuous improvement as well as foster excellence in all program activities.

Finding: Hanford has not developed a comprehensive, integrated self-assessment program that involves all levels of organization at the site.

Discussion: Under DOE 5480.19, "Conduct of Operations Requirements for DOE Facilities," and the December 1992 DOE self-assessment guidance, DOE suggests that all selfassessment activities be formalized into a comprehensive program that is integrated into the site's day-to-day activities. The purpose of this formality is to avoid duplication of effort and to institutionalize a culture of accountability and continuous improvement. DOE guidance includes a number of elements that are suggested to implement a comprehensive self-assessment program. These include such items as program charters and program implementation plans; a comprehensive scope; formal performance objectives and criteria and evaluation schedules; and evaluation activities such as monitoring and surveillance, program reviews, and appraisals. Critical to the success of this program is the involvement of line personnel in the self-assessment process. Only by making each person at Hanford evaluate his/her roles, responsibilities and performance can an environment of 
continual quality improvement be achieved. Some examples of weaknesses in the Hanford self-assessment activities include:

- At RL, the only organizations to perform individual self-assessments are the Office of Performance Assessment, the Employee Concern Program Office, and the Laboratory Management Division. In addition, the Office of Performance Assessment performed an "assisted" self-assessment of the Tank Waste Remediation Systems Program. The self-assessments for RL and Hanford were developed by extracting data from oversight audits, assessments, and surveillances documented in the RL Central Information Control System (CICS) (D-E-42 and D-E-43; I-E-2, I-E-3, and I-E-5).

- WHC line organizations did perform individual self-assessments but the inputs were inconsistent, varying widely in content and quality among organizations (D-E-43 and D-E-45; I-E-19).

The PNL self-assessment was performed by a task team looking at PNL line organizations; no attempt was made to directly involve or train line personnel in the self-assessment process (D-E-10; I-E-10 and I-E-25).

The site maintains at least three separate tracking systems from which Hanford managers can extract assessinent data. These individual tracking . systems are loosely linked in a database known as the Hanford SelfAssessment DataBase (HSADB). This database is of limited usage in tracking significant deficiencies and data can be accessed only by specially trained personnel. There is no sitewide, centralized tracking system (D-E-29; I-E-3 and I-E-4).

- Corrective actions are not managed in a manner that ensures that they are closed in a tirnely manner. Although reports of corrective action status are generated and issued to responsible RL management by the Quality. Safety and Health Programs Division (RL-OSH) on a quarterly basis, and WHC management has on-line access to corrective action status, there appears to be no impetus to complete, verify, and close corrective actions. In the WHC Quality, Environmental, and Safety Tracking System (QUEST) there are 32 actions from the 1990 Tiger Team Assessment that are delinquent; an additional 43 actions are awaiting verification by RL prior to closure (D-E-31). There was some confusion in RL regarding closure authority for Tiger Team findings. In the recent RL CICS Quarterly Report for RL-OSH, 26 RL Tiger Team corrective actions were listed as delinquent (D-E-23). This was identified in the Hanford Self-Assessment Report (D-E-23, D-E-31, and D-E-40; I-E-3 and I-E-24).

RL has not fully incorporated lessons learned from assessment activities into its groundwater monitoring program. Previous audits have cited lack of coordination of monitoring programs. This condition is still an issue of concern at Hanford (see EP Overview and Finding EP-2). 
Although the organizational components of the Self-Assessment Program are in place at Hanford, the implementation of an effective program requires considerable attention from all organizations at the site. 


\subsubsection{Overview}

The purpose of the environmental planning and risk management portion of the audit was to assess the extent and effectiveness of technical and financial planning related to environmental management. Additionally, the audit addressed the site's systems for identifying, assessing, and addressing potential environmental risks. Appendix $E$ lists the regulations, requirements, and guidelines used in t'e evaluation of the site.

The scope of the environmental planning portion of the audit included short- and long-term environmental planning, integration of technical and financial planning, resource allocation, and prioritization of projects. The audit team also considered review of the environmental planning documents for consistency and integration important because of the site's multiple contractors.

The scope of the risk management section was to address the adequacy of systems designed to identify environmental hazards and to minimize and correct environmental risks. This included risk management program design and approach, risk-based prioritization systems, and project review to identify and address environmental risks.

The approach to this portion of the audit included interviews with RL, WHC, and PNL personnel responsible for project and program planning, risk management, Risk-Based Prioritization (RBP) systems, and environmental project review.

\section{Environmental Planning}

Long-range planning for environmental programs at Hanford is conducted through several mechanisms. The Hanford planning process requires participation from Hanford contractors. In this process, the Hanford Strategic Plan is expanded into the Hanford Mission Plan, a long-range vision for the site. The Hanford Mission Plan serves as the foundation for the Multi-Year Program Plan, the various subordinate project plans and fiscal year program or project work plans. Another major element of the planning process is the Hanford Site Management Plan. This plan integrates the Tri-Party Agreement (TPA) objectives, multi-year program plans, and RL requirements into a work breakdown structure and discrete work packages. In addition, there are plans such as the Environmental Protection Implementation Plan, which provides sitewide environmental protection goals and objectives at Hanford. At the project level, each contractor prepares project-specific work and management plans.

Activity Data Sheets (ADSs) are the fundamental budget formulation documents used by both WHC and PNL. ADSs are developed by the various Hanford programs and identify proposed projects, with information on priority and funding levels, budget reporting codes, and a short narrative description. ADSs are the basic units of description necessary to develop a 5-year plan and are updated annually. Prioritization of projects and resource allocation for corrective actions are performed using a RBP system and an Integrated Resource Management System, as described in the Risk Management section (see below). Technical and financial input for the ADSs provided by the individual site divisions is rolled up into program budgets submitted to RL. ADS data are summarized in the fiscal year work plans and multiyear program plans. The technical scope, assumptions, and budget 
for individual activities included in the Work Breakdown Structure of the ADSs are provided in the current year's work plans. ADSs are submitted to DOE Headquarters by RL on an annual fiscal-year basis, along with technical scope summaries and schedules.

Review of the environmental planning processes in place for Hanford programs indicates that short- and long-term strategic, technical, and financial planning is conducted for individual organizational functions at Hanford. Through review of the various environmental programs, however, the audit team determined that management systems are not in place to ensure that sitewide general environmental protection program activities are most effectively integrated among all site contractors (see Finding OS-3). Issues related to planning of environmental monitoring activities have been addressed in the Environmental Protection Programs section of the report (see Findings EP-2 and EP-3).

The environmental planning demands will continue to increase as the transition from a defense programs mission to an environmental management mission continues, during the assimilation of the Environmental Restoration Contract, and during the decontamination and decommissioning and remediation activities.

Risk Management

Formal risk management systems in place at Hanford include risk determination for issues and corrective action projects through the RBP Methodology and the Hanford Site Baseline Risk Assessment Methodology. This method evaluates projects by determining the risk that would exist if the issue is not resolved or the project is not completed.

The risk matrices used by contractors on the site evaluate the relative probability factors which include categories such as: public health and safety, environmental protection, site personnel safety, regulatory compliance, TPA milestones, external confidence, mission and operational performance, and business efficiency. There is an appropriate weighting to account for environmental protection issues. The lowest-level consequence for site personnel safety results is a risk value of $\mathrm{C}-1$, whereas the highest environmental protection issues could be assigned $a$ lower rating value based on the weighting factors (I-F-1, I-F-26, and I-F-38). The practical result of this system is a greater emphasis on occur : :onal safety than environmental protection. While health and safety justifiably are priorities, equal emphasis on environmental issues is essential to support the continued drive for environmental excellence. It was beyond the scope of this audit to determine the adequacy of the probability and consequence estimates for individual projects.

Additionally, a number of systems are in place to review new projects for potential environmental risks. Project-specific planning documents include review of environmental compliance and environmental protection issues. This coordination is typically specified in program-and project-level planning documents and is accomplished through matrix support and oversight from the respective environmental support organizations within RL, WHC and PNL. Additional mechanisms in place include the National Environmental Policy Act review process. Although there are several risk management mechanisms at Hanford, a concern exists regarding the evaluation of the environmental risks associated with the classification of mixed waste, specifically the delay in regulatory notifications related to the 324 Bidg. B-Cell. 
One finding was identified in the environmental planning and risk management portion of the audit relating to the classification of the mixed waste at Hanford. 


\subsubsection{Finding}

RM-1: $\quad$ Classification of Mixed Waste

Performance Objective: DOE 5820.2A, "Radioactive Waste Management," Chapter III, Section 3.d., states "DOE low-level waste that contains non-radioactive hazardous waste components (mixed waste) shall conform to the requirements of this Order, applicable EH Orders, and shall also be regulated by the appropriate regional authorities under the Resource Conservation and Recovory Act" (RCRA).

Finding: PNL and RL have not properly managed certain hazardous materials that are contaminated with radioactivity, as required by RCRA.

Discussion: RCRA established regulating standards for the generation, transportation, storage, treatment, and disposal of hazardous waste. EPA has authorized the Washington State Department of Ecology (WDOE) to implement its dangerous-waste program in the State of Washington. During the course of the audit, a deficiency was noted relating to the management of hazardous materials that are contaminated with radioactivity:

- An application has not been submitted to WDOE for a RCRA permit to store the 324 Bldg. Vault Tanks and B-Cell high-activity mixed waste (D-B-117; I-B-8 and (-B-29). As early as May 16, 1990, interoffice correspondence from PNL to RL stated that the waste in the vault tanks probably was a characteristic waste under RCRA (D-B-115). This memo expressed concern that there was a potential violation of WAC 173-303-016. A letter dated June 4, 1990 from RL to the director of PNL, requested that PNL make a determination of whether the material in the tanks was a hazardous waste as defined by WHC-173-303 (D-B-1 16). Over the next 3 years, PNL made virtually no progress in reaching a determination, nor were the appropriate regulatory officials notified of any potential violation of WAC 173-303. Throughout this 3-year period, RL senior management did not press PNL for closure on this determination, even though there were numerous exchanges of formal correspondence on the subject.

Based on the results of one sample, debris from the floor of B-Cell was found to have elevated concentrations of toxic metals, reported in micrograms per gram of sample, as follows: chromium-236; lead-2850; barium-874; silver-367; selenium-91; cadmium-36. This information was transmitted to RL on April 26, 1993 (D-B-113). WDOE, which had jurisdiction over this waste, still had not been notified-formally or informally-of the potential storage problem. Finally, on April 30, 1993 (3 years after the initial request for mixed waste determination), WDOE and EPA were notified of a number of mixed waste issues at Hanford, including the vault tank solutions and floor debris from B-Cell (D-B-117).

By early May 1993, further clean-up of the B-Cell floor was expected to exceed the 55-gallon limit for satellite accumulation, thus starting the 90-day RCRA clock for movement or approved disposition of the collected. dispersible radioactive mixed waste material to a permitted treatment, storage, or disposal facility. On March 25, 1994, PNL completed an internal 
document, "Mixed Waste Management Plan for the B-Cell Cleanout Project" (D-B-1 14). This report is a review of management options available for handling the high-activity mixed wastes being generated during the B-Cell Cleanout Project. A major consideration regarding this issue is the approximate 3 million curies of fission products in the hot cell, and the very high radiation levels associated with the waste $\left(>10^{6} \mathrm{rem} / \mathrm{hr}\right)$ that is situated just 2 miles from the Richland city limits. The audit team concluded that RL and PNL were not proactive and have not exercised decisiveness and promptness in identifying and reporting serious mixed waste problem.

The incident strongly suggests that site risk management (both environmental and regulatory) is not being properly applied and incorporated into senior management decisionmaking, and that the spirit and intent of DOE's commitment to regulatory compliance is not being fulfilled. 


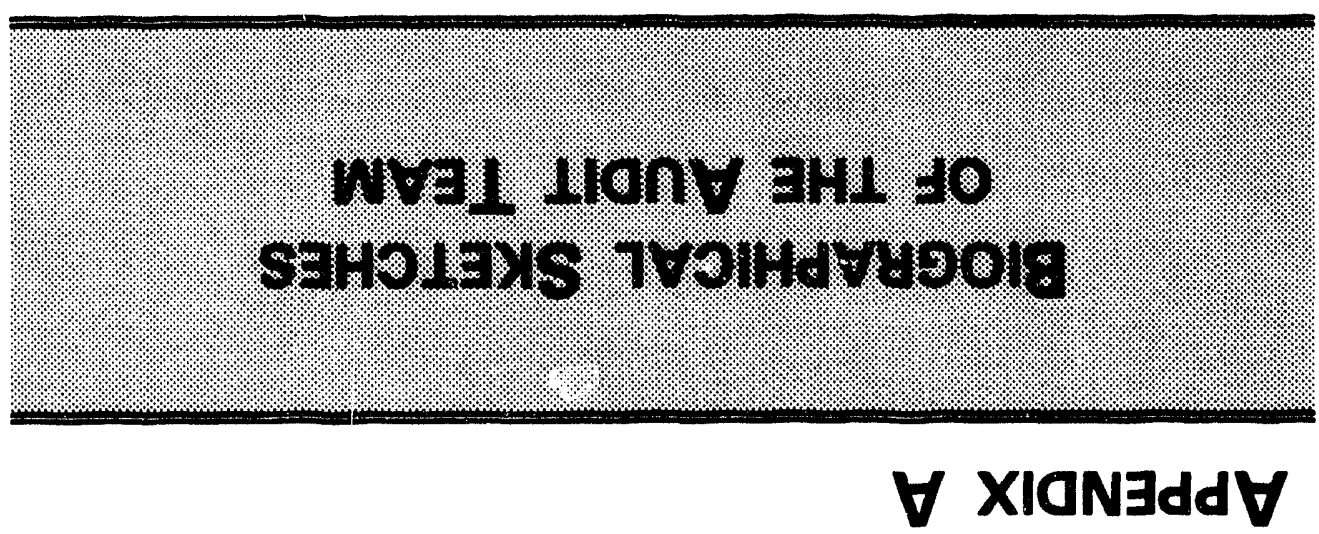




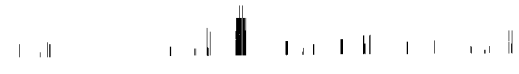

1. 11 111. | , 1 1 1

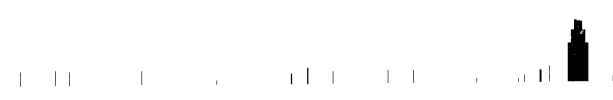

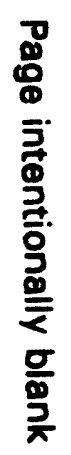


NAME: William N. Hasselkus

AREA OF RESP: Team Leader

ASSOCIATION: U.S. Department of Energy, Office of Environmental Audit

EXPERIENCE: $\quad 21$ Years

- U.S. Department of Energy, Washington, DC

- Environmental Engineer responsible for providing guidance, direction, and assistance to a multidisciplined group of professionals performing environmental audits and assessments at DOE facilities.

- Environmental Engineer supporting environmental compliance support to DOE National Laboratory and ancillary facilities.

- Environment, Health and Safety Manager providing ES\&H support for the Program Office for construction of the world's largest particle accelerator. Co-manager of the environmental impact statement for the project.

- Booz, Allen and Hamilton, Inc., Consultants

- Area Manager supporting Superfund policy development for the Environmental Fiotection Agency, and area manager for environmental compliance support for EPA's facilities, primarily through leading environmental audit teams.

\section{- U.S. Army Materiel Command}

- Chief, Environmental Quality Division, responsible for environmental compliance oversight and guidance. In this capacity, developed and implemented the Command's Environmental Auditing Program. This position also involved operation of the Army's Installation Restoration Program.

- U.S. Army Environmental Hygiene Agency

- Sanitary Engineer serving as project leejer for industrial and domestic wastewater investigations conducted by teams of professionals at Army facilities.

- U.S. Army Electronics Command

- Served as the original facility environmental coordinator at Fort Monmouth, NJ

EDUCATION: M.B.A., Fairleigh Dickinson University

B.S., Chemical Engineering, New Jersey Institute of Technology

OTHER: Executive Excellence Program, Federal Executive Institute

Program for Senior Executives, Massachusetts Institute of Technoiogy 
NAME:

Leroy H. Banicki

AREA OF RESP: Deputy Team Leader

ASSOCIATION: U.S. Department of Energy, Office of Environmental Audit

EXPERIENCE: $\quad 18$ Years

- U.S. Department of Energy, Washington, DC

- Environmental Protection Specialist responsible for providing guidance, direction, and assistance to a multidisciplined group of professionals performing management assessments and environmental audits at DOE facilities nationwide.

- Headquarters, Air National Guard, Andrews AFB, MD

- Project Officer for Installation Restoration Program activities at Air Guard bases nationwide.

- White Sands Missile Range, NM

- Deputy Director, Environmental and Natural Resources Office, with responsibility for hazardous waste management, asbestos abatement, spill control and countermeasure, and environmental training programs.

- U.S. Department of the Army, Fort Carson, CO

- Environmentalist, responsible for hazardous waste management, asbestos abatement, and cultural and natural resources programs.

- U.S. Army Corps of Engineers, Jacksonville, FL

- Biological Scientist, responsible for Environmental Assessment/Environmental Impact Statement preparation and Endangered Species programs.

- U.S. Department of Agriculture, Soil Conservation Service, Prosser, WA

- Soil Conservationist.

- Menominee Indian Nation, Neopit, WI

- Forest Inventory Specialist.

- University of Texas at El Paso and El Paso Community College, El Paso, TX

- Biology Instructor

EDUCATION: M.S., Biology, University of Texas at El Paso

B.S., Wildlife Management, McNeese State University

Postgraduate Studies, Forest Pathology, Louisiana State University 
NAME:

David J. Allard

AREA OF RESP: Environmental Protection Programs; Formality of Environmental Programs

AsSOCIATION: Arthur D. Little, Inc.

EXPERIENCE: $\quad 16$ Years

- $\quad$ Arthur D. Little, Inc.

- Senior Consultant and Certified Health Physisist providing technical support for DOE assessments and audits, and various other government and commercial client cases dealing with radiation protection issues, such as environmental monitoring, waste management, training, operational health physics, and radiation protection management.

- Participated in the Tiger Team assessments of the Morgantown Energy Technology Center, Idaho National Engineering Laboratory, and Los Alamos National Laboratory; the environmental audit of the Fossil Energy Sites in Wyoming; the environmental management assessments of the Continuous Electron Beam Accelerator Facility, Fernald Environmental Management. Project, Superconducting Super Collider, Argonne National Laboratory-West, and Pinellas Plant; and the progress assessment of the Idaho National Engineering Laboratory. Is currently a DOE mentor at the Hanford Site.

- TGM Detectors, Inc.

- Vice President with responsibilities for facility radiation protection, gas-filled radiation detector design, testing, engineering, and business management.

- Nuclear Metals, Inc.

- Supervisor of Health Physics with responsibilities in the areas of environmental monitoring, external and internal dosimetry, shielding. radiation surveys, waste disposal, training, and regulatory affairs regarding various uranium and thorium manufacturing operations.

- Albany Medical Center

- Medical Health Physicist with responsibilities involving worker and patient external and internal dosimetry, laboratory radiation protection, $x$-ray equipment testing, quality assurance, shielding, training, surveys, and waste disposal.

EDUCATION: M.S., Radiological Sciences and Protection, University of Lowell

B.S., Environmental Sciences, State University of New York at Albany

A.A.S., Environmental Health Technology, Hudson Valley Community College 
NAME: $\quad$ Mark O. Heuberger

AREA OF RESP: Environmental Monitoring

ASSOCIATION: Arthur D. Little, Inc.

EXPERIENCE: $\quad 11$ years

- Arthur D. Little, Inc.

- Participated in DOE Tiger Team assessments at the K-25 Site at Oak Ridge, Tennessee; Los Alamos National Laboratory; Pittsburgh Energy Technology Center; Fermilab; and the Strategic Petroleum Reserves. Also performed management systems assessments at the K-25 Site.

- Manage site investigations, RI/FS, and removal actions associated with base closure at Fort Devens, Massachusetts.

- Conduct management systems assessments, due diligence assessments, audits, and site investigations for a variety of commercial and government facilities.

- HMM Associates, Inc.

- Managed a remedial investigation and feasibility study completed at an EPA Superfund site in compliance with the requirements of CERCLA. Served as project manager, technical lead, and primary contact with Potentially Responsible Parties (PRPs), the State environmental agency, and EPA.

- Managed numerous hazardous waste site assessments, hydrogeologic investigations, and remedial investigations involving interfacing with local, State and Federal regulatory agencies.

- Harding - Lawson Associates, Inc.

- Supervised geotechnical and environmental evaluation of sites for excavation and construction of dams, tailings ponds, and waste storage facilities.

- FMC Corporation

- Developed and implemented a wide range of site investigations involving geologic mapping, interpretation of aerial photography and satellite imagery, chemical sampling and analysis and geophysical techniques including magnetic, electromagnetic, gravity, electrical resistivity, and radiometric studies.

EDUCATION: M.S., Geology, University of Nevada - Reno

B.S., Earth Sciences, Dartmouth College

Certified Professional Geologist 
NAME: $\quad$ Joseph Lischinsky

AREA OF RESP: Staff Resources, Training, and Development; Environmental Planning and Risk Management

ASSOCIATION: Applied Consultants, Inc.

EXPERIENCE: $\quad 13$ Years

- Applied Con : sltants, Inc.

- Serves as President and supports a variety of projects in the areas of radiation protection, materials licensing, emergency planning,

decommissioning, waste management, and training.

- Participated in the environmental management assessment of DOE's Waste Isolation Pilot Plant and Sandia National Laboratories, California. Specific responsibilities included review of environmental protection programs, formality of environmental programs, and environmental planning and risk management issues.

- Participated in the DOE Tiger Team Assessment of the K-25 Site at Oak Ridge, Tennessee. Served as an Environmental Health Physicist to the assessment team.

- Participated in the DOE Tiger Team Assessment of the Los Alamos National Laboratory. Served as Emergency Preparedness Expert to the Technical Safety Appraisal Team.

- Participated in the DOE Tiger Team Assessment of the Idaho National Engineering Laboratory. Served as an Environmental Health Physicist to the assessment team.

- Served as consultant Health Physicist to various environmental issues. These assignments included the provision of expertise in radiological site assessment, health and radiation safety, site remediation, decommissioning, and expert witness testimony.

- Performed numerous radiological health and safety reviews and emergency preparedness audits at both production and utilization facilities. These activities have included commercial nuclear power production as well as radioactive materiais manufacturing facilities licensed by both the U.S. Nuclear Regulatory Commission and the Agreement States Program.

EDUCATION: M.Sc., Applied Management, Lesley College

B.S., Biology, Suffolk University 
NAME:

Edward F. Maher, Sc.D., CHP

AREA OF RESP: Environmental Protection Programs; Formality of Environmental Programs

ASSOCIATION: Arthur D. Little, Inc.

EXPERIENCE: 21 Years

- $\quad$ Arthur D. Little, Inc.

- Senior Consultant, Certified Health Physicist, and Manager of the Radiation Technology and Policy Unit providing technical and managerial support for DOE assessments and audits, and various other government and commercial clients involving environmental management, health physics, environmentai quality and risk estimation.

- Participated in the routine environmental audit of the Pinellas Plant as the Organizational Structure/Enviromental Commitment Management Specialist.

- United States Air Force (USAF), Armstrong Laboratory, Brooks AFB, TX

- Chief, Bioenvironmental Engineering Division. Overall manager and director of comprehensive environmental and occupational health services support to worldwide USAF installations. Responsible for the overall management and technical content in the specialty areas of air and water quality, environmental and occupational health physics, hazardous waste and material management and environmental noise.

- USAF Occupational and Environmental Health Laboratory, Brooks AFB, TX

- Chief, Radiation Services Division. Overall director and provider of a wide range of health physics support to worldwide USAF installations. Support included environmental and occupational radiological protection consultation and field investigations, radioanalytical laboratory services, radiation dosimetry, radioactive source permitting and transportation safety, and radiological accident contingency response planning and risk assessment. Directed the Air Force's Radiation Assessment Team (AFRAT) that provided immediate and global response to nuclear weapon accidents and mishaps in concert with DOE's Accident Response Group.

- USAF Electronics Systems Division, Hanscom AFB, MA

- Chief, Environmental Health Section. Responsible for providing comprehensive industrial hygiene, environmental engineering, public health, and radiological protection services to the base community and acquisition centers.

- USAF School of Aerospace Medicine, Brooks AFB, TX

- Project Scientist, Laser Effects Branch. Conducted experimental-based research and modeling studies in ocular laser damage, bioeffects of ultrashort pulsed lasers and broad-band optical hazard sources, and developed laser exposure standards for adoption by the USAF Surgeon General.

EDUCATION: Sc.D., Radiological Health and Protection, Harvard University M.S. Biomedical Engineering, Worcester Polytechnic Institute B.S., Electrical Engineering, Lowell Technological Institute 
NAME: James W. Melloni, Jr.

AREA OF RESP: Quality Assurance Technical Specialist

ASSOCIATION: Arthur D. Little, Inc.

EXPERIENCE: $\quad 14$ Years

- $\quad$ Arthur D. Little, Inc.

- Served as Quality Assurance Specialist for the Tiger Team assessments of the Strategic Petroleum Reserves, Los Alamos National Laboratory, Sandia National Laboratory-Albuquerque, and Fermi National Accelerator Laboratory; environmental audits of the West Valley Demonstration Project and the Fernald Environmental Management Projects; and the progress assessment of Rocky Flats Plant.

- Served as Quality Assurance Manager for a DOE program through Westinghcuse Savannah River Company. Responsible for implementing a manufacturing/quality program that received certification from the American Society of Mechanical Engineers.

- Served as Quality Assurance Manager for a major project for the U.S. Army which involved oversight of the design, fabrication, test, and delivery of several prototype air-monitoring laboratories and shelters. This project required the generation of the Quality Assurance Program Plan covering all phases of the project. The program encompassed both test and inspection.

- Served the U.S. Air Force Prototype Flight Cryocooler (PFC) program office as Quality Assurance Manager; revised the quality assurance manual to update and improve Arthur D. Little, Inc.'s quality practices, primarily in the area of quality systems; implemented a failure analysis and corrective action system, and initiated audits and reviews of all the quality and manufacturing operations.

EDUCATION: M.B.A., Business Administration, New Hampshire College B.S., Biology, Boston College 
NAME: Raeann Reid

AREA OF RESP: Team Coordinator

ASSOCIATION: Arthur D. Little, Inc.

EXPERIENCE: $\quad 22$ Years

- $\quad$ Arthur D. Little, Inc.

- Team Coordinator for the Tiger Team assessments of the Energy Technology Engineering Certer, Naval Petroleum Reserves in California, Strategic Petroleum Reserves, and Naval Petroleum and Oil Shale Reserves in Colorado, Utah, and Wyoming; the Waste Isolation Pilot Plant environmental management assessment; and the routine environmental audits of Argonne National Laboratory-West and the Pinellas Plant. Defuuty Team Coordinator for the Tiger Team Assessment of Idaho National Engineering Laboratory and for the environmental management assessment of the Fernald Environmental Management Project; Technical Specialist evaluating toxic and chemical materials management for the Tiger Team assessment of Energy Technology Engineering Center; and Management Specialist for the environmental management assessment of the Superconducting Super Collider.

- Led and participated in audits and risk assessments for several Arthur D. Little clients, primarily in the petrochemical and refining industries including chemical manufacturing plants, chemical and oil terminals, oil refineries, and oil and gas production facilities.

- Other Industry Experience

- Twenty-two years experience including environmental operations; environmental regulatory affairs; industrial and commercial hazardous waste management, site evaluation, remediation, and offsite disposal; and industrial and commercial laboratory management.

- While working for a major petrochemical manufacturer, audited toll manufacturers, bulk terminals, repackaging plants, recyclers, and commercial disposal facilities.

EDUCATION: B.S., Mathematics, Minor Chemistry, Texas Technological University 
NAME: $\quad$ Vee Richardson

AREA OF RESP: Administrator

ASSOCIATION: Development Technologies, Inc.

EXPERIENCE: 28 Years

- Development Technologies, Inc.

- Administrative Team Coordinator providing support to the Department of Energy, Office of Environmental Audit, in conducting environmental assessments of DOE sites. Served as Administrator for the routine environmental audit of Sandia National Laboratories, California.

- Provided administrative and technical support to an interdepartmental, 27-agency task force and five of its working groups, to update the National Response Plan. The Plan defines the Federal government's response to natural and manmade disasters.

- Consultant

- Coordinated Inaugural Prayer Service honoring President-elect Bill Clinton, and was responsible for logistical arrangements; coordination with Presidential Inaugural Committee, Secret Service, and religious leaders; recruiting and briefing volunteers; and supervising onsite activities.

- Wrote information materials for national convocation attended by more than 2,000 people.

- Served as Deputy to the Managing Director of Administration for the Desert Storm National Victory Celebration; coordinated and supervised set-up of headquarters operation, making facilities for more than 125 staff and volunteers fully operational within one week; designed and managed computer system; scheduled transportation systems; and supervised staff.

- The Ability Group

- Owned and managed business services bureau; managed projects, hired and trained support staff and contractors, marketed and maintained working relationships with clients.

- Other Experience

- Fifteen years in administrative management with law firms, staff assistant at Department of State, member of trial team during U.S. v. AT\&T, and highlevel secretarial positions.

EDUCATION: Oklahoma Baptist University 
NAME:

Mead Summer

AREA OF RESP: Technical Editor

ASSOCIATION: Development Technologies, Inc.

EXPERIENCE: $\quad 11$ Years

- Development Technologies, Inc.

- Technical Editor providing support to the Department of Energy, Office of Environmental Audit, in conducting environmental assessments of DOE sites.

- National Endowment for the Arts

- Information Specialist, responsible for responding, both orally and in writing, to public and press inquiries regarding Endowment activities. Also was responsible for compiling staff biographies, official statements and other information released to the print and broadcast media.

- Daytona Beach News-Journal

- Assistant Business Editor. Principal duties included assigning, writing and editing stories for business and real estate sections of newspaper, and designing layout of pages for those sections. Also was responsible for supervising staff of four reporters and three columnists and for coordinating with other editors, photography staff and composing room.

- Columnist. Wrote weekly column on local and regional business and real estate issues, and was a regular participant in cable television roundtable on Florida business.

- The Mesa Tribune

- Sports Writer, responsible for coverage of professional, collegiate, high school, and amateur athletic events.

- Other Experience

- Editor of two "how-to" books, Selling Your Own Home and Associations: Maintaining a Community.

- Wrote travel articles for various newspapers and magazines.

EDUCATION: B.S., Journalism, Arizona State University 
NAME: $\quad$ Stow Walker

AREA OF RESP: Organizational Structure and Environmental Commitment

ASSOCIATION: Arthur D. Little, Inc.

EXPERIENCE: $\quad 11$ Years

- $\quad$ Arthur D. Little, Inc.

- Served as Team Coordinator for the Grand Junction Project Office Environmental Audit and the environmental management systems assessments at Western Area Power Authority and The Superconducting Super Collider.

- Served as Team Specialist for organizational structure and environmental commitment at the Southwestern Area Power Authority.

- Responsible for analyzing waste management and site clean-up regulatory programs and requirements, and determining necessary public and private sector compliance activities.

- Participated in numerous environmental audits for private-sector clients.

- Managed several projects for private-sector clients seeking to identify companies and technologies capable of addressing specific site clean-up requirements.

EDUCATION: M.B.A., Boston University

M.A., Environmental Policy, Tufts University

B.A., Trinity College 
Page intentionally blank

A-12 
APPENDIX B

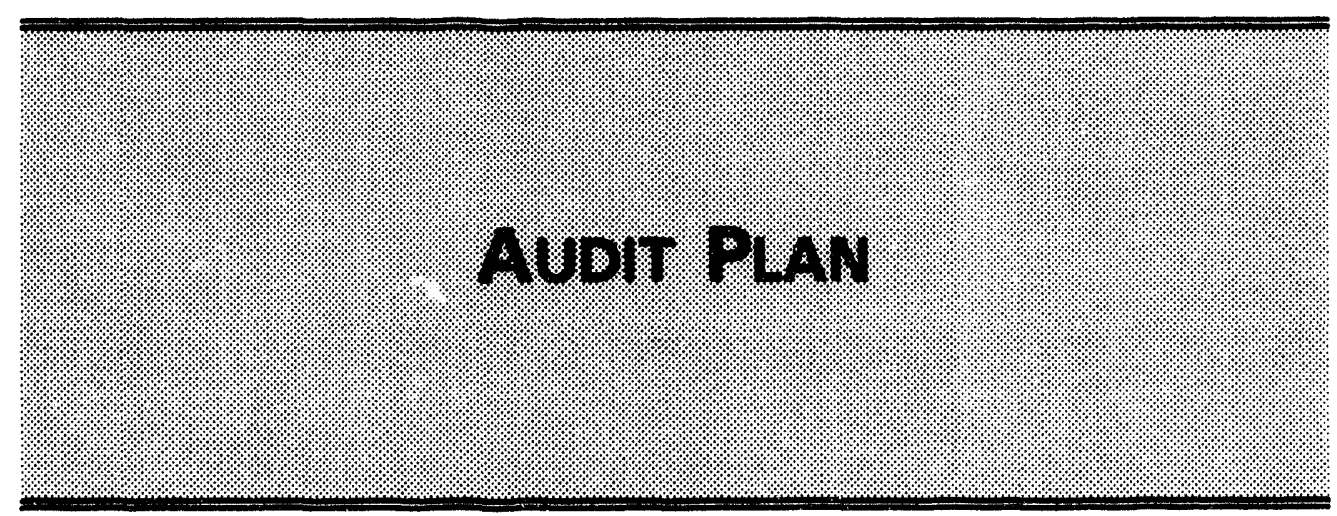


Page intentionally blank 


\section{Plan for the}

DOE Routine Environmental Audit

of the

Hanford Site

Richland, Washington

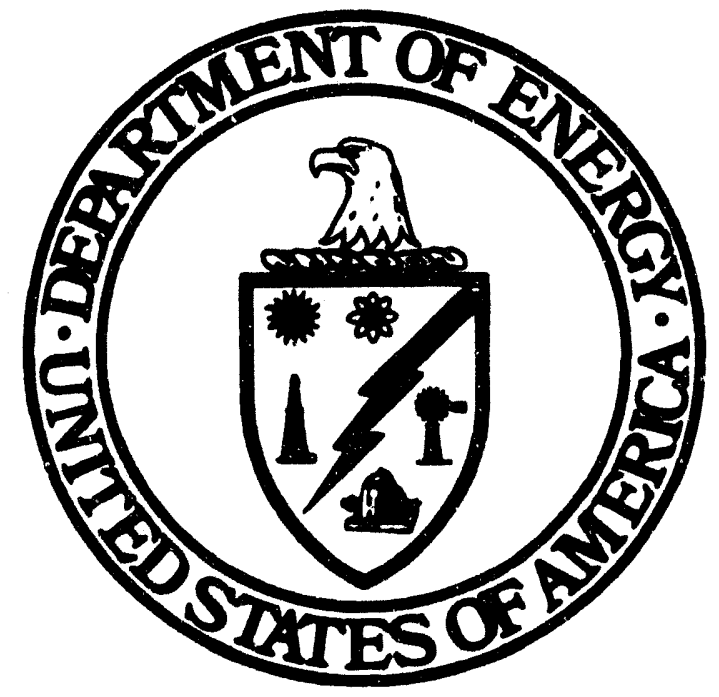

U.S. Department of Energy

Office of Environmental Audit

May 2 - May 13, 1994 
TABLE OF CONTENTS

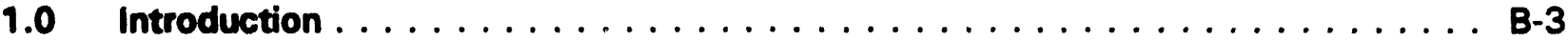

2.0 Routine Environmental Audit Implementation $\ldots \ldots \ldots \ldots \ldots \ldots \ldots$ B-5

2.1 Pre-Audit Activities $\ldots \ldots \ldots \ldots \ldots \ldots \ldots \ldots \ldots \ldots \ldots \ldots$ B-5

2.2 Onsite Activities and Reports $\ldots \ldots \ldots \ldots \ldots \ldots \ldots \ldots \ldots$ B-6

2.3 Post-Audit Activities $\ldots \ldots \ldots \ldots \ldots \ldots \ldots \ldots \ldots \ldots$ B-6

\author{
LIST OF ATTACHMENTS \\ (attachments not included in report)
}

Attachment A Audit Team Schedule of Onsite Activities

Attachment B Protocol for Conducting Environmental Management Assessments of DOE Oraanizations (DOE/EH-0326)

Attachment C Performance Objectives and Criteria for Conducting DOE Environmental Audits (DOE/EH-0358) 


\section{PLAN FOR THE DOE ROUTINE ENVIRONMENTAL AUDIT OF THE HANFORD SITE}

The DOE Environmental Audit Program is carried out by the Office of Environmental Audit (EH-24) within the Office of Environment, Safety and Health (EH). The program was created in 1985 with a goal to provide a continuing program of internal, independent oversight of line management's environmental performance, in support of DOE's broader goal of achieving full compliance and excellence in the environmental area. The objectives of the program in achieving this goal include:

- Conducting comprehensive baseline environmental audits of facilities that were not addressed in the Environmental Survey and that were not assessed by a Tiger Team;

- Conducting assessments of environmental management within line programs, including adequacy of self-assessment programs;

- Conducting a continuing program of field/technical re-audits of major and other DOE facilities;

- Conducting special issue reviews to assess high priority issues at a particular site, or to assess issues which cut across site and program lines; and

- Supporting line management self-assessment programs through continuing updates and automation of audit protocols, training, and other mechanisms of transferring the special auditing expertise of EH-24 to the field.

The Routine Environmental Audit (audit) of the Hanford Site during the period of May 2 May 13, 1994, will be an Environmental Management Assessment, with emphasis on the management of environmental groundwater and surface water monitoring programs. It will evaluate the effectiveness of environmental management programs established by the DOE Richland Operations Office (RL) line organizations; the RL support contractors, Westinghouse Hanford Company (WHC) and Battelle Pacific Northwest Laboratory (PNL); and ICF Kaiser, the construction subcontractor to WHC. The audit will be conducted in accordance with DOE Environmental Audit Proaram Guidance (DOE/EH-0232), Protocol for Conductina Environmental Management Assessments of DOE Oroanizations (DOE/EH0326), and Performance Obiectives and Criteria for Conductina DOE Environmental Audits (DOE/EH-0358). The sections of the DOE/EH-0358 performance objectives and criteria for surface water quality, groundwater, inactive waste sites and releases, and environmental quality assurance which apply to environmental monitoring will be emphasized.

From an organizational perspective, the scope of the audit will include the Office of Defense Programs (DP), the Office of Environmental Restoration and Waste Management (EM), the Office of Field Management (FM), the RL and the contractors and subcontractor mentioned above. The audit team will focus on line management's performance in developing and implementing environmental management systems and programs, consistent with DOE expectations for environmental excellence. 
The scope of the Environmental Management Assessment is comprehensive in that it covers a full range of relevant management systems, including:

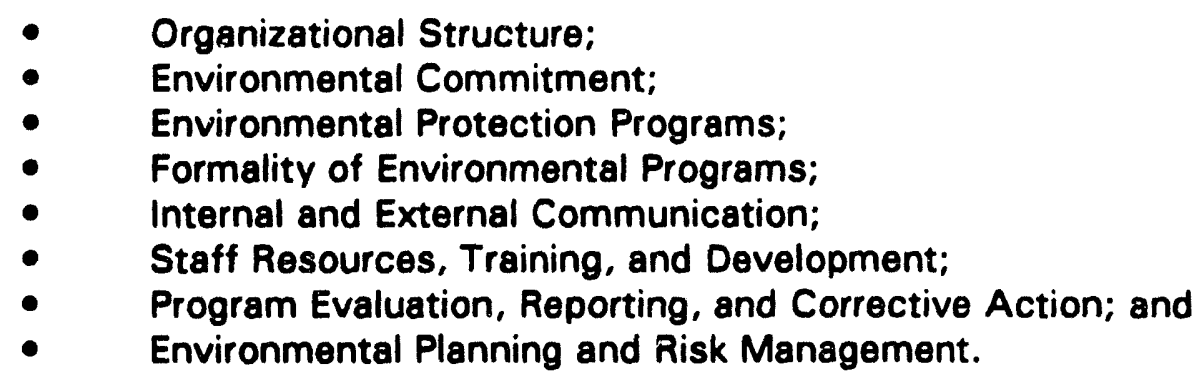

Coordination among the audit team members will be routine and extensive, since each of the management systems are interrelated.

At the request of $R L$, the audit will emphasize management systems associated with the environmental monitoring programs. The results of the evaluations of these technical areas will be included in the Environmental Protection Programs subsection of the report.

The information in this Audit Plan is based on information received by the audit team as of the end of the day on April 15, 1994. 
The Routine Environmental Audit (audit) of the Hanford Site will be conducted by a team consisting of a Team Leader and Deputy Team Leader from the DOE Office of

Environmental Audit (EH-24); a team coordinator, management systems specialists, and a technical specialist from Arthur D. Little, Inc. (ADL); and an administrator and editor from Development Technologies, Inc. (DevTech). The names and assignments are listed below:

\begin{tabular}{|c|c|c|}
\hline Bill Hasselkus & DOE & Team Leader \\
\hline Lee Banicki & DOE & Deputy Team Leader \\
\hline Raeann Reid & ADL & Team Coordinator \\
\hline David Allard & $A D L$ & $\begin{array}{l}\text { Environmental Protection Programs (Rad) } \\
\text { Formality of Environmental Programs } \\
\text { (Rad) }\end{array}$ \\
\hline Mark Heuberger & ADL & Environmental Monitoring \\
\hline Joe Lischinsky & ADL & $\begin{array}{l}\text { Staff Resources, Training, and } \\
\text { Development } \\
\text { Environmental Planning and Risk } \\
\text { Management }\end{array}$ \\
\hline Ed Maher & $A D L$ & $\begin{array}{l}\text { Environmental Protection Programs } \\
\text { (Non-Rad) } \\
\text { Formality of Environmental Programs } \\
\text { (Non-Rad) }\end{array}$ \\
\hline Jim Melloni & $A D L$ & $\begin{array}{l}\text { Internal and External Communication } \\
\text { Program Evaluation, Reporting, and } \\
\text { Corrective Action }\end{array}$ \\
\hline Stow Walker & $A D L$ & $\begin{array}{l}\text { Organizational Structure } \\
\text { Environmental Commitment }\end{array}$ \\
\hline Vee Richardson & DevTech & Administrator \\
\hline Mead Summer & DevTech & Technical Editor \\
\hline
\end{tabular}

\subsection{PRE-AUDIT ACTIVITIES}

Pre-audit activities for the Hanford Site audit included a scoping meeting at the Hanford Site, issuing an introduction and information request memorandum, a pre-site visit to the Hanford Site, and initial review of documentation provided to the audit team by RL, WHC, PNL, and ICF Kaiser.

On March 10, 1994, the DOE Team Leader and Deputy Team Leader and two Arthur D. Little specialists met with RL, WHC, and PNL staff to discuss the environmental 
management assessment process and the scope of the audit. The pre-site visit was attended on April 7, 1994, by the DOE Team Leader and Deputy Team Leader, the ADL Team Coordinator, and the Team Administrator from DevTech. During the pre-site visit, site personnel were briefed on the purpose and scope of the audit; and the team members were briefed on the effluent and groundwater monitoring and surveillance programs of WHC and PNL. Additional documents were requested, and onsite audit activities and logistics were discussed. The Team Administrator continued logistics discussions on April 8. The visit included presentations by EH-24, RL, WHC, and PNL.

\subsection{ONSITE ACTIVITIES AND REPORTS}

The onsite activities for the audit will begin May 2 and continue through May 13, 1994. Onsite activities will include interviews with RL, WHC, PNL, and ICF Kaiser management and staff; record and document reviews; and may include field inspections of selected site operations and various environmental media sampling events.

The agenda for the audit (including a preliminary interview schedule) is shown in Attachment $A$ (not included). The interview schedule reflects the audit team's best attempt to identify relevant personnel to be interviewed. Based on past experience, these schedules will change as additional information is gathered by the audit team members and based on the availability of site personnel. Modifications to the interview schedule, or other elements of the agenda, will be coordinated with the designated RL contacts and counterparts.

During the audit, the team will conduct daily debriefing sessions with the RL, WHC, PNL, and ICF Kaiser management and site representatives who were interviewed to review progress and concerns to date. Factual accuracy reviews of all findings will occur during the second week of the audit. At the conclusion of the onsite portion of the audit, on May 13, 1994, a closeout briefing will be conducted. A summary of the results of the audit, including key findings and program strengths, will be presented by the Team Leader at that time. Also at the closeout, a draft report will be provided to DP, EM, RL, WHC, PNL, and ICF Kaiser for review and comment.

POST-AUDIT ACTIVITIES

Following the onsite activities, DP, EM, General Counsel for the Environment (GC-11), RL, WHC, PNL, and ICF Kaiser will have the opportunity to submit final comments on the draft report. After reviewing these comments, EH-24 will issue a final report. RL, WHC, PNL, and ICF Kaiser will be responsible for preparing a corrective action plan that will be reviewed by EH-24.

Following is a tentative schedule for completion of these post-audit activities:

June 6

June 20

July 8

July 18

July 18

August 15
Site comments on draft report due to EH-24

Response to comments on draft report to site

Draft corrective action plan due to $\mathrm{EH}-24$

Final audit report issued by $\mathrm{EH}-24$

Comments on draft corrective action plan to site

Final corrective action plan due to EH-24 


\section{Appendix C}

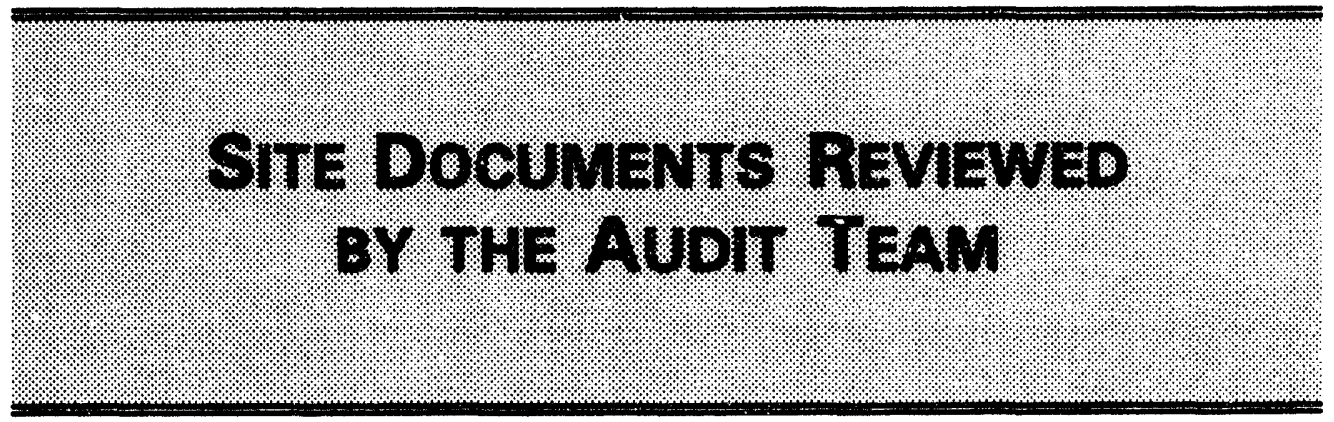


Page intentionally blank 
SITE DOCUMENTS REVIEWED BY THE AUDIT TEAM

\begin{tabular}{|c|c|c|c|c|c|}
\hline 3.:. & $x_{1}$ & $4 \%$ & 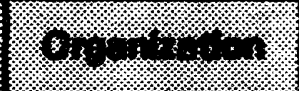 & 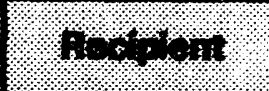 & 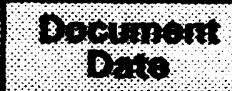 \\
\hline \multicolumn{6}{|c|}{ 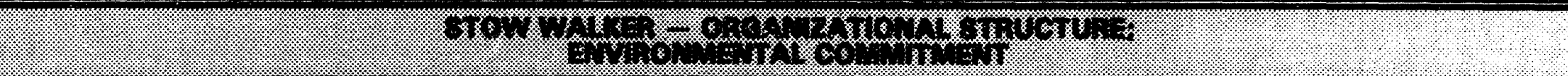 } \\
\hline D-A-1 & $\begin{array}{l}\text { United Stotes Depertment of Eneroy Richland } \\
\text { Operation Office Environmental Protection } \\
\text { Implementation Pian, 11/8/93-11/9/84 }\end{array}$ & Regulatory Analysis & WHC & $\begin{array}{l}\text { RL-Quality, } \\
\text { Safety, \& Health } \\
\text { Programs } \\
\text { Division (QSH) } \\
\end{array}$ & $\begin{array}{l}\text { November } \\
1993\end{array}$ \\
\hline D-A-2 & $\begin{array}{l}\text { Hanford Federal Facility Agreement and Consent } \\
\text { Order, Annual Update }\end{array}$ & - & $\begin{array}{l}\text { Weshington Dept. } \\
\text { of Ecology } \\
\text { (WDOEI/EPA/DOE }\end{array}$ & - & $\begin{array}{l}\text { September } \\
1992\end{array}$ \\
\hline D-A-3 & $\begin{array}{l}\text { Letter re: Operationel Environmental Progrem Self- } \\
\text { Assessment }\end{array}$ & J.W. Schmidt & WHC & R.H. Holten (RL) & $\begin{array}{l}\text { March 31, } \\
1993\end{array}$ \\
\hline D-A-4 & $\begin{array}{l}\text { Routine Operational Environmental Monitoring } \\
\text { Schedule, CY } 1994\end{array}$ & J.W. Schmidt & WHC & DOE & $\begin{array}{l}\text { December } \\
1993\end{array}$ \\
\hline D-A-5 & 1994 Compliance Assessment Schedule & J.J. Dorian & WHC & $\begin{array}{l}\text { S.M. McKinney } \\
\text { C.J. Perkins }\end{array}$ & $\begin{array}{l}\text { February } 18 \\
1994\end{array}$ \\
\hline D-A-6 & $\begin{array}{l}\text { The Westinghouse Hanford Company Operational } \\
\text { Environmentel Monitoring Program CY-93 }\end{array}$ & J.W. Schmidt & WHC & DOE & October 1993 \\
\hline D-A-7 & Organization Charts and Charters & - & WHC & - & - \\
\hline D-A-8 & Environmental Compliance Manual & Regulatory Analysis & WHC & - & - \\
\hline D-A-9 & Training Past Due Tabulation & - & PNL & - & $\begin{array}{l}\text { February } 11 \\
1994\end{array}$ \\
\hline D-A-10 & $\begin{array}{l}\text { Westinghouse Hanford Company Waste Minimization } \\
\text { and Pollution Prevention Awareness Program Plan }\end{array}$ & $\begin{array}{l}\text { P.A. Craig. } \\
\text { et al. }\end{array}$ & WHC & DOE & - \\
\hline D-A-11 & Leadership Expectations & A.L. Trego & WHC & - & March 9, 1994 \\
\hline D-A-12 & Site-Wide Environmental Surveillance Progrem & - & WHC & - & $\begin{array}{l}\text { September } \\
1993\end{array}$ \\
\hline D-A-13 & Hanford Environmental Publications List, 1989-1994 & R.H. Gray & PNL & Distribution & $\begin{array}{l}\text { February 28, } \\
1994\end{array}$ \\
\hline
\end{tabular}


SITE DOCUMENTS REVIEWED BY THE AUDIT TEAM (continued)

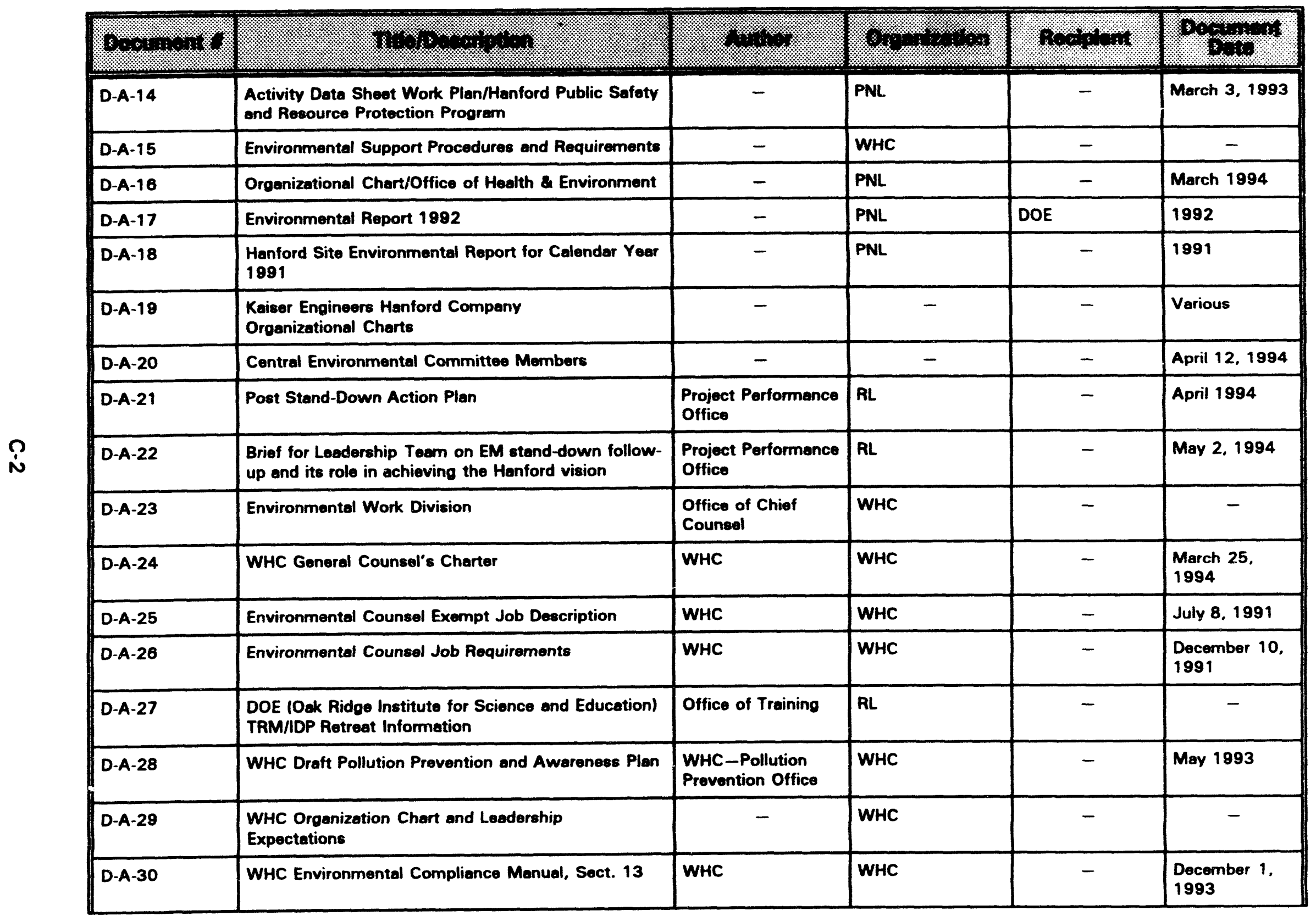


SITE DOCUMENTS REVIEWED BY THE AUDIT TEAM (continued)

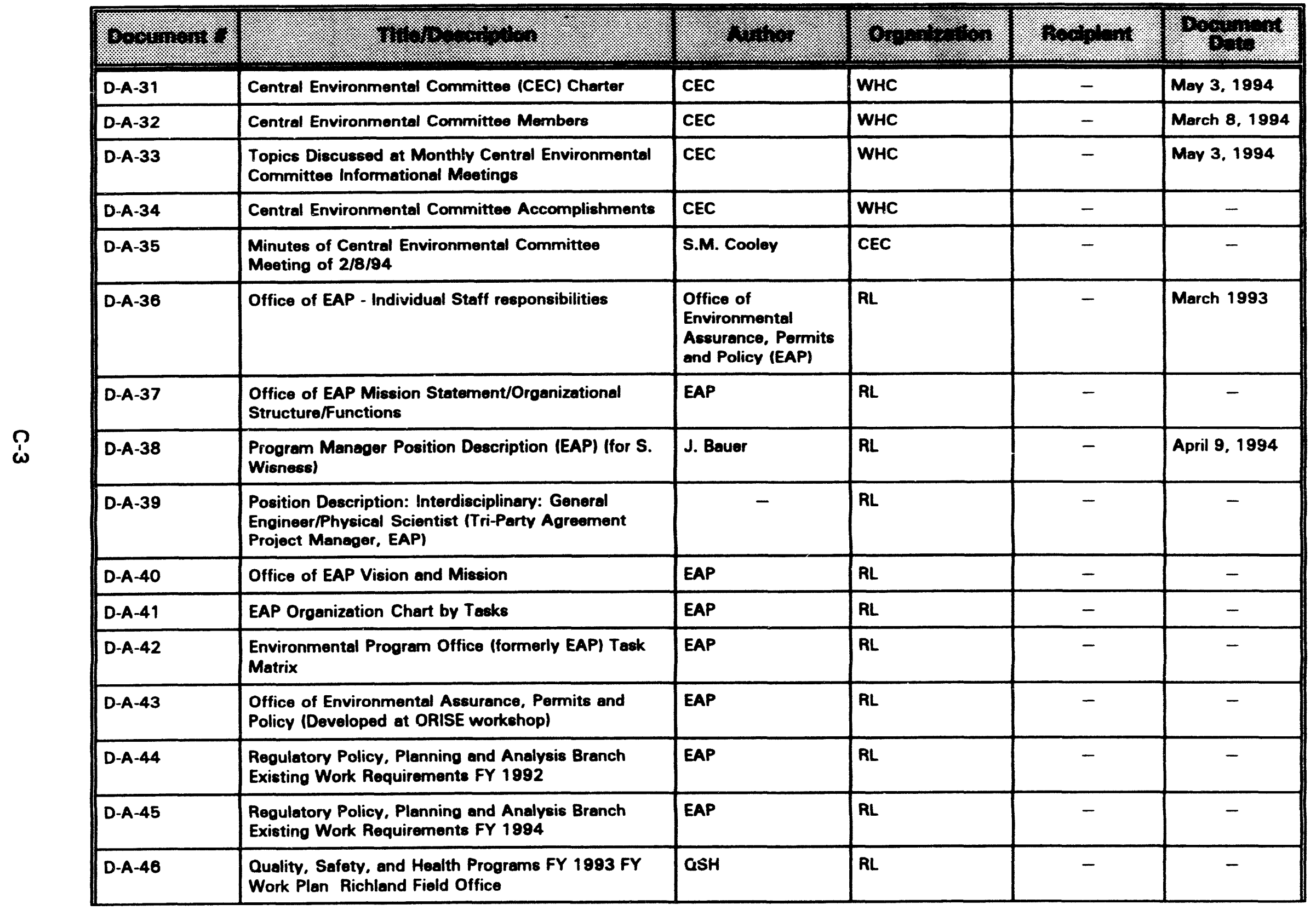




\section{SITE DOCUMENTS REVIEWED BY THE AUDIT TEAM (continued)}

\begin{tabular}{|c|c|c|c|c|c|}
\hline \% & 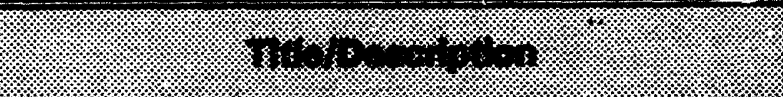 & 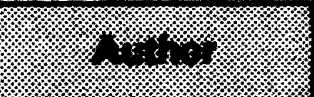 & 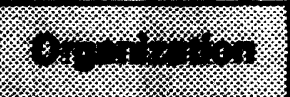 & 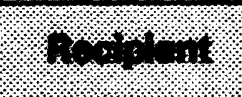 & +3 \\
\hline D-A-47 & QSH Division Misaion/Organizational Structure & ash & RL & - & - \\
\hline D-A-48 & $\begin{array}{l}\text { Environmental Scientist GS-12/13 Position } \\
\text { Description (Doug Hildebrand) }\end{array}$ & OSH & $\mathbf{R L}$ & - & - \\
\hline D-A-49 & QUEST Subjects and Actions & $\begin{array}{l}\text { QUEST System (L. } \\
\text { Kembergl }\end{array}$ & WHC & - & - \\
\hline D-A-50 & Geohydrological Support Total Quality Program & Geosciences & WHC & - & - \\
\hline D-A-51 & Geohydrologic Engineering Staffing Chart & Geosciences & WHC & - & - \\
\hline D-A-52 & WHC Environmental Compliance Report & Program Integration & WHC & - & $\begin{array}{l}\text { Fobruary } 17 \\
1994\end{array}$ \\
\hline D-A-53 & $\begin{array}{l}\text { Implementation Pian For the Integration of WHC and } \\
\text { KH Procedures and ICF Kaiser Hanford } \\
\text { Environmental Protection Progrem (overview) }\end{array}$ & $\begin{array}{l}\text { ICF KH-Manager } \\
\text { of Environmental } \\
\text { Services }\end{array}$ & ICF KH & - & - \\
\hline D-A-54 & Environmental Services Organization Charter & ICF KH & ICF $\mathrm{KH}$ & - & - \\
\hline D-A-55 & $\begin{array}{l}\text { Total Quality Management Applications For } \\
\text { Hanford's 5-yr Plan and Public Outreach }\end{array}$ & J. Petereon & 5-Yr. Plan Office & - & - \\
\hline D-A-56 & $\begin{array}{l}\text { Environmental Remediation Division Organizational } \\
\text { Structure and Mission }\end{array}$ & $\begin{array}{l}\text { Remediation } \\
\text { Division }\end{array}$ & $\mathbf{R L}$ & - & - \\
\hline D-A-57 & $\begin{array}{l}\text { Environmental Manegoment/Richlend Operations } \\
\text { Office/FY } 1984 \text { Reprogramming }\end{array}$ & Budget Office & RL & - & - \\
\hline D-A-58 & $\begin{array}{l}\text { Hanford Transition Program Office Multivear } \\
\text { Management Plan }\end{array}$ & $\begin{array}{l}\text { Henford Transition } \\
\text { Program Office }\end{array}$ & RL & - & - \\
\hline D-A-59 & Facilitating Change & J. Wiley & $\begin{array}{l}\text { Hanford Transition } \\
\text { Program Office }\end{array}$ & - & - \\
\hline D-A-60 & Memorandum: Departmental Programming & N.M. Highland & $\mathbf{R L}$ & $\begin{array}{l}\text { E. Smedley, } \\
\text { Acting CFO, } \\
\text { CR-1, DOE HQ }\end{array}$ & May 3. 1994 \\
\hline D-A-81 & PNL Facilities and Operations Porsonnel List & - & PNL & - & May 1893 \\
\hline D-A-62 & $\begin{array}{l}\text { Hanford Federal Facility Agreement and Consent } \\
\text { Order, 4th Amendment, January } 1984\end{array}$ & - & WDOE/EPA/DOE & - & January 1994 \\
\hline
\end{tabular}


SITE DOCUMENTS REVIEWED BY THE AUDIT TEAM (continued)

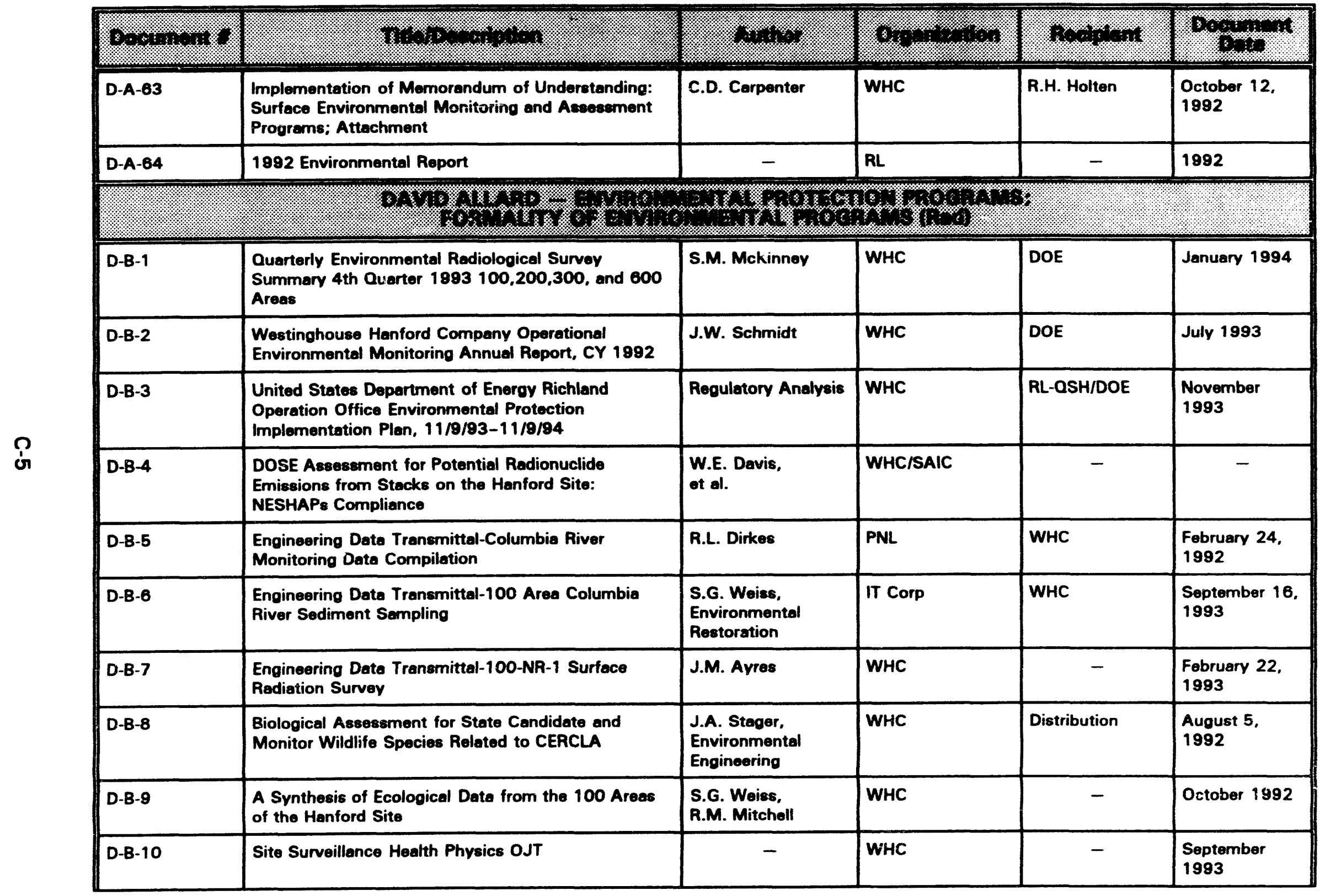




\section{SITE DOCUMENTS REVIEWED BY THE AUDIT TEAM (continued)}

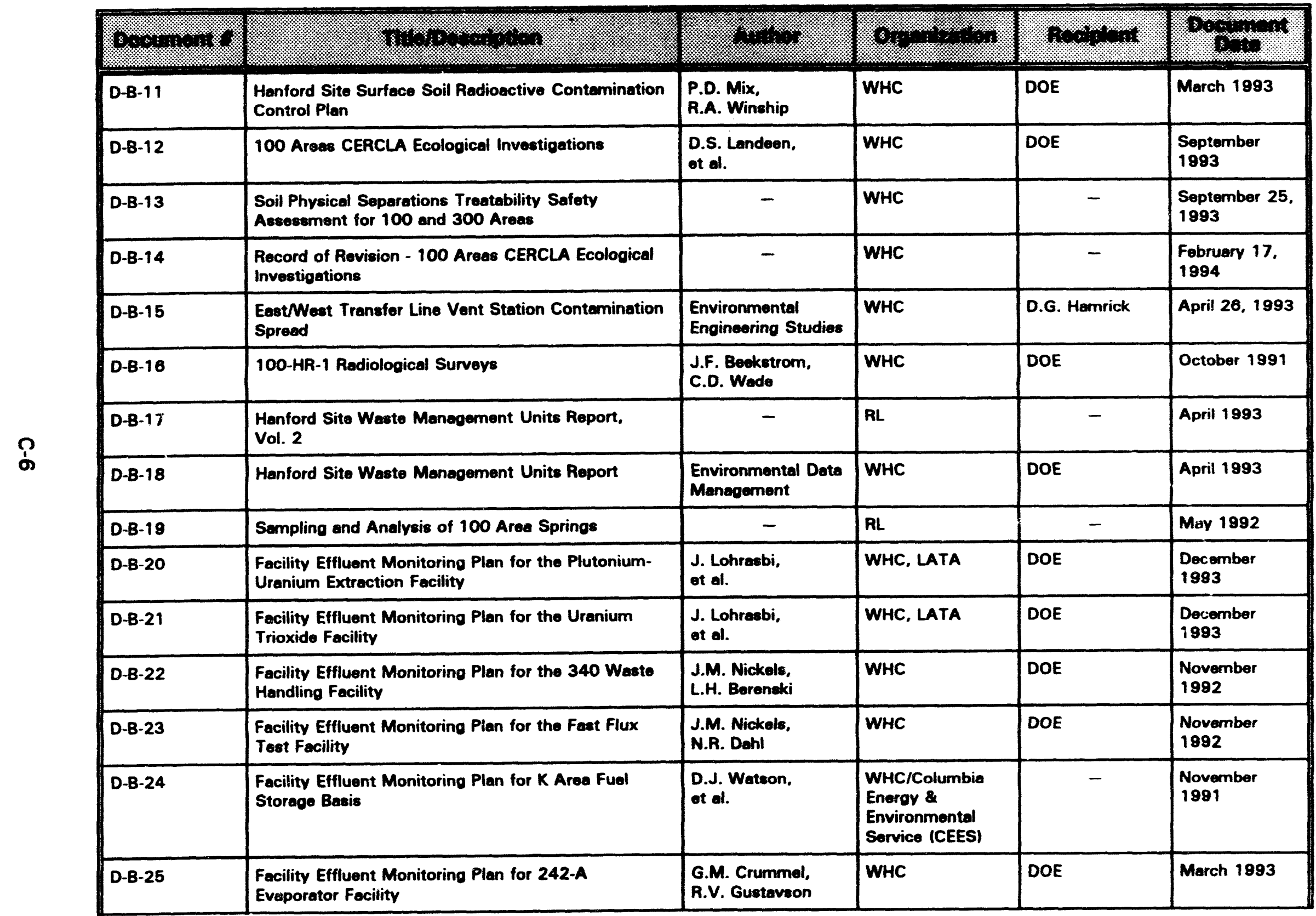




\section{SITE DOCUMENTS REVIEWED BY THE AUDIT TEAM (continued)}

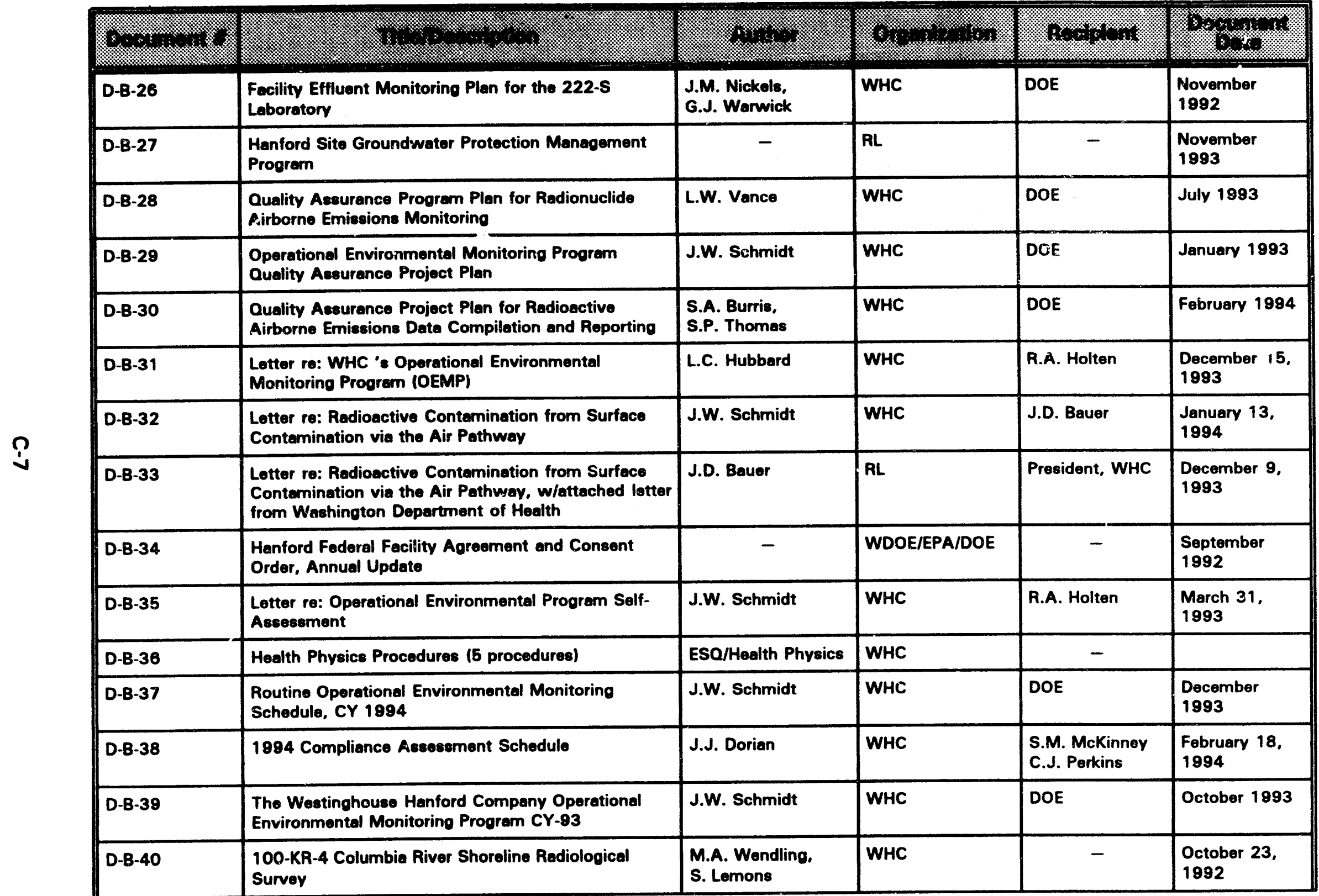




\section{SITE DOCUMENTS REVIEWED BY THE AUDIT TEAM (continued)}

\begin{tabular}{|c|c|c|c|c|c|}
\hline s.t. & (3) & 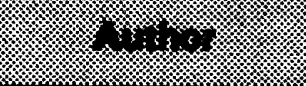 & 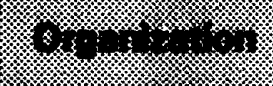 & 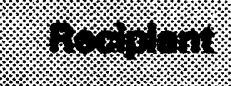 & 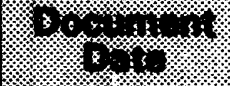 \\
\hline D-B-41 & $\begin{array}{l}\text { 100-HR-3 Columbia River Shoreline Radiological } \\
\text { Survey }\end{array}$ & $\begin{array}{l}\text { C.D. Wade, } \\
\text { ot al. }\end{array}$ & WHC & - & May 5, 1993 \\
\hline D-8-42 & $\begin{array}{l}\text { Characterization of Mobile Rediation Detection } \\
\text { Systems at the Hanford Site }\end{array}$ & $\begin{array}{l}\text { E.J. Antonio, } \\
\text { ot al. }\end{array}$ & PNLMHC & DOE & January 1993 \\
\hline D-8-43 & $\begin{array}{l}\text { Operational Environmental Monitoring Manual } \\
\text { (14 procedures) }\end{array}$ & - & WHC & - & Various \\
\hline D-B-44 & Organization Charte and Charters & - & WHC & - & - \\
\hline D-B-45 & Environmental Compliance Manual & Regulatory Analysis & WHC & - & - \\
\hline D-B-46 & $\begin{array}{l}\text { Hanford Site Ground-Water Model: Geographic } \\
\text { Information System Linkages and Modol } \\
\text { Enhancements, FY } 1983\end{array}$ & $\begin{array}{l}\text { S.K. Wurstner } \\
\text { J.L. Devary }\end{array}$ & PNL & DOE & $\begin{array}{l}\text { December } \\
1993\end{array}$ \\
\hline D-B-47 & $\begin{array}{l}\text { Services Provided by the 222-S Laboratory for } \\
\text { Regulatory Support }\end{array}$ & S.P. Thomas & WHC & DOE & $\begin{array}{l}\text { November } \\
1993\end{array}$ \\
\hline D-B-48 & $\begin{array}{l}\text { A Quality Mothod for Groundwater \& iveillance } \\
\text { Monitoring Network Desion at the Hanford Site }\end{array}$ & - & WHC & - & $\begin{array}{l}\text { December } \\
1993\end{array}$ \\
\hline D-B-49 & $\begin{array}{l}\text { Three-Dimensional Conceptual Model for the Hanford } \\
\text { Site Unconfined Aquifer Sretem, FY } 1983 \text { Status } \\
\text { Report }\end{array}$ & $\begin{array}{l}\text { P.D. Thorne, } \\
\text { et el. }\end{array}$ & PNL & DOE & $\begin{array}{l}\text { December } \\
1993\end{array}$ \\
\hline D-B-50 & $\begin{array}{l}\text { Facility Effluent Monitoring Plen for the Plutonium } \\
\text { Finishing Plant }\end{array}$ & P.J. Sullivan & WHC & DOE & $\begin{array}{l}\text { December } \\
1993\end{array}$ \\
\hline D-B-51 & $\begin{array}{l}\text { Facility Effluent Monitoring Plan for the 2724-W } \\
\text { Protective Equipment Decontemination Fecility }\end{array}$ & $\begin{array}{l}\text { J.M. Nickels, } \\
\text { G.H. Lavey }\end{array}$ & WHC & DOE & $\begin{array}{l}\text { December } \\
1892\end{array}$ \\
\hline D-B-52 & $\begin{array}{l}\text { Facility Effluent Monitoring Plan for the T Plant } \\
\text { Facility }\end{array}$ & $\begin{array}{l}\text { M.A. Ortega, } \\
\text { J.M. Nickels }\end{array}$ & WHC & DOE & $\begin{array}{l}\text { November } \\
1992\end{array}$ \\
\hline D-8-53 & $\begin{array}{l}\text { United Stetes Department of Energy Pichland } \\
\text { Operations Office Environmental Protection } \\
\text { Implementetion Plan }\end{array}$ & Regulatory Analysis & WHC & DOE & $\begin{array}{l}\text { November } \\
1993\end{array}$ \\
\hline D-B-54 & Henford Site Ground-Water Monitoring for 1892 & - & WHC & - & June 1993 \\
\hline D-B-55 & $\begin{array}{l}\text { Environmental Surveillence Mester Sempling } \\
\text { Schedule }\end{array}$ & L.E. Bisping & PNL & DOE & Jonuery 1993 \\
\hline
\end{tabular}


SITE DOCUMENTS REVIEWED BY THE AUDIT TEAM (continued)

\begin{tabular}{|c|c|c|c|c|c|}
\hline 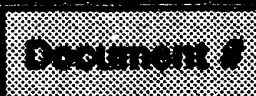 & 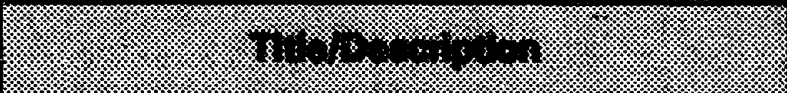 & 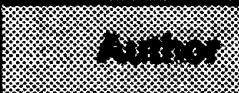 & 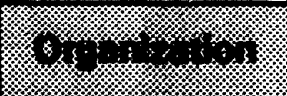 & 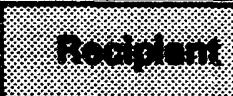 & $1 \%$ \\
\hline D-8-56 & Site-Wide Environmental Survoillance Progrem & - & PNL & - & $\begin{array}{l}\text { September } \\
1993\end{array}$ \\
\hline D-B-67 & Henford Environmental Publications List, 1989-1994 & R.H. Gray & PNL & Distribution & $\begin{array}{l}\text { February } 28, \\
1994\end{array}$ \\
\hline D-B-58 & $\begin{array}{l}\text { Facility Effluent Monitoring Plan for the } 300 \text { Area } \\
\text { Fuels Fabrication Facility }\end{array}$ & $\begin{array}{l}\text { J.M. Nickels } \\
\text { D.F. Brendel }\end{array}$ & WHC/CEES & DOE & $\begin{array}{l}\text { November } \\
1991\end{array}$ \\
\hline D-B-69 & Facility Effluent Monitoring Plan for the N Reactor & $\begin{array}{l}\text { D.J. Watson, } \\
\text { et al. }\end{array}$ & WHC/CEES & DOE & $\begin{array}{l}\text { November } \\
1991\end{array}$ \\
\hline D-B-60 & Facility Effluent Monitoring Plan for the B Plant & $\begin{array}{l}\text { K.A. Peterson, } \\
\text { R.L. Daubert }\end{array}$ & $\begin{array}{l}\text { WHC/Environment } \\
\text { al and Energy } \\
\text { Service Company } \\
\text { (ERCE) }\end{array}$ & DOE & $\begin{array}{l}\text { November } \\
1991\end{array}$ \\
\hline D-B-61 & $\begin{array}{l}\text { Hanford Site Environmental Report for Calendar Year } \\
1990\end{array}$ & - & PNL & DOE & $\begin{array}{l}\text { December } 20, \\
1991\end{array}$ \\
\hline D-B-62 & $\begin{array}{l}\text { OA Plan for the Surface Environmental Surveillance } \\
\text { and Drinking Woter Monitoring Projects }\end{array}$ & - & WHC & - & August 1993 \\
\hline D-B-63 & Environmental Support Procedures and Requirements & - & WHC & - & - \\
\hline D-B-64 & $\begin{array}{l}\text { Environmental Monitoring Plan, United States } \\
\text { Department of Eneroy Richland Field Office }\end{array}$ & - & RL & - & $\begin{array}{l}\text { November } 9 \text {, } \\
1991\end{array}$ \\
\hline D-B-65 & Alphabetical Directory/Hanford Site & - & - & - & August 1993 \\
\hline D-B-66 & (Duplicate document) & - & - & - & - \\
\hline D-B-67 & $\begin{array}{l}\text { Changes in the Henford Site Environmental Report } \\
\text { for Calendar Year } 1992\end{array}$ & R.E. Jaquish & PNL & Distribution & $\begin{array}{l}\text { February } 8 \\
1994\end{array}$ \\
\hline D-B-68 & Environmental Report 1992 & - & PNL & DOE & 1992 \\
\hline D-B-69 & In Summary-Environmental Monitoring 1981 & - & PNL & DOE & 1991 \\
\hline D-8-70 & $\begin{array}{l}\text { Henford Site Environmental Report for Calendar Year } \\
1991\end{array}$ & - & PNL & - & 1991 \\
\hline D-8-71 & $\begin{array}{l}\text { Surface Environmental Survaillance Project/Project } \\
\text { Date Manegement Syetem }\end{array}$ & L.E. Bisping & PNL & - & - \\
\hline
\end{tabular}




\section{SITE DOCUMENTS REVIEWED BY THE AUDIT TEAM (continued)}

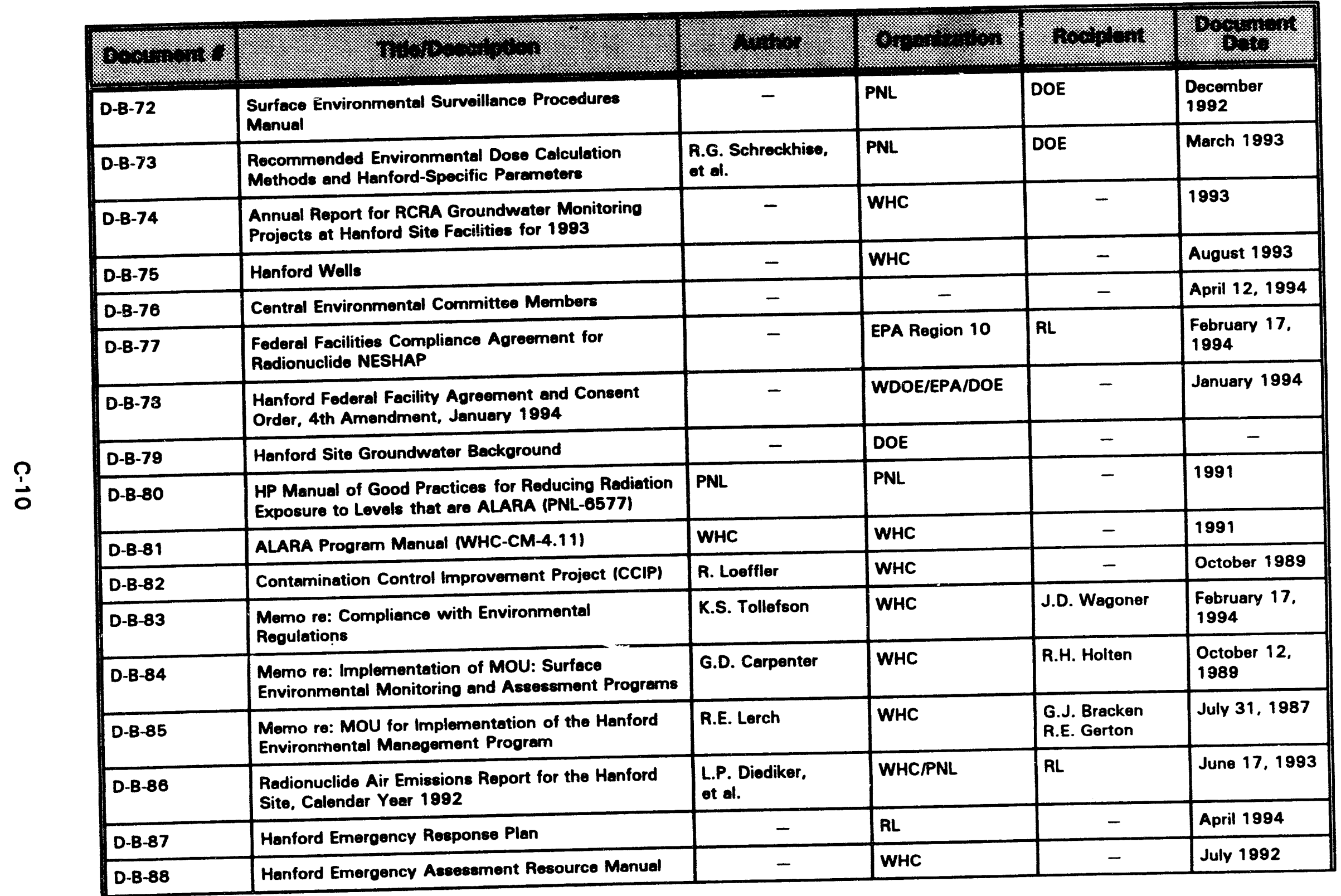


SITE DOCUMENTS REVIEWED BY THE AUDIT TEAM (continued)

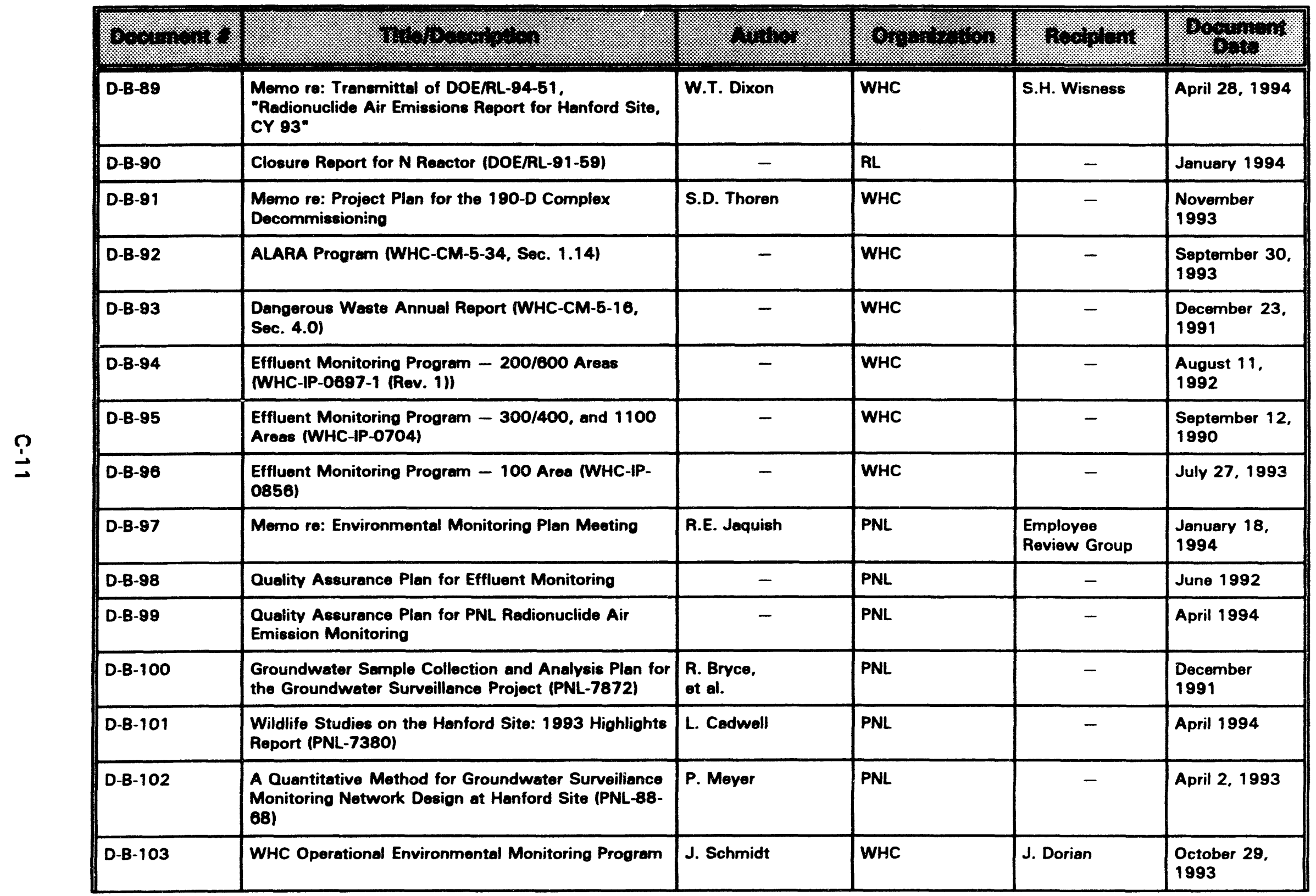




\section{SITE DOCUMENTS REVIEWED BY THE AUDIT TEAM (continued)}

\begin{tabular}{|c|c|c|c|c|c|}
\hline 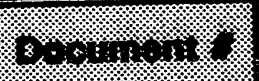 & 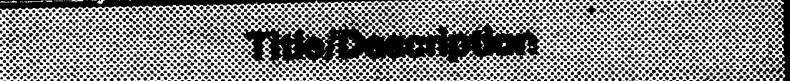 & 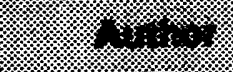 & 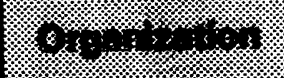 & 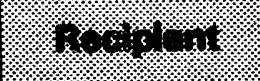 & 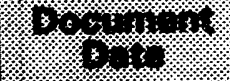 \\
\hline D-B-104 & Operational Environmentel Program Self-Assesement & R. Holten & WHC & J. Schmidt & $\begin{array}{l}\text { March 31, } \\
1993\end{array}$ \\
\hline D-B-105 & PPG Quest Tracking System Ranking Matrix & - & WHC & - & - \\
\hline D-B-106 & $\begin{array}{l}\text { Bsttelle/IT Corp. Radiochem Contract No. 163589-A- } \\
\text { M1 }\end{array}$ & - & PNL & - & $\begin{array}{l}\text { October } 23 \\
1991\end{array}$ \\
\hline D-B-107 & $\begin{array}{l}\text { Procedure-Gaseous Effluent Monitoring System } \\
\text { Inspection and Sampling Exchange (WHC-(P-0718) }\end{array}$ & - & WHC & - & April 15, 1994 \\
\hline D-B-108 & $\begin{array}{l}\text { Environmental Support Procedures and Requirements } \\
\text { (WHC-CM-7-8) }\end{array}$ & - & WHC & - & April 1. 1994 \\
\hline D-B-109 & Solf-Assessment Effluent and Emission Monitoring & - & WHC & - & - \\
\hline D-B-110 & $\begin{array}{l}\text { Environmental Releases for Calendar Year } 1992 \\
\text { (WHC-EP-0527-2) }\end{array}$ & - & WHC & - & July 1993 \\
\hline D-B-111 & $\begin{array}{l}\text { Environmental Radiation Program - } 1991 \text { Annual } \\
\text { Report }\end{array}$ & - & $\begin{array}{l}\text { Weshington State } \\
\text { Department of } \\
\text { Health (WDOH) }\end{array}$ & - & June 1993 \\
\hline D-B-112 & $\begin{array}{l}\text { Surface Environmental Surveillance Procedures } \\
\text { Manual (PNL-MA-580) }\end{array}$ & $\begin{array}{l}\text { R. Hand and } \\
\text { R. Dierks }\end{array}$ & PNL & - & $\begin{array}{l}\text { January } 1 . \\
1993\end{array}$ \\
\hline D-B-113 & $\begin{array}{l}\text { Letter-Notification of Results of Laboratory Analysis } \\
\text { of Potential High-Activity Radioactive Mixed Waste }\end{array}$ & $\begin{array}{l}\text { W. Apley and } \\
\text { A. King }\end{array}$ & PNL & J. Bauer & $\begin{array}{l}\text { April } 26 \\
1993\end{array}$ \\
\hline D-8-114 & $\begin{array}{l}\text { Internal Report-Mixed Waste Management Plan for } \\
\text { the B-Cell Cleanout Project }\end{array}$ & P. Weaver & PNL & - & $\begin{array}{l}\text { March 25, } \\
1994\end{array}$ \\
\hline D-8-115 & $\begin{array}{l}\text { Memo: } 324 \text { Building-Potential Hazardous Waste } \\
\text { Tanks }\end{array}$ & T. Knepp & $\begin{array}{l}\text { RL-Environmental } \\
\text { Remediation } \\
\text { Division (ERD) }\end{array}$ & J. Hunter, AMO & $\begin{array}{l}\text { May 16, } \\
1990\end{array}$ \\
\hline D-B-116 & $\begin{array}{l}\text { Letter-Designation of Materials in the } 324 \text { Building } \\
\text { Voult Tanks }\end{array}$ & J. Sutoy & RL-R\&D Division & $\begin{array}{l}\text { Director, } \\
\text { PNL }\end{array}$ & $\begin{array}{l}\text { June 4, } \\
1990\end{array}$ \\
\hline D-B-117 & $\begin{array}{l}\text { Letter-High-Activity Radioactive Waste lssues at } \\
\text { Hanford }\end{array}$ & J. Bauer & RL-EAP & $\begin{array}{l}\text { R. Stanley } \\
\text { (WDOE) and } \\
\text { G. Hofer (EPA) }\end{array}$ & $\begin{array}{l}\text { April 30, } \\
1993\end{array}$ \\
\hline D-B-118 & Letter-DOE Guidance on ALARA & R. Holten & $\begin{array}{l}\mathrm{RL}-\text { Technical } \\
\text { Support Division }\end{array}$ & R. Pelletier & $\begin{array}{l}\text { June } 26 . \\
1991\end{array}$ \\
\hline
\end{tabular}


SITE DOCUMENTS REVIEWED BY THE AUDIT TEAM (continued)

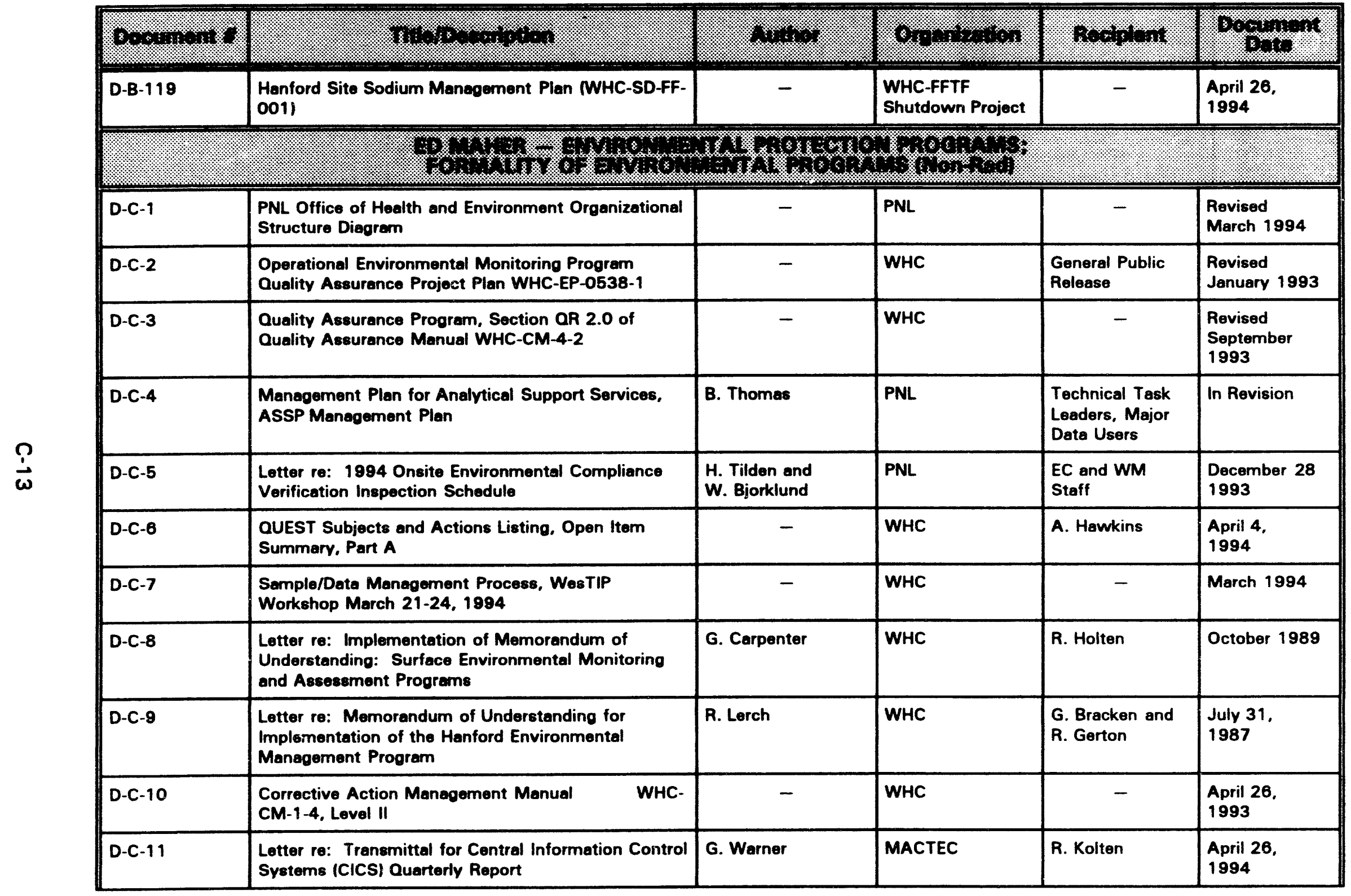


SITE DOCUMENTS REVIEWED BY THE AUDIT TEAM (continued)

\begin{tabular}{|c|c|c|c|c|c|}
\hline 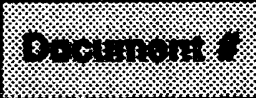 & 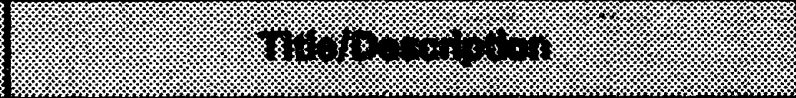 & 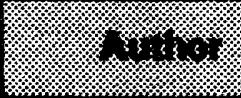 & 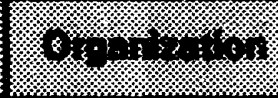 & 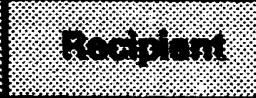 & 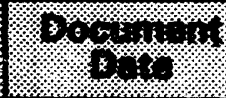 \\
\hline D-C-12 & $\begin{array}{l}\text { RCRA \& Operational Monitoring Organizational } \\
\text { Management Diegram, Work Breakdown Structure } \\
\text { By Performing Organizations }\end{array}$ & - & WHC & - & - \\
\hline D-C-13 & $\begin{array}{l}\text { Office of Laboratory Director Organizational } \\
\text { Management Diagram }\end{array}$ & - & PNL & - & March 1994 \\
\hline D-C-14 & $\begin{array}{l}\text { The Resource Conservation \& Recovery Act (RCRA) } \\
\text { and Operational Ground-Water Monitoring Support } \\
\text { Project Quality Assurance Project Plan, QA Project } \\
\text { Plan OHE-018 }\end{array}$ & - & PNL & - & $\begin{array}{l}\text { February } 1 . \\
1994\end{array}$ \\
\hline D-C-15 & $\begin{array}{l}\text { FY } 1994 \text { Project Management Plan, RCRA and } \\
\text { Operational Ground-Water Monitoring Support } \\
\text { Project, WHC Work Order ED4057, PNL Subaccount } \\
\text { 16729. }\end{array}$ & - & PNL & - & $\begin{array}{l}\text { February } 18 \\
1994\end{array}$ \\
\hline D-C-16 & $\begin{array}{l}\text { Waste Minimization and Pollution Prevention } \\
\text { Awareness Program PNL-MA-822 }\end{array}$ & $\begin{array}{l}\text { E. Hauth and } \\
\text { G. Hoones }\end{array}$ & PNL & - & $\begin{array}{l}\text { October } 9 . \\
1991\end{array}$ \\
\hline D-C-17 & $\begin{array}{l}\text { Ground-Water Surveillance Project Quality Assurance } \\
\text { Project Plan QA Project Plan EES059, Rev } 2\end{array}$ & S. Luttrell & PNL & - & $\begin{array}{l}\text { December } 3 . \\
1993\end{array}$ \\
\hline D-C-18 & Environmental Compliance Plan & - & HEHF & - & - \\
\hline D-C-19 & $\begin{array}{l}\text { Waste Minimization and Pollution Prevention } \\
\text { Awareness Program Plan }\end{array}$ & - & HEHF & - & January 1994 \\
\hline D-C-20 & $\begin{array}{l}\text { Reengineering Program Office Organizational } \\
\text { Management Diegram }\end{array}$ & - & WHC & - & $\begin{array}{l}\text { April 20. } \\
1994\end{array}$ \\
\hline D-C-21 & $\begin{array}{l}\text { OA Plan for the Surface Environmental Surveillance } \\
\text { and Drinking Woter Monitoring Projects PNL-MA-70 }\end{array}$ & R. Woodruff & PNL & - & August 1993 \\
\hline D-C-22 & $\begin{array}{l}\text { Letter re: Transmittal Lotter for "Review of } \\
\text { Radiochemical Data Validation" }\end{array}$ & C. Bosted & RL & $\begin{array}{l}\text { J. Erickson and } \\
\text { R. Freoberg }\end{array}$ & $\begin{array}{l}\text { April } 11 \\
1934\end{array}$ \\
\hline D-C-23 & $\begin{array}{l}\text { Briefing Papers: RCRA and Operational Ground- } \\
\text { Water Monitorine Support Program }\end{array}$ & D. Stewart & PNL & - & $\begin{array}{l}\text { April } 20 \\
1994\end{array}$ \\
\hline D-C-24 & $\begin{array}{l}\text { Waste, Analytical, and Environmental Services } \\
\text { Organizational Management Diagram }\end{array}$ & - & WHC & - & $\begin{array}{l}\text { April 25. } \\
1994\end{array}$ \\
\hline D-C-25 & $\begin{array}{l}\text { Request for } 1993 \text { Air Emission Inventory } \\
\text { Information, Department of Ecologv }\end{array}$ & S. Stites & WHC & WDOE & $\begin{array}{l}\text { April } 21 . \\
1994\end{array}$ \\
\hline
\end{tabular}


SITE DOCUMENTS REVIEWED BY THE AUDIT TEAM (continued)

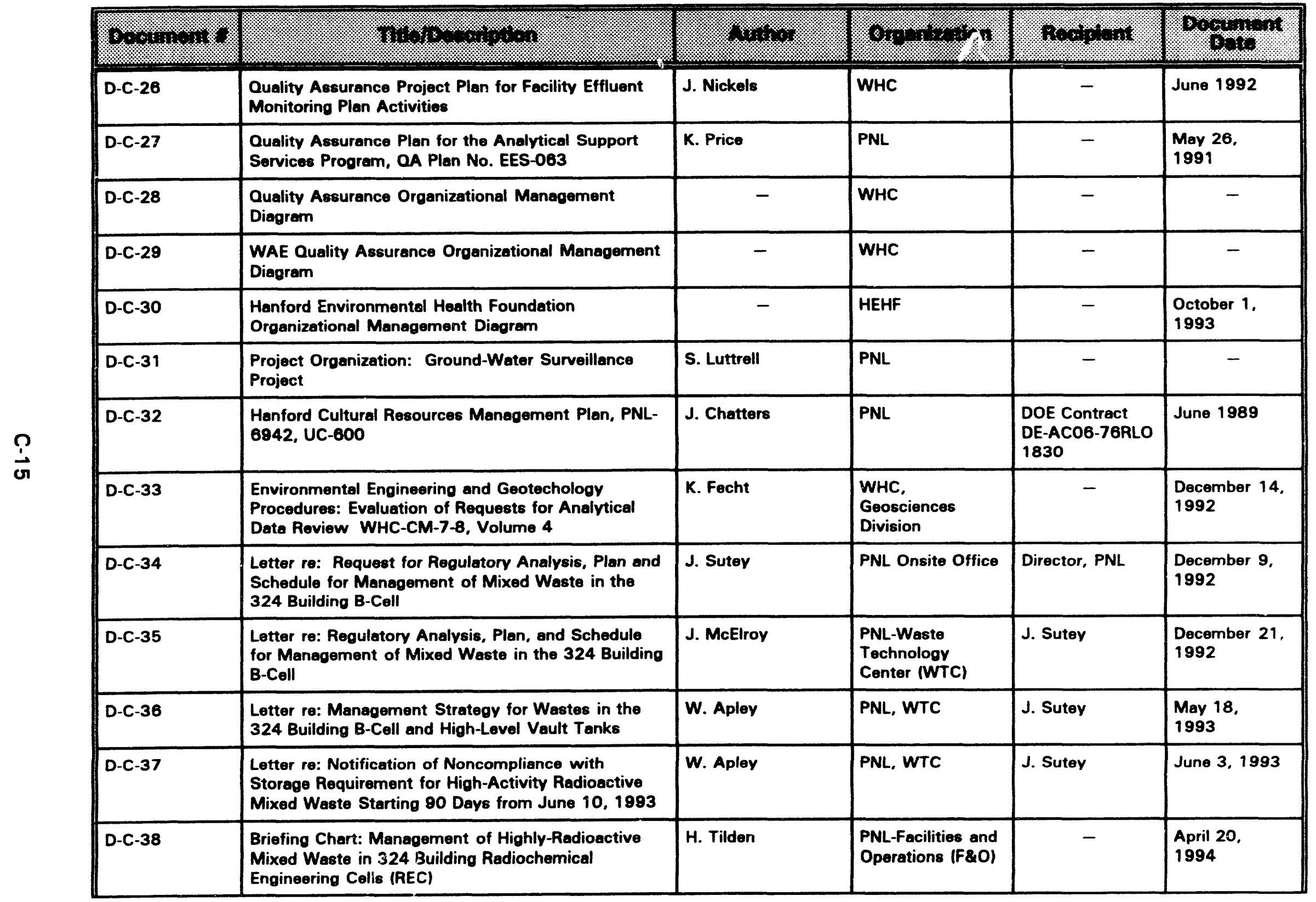


SITE DOCUMENTS REVIEWED BY THE AUDIT TEAM (continued)

\begin{tabular}{|c|c|c|c|c|c|}
\hline 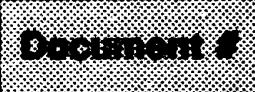 & xy. & 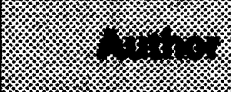 & 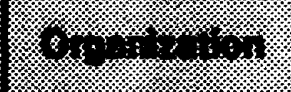 & 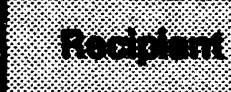 & $x^{3}$ \\
\hline D-C-39 & $\begin{array}{l}\text { Letter re: Notification of Noncompliance with } \\
\text { Storage Requirements for High-Activity Radiosctive } \\
\text { Mixed Waste Starting } 90 \text { Days from February 14. } \\
1994\end{array}$ & B.D. Shipp & $\begin{array}{l}\text { Maneger, } \\
\text { Engineering } \\
\text { Technology } \\
\text { Center }\end{array}$ & J. Sutey & $\begin{array}{l}\text { March 3, } \\
1994\end{array}$ \\
\hline D-C-40 & $\begin{array}{l}\text { Guideline for Hanford Site Implementation of the } \\
\text { National Environmental Policy Act }\end{array}$ & S.E. King & PNL & - & March 1989 \\
\hline D-C-41 & $\begin{array}{l}\text { Hanford Site Waste Minimization and Pollution } \\
\text { Prevention Awareness Progrem Plan DOE/RL-91-31 }\end{array}$ & - & $\mathbf{R L}$ & - & May 1991 \\
\hline D-C-42 & $\begin{array}{l}\text { Guide for Preparing and Maintaining Facility-Specific } \\
\text { Waste Minimization Plans WHC-SD-WM-EV-014 } \\
\text { Revision } 1\end{array}$ & - & $\begin{array}{l}\text { WHC-Waste } \\
\text { Minimization } \\
\text { Toam }\end{array}$ & - & $\begin{array}{l}\text { January } 1989 . \\
\text { Revised } 1993\end{array}$ \\
\hline D-C-43 & $\begin{array}{l}\text { Hanford Site Annual Dangerous Weste Report, } \\
\text { DOE/RL-94-10: Volume } 5 \text { Supplement Weste } \\
\text { Minimization Report for Calender Year } 1893\end{array}$ & - & RL-EAP & - & $\begin{array}{l}\text { December } 16 . \\
1992\end{array}$ \\
\hline D-C-44 & 1994 Environment, Safety and Health Plen & W. Wiley & $\begin{array}{l}\text { PNL-Laboratory } \\
\text { Director }\end{array}$ & - & - \\
\hline D-C-45 & $\begin{array}{l}\text { Letter re: Formal Transmittal of } 1993 \text { Annual } \\
\text { Dangerous Waste and Biennial Weste Minimization } \\
\text { Report }\end{array}$ & T. Chikalla & PNL-F\&O Director & J. Bauer & January 1994 \\
\hline D-C-46 & $\begin{array}{l}\text { Letter re: Environmental Requirements for } \\
\text { Rofrigerants }\end{array}$ & H. Tilden & PNL-F\&O & L. Eberhardt & $\begin{array}{l}\text { December } 3, \\
1992\end{array}$ \\
\hline D-C-47 & $\begin{array}{l}\text { Letter re: Potential Radioactive Mixed Waste in } 324 \\
\text { Building B-Cell (Unsigned Copy) }\end{array}$ & J. McElroy & $\begin{array}{l}\text { PNL-WTC } \\
\text { Manager }\end{array}$ & J. Sutey & $\begin{array}{l}\text { October } 30 \\
1992\end{array}$ \\
\hline D-C-48 & $\begin{array}{l}\text { Letter re: Request for Regulatory Analysis, Plan and } \\
\text { Schedule for Management of Mixed Waste in the } \\
324 \text { Building B-Cell }\end{array}$ & J. Sutey & PNL Offsite Office & Director, PNL & $\begin{array}{l}\text { December } 11 . \\
1992\end{array}$ \\
\hline D-C-49 & $\begin{array}{l}\text { Letter re: Regulatory Analysis, Plan, and Schedule } \\
\text { for Manegement of Mixed Waste in the } 324 \text { Building } \\
\text { B-Cell }\end{array}$ & J. McElroy & PNL-WTC & J. Sutey & $\begin{array}{l}\text { December } 23 . \\
1992\end{array}$ \\
\hline D-C-50 & $\begin{array}{l}\text { Letter re: Preliminary Notification of Potential } \\
\text { Noncompliance with Storege Requirements for High- } \\
\text { Activity Radioactive Mixed Waste }\end{array}$ & W. Aploy & PNL-WTC & J. Bauer & $\begin{array}{l}\text { February } 22 . \\
1993\end{array}$ \\
\hline
\end{tabular}


SITE DOCUMENTS REVIEWED BY THE AUDIT TEAM (continued)

\begin{tabular}{|c|c|c|c|c|c|}
\hline \% & 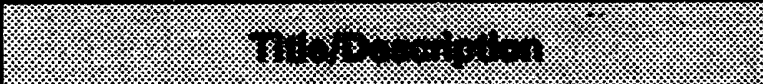 & 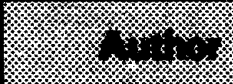 & 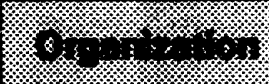 & 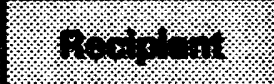 & 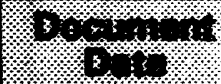 \\
\hline D-C-51 & $\begin{array}{l}\text { Letter re: Manegement Strategy for Wastes in the } \\
324 \text { Building B-Cell and High-Loval Voult Tanks }\end{array}$ & W. Aploy & PNL-WTC & J. Sutey & $\begin{array}{l}\text { May } 18 \\
1993\end{array}$ \\
\hline D-C-52 & $\begin{array}{l}\text { Letter re: PNL Management of Radioactive Mixed } \\
\text { Waste (RMW) in } 324 \text { Building Hot Cell }\end{array}$ & J. Sutey & $\begin{array}{l}\text { RL-Laboratory } \\
\text { Management } \\
\text { Division }\end{array}$ & Director, PNL & $\begin{array}{l}\text { June } 21 \\
1993\end{array}$ \\
\hline D-C-53 & $\begin{array}{l}\text { Letter re: Dry Run Presentation on Status and } \\
\text { Recommended Strategy for Management of } \\
\text { Radioactive Mixed Waste (RMW) in } 324 \text { Building }\end{array}$ & W. Apley & PNL-WTC & J. Sutey & $\begin{array}{l}\text { July } 22 . \\
1993\end{array}$ \\
\hline D-C-54 & $\begin{array}{l}\text { Letter re: Review of Draft Surveillance Report: } \\
\text { Building } 324 \text { Hot Cell Environmental Status }\end{array}$ & W. Apley & PNL-WTC & J. Sutey & $\begin{array}{l}\text { August } 11 \\
1993\end{array}$ \\
\hline D-C-55 & Letter re: Mixed Waste lssue 324 Facility & J. Sutey & RL-LMD & Director, PNL & $\begin{array}{l}\text { May } 4 . \\
1994\end{array}$ \\
\hline D-C-56 & $\begin{array}{l}\text { Letter re: Need for Special Case and Radioactive } \\
\text { Mixed Waste Storage Capability to Help Solve a } \\
\text { Significant Safety Problem in } 324 \text { Building B-Cell }\end{array}$ & W. Apley & PNL-WTC & w. Hamilton & $\begin{array}{l}\text { June } 14 . \\
1993\end{array}$ \\
\hline D-C-57 & $\begin{array}{l}\text { Letter re: Capacity Required for Special Case Weste } \\
\text { (SCW) Storage Rolated to the } 324 \text { Building Hot-Cell } \\
\text { Cleanout }\end{array}$ & D. Knowiton & $\begin{array}{l}\text { PNL-Remote } \\
\text { Technology } \\
\text { Department }\end{array}$ & w. Hamilton & $\begin{array}{l}\text { December } 3 . \\
1993\end{array}$ \\
\hline D-C-58 & Letter re: PNL Line Managers Inspection Guidelines & T. Chikalla & PNL-F\&O & Center Managers & $\begin{array}{l}\text { November 24, } \\
1992\end{array}$ \\
\hline D-C-59 & $\begin{array}{l}\text { F\&O Inspection Process, Complience Database } \\
\text { System's User's Guide }\end{array}$ & - & PNL-F\&O & $\begin{array}{l}\text { Center Line } \\
\text { Managers }\end{array}$ & - \\
\hline D-C-60 & $\begin{array}{l}\text { Environmental Engineering and Geotechnology } \\
\text { Procedures: Eveluation of Requests for Analytical } \\
\text { Date Review WHC-CM-7-8, Volume } 4\end{array}$ & K. Fecht & $\begin{array}{l}\text { WHC-Manager, } \\
\text { Geosciences }\end{array}$ & - & $\begin{array}{l}\text { December } 14 . \\
1992\end{array}$ \\
\hline D-C-61 & $\begin{array}{l}\text { Hanford Site National Environmental Act (NEPA) } \\
\text { Charecterization PNL-6415 Revision } 5\end{array}$ & C. Cushing & PNL & - & $\begin{array}{l}\text { December } \\
1992\end{array}$ \\
\hline D-C-62 & $\begin{array}{l}\text { Revised Address List for National Environmental } \\
\text { Policy Act (NEPA) Notifications to the State of } \\
\text { Washington and Henford Tribes }\end{array}$ & P. Dunigan Jr. & $\begin{array}{l}\text { RL-NEPA } \\
\text { Compliance } \\
\text { Officer }\end{array}$ & Distribution & $\begin{array}{l}\text { February } 28 \\
1994\end{array}$ \\
\hline D-C-63 & NEPA Tracking System User's Guide & P. Dunigan Jr. & $\begin{array}{l}\text { RL-NEPA } \\
\text { Compliance } \\
\text { Officer }\end{array}$ & - & - \\
\hline
\end{tabular}


SITE DOCUMENTS REVIEWED BY THE AUDIT TEAM (cominUSd)

\begin{tabular}{|c|c|c|c|c|c|}
\hline 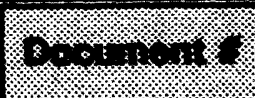 & $x_{1}$ & \% & Q & $\frac{1}{4}+\infty, 1 \%$ & $w^{3}$ \\
\hline D-C.64 & NEPA Approval Process Flowchart & P. Dunigan Jr. & $\begin{array}{l}\text { RL-NEPA } \\
\text { Compliance } \\
\text { Officer }\end{array}$ & - & - \\
\hline D-C-65 & $\begin{array}{l}\text { Draft Guidance on Processing RL National } \\
\text { Environmental Policy Act (NEPA) Documents }\end{array}$ & P. Dunigan Jr. & $\begin{array}{l}\text { RL-NEPA } \\
\text { Compliance } \\
\text { Officer }\end{array}$ & - & - \\
\hline D-C-68 & $\begin{array}{l}\text { Draft RL Implementing Procedures, RLIP 5440.1B: } \\
\text { RL National Environmental Policy Act Compliance } \\
\text { Progrem }\end{array}$ & P. Dunigan Jr. & $\begin{array}{l}\text { RL-NEPA } \\
\text { Compliance } \\
\text { Officer }\end{array}$ & - & - \\
\hline D-C-67 & Status of NEPA Document Roviow, ElA List & P. Dunigan Jr. & $\begin{array}{l}\text { RL-NEPA } \\
\text { Compliance } \\
\text { Officer }\end{array}$ & - & $\begin{array}{l}\text { May } 6 . \\
1994\end{array}$ \\
\hline D-C-68 & Status of RL CXs & P. Dunigan Jr. & $\begin{array}{l}\text { RL-NEPA } \\
\text { Compliance } \\
\text { Officer }\end{array}$ & - & $\begin{array}{l}\text { May } 6 . \\
1994\end{array}$ \\
\hline D-C-69 & $\begin{array}{l}\text { NEPA Source Guide for the Hanford Site, WHC-SP- } \\
\text { 0903. Revision } 0\end{array}$ & - & $\begin{array}{l}\text { WHC-Compliance } \\
\text { Group }\end{array}$ & - & October 1992 \\
\hline D-C-70 & Letter re: Exercise "TADPOLE" Final Critique & J. Tritz & $\begin{array}{l}\text { WHC-Emeroency } \\
\text { Preparedness (EP) }\end{array}$ & R. Holten & $\begin{array}{l}\text { November } 18, \\
1992\end{array}$ \\
\hline D-C-71 & WHC Facility Waste Minimization Certification & D. Nichols & $\begin{array}{l}\text { WHC-Pollution } \\
\text { Provention \& } \\
\text { Recycling }\end{array}$ & - & - \\
\hline D-C-72 & Pollution Provention Awareness Plan, PNL-MA-8 & - & PNL-F\&O & - & August 1989 \\
\hline D-C-73 & $\begin{array}{l}\text { Environmental Restoration (ER) Program } \\
\text { Environmental Programs Division, Geotechnical } \\
\text { Support Branch Responsibilities Summary \& Branch } \\
\text { Staff Assignments }\end{array}$ & B. Stowart & RL & - & $\begin{array}{l}\text { April 12, } \\
1994\end{array}$ \\
\hline D-C-74 & Legal and Contracts Organizational Chart & - & $\begin{array}{l}\text { PNL-Legal and } \\
\text { Controcts }\end{array}$ & - & March 1993 \\
\hline D-C-75 & $\begin{array}{l}\text { Emergency Preparadness Exercise Schedule for FY } \\
1984\end{array}$ & - & WHC-EP & - & $\begin{array}{l}\text { May } 6 . \\
1994\end{array}$ \\
\hline D-C-76 & List of Building Emergency Directors & - & WHC-EP & - & $\begin{array}{l}\text { January } 5 \text {. } \\
1994\end{array}$ \\
\hline
\end{tabular}


SITE DOCUMENTS REVIEWED BY THE AUDIT TEAM (continued)

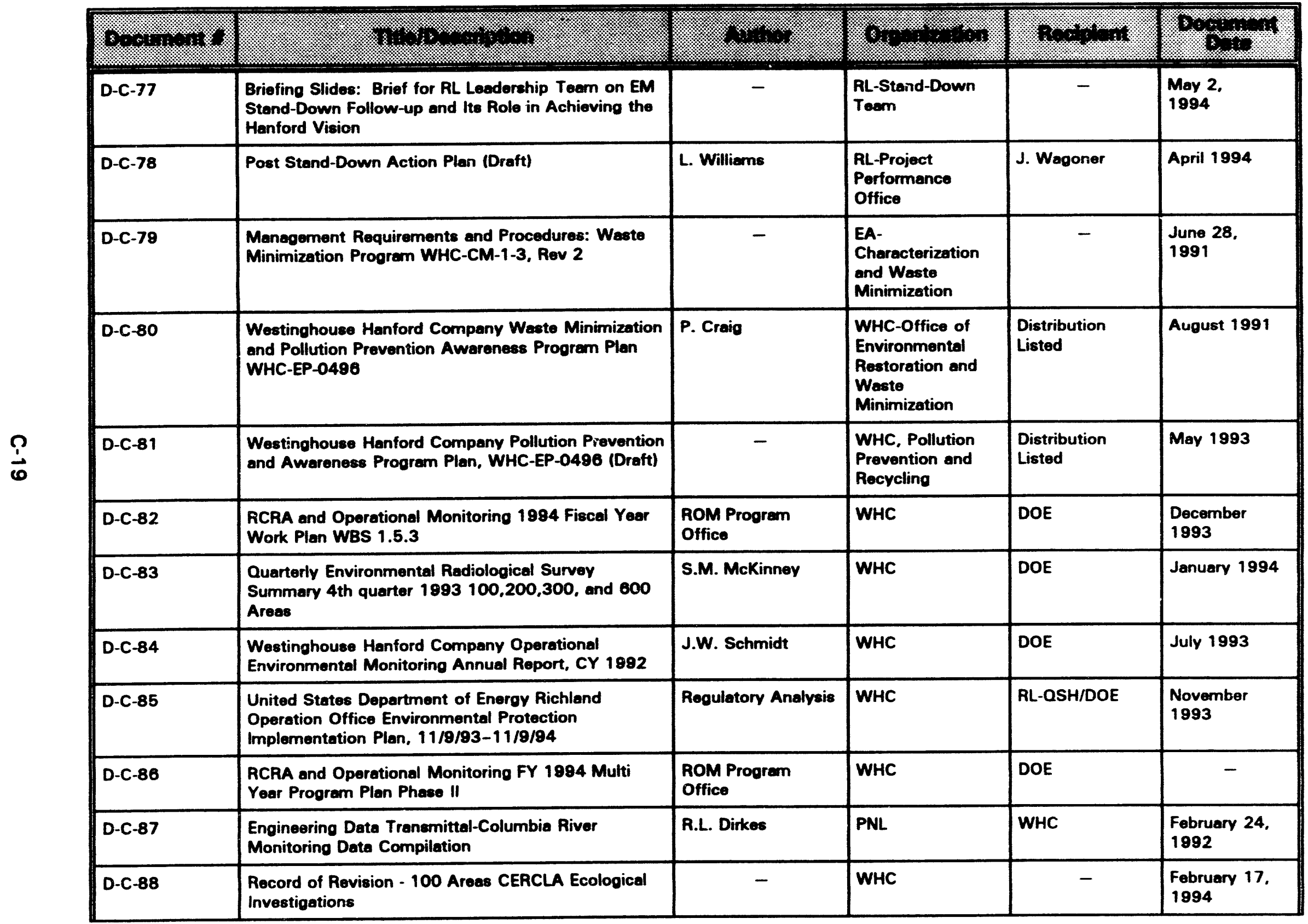




\section{SITE DOCUMENTS REVIEWED BY THE AUDIT TEAM (continued)}

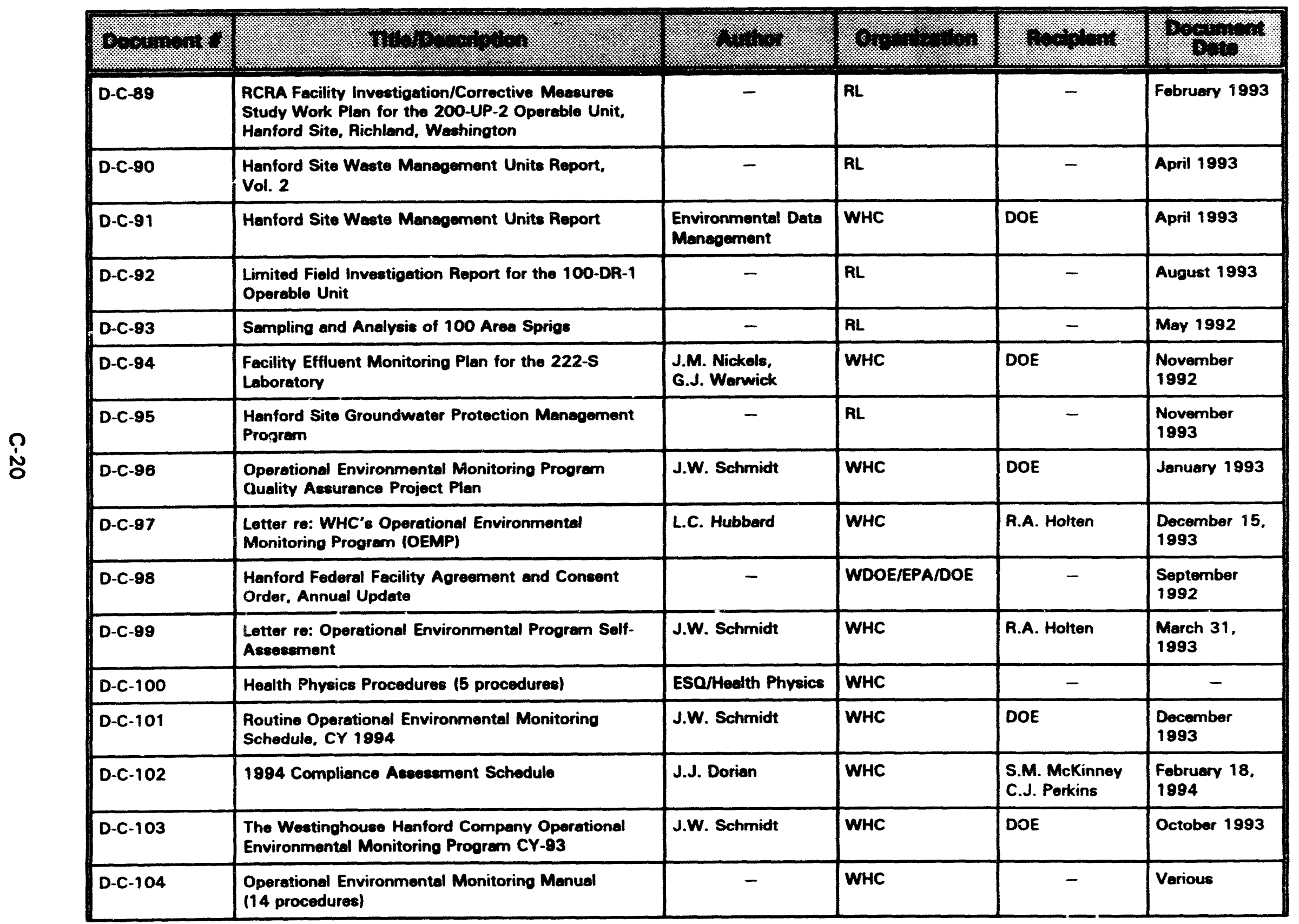


SITE DOCUMENTS REVIEWED BY THE AUDIT TEAM (continued)

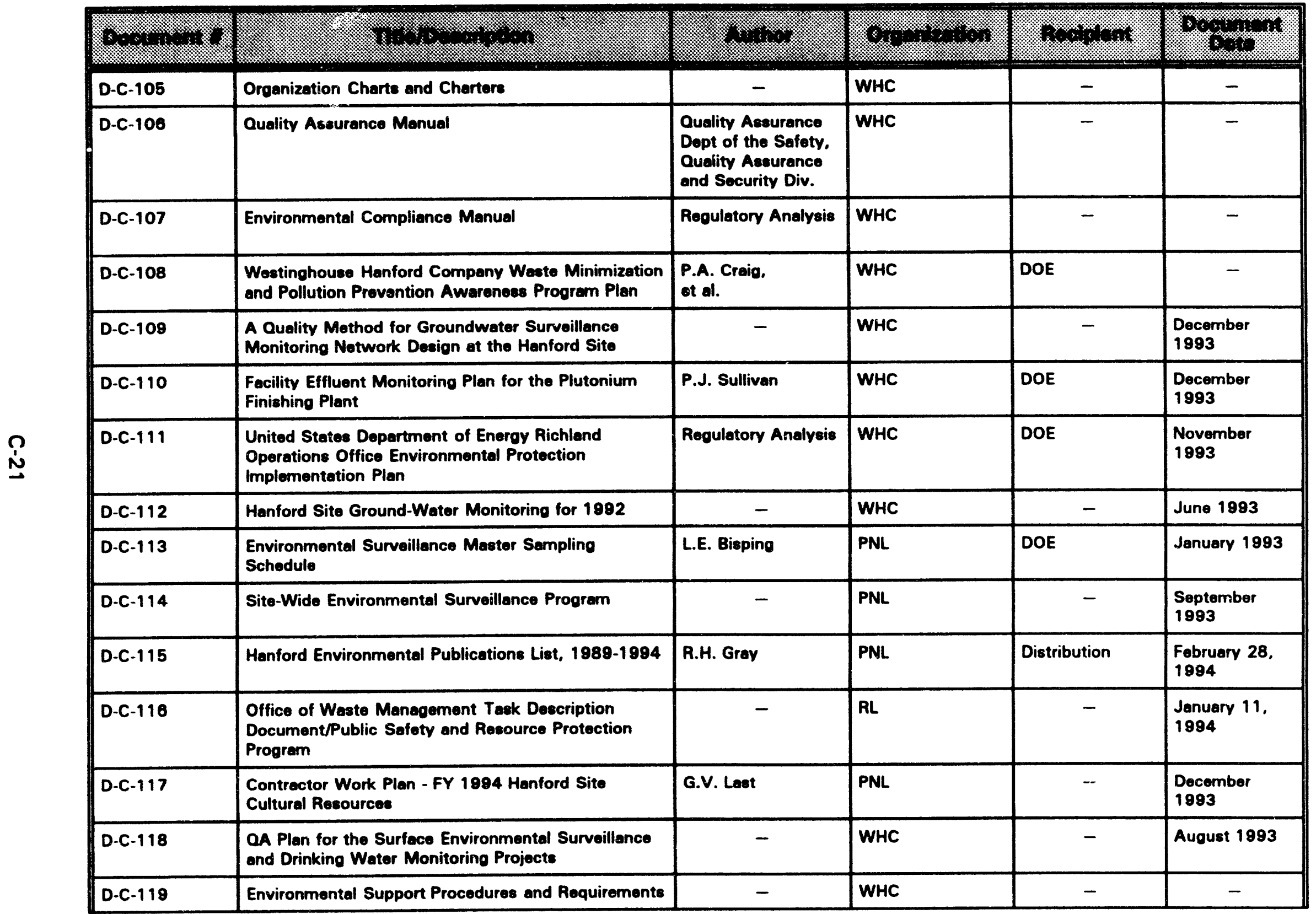




\begin{tabular}{|c|c|c|c|c|c|}
\hline E66ட 4010W & 300 & OHM & nosuyor 9 ' & 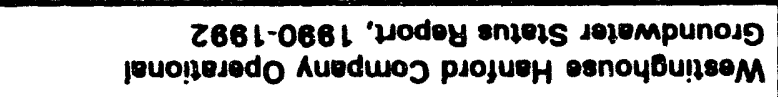 & †ยเ-ว-0 \\
\hline- & - & $7 \boldsymbol{y}$ & - & 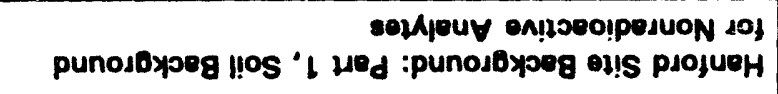 & ยะเ-ว-ם \\
\hline- & - & - & - & 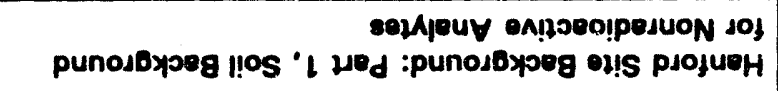 & 乙Eเ-ว-ด \\
\hline- & - & 300 & - & punojoxpeg sejempunojs ou!s pjojueH & เEเ-ว-O \\
\hline $766 \iota$ Asenuer & - & $\Xi 00 / \forall d \exists / 300 M$ & - & 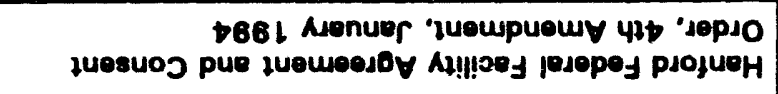 & oEl-כ-0 \\
\hline 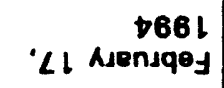 & 78 & OL vo!̣bey $\forall d \exists$ & - & 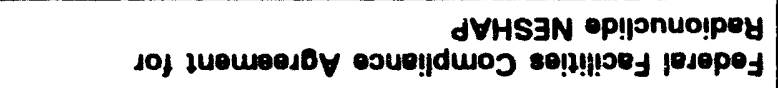 & $62 L-5-0$ \\
\hline sno!sen & - & - & - & 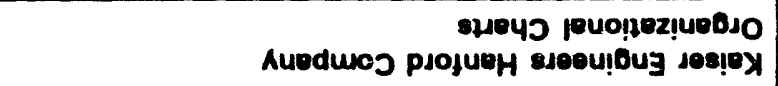 & $82 L-5-0$ \\
\hline$\varepsilon 661$ & - & SHM & - & 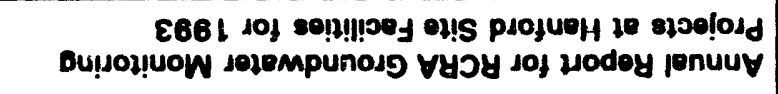 & LZL-כ-0 \\
\hline $\begin{array}{r}266 \downarrow \\
10 q u e s e 0\end{array}$ & 300 & TNd & - & 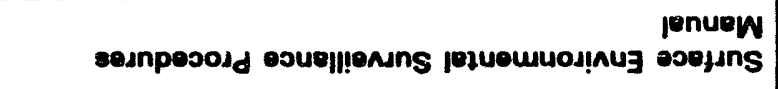 & 8Zレ-ว-0 \\
\hline- & - & TNd & Du!ds! 377 & 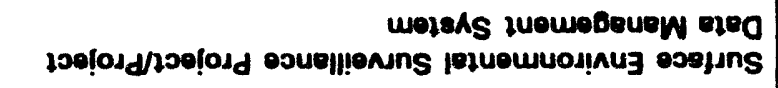 & 9ZL-ว-0 \\
\hline 166$\rfloor$ & - & TNd & - & 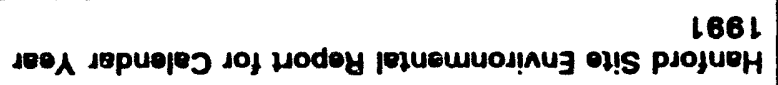 & $\bullet 乙 \downarrow-כ-0$ \\
\hline $166 \downarrow$ & 300 & 7Nd & - & 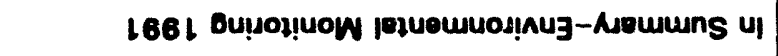 & $\varepsilon 乙\llcorner-ว-0$ \\
\hline 2661 & 300 & TNd & - & 2661 Hodoy pojuousuos!nug & $22 \downarrow-3-a$ \\
\hline- & - & - & - & 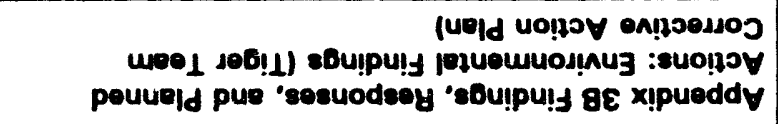 & เてเ-כ-0 \\
\hline E68L tanony & - & - & - & 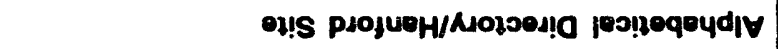 & $0 Z L-0-0$ \\
\hline $1 \%$ & \%... & 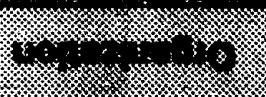 & & 13 & $x^{3}$ \\
\hline
\end{tabular}


SITE DOCUMENTS REVIEWED BY THE AUDIT TEAM (continued)

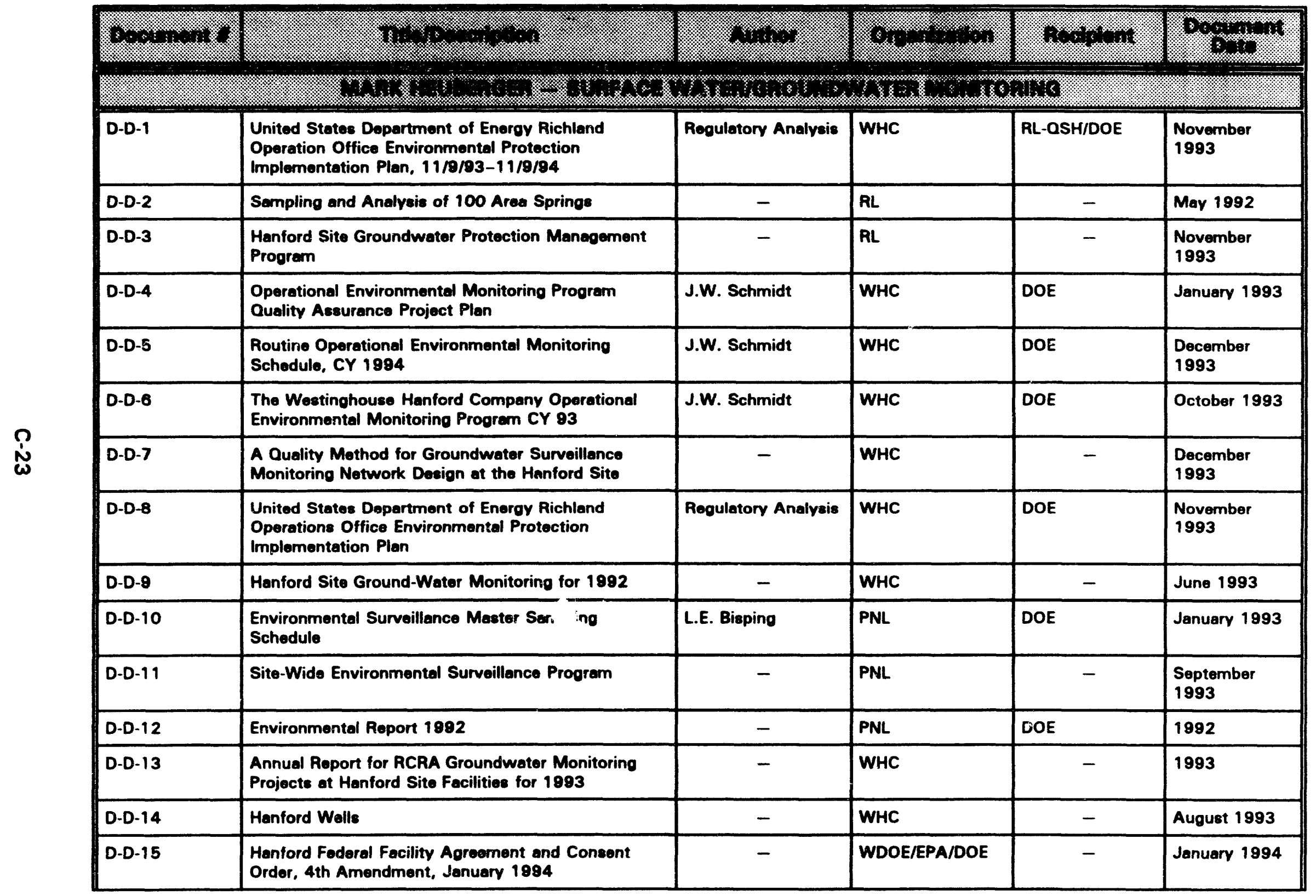


SITE DOCUMENTS REVIEWED BY THE AUDIT TEAM (continued)

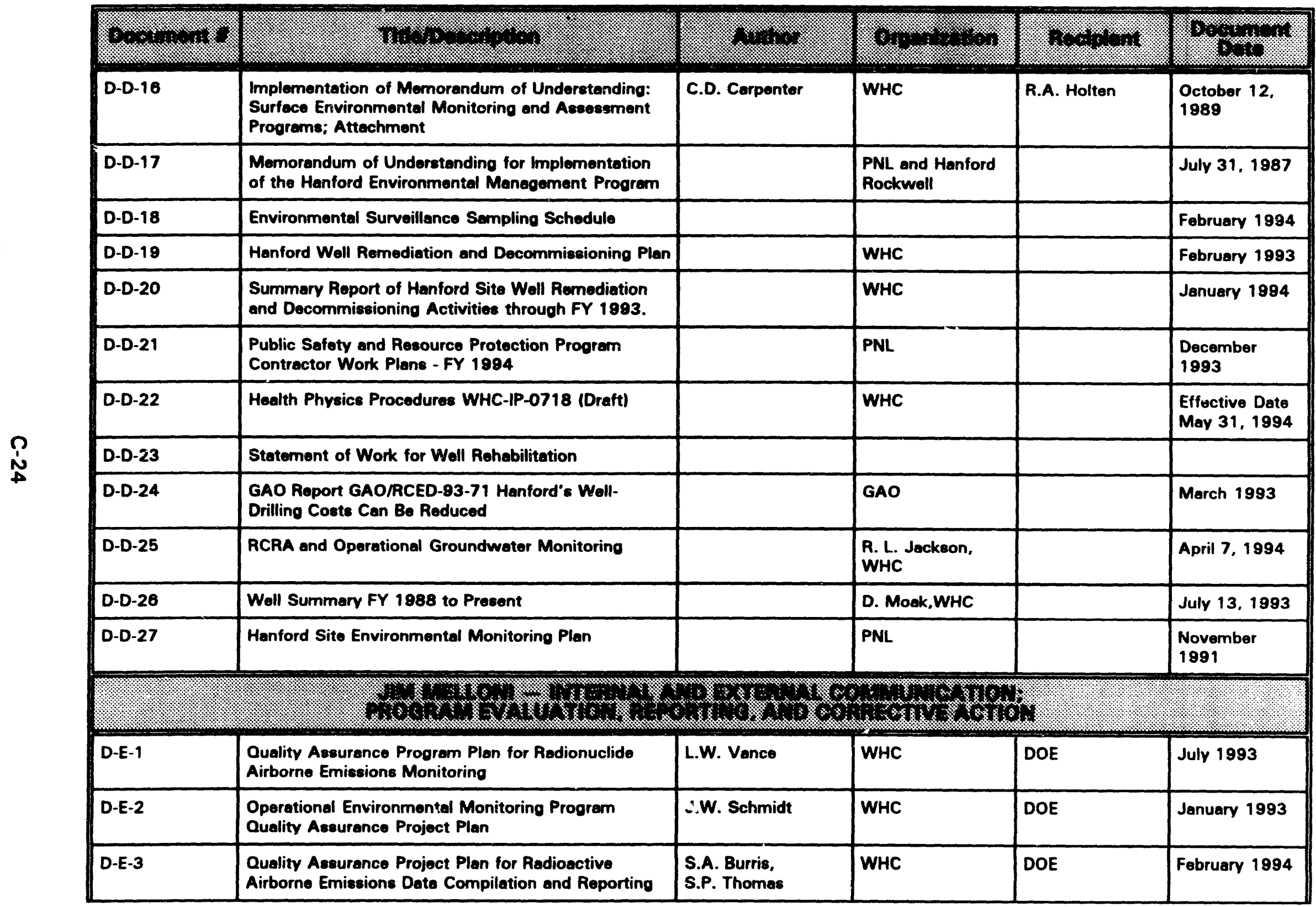


SITE DOCUMENTS REVIEWED BY THE AUDIT TEAM (continued)

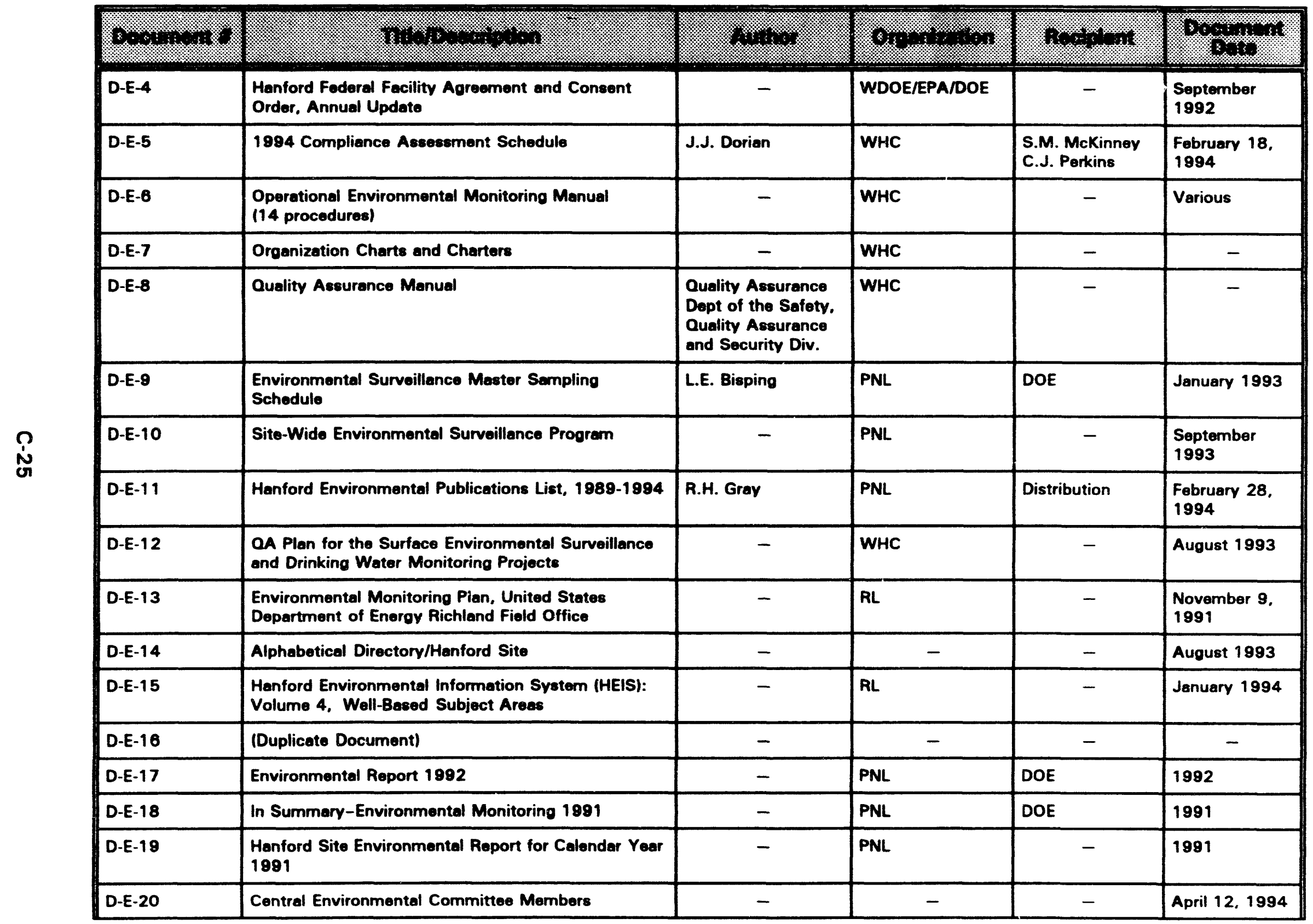


SITE DOCUMENTS REVIEWED BY THE AUDIT TEAM (continued)

\begin{tabular}{|c|c|c|c|c|c|}
\hline 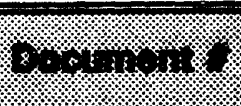 & 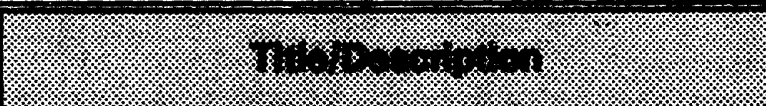 & 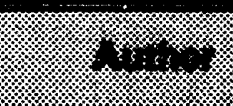 & 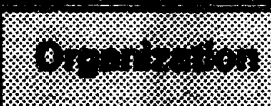 & 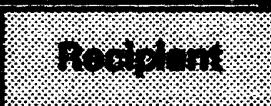 & $\operatorname{los}^{3}$ \\
\hline D-E-21 & $\begin{array}{l}\text { Honford Federal Facility Agreement and Consent } \\
\text { Order, 4th Amendment, January } 1994\end{array}$ & - & WDOE/EPA/DOE & - & Jenuary 1994 \\
\hline D-E-22 & $\begin{array}{l}\text { Implementation of Memorandum of Understending: } \\
\text { Surfece Environmental Monitoring and Assesement } \\
\text { Progrems; Attechment }\end{array}$ & C.D. Carpenter & WHC & R.A. Holten & $\begin{array}{l}\text { October } 12, \\
1989\end{array}$ \\
\hline D-E-23 & $\begin{array}{l}\text { Contral Information Control Systems (CICS) } \\
\text { Quarterly Roport }\end{array}$ & L.J. Voigt & MACTEC & R.A. Holten & $\begin{array}{l}\text { April 26, } \\
1994\end{array}$ \\
\hline D-E-24 & Draft-Resource Material Use Survey Results & G. Harvey & $\begin{array}{l}\text { PNL- } \\
\text { Communications }\end{array}$ & - & $\begin{array}{l}\text { June } 14 \\
1993\end{array}$ \\
\hline D-E-25 & In Summary Environmental Report, 1992 & - & $\begin{array}{l}\text { PNL- } \\
\text { Communications }\end{array}$ & - & - \\
\hline D-E-28 & $\begin{array}{l}\text { Mission and Function Statement, Office of } \\
\text { Performance Assessment }\end{array}$ & - & RL-OPA & - & $\begin{array}{l}\text { Draft } \\
\text { April 4, } 1994\end{array}$ \\
\hline D-E-27 & EQA/ESQA/EMSI Surveillances & - & WHC & - & $\begin{array}{l}\text { May } 2 . \\
1994\end{array}$ \\
\hline D-E-28 & ISR Log & - & WHC & - & $\begin{array}{l}\text { May } 2 \\
1994\end{array}$ \\
\hline D-E-29 & Henford Deficiency Tracking System & - & RL & - & $\begin{array}{l}\text { March 9, } \\
1994\end{array}$ \\
\hline D-E-30 & 1994 Compliance Assessment Schedule & J. Dorian & WHC & $\begin{array}{l}\text { S. McKinney } \\
\text { C. Perkins } \\
\end{array}$ & $\begin{array}{l}\text { February } 18 . \\
1994\end{array}$ \\
\hline D-E-31 & QUEST Subjects and Actions & - & WHC & - & $\begin{array}{l}\text { May } 5 \\
1994\end{array}$ \\
\hline D-E-32 & Corrective Action Management Manual & - & WHC & - & $\begin{array}{l}\text { April 29, } \\
1993\end{array}$ \\
\hline$D-E-33$ & SCP Chocklist & L. Musen & RL-ECP & - & - \\
\hline D-E-34 & Formal Safety Concerns Resolution Process & L. Musen & RL-ECP & - & - \\
\hline D-E-35 & Quality Assurance Quartorly Assessment Report & M. Garrity & WHC & M. Adams, et al. & $\begin{array}{l}\text { May } 2 . \\
1994\end{array}$ \\
\hline D-E-36 & Third Quarter Surveillance Schedule & P. Preetorius. & WHC & M. Adams, ot al. & $\begin{array}{l}\text { March 22, } \\
1994\end{array}$ \\
\hline
\end{tabular}


SITE DOCUMENTS REVIEWED BY THE AUDIT TEAM (continued)

\begin{tabular}{|c|c|c|c|c|c|}
\hline 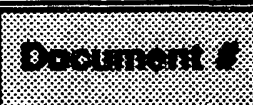 & 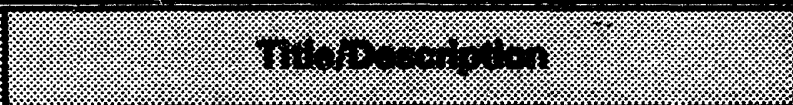 & 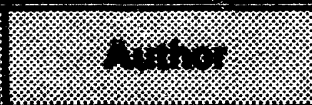 & 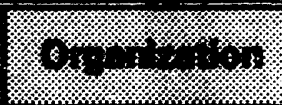 & $8 \% 2 \%: 5 \% 1 \%$ & 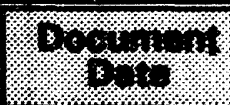 \\
\hline D-E-37 & Employee Concerns Reporting Form (RL No. 81-120) & L. Musen & - & - & - \\
\hline D-E-39 & $\begin{array}{l}\text { Public Outreach Presontations/Activities } \\
\text { Office of Health and Environment }\end{array}$ & R. Gray & PNL & J. Hall & $\begin{array}{l}\text { January } 5 . \\
1994\end{array}$ \\
\hline D-E-41 & Hanford Mid-year Self-assessment Report - Draft & - & RL & - & \begin{tabular}{|l} 
May 2. \\
1994
\end{tabular} \\
\hline D-E-42 & $\begin{array}{l}1993 \text { Hanford Annual Self-assesement Performance } \\
\text { Report }\end{array}$ & J. Wegoner & RL & R. Scott & $\begin{array}{l}\text { November } 12, \\
1993\end{array}$ \\
\hline D-E-43 & Office of Compliance Self-essessment & S. Voitenheimer & RL & - & October 1992 \\
\hline D-E-44 & Mid-year Self-assessment Performance Status Report & A. Howkins & WHC & - & - \\
\hline D-E-45 & $\begin{array}{l}\text { CMA-93-0001, Solid Waste Disposal Managernent } \\
\text { Appraisal }\end{array}$ & D. Swaim & WHC-ESO & W. Hamilton & $\begin{array}{l}\text { January } 4 . \\
1994\end{array}$ \\
\hline \multicolumn{6}{|c|}{ 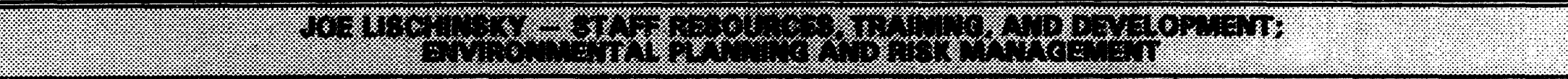 } \\
\hline D-F-1 & Site Surveillance Health Physics OJT & - & WHC & - & $\begin{array}{l}\text { September } \\
1993\end{array}$ \\
\hline D-F-2 & Organization Charts and Charters & - & WHC & - & - \\
\hline D-F-3 & Environmental Complience Manual & Regulatory Analysis & WHC & - & - \\
\hline$D-F-4$ & Training Past Due Tabulation & - & PNL & - & $\begin{array}{l}\text { February } 11 . \\
1994\end{array}$ \\
\hline D-F-5 & $\begin{array}{l}\text { Management Requirements and Procedures and Job } \\
\text { Descriptions }\end{array}$ & Human Resources & WHC & - & May 3, 1993 \\
\hline D-F-6 & Leadership Expectations & A.L. Treoo & WHC & - & March 9, 1994 \\
\hline D-F-7 & $\begin{array}{l}\text { United States Department of Energy Richland } \\
\text { Operations Office Environmental Protection } \\
\text { Implementation Plan }\end{array}$ & Reguletory Analysis & WHC & DOE & $\begin{array}{l}\text { November } \\
1993\end{array}$ \\
\hline
\end{tabular}




\section{SITE DOCUMENTS REVEWED BY THE AUDIT TEAM (continued)}

\begin{tabular}{|c|c|c|c|c|c|}
\hline 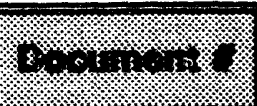 & 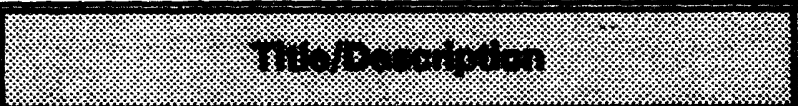 & 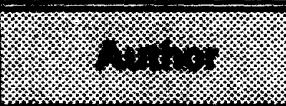 & 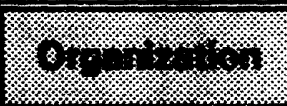 & 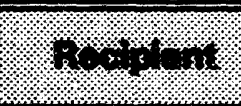 & 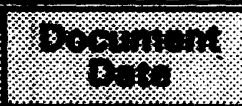 \\
\hline D.F-B & Resume Examples & - & PNL & - & - \\
\hline D-F-9 & $\begin{array}{l}\text { Appendix 3B Findings, Responses, and Planned } \\
\text { Actions: Environmental Findings (Tiger Team } \\
\text { Corrective Action Plan) }\end{array}$ & - & WHC & - & - \\
\hline D-F-10 & Organizational Chart/Office of Hoalth \& Environment & - & PNL & - & March 1994 \\
\hline D-F-11 & $\begin{array}{l}\text { WHC Operational Environmental Monitoring Progrem, } \\
\text { CY } 93\end{array}$ & J.W. Schmidt & WHC & DOE/ER & October 1993 \\
\hline D-F-12 & $\begin{array}{l}\text { Henford Federal Facility Agreement and Consent } \\
\text { Order }\end{array}$ & WDOE/EPA/DOE & - & - & January 1994 \\
\hline D-F-13 & $\begin{array}{l}\text { Quality, Safoty, and Health Progrems FY } 93 \text { Work } \\
\text { Plan }\end{array}$ & OSH & RL & RL & - \\
\hline D-F-14 & Position Standard (Draft) & Office of Training & RL & RL & February 1994 \\
\hline D-F-15 & $\begin{array}{l}\text { Quality, Safoty, and Hoalth Progrems FY } 94 \text { Draft } \\
\text { Work Plan }\end{array}$ & QSH & RL & RL & - \\
\hline D-F-16 & EM Bid Proposal & asH & RL & EM & - \\
\hline D-F-17 & Community Environmental Monitoring 5-year Plan & R.H. Gray & Battelle & $\begin{array}{l}\text { R. Holten, } \\
\text { RL-QSH }\end{array}$ & $\begin{array}{l}\text { March 31. } \\
1994\end{array}$ \\
\hline D.F-18 & Hanford Site Baseline Risk Assessment Methodology & DOE & RL & - & March 1993 \\
\hline D-F-19 & $\begin{array}{l}\text { Regulatory Policy, Planning, and Analysis Branch } \\
\text { oxisting work requirements FY } 1992\end{array}$ & aSH & RL & RL & - \\
\hline D-F-20 & $\begin{array}{l}\text { Regulatory Policy, Planning, and Analysis Branch } \\
\text { existing work requirements FY } 1994\end{array}$ & OSH & RL & RL & - \\
\hline D-F-21 & $\begin{array}{l}\text { Position Description Chief, Regulatory Policy. } \\
\text { Planning. and Analysis Branch }\end{array}$ & - & RL & RL & - \\
\hline D-F-22 & 5-year Manpower Projections (1995-2000) & D. Kranz & RL & $\begin{array}{l}\text { RL Division } \\
\text { Directors and } \\
\text { above }\end{array}$ & $\begin{array}{l}\text { December } 27 \\
1993\end{array}$ \\
\hline D.F-23 & $\begin{array}{l}\text { FY } 1995 \text { IRB Staffing Requirements - Follow-up } \\
\text { matrix }\end{array}$ & J. Resmussen & RL & D. Kranz & $\begin{array}{l}\text { September 3, } \\
1993\end{array}$ \\
\hline
\end{tabular}


SITE DOCUMENTS REVIEWED BY THE AUDIT TEAM (continued)

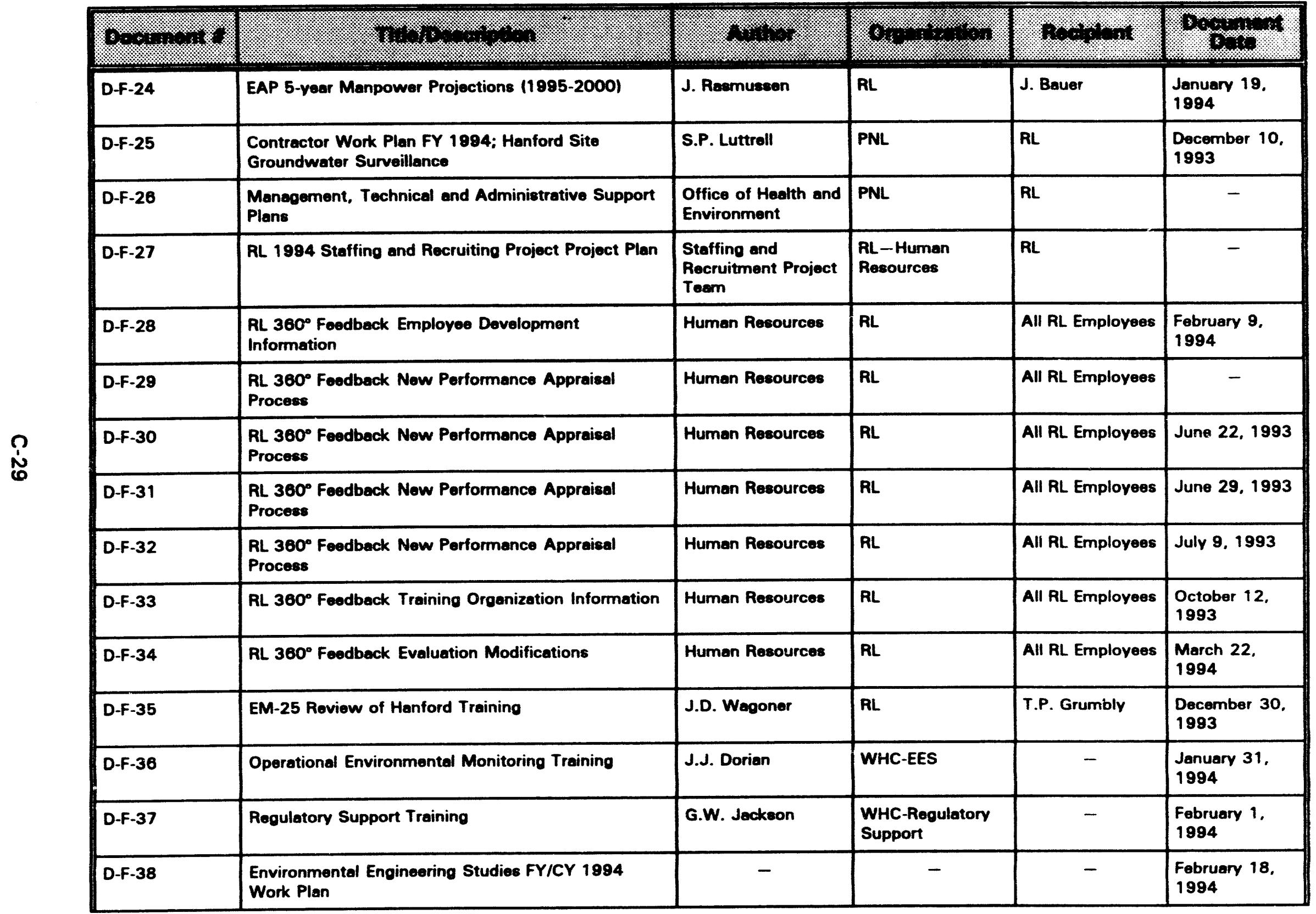


SITE DOCUMENTS REVIEWED BY THE AUDIT TEAM (comtinued)

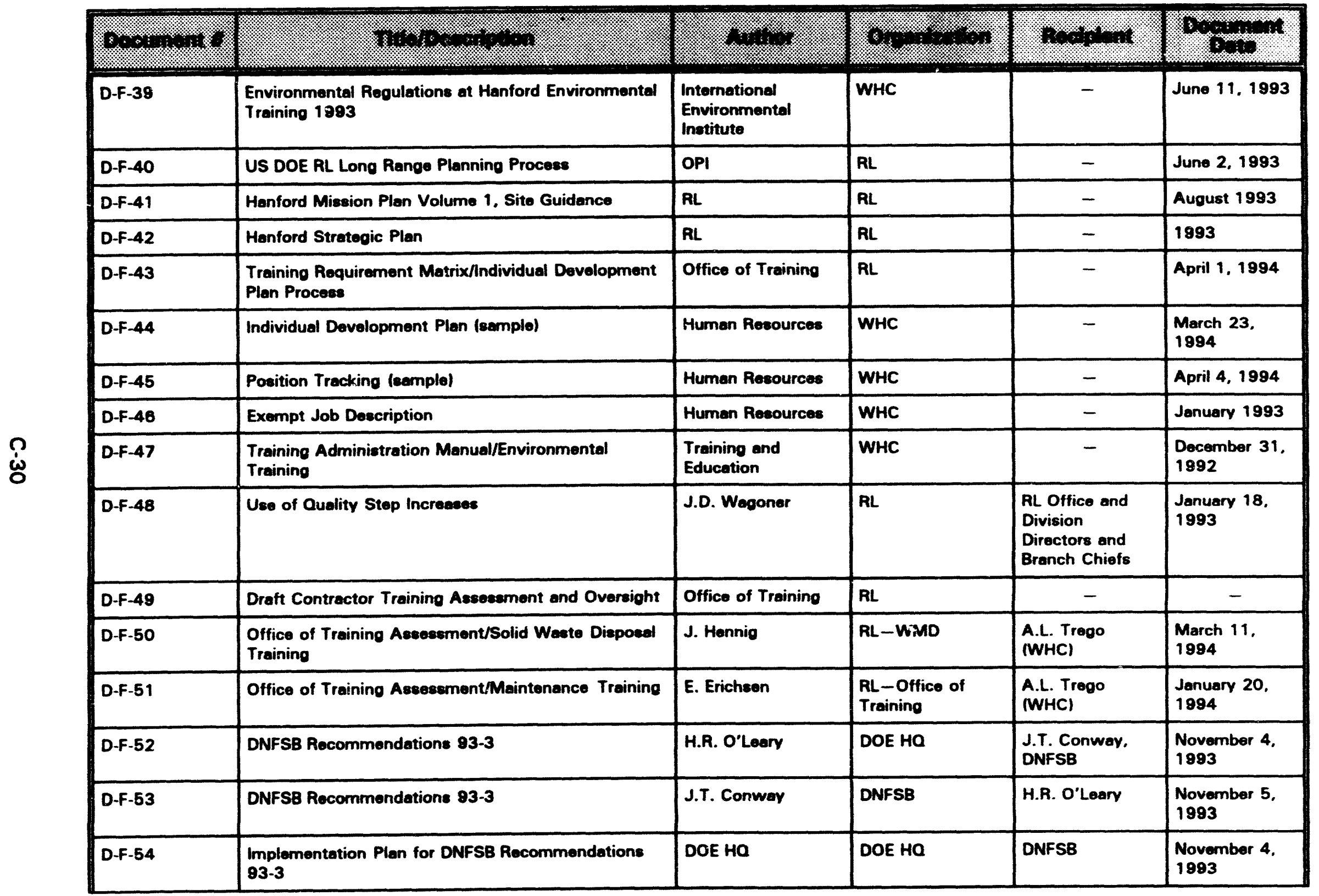


SITE DOCUMENTS REVIEWED BY THE AUDIT TEAM (continued)

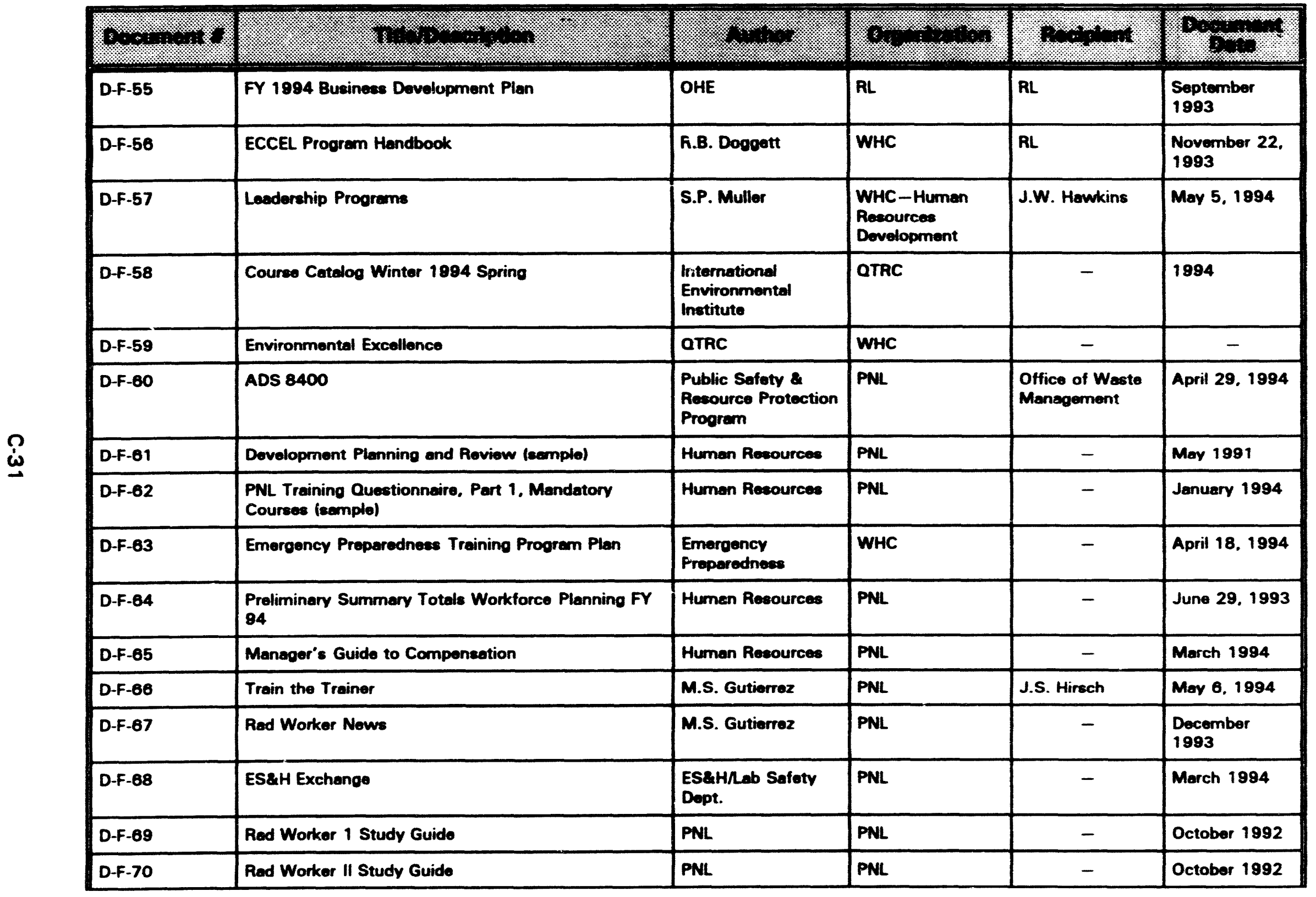


SITE DOCUMENTS REVIEWED BY THE AUDTT TEAM (continued)

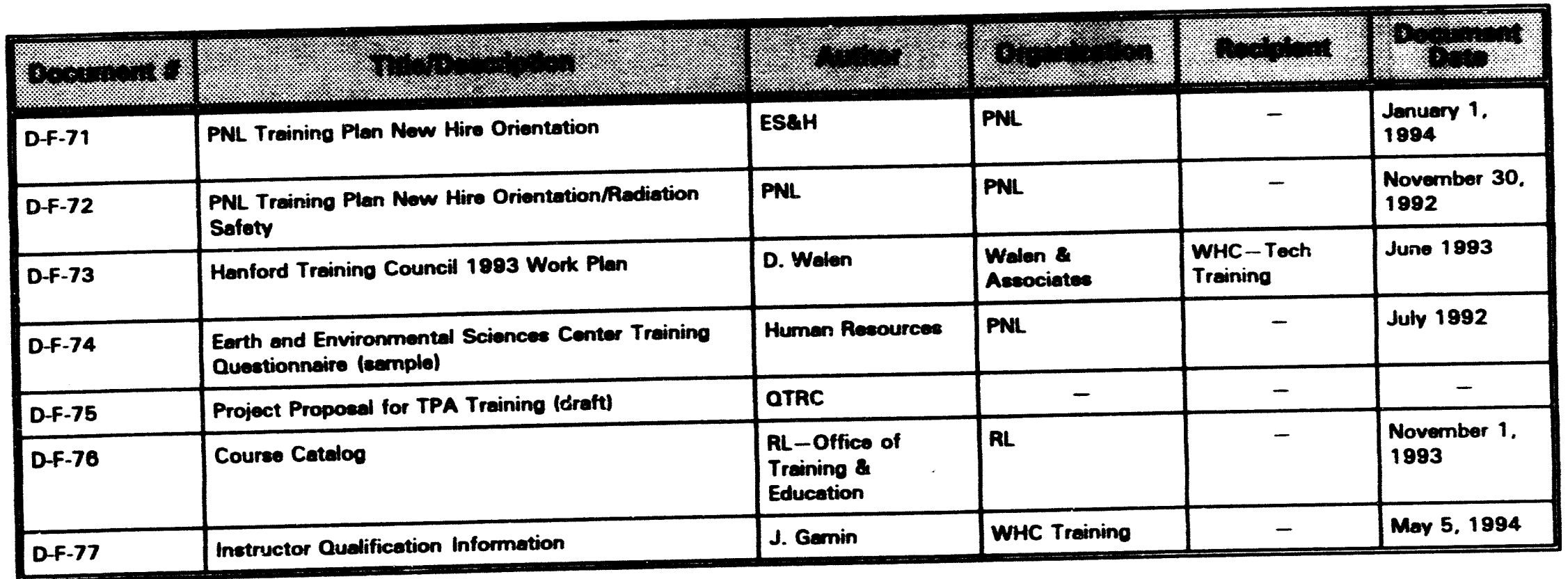




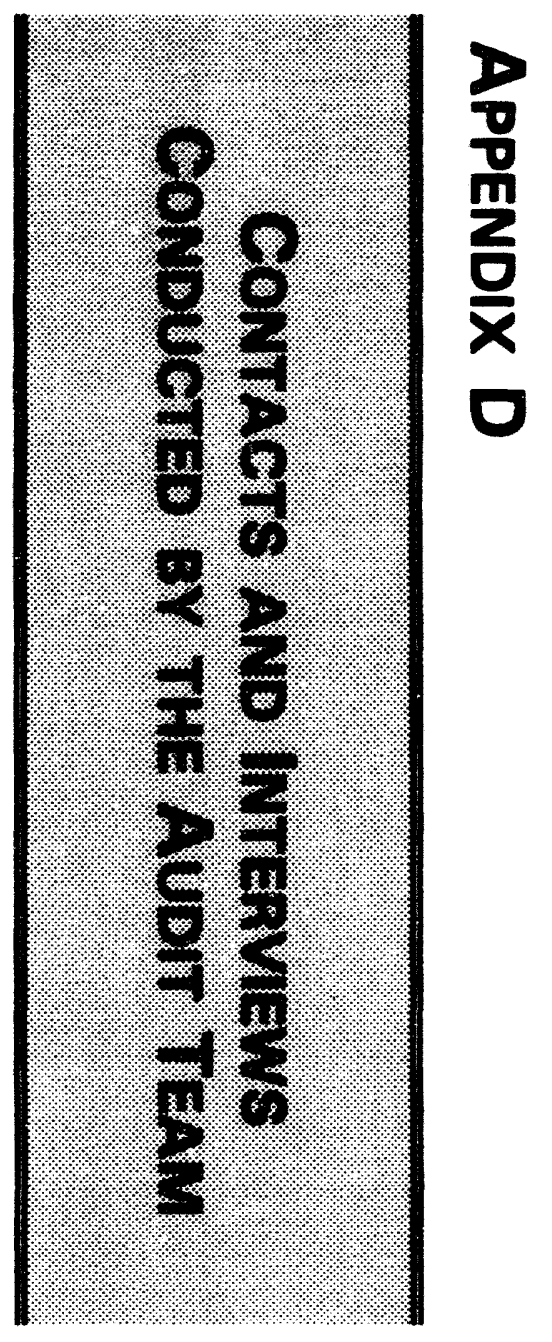


Page intentionally blank 


\section{CONTACTS AND INTERVIEWS CONDUCTED BY THE AUDIT TEAM}

\begin{tabular}{|c|c|c|c|c|c|}
\hline . & is & . & \& & ㄱ. & $\mathrm{H}_{\mathrm{s}}=\mathrm{s}$ \\
\hline & & & 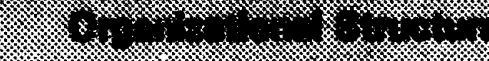 & 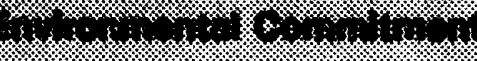 & \\
\hline $1-A-1$ & $5 / 2 / 94$ & S. Walker & $\begin{array}{l}\text { RL-Quality, Safety, \& Health } \\
\text { Proorams Div. (RL-OSH) }\end{array}$ & $\begin{array}{l}\text { Public Safoty and Medical } \\
\text { Proorem Branch }\end{array}$ & $\begin{array}{l}\text { Oroanizational structure; environmental } \\
\text { commitment }\end{array}$ \\
\hline $1-A-2$ & $5 / 2 / 94$ & S. Walker & $\begin{array}{l}\text { RL-Environmental Remediation } \\
\text { Division (RL-ERD) }\end{array}$ & & $\begin{array}{l}\text { Organizational structure; environmental } \\
\text { commitment }\end{array}$ \\
\hline 1-A-3 & $5 / 2 / 94$ & S. Walker & AL-Transition Tearn & & $\begin{array}{l}\text { Organizational structure; environmental } \\
\text { commitment }\end{array}$ \\
\hline $1-A-4$ & $5 / 2 / 84$ & S. Wolker & RL-OSH & & $\begin{array}{l}\text { Organizational structure; environmental } \\
\text { commitment }\end{array}$ \\
\hline 1-A-5 & $5 / 3 / 94$ & S. Walker & RL_-Environmental Management & & $\begin{array}{l}\text { Organizational structure; environmental } \\
\text { commitment }\end{array}$ \\
\hline 1-A-7 & $5 / 3 / 94$ & S. Walker & $\begin{array}{l}\text { WHC-Waste, Analytical } \\
\text { Environmentel Services MHC- } \\
\text { WAEIRiquid Effluents Services }\end{array}$ & Geohydrologic Support & $\begin{array}{l}\text { Organizational structure; environmental } \\
\text { commitment }\end{array}$ \\
\hline $1-A-8$ & $5 / 3 / 94$ & S. Walker & WHC-WAE & Regulatory Support (RS) & $\begin{array}{l}\text { Organizational structure; environmental } \\
\text { commitment }\end{array}$ \\
\hline I-A-9 & $5 / 3,94$ & S. Walker & WHC-WAE & Tri-Party Agreement (TPA) & $\begin{array}{l}\text { Orgenizetional structure; environmental } \\
\text { commitment }\end{array}$ \\
\hline $1-A-10$ & $5 / 3 / 94$ & S. Wolker & WHC-General Counsel's Office & & $\begin{array}{l}\text { Organizational structure; environmental } \\
\text { commitment }\end{array}$ \\
\hline |-A-11 & $5 / 4 / 94$ & s. Wolker & $\begin{array}{l}\text { RL-Environmental Assurance, } \\
\text { Permits Policy (RL-EAP) }\end{array}$ & $\begin{array}{l}\text { Regulatory Policy, Planning and } \\
\text { Analyeis (RPA) }\end{array}$ & $\begin{array}{l}\text { Organizational structure; environmental } \\
\text { commitment }\end{array}$ \\
\hline 1-A-12 & $5 / 4 / 94$ & S. Wolker & $\begin{array}{l}\text { WHC-OPNS Progrem } \\
\text { Manegement }\end{array}$ & $\begin{array}{l}\text { Environmental Protection } \\
\text { Program }\end{array}$ & $\begin{array}{l}\text { Organizational structure; environmental } \\
\text { commitment }\end{array}$ \\
\hline
\end{tabular}


CONTACTS AND INTERVIEWS CONDUCTED BY THE AUDIT TEAM (continued)

\begin{tabular}{|c|c|c|c|c|c|}
\hline $1+1$ & 3 & +4 & $s^{2}$ & 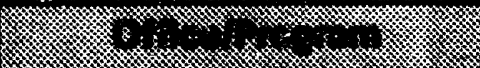 & $4 \%$ \\
\hline I-A-13 & $5 / 4 / 94$ & S. Walker & $\begin{array}{l}\text { PNL-Facilitioe and } \\
\text { Operationanaboratory Safoty } \\
\text { Dopt(PNL-FaOMAB SAF) }\end{array}$ & Environmentel Complience & $\begin{array}{l}\text { Orgenizational structure; environmental } \\
\text { commitmerit }\end{array}$ \\
\hline 1-A-14 & $5 / 4 / 94$ & S. Walker & PNL-FEONAB SAF & Weste Managoment & $\begin{array}{l}\text { Organizational structure; environmental } \\
\text { commitment }\end{array}$ \\
\hline I-A-15 & $5 / 4 / 94$ & S. Walker & $\begin{array}{l}\text { WHC-Planning and Systom } \\
\text { Intogration }\end{array}$ & Staff & $\begin{array}{l}\text { Organizational structure; environmental } \\
\text { commitment }\end{array}$ \\
\hline 1-A-16 & $5 / 4 / 84$ & S. Walker & RL_-Office of the Moneger & & $\begin{array}{l}\text { Orgenizationel structure; environmental } \\
\text { commitment }\end{array}$ \\
\hline $1-A-17$ & $5 / 4 / 84$ & S. Walker & $\begin{array}{l}\text { Oak Ridee Institute for Science a } \\
\text { Education }\end{array}$ & Staff & $\begin{array}{l}\text { Organizotional structure; environmental } \\
\text { commitment }\end{array}$ \\
\hline I-A-18 & $5 / 4 / 94$ & S. Walker & RL-EAP & $\begin{array}{l}\text { Regulatory Policy, Plenning and } \\
\text { Analysis }\end{array}$ & $\begin{array}{l}\text { Organizational structure; environmental } \\
\text { commitment }\end{array}$ \\
\hline $1-A-18$ & $5 / 8 / 94$ & S. Walker & $\begin{array}{l}\text { RL-Hanford Transition Projects } \\
\text { Office }\end{array}$ & & $\begin{array}{l}\text { Organizational structure; environmental } \\
\text { commitment }\end{array}$ \\
\hline$\overline{1-A-20}$ & $5 / 8 / 94$ & s. Wolkor & $\begin{array}{l}\text { ICF Kaiser Henford Compeny IICF } \\
\text { KH)/Environmental Services }\end{array}$ & & $\begin{array}{l}\text { Organizational structure; environmental } \\
\text { commitment }\end{array}$ \\
\hline $1-A-21$ & $5 / 8 / 94$ & s. Wolker & RL-Tochnical Sorvices & & $\begin{array}{l}\text { Orgenizational structure; environmental } \\
\text { commitment }\end{array}$ \\
\hline 1-A.22 & $5 / 8 / 94$ & S. Wolker & RL-Intogration and Planning & & $\begin{array}{l}\text { Organizational structure; environmental } \\
\text { commitment }\end{array}$ \\
\hline 1-A-23 & $5 / 8 / 94$ & S. Walker & $\begin{array}{l}\text { RL-EAP; RL-Budget Division; } \\
\text { RL-Office of Chief Couneel }\end{array}$ & & $\begin{array}{l}\text { Orgenizational structure; environmental } \\
\text { commitment }\end{array}$ \\
\hline$\overline{1-A-24}$ & $5 / 5 / 94$ & S. Walker & RL-EAP & & $\begin{array}{l}\text { Orgenizational structure; environmental } \\
\text { commitment }\end{array}$ \\
\hline 1-A-25 & $5 / 5 / 94$ & 5. Walker & $\begin{array}{l}\text { RL-Office of Chiof Financial } \\
\text { Officer (RL_-CFO) }\end{array}$ & & $\begin{array}{l}\text { Organizotional structure; environmental } \\
\text { commitment }\end{array}$ \\
\hline 1-A-2B & $5 / 5 / 94$ & S. Walker & RL-CFO/Budget Division & & $\begin{array}{l}\text { Oroanizational structure; onvironmental } \\
\text { commitment }\end{array}$ \\
\hline
\end{tabular}


CONTACTS AND INTERVIEWS CONDUCTED BY THE AUDIT TEAM (continued)

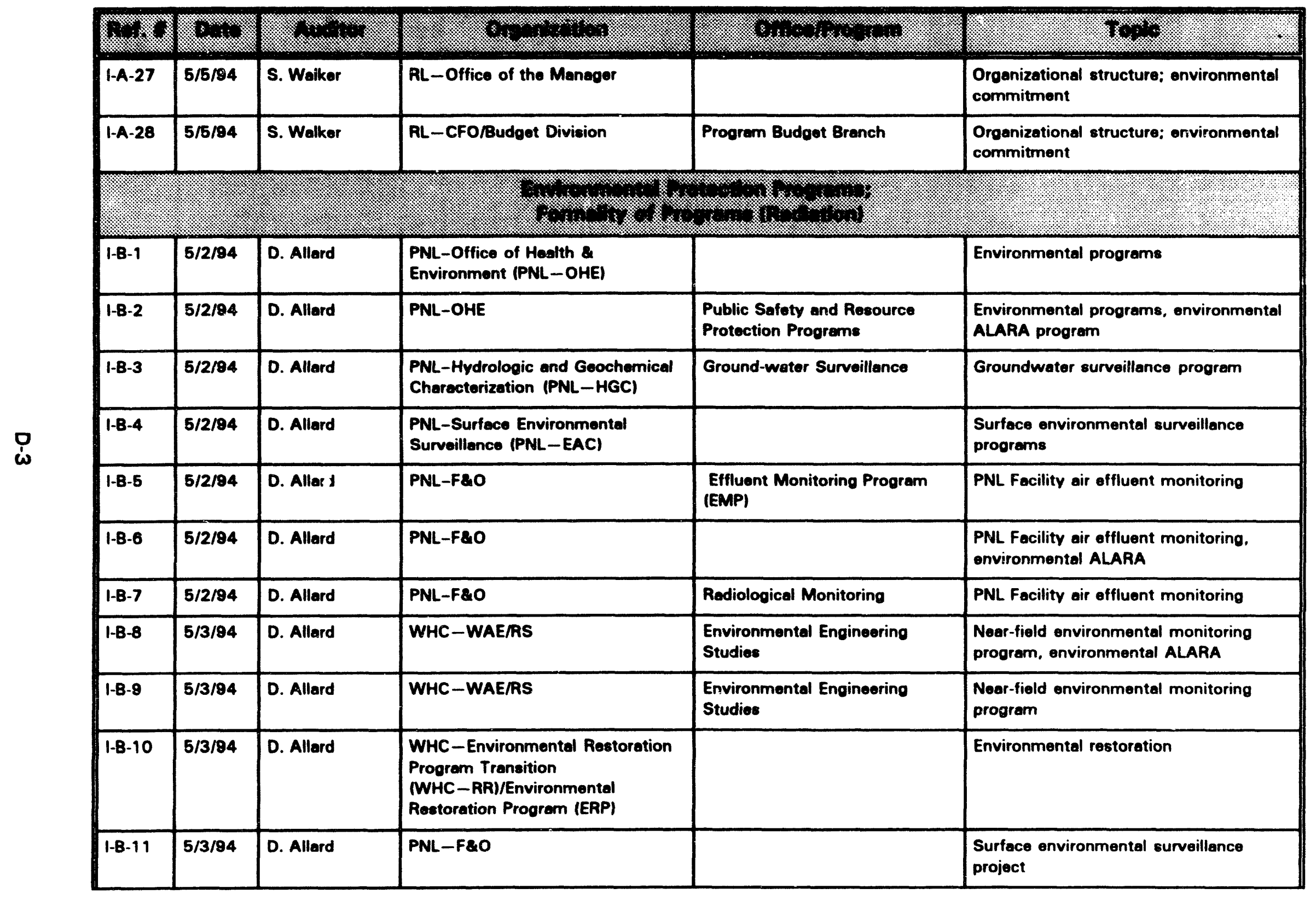


CONTACTS AND INTERVIEWS CONDUCTED BY THE AUDIT TEAM (continued)

\begin{tabular}{|c|c|c|c|c|c|}
\hline 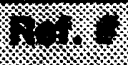 & 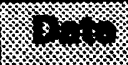 & 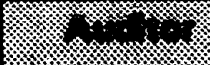 & 6 & 8 & $4 \%$ \\
\hline $1-8-12$ & $5 / 3 / 94$ & D. Allard & RL-OSH & $\begin{array}{l}\text { Public Safoty and Modical } \\
\text { Progrem Branch }\end{array}$ & Groundwater surveillance, wildlife \\
\hline 1-B-13 & $5 / 4 / 94$ & D. Allard & WHC-WAERS & Effluent Emissions Monitoring & Air and liquid effluent monitoring \\
\hline 1-8-14 & $5 / 4 / 94$ & D. Allard & $\begin{array}{l}\text { WHC-Emergency, Sofoty, Qualitiv } \\
\text { Services (WHC-ESO) }\end{array}$ & Health Phyaice & $\begin{array}{l}\text { HP procedures ond onvironmental } \\
\text { ALARA }\end{array}$ \\
\hline 1-B-15 & $5 / 4 / 94$ & D. Allord & RL-OSH & $\begin{array}{l}\text { Public Safoty and Modical } \\
\text { Progrems }\end{array}$ & $\begin{array}{l}\text { Oversight, emergency response } \\
\text { program, and environmentel ALARA }\end{array}$ \\
\hline 1-B-16 & $5 / 4 / 94$ & D. Allard & PNL-OHE & Anolytical Services Project & $\begin{array}{l}\text { Environmentel semple lab quality } \\
\text { assurance (OA) }\end{array}$ \\
\hline $1-8-17$ & $5 / 5 / 94$ & D. Allard & PNL - Hoolth Phyaics (PNL-HRAD) & & Offsite dose modeling \\
\hline 1-8.18 & 6/5/84 & D. Allard & PNL-HRAD & & Offsite dose modeling \\
\hline 1-B-19 & $5 / 5 / 94$ & D. Allard & $\begin{array}{l}\text { RL-Weste Manegement Division } \\
\text { (RL-WMDI) }\end{array}$ & Liquid Waste Branch & $\begin{array}{l}\text { RCRA groundwater monitoring and } \\
\text { waste management }\end{array}$ \\
\hline I-B-20 & $5 / 5 / 94$ & D. Allard & WHC-ESO & Henford Hazard Assessment & Radiological emergency response \\
\hline I-B-21 & $5 / 5 / 94$ & D. Allard & WHC-ESO & Emergency Preparedness & Rediological emergency response \\
\hline 1-B-22 & 5/5/94 & D. Allard & $\begin{array}{l}\text { WHC-Effluent \& Emissions } \\
\text { Monitoring }\end{array}$ & & Effluent data reduction and transmittal \\
\hline $1-8-23$ & $5 / 8 / 84$ & D. Allard & WHC-222-S Laboratory & & $\begin{array}{l}\text { Air filter gross alpho beto cross-checks } \\
\text { with EPA }\end{array}$ \\
\hline I-B-24 & $5 / 8 / 94$ & D. Allard & WHC-WAE/RS & Effluent \& Emissions Monitoring & $\begin{array}{l}\text { Data tracking of air and liquid effluent } \\
\text { data trending and tracking }\end{array}$ \\
\hline I-B-25 & $5 / 8 / 94$ & D. Allard & WHC-WAE & $\begin{array}{l}\text { Facility Engineering \& Waste } \\
\text { Manegoment }\end{array}$ & D\&D planning \\
\hline I-B-26 & 5/6/94 & D. Aliard & $\begin{array}{l}\text { WHC-RR/ER Program Trensition } \\
\text { (ER) }\end{array}$ & $\begin{array}{l}\text { 100/200/300 Area } \\
\text { Environmentel Projects }\end{array}$ & $\begin{array}{l}\text { Environmental restoration and } \\
\text { Environmental ALARA }\end{array}$ \\
\hline I-B-27 & $5 / 8 / 94$ & D. Allerd & WHC-WAE & Solid Weste & Rad and mixed waste menegement \\
\hline I-B-28 & $5 / 6 / 94$ & D. Allard & RL-EAP & & PNL hot cell mixed waste \\
\hline
\end{tabular}


CONTACTS AND INTERVIEWS CONDUCTED BY THE AUDIT TEAM (continued)

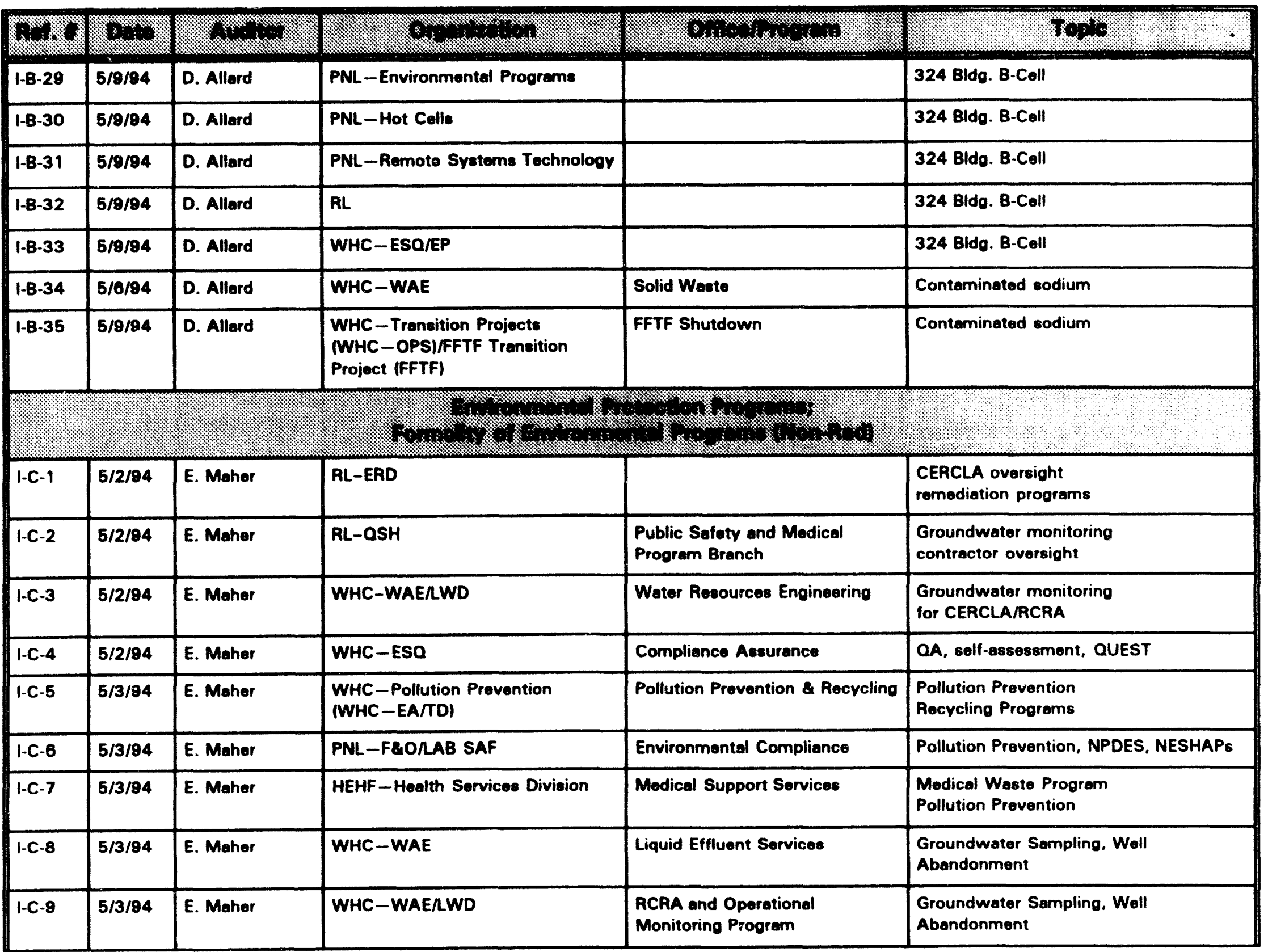


CONTACTS AND INTERVIEWS CONDUCTED BY THE AUDIT TEAM (continued)

\begin{tabular}{|c|c|c|c|c|c|}
\hline 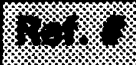 & 3 & 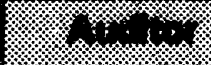 & 8 & 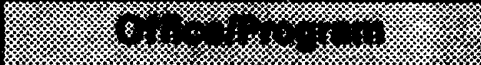 & 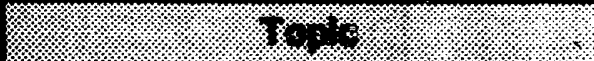 \\
\hline $1-C-10$ & $5 / 4 / 94$ & E. Maher & PNL-OHE & Analytical Support Services & $\begin{array}{l}\text { QA of Laboratory Data, Sample } \\
\text { Management }\end{array}$ \\
\hline $1-C-11$ & $5 / 4 / 94$ & E. Maher & WHC-ESO & Quelity Aesurence & $\begin{array}{l}\text { Leboratory QA Plans, Data } \\
\text { Verification/Nolidation }\end{array}$ \\
\hline $1-C-12$ & 5/4/94 & E. Mahor & WHC-ESO & $\begin{array}{l}\text { Analytical Services Quality } \\
\text { Assurance }\end{array}$ & Leboratory Oversight and OA \\
\hline $1-C-13$ & $5 / 4 / 94$ & E. Maher & WHC-ESO & $\begin{array}{l}\text { Environmontal Quality } \\
\text { Assurance }\end{array}$ & Laboratory Oversight and QA Plans \\
\hline $1-C-14$ & $5 / 4 / 94$ & E. Maher & $\begin{array}{l}\text { HEHF-Industrial Hyoiene Sorvices } \\
\text { (IHL) }\end{array}$ & & $\begin{array}{l}\text { SDWA Compliance, Laboratory OA, and } \\
\text { Plans }\end{array}$ \\
\hline I-C-15 & $5 / 4 / 94$ & E. Maher & PNL-OHE & $\begin{array}{l}\text { Public Safoty and Resource } \\
\text { Protection Programs }\end{array}$ & Sitewide Environmental Sampling Plan \\
\hline 1-C-16 & $5 / 4 / 94$ & E. Maher & PNL-OHE & $\begin{array}{l}\text { Surface Environmental } \\
\text { Surveillence }\end{array}$ & $\begin{array}{l}\text { Sitewide Environmental Sampling Plan } \\
\text { (Surface) }\end{array}$ \\
\hline I-C-17 & 5/4/94 & E. Maher & RL_ERD & Analytical Support & ER Sample Validation and $Q A$ \\
\hline I-C-18 & $5 / 4 / 94$ & E. Maher & RL-EAP & Regulatory Permits Stoff & $\begin{array}{l}\text { RL Oversight, NESHAPS, Permits, } \\
\text { Trecking }\end{array}$ \\
\hline I-C-19 & $5 / 5 / 94$ & E. Maher & $\begin{array}{l}\text { PNL_RCRA and Ground-water } \\
\text { Monitoring Projoct }\end{array}$ & & $\begin{array}{l}\text { Laboratory Support, Monitoring } \\
\text { Program, Formality }\end{array}$ \\
\hline $1-C-20$ & $5 / 5 / 94$ & E. Maher & PNL-HGC & Ground-water Surveillance & $\begin{array}{l}\text { Laboratory Support, Monitoring } \\
\text { Program, Formality }\end{array}$ \\
\hline $1-C-21$ & 5/5/84 & E. Maher & RL-WMD & Liquid Weste Branch & $\begin{array}{l}\text { Laboratory Support, RCRA Monitoring } \\
\text { Program, Formality }\end{array}$ \\
\hline 1-C-22 & 5/5/94 & E. Maher & \begin{tabular}{|l} 
RL-Environmental Progrems \\
Division (RL-EPD)
\end{tabular} & Geotechnical Support Branch & $\begin{array}{l}\text { Laboratory Support, ER Monitoring } \\
\text { Program, Formality }\end{array}$ \\
\hline $1-C-23$ & $5 / 5 / 94$ & E. Maher & $R L-E P D$ & Geotochnical Support Branch & Field Surveillance, Formality \\
\hline I-C-24 & $5 / 5 / 94$ & E. Maher & $\begin{array}{l}\text { PNL_OHE/Analytical Support } \\
\text { Sorvices }\end{array}$ & Groundwater Rediochemistry & Laboratory Support, Formality \\
\hline 1-C-25 & $5 / 5 / 94$ & E. Maher & WHC-WAE/RS & Effluent \& Emissions Monitoring & Laboratory Support, Air Sampling \\
\hline
\end{tabular}


CONTACTS AND INTERVIEWS CONDUCTED BY THE AUDIT TEAM (continued)

\begin{tabular}{|c|c|c|c|c|c|}
\hline $2 \%$ & w & . & 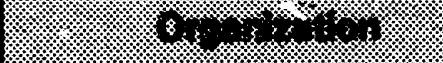 & 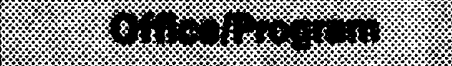 & 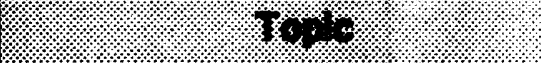 \\
\hline 1-C-26 & $5 / 6 / 94$ & E. Maher & WHC-ESO & Hanford Hazard Assessment & SPCC, Site Emergency Planning \\
\hline 1-C-27 & $5,6 / 84$ & E. Mahor & PNL-OHE & & Laboratory Support, Formality \\
\hline I-C-28 & $5 / 6 / 94$ & E. Mahar & $\begin{array}{l}\text { RL-Laboratory Management } \\
\text { Division (RL-LMD) }\end{array}$ & Programs Branch & RL Oversight Programs, Formality \\
\hline I-C-29 & $5 / 6 / 94$ & E. Maher & RL-EAP & & $\begin{array}{l}\text { NEPA Oversight, NEPA Guidance to } \\
\text { Contractors }\end{array}$ \\
\hline $1-C-30$ & $5 / 6 / 84$ & E. Maher & WHC-WAE & Solid Weste Disposal Division & $\begin{array}{l}\text { Mixed Waste Procedures, RCRA } \\
\text { Permitting }\end{array}$ \\
\hline $1-C-31$ & $5 / 6 / 84$ & E. Maher & RL-EAP & & $\begin{array}{l}324 \text { Bidg. B-Cell Mixed Waste } \\
\text { Management }\end{array}$ \\
\hline I-C-32 & $5 / 8 / 94$ & E. Maher & RL-EAP & & $\begin{array}{l}324 \text { Bidg. B-Cell Mixed Waste } \\
\text { Management }\end{array}$ \\
\hline I-D-1 & $5 / 2 / 94$ & M. Heuberger & RL: WMD & Liquid Waste Branch & $\begin{array}{l}\text { RCRA and operational groundwater } \\
\text { monitoring }\end{array}$ \\
\hline $1-0-2$ & $5 / 2 / 94$ & M. Heuberger & RL-QSH & $\begin{array}{l}\text { Public Safoty and Medical } \\
\text { Programs }\end{array}$ & Surveillance monitoring \\
\hline I-D-3 & $5 / 2 / 84$ & M. Heuberger & RL-ERD & & CERCLA/RCRA monitoring \\
\hline I-D-4 & $5 / 2 / 94$ & M. Houberger & RL-EAP & & NPDES monitoring \\
\hline I-D-5 & $5 / 3 / 94$ & M. Heuberger & RL-QSH & $\begin{array}{l}\text { Public Safoty and Medical } \\
\text { Program Branch }\end{array}$ & $\begin{array}{l}\text { Groundwater surveillance; sitewide } \\
\text { groundwater programs }\end{array}$ \\
\hline I-D-6 & $5 / 3 / 84$ & M. Heuberger & WHC-WAE/EP & & $\begin{array}{l}\text { CERCLA groundwater } \\
\text { operable units }\end{array}$ \\
\hline I-D.7 & $5 / 3 / 94$ & M. Houberoer & WHC-WAE/EP & & CERCLA groundwater operabie units \\
\hline I-D-8 & $5 / 3 / 94$ & M. Houberger & WHC-WAE/EP & & CERCLA groundwater operable units \\
\hline 1-D-9 & $5 / 3 / 94$ & M. Houberger & WHC-WAERWD & Goohydrologic Support & Operational groundwater monitoring \\
\hline
\end{tabular}


CONTACTS AND INTERVIEWS CONDUCTED BY THE AUDIT TEAM (continued)

\begin{tabular}{|c|c|c|c|c|c|}
\hline \% & 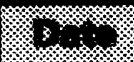 & . & 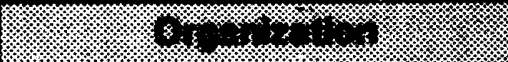 & 多 & $4 \%$ \\
\hline I-D-10 & $5 / 3 / 84$ & M. Heuberger & WHC-WAERS & $\begin{array}{l}\text { Environmental Engineering } \\
\text { Studies }\end{array}$ & Operational surface weter monitoring \\
\hline I-D-11 & $5 / 4 / 84$ & M. Heuberger & PNL-HGC & Ground-water Surveillance & Groundweter surveillance \\
\hline 1-D-12 & $5 / 4 / 94$ & M. Heuberger & $\begin{array}{l}\text { PNL_Field Sempling \& Analyais } \\
\text { Group (PNL_EESC) }\end{array}$ & & Groundwater sampling \\
\hline 1-D-13 & $5 / 4 / 94$ & M. Heuberger & PNL_EESC & Sempling Crow & Groundwater sampling \\
\hline 1-D-14 & $5 / 4 / 94$ & M. Heuberger & PNL-EESC & Sempling Crow & Groundwater sempling \\
\hline 1-D-15 & $5 / 4 / 94$ & M. Heuberoer & PNL-EESC & & Groundwater sampling \\
\hline 1-D-18 & $5 / 4 / 94$ & M. Heuberger & WHC-WAE/RS & Effluent Emiseion Monitoring & Effluent monitoring. NPDES monitoring \\
\hline 1-D-17 & $5 / 4 / 94$ & M. Heuberger & PNL-F8O & Effluent Monitoring Proaram & Effluent monitoring. NPDES monitoring \\
\hline I-D-18 & $5 / 4 / 94$ & M. Heuberger & PNL-OHE & $\begin{array}{l}\text { Public Safety and Resource } \\
\text { Protection Progrems }\end{array}$ & $\begin{array}{l}\text { Groundwater and surface water } \\
\text { surveillance monitoring }\end{array}$ \\
\hline I-D-19 & $5 / 5 / 94$ & M. Houberger & $\begin{array}{l}\text { Weshington Depertment of } \\
\text { Ecolooy (WOOE) }\end{array}$ & $\begin{array}{l}\text { Environmental Restoration and } \\
\text { Remediation }\end{array}$ & Oversight of Tri-Party Agreement \\
\hline 1-D-20 & $5 / 5 / 94$ & M. Heuberger & WHC-WAE/ENG & $\begin{array}{l}\text { Environmental Data } \\
\text { Manegement Group }\end{array}$ & HEIS, data management \\
\hline 1-D.21 & $5 / 5 / 94$ & M. Heuberger & WHC - WAE/ENG & $\begin{array}{l}\text { Environmental Data } \\
\text { Management Group }\end{array}$ & HEIS, data management \\
\hline 1-D.22 & $5 / 5 / 94$ & M. Heuberger & PNL-EAC & & Surface water surveillance \\
\hline 1-D-23 & $5 / 5 / 94$ & M. Heuberger & WHC-WAERWD & Interim Compliance Streams & Liquid effluent Consent Order \\
\hline 1-D-24 & $5 / 6 / 94$ & M. Heuberger & WHC-WAERWD & $\begin{array}{l}\text { Subsurface Investigation } \\
\text { Support }\end{array}$ & $\begin{array}{l}\text { Well construction, maintenance, and } \\
\text { abandonment }\end{array}$ \\
\hline I-D-25 & $5 / 6 / 94$ & M. Heuberger & $\begin{array}{l}\text { U.S. Amry Corps of Engineers (RL } \\
\text { Support) }\end{array}$ & $\begin{array}{l}\text { Envirormental Program Division, } \\
\text { Geotech Support Branch }\end{array}$ & Groundwater program coordination \\
\hline I-D-26 & $5 / 6 / 94$ & M. Heuberger & WHC-WAERWD & Geohydrologic Support & Woll administration team \\
\hline 1-D-27 & $5 / 6 / 84$ & M. Heuberger & PNL-EESC & Geology Geophysics & Woll administration team \\
\hline 1-D-28 & $5 / 9 / 94$ & M. Heuberger & PNL-EESC & Geology \& Geophysics & Well maintenance and abandonment \\
\hline
\end{tabular}


CONTACTS AND INTERVIEWS CONDUCTED BY THE AUDIT TEAM (continued)

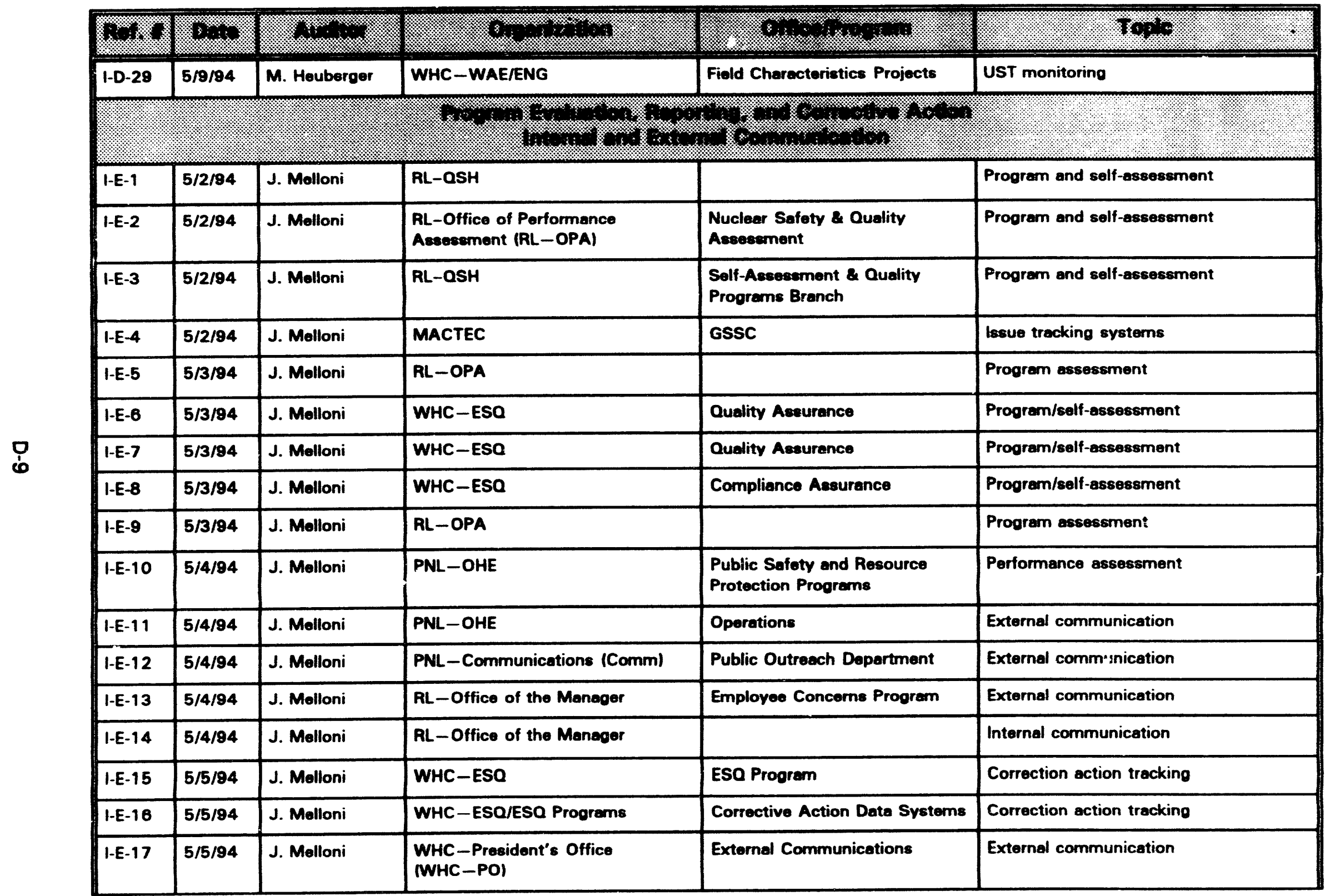


CONTACTS AND INTERVIEWS CONDUCTED BY THE AUDIT TEAM (continued)

\begin{tabular}{|c|c|c|c|c|c|}
\hline 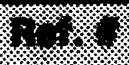 & 3 & $=1$ & 4 & 16 & 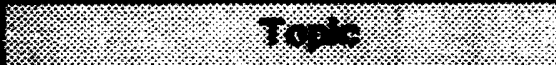 \\
\hline I-E-18 & $5 / 3 / 94$ & J. Melloni & RL_OPA & $\begin{array}{l}\text { Safoty. Environment \&ecurity } \\
\text { Asecesmont }\end{array}$ & Porformance esseserment \\
\hline I-E-19 & $5 / 3 / 94$ & J. Melloni & WHC-ESO & Compliance Aseesement & Self-cosesement \\
\hline I-E-20 & $5 / 6 / 94$ & J. Melloni & WHC-ESO & & $\begin{array}{l}\text { Communications performance } \\
\text { oveluations }\end{array}$ \\
\hline $1-E-21$ & $5 / 6 / 94$ & J. Melloni & WHC-WAE & & $\begin{array}{l}\text { Communications performance } \\
\text { evaluations }\end{array}$ \\
\hline 1-E-22 & $5 / 8 / 94$ & J. Molloni & RL-Transition Toam & & Communications and operations \\
\hline $1-E-23$ & $5 / 8 / 94$ & J. Molloni & RL-Comm & & External communication \\
\hline I-E-24 & $5 / 6 / 94$ & J. Melloni & WHC-ESQ/ESO Progrems & Closurs Vorification & Corrective action tracking \\
\hline I-E-25 & $5 / 10 / 94$ & J. Molloni & PNL-Progrem Quality & & Program ovaluation, OA \\
\hline & & & 4 & 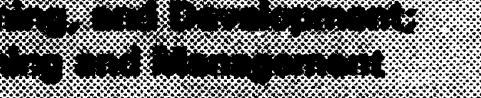 & \\
\hline I-F-1 & $5 / 2 / 94$ & J. Lischinsky & RL-OSH & $\begin{array}{l}\text { Public Safoty \& Modical } \\
\text { Progrems }\end{array}$ & $\begin{array}{l}\text { Staffing of environmental groups } \\
\text { development, budget and planning }\end{array}$ \\
\hline I-F-2 & $5 / 2 / 94$ & J. Lischinaky & RL-Budget Division & & Resources \\
\hline I-F-3 & $5 / 2,94$ & J. Lischinsky & RL-WMD & Liquid Westo Branch & Training and dovelopment, budgeting \\
\hline I-F-4 & $5 / 2 / 94$ & J. Lischineky & RL-ERD & & $\begin{array}{l}\text { Staffing, budgeting and risk } \\
\text { management }\end{array}$ \\
\hline I-F-5 & $5 / 2 / 94$ & J. Lischinsky & RL-EAP & & Training. risk manaoernent \\
\hline $1-F-6$ & $5 / 3 / 94$ & J. Lischinsky & PNL-OHE & & Budgeting of EMP process \\
\hline I-F-7 & $5 / 3 / 94$ & J. Lischineky & RL-Human Resources & Recruitment & $\begin{array}{l}\text { Staffing, recruitment process, } \\
\text { development }\end{array}$ \\
\hline I-F-8 & 5/3/94 & J. Lischinsky & WHC-WAE/RS & $\begin{array}{l}\text { Environmontal Engineoring } \\
\text { Studies }\end{array}$ & $\begin{array}{l}\text { Environmental monitoring, staff } \\
\text { development, planning, and training }\end{array}$ \\
\hline
\end{tabular}


CONTACTS AND INTERVIEWS CONDUCTED BY THE AUDIT TEAM (cominued)

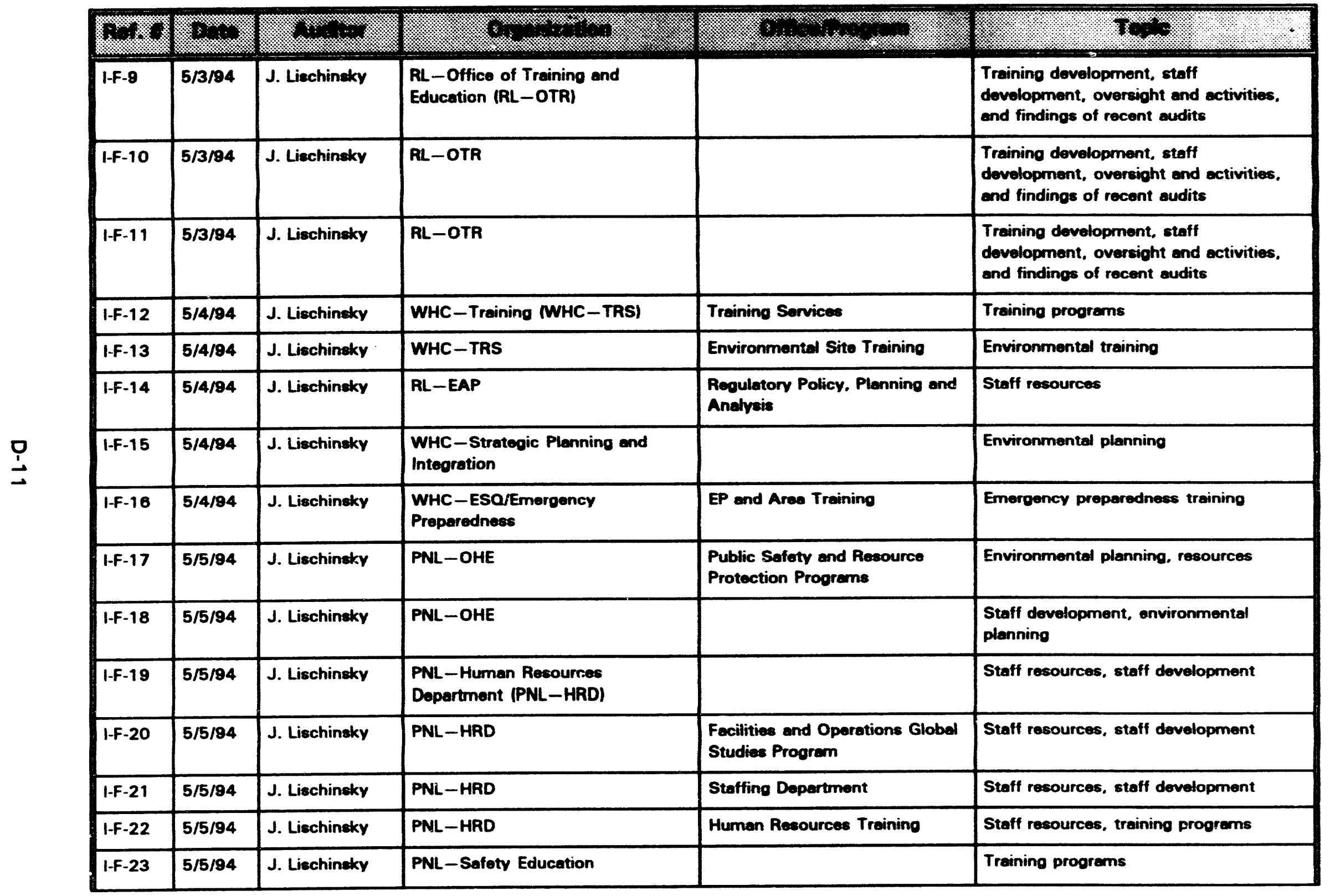


CONTACTS AND INTERVEWS CONDUCTED BY THE AUDT TEAM (coninuOd)

\begin{tabular}{|c|c|c|c|c|c|}
\hline 4 & 3 & 4 & 23 & x & 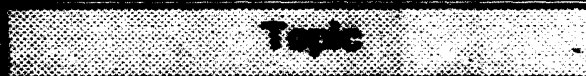 \\
\hline I-F-24 & $5 / 5 / 94$ & J. Liechinaky & PNL-HRD & & $\begin{array}{l}\text { Staff resources, recruitmont. staff } \\
\text { denelopment }\end{array}$ \\
\hline I-F-25 & $5 / 5 / 94$ & J. Lischinaky & PNL_EESC & Field Semplino \& Analyais Group & Environmentel monitoring trainino \\
\hline I-F-26 & 5/6/84 & J. Liechinaky & RL-Office of the Meneger & & $\begin{array}{l}\text { Environmentel plenning, recources, rick } \\
\text { meneoement }\end{array}$ \\
\hline I-F-27 & $5 / 8 / 94$ & J. Lischinaky & $\begin{array}{l}\text { ICF KH-Environmentel } \\
\text { Compliance }\end{array}$ & & Environmontal training \\
\hline $1-F-28$ & $5 / 8 / 94$ & J. Lischinaky & PNL-OTRC & & $\begin{array}{l}\text { Environmontel training, dovelopment, } \\
\text { integration }\end{array}$ \\
\hline 1-F-29 & $5 / 8 / 94$ & J. Lischinaky & WHC-OTRC & Treining Menegement Support & $\begin{array}{l}\text { Environmented training, dovelopment, } \\
\text { integration, OTRC resources }\end{array}$ \\
\hline $1-F-30$ & $5 / 8 / 94$ & J. Liechinaky & WHC-ESO & Hoatth Phyaice & Environmentel monitoring trainino \\
\hline $1+-31$ & $5 / 8 / 94$ & J. Lischinaky & RL_EAP/APA & & NEPA planning \\
\hline $1-F-32$ & 5/8/84 & J. Lischinaky & PNL_Finance & & Resources, budget process \\
\hline $1-F-33$ & $5 / 8 / 94$ & J. Liechinaky & PNL_Finance & & Resources, budoet process \\
\hline $1-F-34$ & $5 / 8 / 94$ & J. Lischinaky & RL-Progrem Budget Brench & & $\begin{array}{l}\text { Resources, FTE allocation and bid } \\
\text { process }\end{array}$ \\
\hline I-F-35 & $5 / 5 / 94$ & J. Lischinaky & PNL-EESC & $\begin{array}{l}\text { Fiold Sempling and Anatysis } \\
\text { Group }\end{array}$ & Environmentel monitoring training \\
\hline $1-F-36$ & $5 / 9 / 94$ & J. Liechinaky & PNL-Hot Colls & & 324 Bido. B-Coll Risk Manecoment \\
\hline 1-F-37 & $5 / 9 / 94$ & J. Liechinsky & PNL-Rernote Syeterns Technolooy & & 324 Bido. B-Cell Risk Moneoement \\
\hline 1-F-38 & $5 / 9 / 94$ & J. Liechinaky & RL & & 324 Bido. B-Coll Risk Moneogment \\
\hline
\end{tabular}




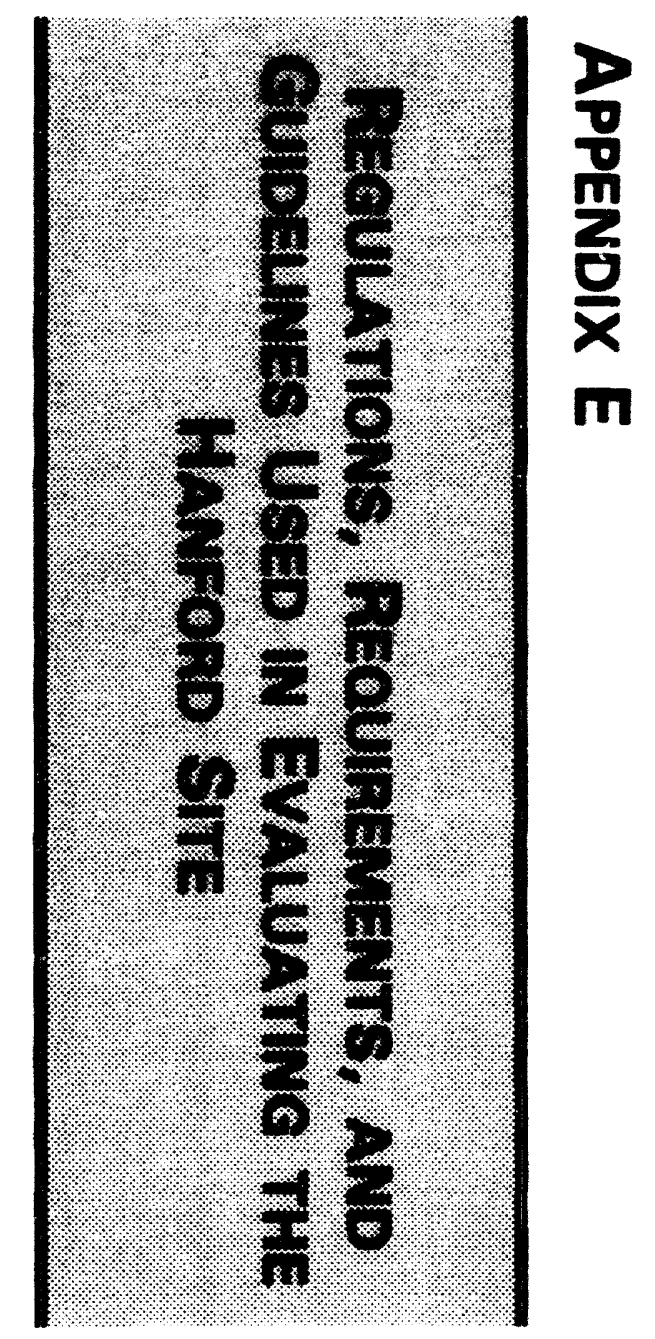




\section{Page intentionally blank}


REGULATION, REQUIREMENTS AND GUIDELINES

USED IN EVALUATING THE HANFORD SITE

\begin{tabular}{|c|c|c|}
\hline 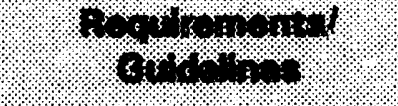 & 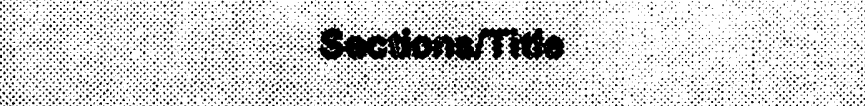 & Authority \\
\hline $\begin{array}{l}\text { Executive Orders } \\
11514 \text { and } 11991\end{array}$ & $\begin{array}{l}\text { Protection and Enhancement of Environmental } \\
\text { Quality }\end{array}$ & $\begin{array}{l}\text { Office of the } \\
\text { President }\end{array}$ \\
\hline $\begin{array}{l}\text { Executive Order } \\
12088\end{array}$ & $\begin{array}{l}\text { Federal Compliance with Pollution Control } \\
\text { Standards }\end{array}$ & $\begin{array}{l}\text { Office of the } \\
\text { President }\end{array}$ \\
\hline $\begin{array}{l}\text { Executive Order } \\
12586\end{array}$ & $\begin{array}{l}\text { Federal Compliance with Right-to-Know Laws } \\
\text { and Pollution Prevention Requirements }\end{array}$ & $\begin{array}{c}\text { Office of the } \\
\text { President }\end{array}$ \\
\hline Public Law 102-386 & Federal Facilities Compliance Act & EPA \\
\hline $\begin{array}{l}33 \text { U.S.C. } 1251 \\
\text { et seq. }\end{array}$ & Clean Water Act & EPA \\
\hline $\begin{array}{l}42 \text { U.S.C. } 13101 . \\
13109\end{array}$ & Pollution Prevention Act & EPA \\
\hline $\begin{array}{l}42 \text { U.S.C. } 6901 \\
\text { et seq. }\end{array}$ & Resource Conservation and Recovery Act & EPA \\
\hline $\begin{array}{l}42 \text { U.S.C. } 7401 \\
\text { et seq. }\end{array}$ & Clean Air Act & EPA \\
\hline SEN 15-90 & & DOE \\
\hline DOE 3410.1B & Training & DOE \\
\hline DOE 4320.1B & Site Development Planning & DOE \\
\hline DOE 4700.1 & Project Management System & DOE \\
\hline DOE 5000.3B & $\begin{array}{l}\text { Occurrence Reporting and Processing of } \\
\text { Operations Information }\end{array}$ & DOE \\
\hline DOE 5100.3 & Field Budget Process & DOE \\
\hline DOE 5400.1 & General Environmental Protection Program & DOE \\
\hline DOE 5400.2A & Environmental Compliance Issue Coordination & DOE \\
\hline DOE 5400.3 & $\begin{array}{l}\text { Hazardous and Radioactive Mixed Waste } \\
\text { Program }\end{array}$ & DOE \\
\hline DOE 5400.5 & $\begin{array}{l}\text { Radiation Protection of the Public and the } \\
\text { Environment }\end{array}$ & DOE \\
\hline DOE 5440.1E & $\begin{array}{l}\text { National Environmental Policy Act Compliance } \\
\text { Program }\end{array}$ & DOE \\
\hline
\end{tabular}


REGULATIONS, REQUIREMENTS AND GUIDELINES

USED IN EVALUATING THE HANFORD SITE (continued)

\begin{tabular}{|c|c|c|}
\hline$\frac{1}{4}$ & Tा? & 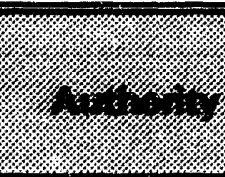 \\
\hline DOE 5480.1B & $\begin{array}{l}\text { Environment, Safety, and Health Program for } \\
\text { Department of Energy Operations }\end{array}$ & DOE \\
\hline DOE 5480.4 & $\begin{array}{l}\text { Environmental Protection, Safety, and Health } \\
\text { Protection Standards }\end{array}$ & DOE \\
\hline DOE 5480.19 & $\begin{array}{l}\text { Conduct of Operations Requirements for DOE } \\
\text { Facilities }\end{array}$ & DOE \\
\hline DOE 5480.20 & $\begin{array}{l}\text { Personnel Selection, Qualification, Training, } \\
\text { and Staffing Requirements at DOE Reactor and } \\
\text { Non-Reactor Nuclear Facilities }\end{array}$ & DOE \\
\hline DOE 5482.1B & $\begin{array}{l}\text { Environment, Safety, and Health Appraisal } \\
\text { Program }\end{array}$ & DOE \\
\hline DOE 5484.1 & $\begin{array}{l}\text { Environmental Protection, Safety, and Health } \\
\text { Protection Information Reporting Requirements }\end{array}$ & DOE \\
\hline DOE 5500.2B & $\begin{array}{l}\text { Emergency Categories Notification Classes, } \\
\text { and Reporting and Requirements }\end{array}$ & DOE \\
\hline DOE 5500.3A & $\begin{array}{l}\text { Planning and Preparedness for Operational } \\
\text { Emergencies }\end{array}$ & DOE \\
\hline DOE 5700.6C & Quality Assurance & DOE \\
\hline DOE 5820.2A & Radioactive Waste Management & DOE \\
\hline DOE 6430.1A & General Design Criteria & DOE \\
\hline DOE/LAT-0070 & $\begin{array}{l}\text { External Dose Conversion Factors for } \\
\text { Calculation of Dose to the Public }\end{array}$ & DOE \\
\hline DOE/EH-OO71 & $\begin{array}{l}\text { Internal Dose Conversion Factors for } \\
\text { Calculation of Dose to the Public }\end{array}$ & DOE \\
\hline DOE/EH-0173T & $\begin{array}{l}\text { Environmental Regulatory Guide for } \\
\text { Radiological Efficient Monitoring and } \\
\text { Environmental Surveillance }\end{array}$ & DOE \\
\hline $\begin{array}{l}\text { January } 1994 \\
\text { Draft Final }\end{array}$ & DOE Environmental Audit Program Guidance & DOE \\
\hline DOE/EH-0256T & Radiological Control Manual & DOE \\
\hline
\end{tabular}


REGULATIONS, REQUIREMENTS AND GUIDELINES

USED IN EVALUATING THE HANFORD SITE (continued)

\begin{tabular}{|c|c|c|}
\hline 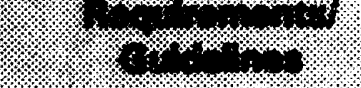 & 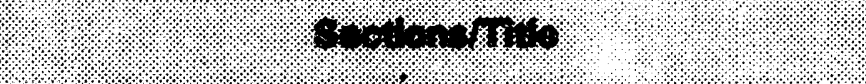 & $4: 3: 4 \%$ \\
\hline DOE/EH-0326 & $\begin{array}{l}\text { Protocols for Conducting Environmental } \\
\text { Management Assessments of DOE } \\
\text { Organizations }\end{array}$ & DOE \\
\hline DOE/EH-0358 & $\begin{array}{l}\text { Performance Objectives and Criteria for } \\
\text { Conducting DOE Environmental Audits }\end{array}$ & DOE \\
\hline $\begin{array}{l}\text { July } 31,1990, \\
\text { Secretarial } \\
\text { Memorandum }\end{array}$ & $\begin{array}{l}\text { Guidance on Environment, Safety, and Health } \\
\text { (ES\&H) Self-Assessment }\end{array}$ & DOE \\
\hline $\begin{array}{l}\text { Interim Guide } \\
\text { March 8, } 1991\end{array}$ & $\begin{array}{l}\text { DOE Guidance on the Procedures in Applying } \\
\text { the ALARA Process for Compliance with DOE } \\
5400.5\end{array}$ & DOE \\
\hline $\begin{array}{l}\text { December } 1992 \\
\text { Guidance }\end{array}$ & Self-Assessment Guidance Document & DOE \\
\hline $\begin{array}{l}\text { November } 1992 \\
\text { Guidance }\end{array}$ & $\begin{array}{l}\text { Environmental Implementation Guide for } \\
\text { Radiological Survey Procedures (Draft) }\end{array}$ & DOE \\
\hline $\begin{array}{l}\text { June } 1993 \\
\text { Secretarial Policy } \\
\text { Statement }\end{array}$ & $\begin{array}{l}\text { Environment, Safety and Health Policy for the } \\
\text { Department of Energy Complex }\end{array}$ & DOE \\
\hline $\begin{array}{l}\text { June } 8,1993 \\
\text { Secretariai Policy } \\
\text { Statement } \\
58 \text { FR } 33804-5 \\
\end{array}$ & Radiological Health and Safety Policy & DOE \\
\hline $\begin{array}{l}\text { March 24, } 1990 \\
\text { Toxicity } \\
\text { Characteristics } \\
\text { Revisions } \\
55 \text { FR } 11798\end{array}$ & $\begin{array}{l}\text { Hazardous Waste Management System, } \\
\text { Identification and Listing of Hazardous Waste }\end{array}$ & \\
\hline 29 CFR 1910.120 & $\begin{array}{l}\text { Hezardous Waste Operations and Emergency } \\
\text { Response }\end{array}$ & EPA \\
\hline 40 CFR 61 & $\begin{array}{l}\text { National Emission Standards for Hazardous Air } \\
\text { Pollutants }\end{array}$ & EPA \\
\hline 40 CFR 82 & Protection of Stratospheric Ozone & EPA \\
\hline 40 CFR 110 & Discharge of Oil & EPA \\
\hline 40 CFR 112 & Oil Pollution Prevention & EPA \\
\hline
\end{tabular}


REGULATIONS, REQUIREMENTS AND GUIDELINES USED IN EVALUATING THE HANFORD SITE (continued)

\begin{tabular}{|c|c|c|}
\hline ( & 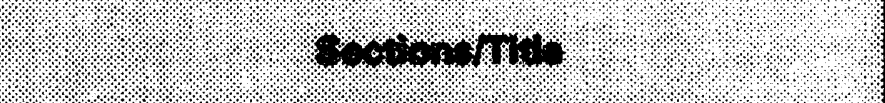 & 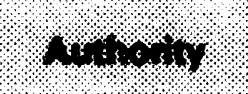 \\
\hline 40 CFR $122 / 123$ & $\begin{array}{l}\text { National Pollutant Discharge Elimination } \\
\text { System (NPDES)/State Pollutant Discharge } \\
\text { Elimination System (SPDES) }\end{array}$ & EPA \\
\hline 40 CFR 141 & National Primary Drinking Water Regulations & EPA \\
\hline 40 CFR 142 & $\begin{array}{l}\text { National Primary Drinking Water Regulations } \\
\text { Implementation }\end{array}$ & EPA \\
\hline 40 CFR 143 & National Secondary Drinking Water Regulations & EPA \\
\hline 40 CFR 191 & $\begin{array}{l}\text { Environmental Radiation Protection Standards } \\
\text { for Management and Disposal of Spent Nuclear } \\
\text { Fuel, High-Level and Transuranic Radioactive } \\
\text { Wastes }\end{array}$ & EPA \\
\hline 40 CFR 262 & $\begin{array}{l}\text { Standards Applicable to Generators of } \\
\text { Hazardous Waste }\end{array}$ & EPA \\
\hline 40 CFR 264 & $\begin{array}{l}\text { Standards for Owners and Operators of } \\
\text { Hazardous Waste Treatment, Storage, and } \\
\text { Disposal Facilities }\end{array}$ & EPA \\
\hline 40 CFR 265 & $\begin{array}{l}\text { Interim Status Standards for Owners and } \\
\text { Operators of Hazardous Waste Treatment, } \\
\text { Storage, and Disposal Facilities }\end{array}$ & EPA \\
\hline 40 CFR 268 & Land Disposal Restrictions & EPA \\
\hline CERCLA & Section 120 Federal Facilities & EPA \\
\hline EPA-520/1-88-020 & $\begin{array}{l}\text { Limiting Values of Radionuclide Intake and Air } \\
\text { Concentration and Dose Conversion Factors for } \\
\text { Inhalation, Submersion, and Ingestion - Federal } \\
\text { Guidance Report No. } 11\end{array}$ & EPA \\
\hline ASME NOA-1-1989 & $\begin{array}{l}\text { Quality Assurance Program for Nuclear } \\
\text { Facilities }\end{array}$ & ANSI/ASME \\
\hline ANSI N13.1-1969 & $\begin{array}{l}\text { Guide to Sampling Airborne Radioactive } \\
\text { Materials in Nuclear Facilities }\end{array}$ & ANSI \\
\hline WAC $173-160$ & $\begin{array}{l}\text { Minimum Standards for Construction and } \\
\text { Maintenance of Wells }\end{array}$ & WDOE \\
\hline
\end{tabular}


REGULATIONS, REQUIREMENTS AND GUIDELINES

USED IN EVALUATING THE HANFORD SITE (continued)

\begin{tabular}{|c|c|c|}
\hline 9. om & 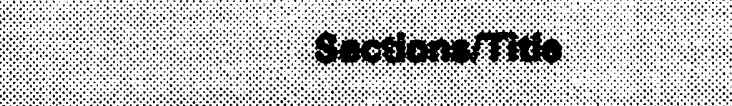 & $43: 4,40 \%$ \\
\hline WAC 173-216 & State Waste Discharge Permit Program & WDOE \\
\hline \multicolumn{3}{|l|}{ WAC 173-303 } \\
\hline RCW 90.44 & Regulation of Public Groundwater & WDOE \\
\hline
\end{tabular}


Page intentionally blank

$$
\text { E-6 }
$$




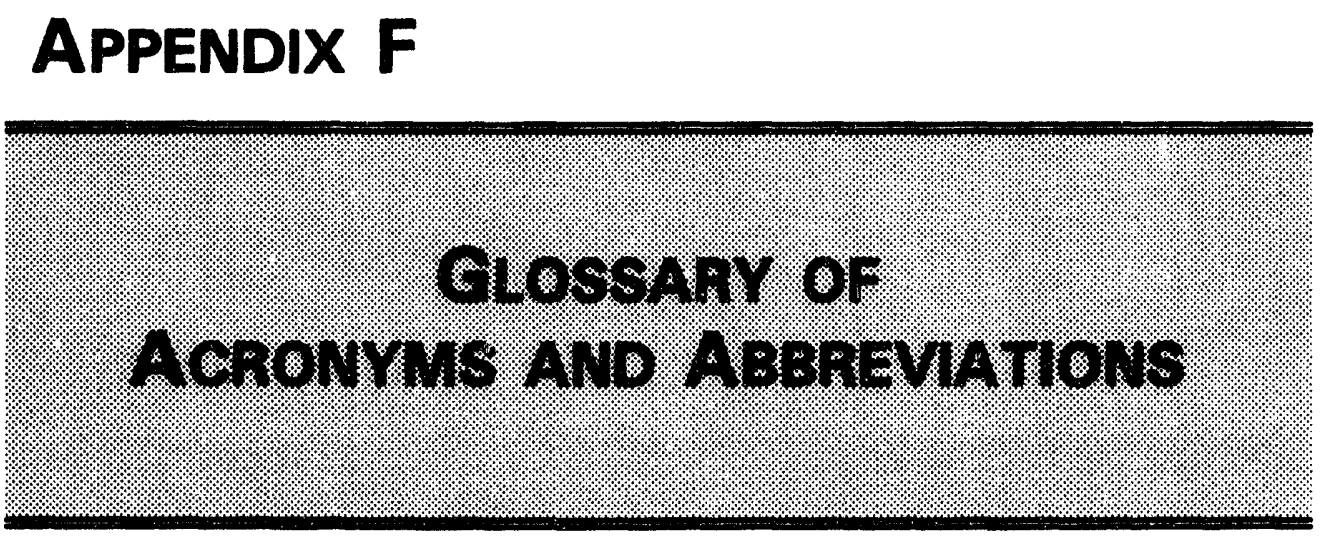


Page intentionally blank 


\section{GLOSSARY OF ACRONYMS AND ABBREVIATIONS}

\begin{tabular}{|c|c|}
\hline Acronym & Dofinition \\
\hline ADS & Activity Data Sheet \\
\hline ALARA & As Low As Reasonably Achievable \\
\hline ASSP & Analytical Support Services Project \\
\hline BED & Building Emergency Directors \\
\hline BEP & Building Emergency Plan \\
\hline $\mathrm{BHI}$ & Bechtel Hanford, Inc. \\
\hline CATS & Compliance Action Tracking System \\
\hline CEC & Central Environmental Committee \\
\hline CERCLA & $\begin{array}{l}\text { Comprehensive Environmental Response, Compensation, and } \\
\text { Liability Act }\end{array}$ \\
\hline CFR & Code of Federal Regulations \\
\hline CICS & Central Information Control System \\
\hline $\mathrm{CY}$ & Calendar Year \\
\hline D\&D & Decontamination and Decommissioning \\
\hline DOE* & U.S. Department of Energy \\
\hline DOE HQ & U.S. Department of Energy - Headquarters \\
\hline DP & Defense Programs \\
\hline EH & DOE Office of Environment, Safety and Health \\
\hline EH-5 & DOE Office of Special Projects \\
\hline EH-24 & DOE Office of Environmental Audit \\
\hline EM & $\begin{array}{l}\text { Office of Environmental Management (formerly Office of } \\
\text { Environmental Restoration and Waste Management) }\end{array}$ \\
\hline EMP & Environmental Monitoring Plan \\
\hline EPA * & U.S. Environmental Protection Agency \\
\hline EPIP & Environmental Protection Implementation Plan \\
\hline EP & Environmental Protection Programs \\
\hline ES\&H & Environment, Safety \& Health \\
\hline FEMP & Facility Effluent Monitoring Plan \\
\hline FFCA & Federal Facilities Compliance Act \\
\hline
\end{tabular}


GLOSSARY OF ACRONYMS AND ABBI EVIATIONS (continued)

\begin{tabular}{|c|c|}
\hline Acronym & Definition \\
\hline FFTF & Fast Flux Test Facility \\
\hline FR & Federal Register \\
\hline FTE & Full-Time Equivalent \\
\hline FY & Fiscal Year \\
\hline GPMP & Groundwater Protection Management Program \\
\hline GPMPP & Groundwater Protection Management Program Plan \\
\hline HEHF & Hanford Environmental Health Foundation \\
\hline $\begin{array}{l}\text { HEHF-Industrial } \\
\text { Hygiene Services }\end{array}$ & Hanford Environmental Management Program \\
\hline HSADB & Hanford Self-Assessment DataBase \\
\hline ICF KH & ICF Kaiser Hanford Company \\
\hline MMP & Meteorological Monitoring Plan \\
\hline MOU & Memorandum of Understanding \\
\hline NEPA & National Environmental Policy Act \\
\hline NESHAPS & National Emission Standards for Hazardous Air Pollutants \\
\hline NPDES & National Pollutant Discharge Elimination System \\
\hline ODC & Ozone Depleting Chemical \\
\hline OEM & Operational Environmental Monitoring Program \\
\hline PNL* & Pacific Northwest Laboratory \\
\hline PNL-EESC & PNL-Field Sampling and Analysis Group \\
\hline PNL-F\&O & PNL-Facilities \& Operations \\
\hline PNL-HGC & PNL-Hydrogeologic and Geochemical Characterization \\
\hline PNL-HRAD & PNL-Health Physics \\
\hline PNL-OHE & PNL-Office of Health and Environment \\
\hline PP & Pollution Prevention \\
\hline PPAP & Pollution Prevention Awareness Program \\
\hline QA & Quality Assurance \\
\hline QUEST & Quality, Environmental, and Safety Tracking \\
\hline
\end{tabular}


GLOSSARY OF ACRONYMS AND ABBREVIATIONS (continued)

\begin{tabular}{|l|l|}
\hline \multicolumn{1}{|c|}{ ACronym } & \\
\hline R\&D & Research and Development \\
\hline RBP & Risk-Based Prioritization \\
\hline RCRA & Resource Conservation and Recovery Act \\
\hline RCW & Revised Code of Washington \\
\hline RL* & U.S. Department of Energy - Richland Operations Office \\
\hline RL-CFO & RL-Office of Chief Financial Officer \\
\hline RL-EAP & RL-Office of Environmental Assurance, Permits and Policy \\
\hline RL-EPD & RL-Environmental Protection Division \\
\hline RL-ERD & RL-Environmental Remediation Division \\
\hline RL-LMD & RL-Laboratory Management Division \\
\hline RL-OPA & RL-Office of Performance Assessment \\
\hline RL-OTR & RL-Office of Training \& Education \\
\hline RL-OSH & RL-Quality, Safety, and Health Programs Division \\
\hline RL-WMD & RL-Waste Management Division \\
\hline SDWA & Safe Drinking Water Act \\
\hline SEN & Secretary of Energy Notice \\
\hline TPA & Tri-Party Agreement \\
\hline TSD & Treatment, Storage, Disposal \\
\hline TWRS & Tank Waste Remediation Systems \\
\hline USACE & U.S. Army Corps of Engineers \\
\hline UST & Underground Storage Tank \\
\hline WAC & Washington Administrative Code \\
\hline WDOE & Washington State Department of Ecology \\
\hline WDOH & Washington State Department of Health \\
\hline WHC* & Westinghouse Hanford Company \\
\hline WHC-ER & WHC-Environmental Remediation Division \\
\hline WHC-ESO & WHC-Emergency, Safety, Quality Services \\
\hline WHC-HRD & WHC-Human Resources Division \\
\hline
\end{tabular}




\section{GLOSSARY OF ACRONYMS AND ABBREVIATIONS (continued)}

\begin{tabular}{|l|l|}
\hline \multicolumn{1}{|c|}{ ACronym } & \multicolumn{1}{c|}{ Definition } \\
\hline WHC-RR & WHC-Environmental Restoration Program Transition \\
\hline WHC-TRS & Training \\
\hline WHC-WAE & WHC-Waste, Analytical, and Environmental Services \\
\hline WM & Waste Management \\
\hline WSLECO & Washington State Liquid Effluent Consent Order \\
\hline
\end{tabular}

"These commonly used acronyms are spelled out only on first reference in the report. All others are spelled out on first reference in each subsection. 

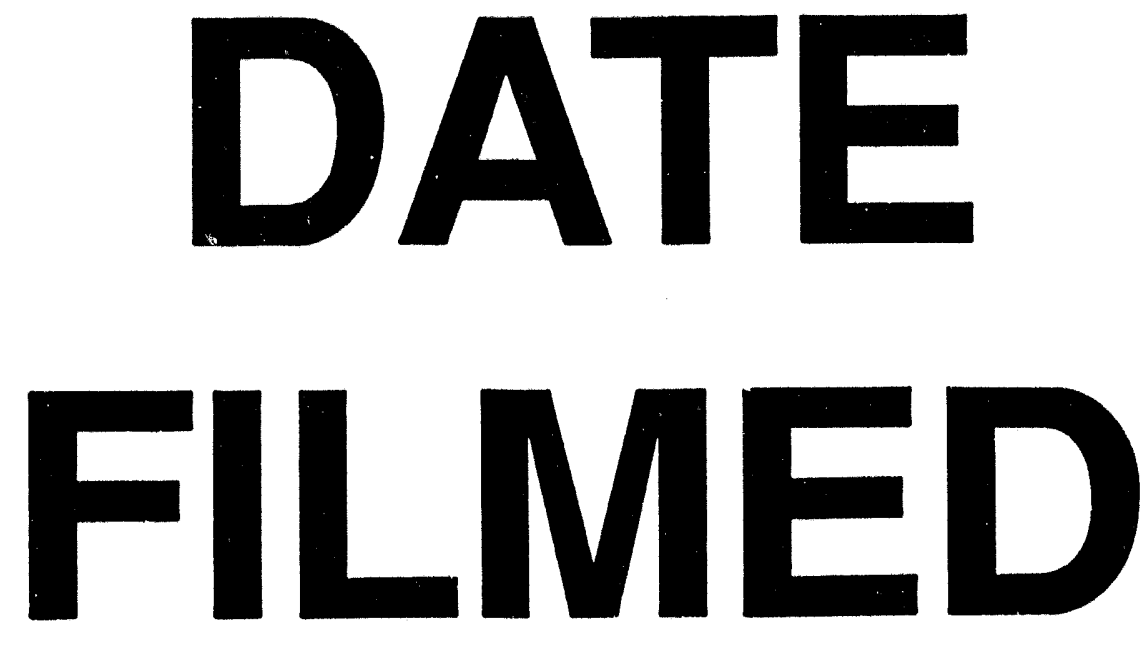

$10 / 24 / 94$
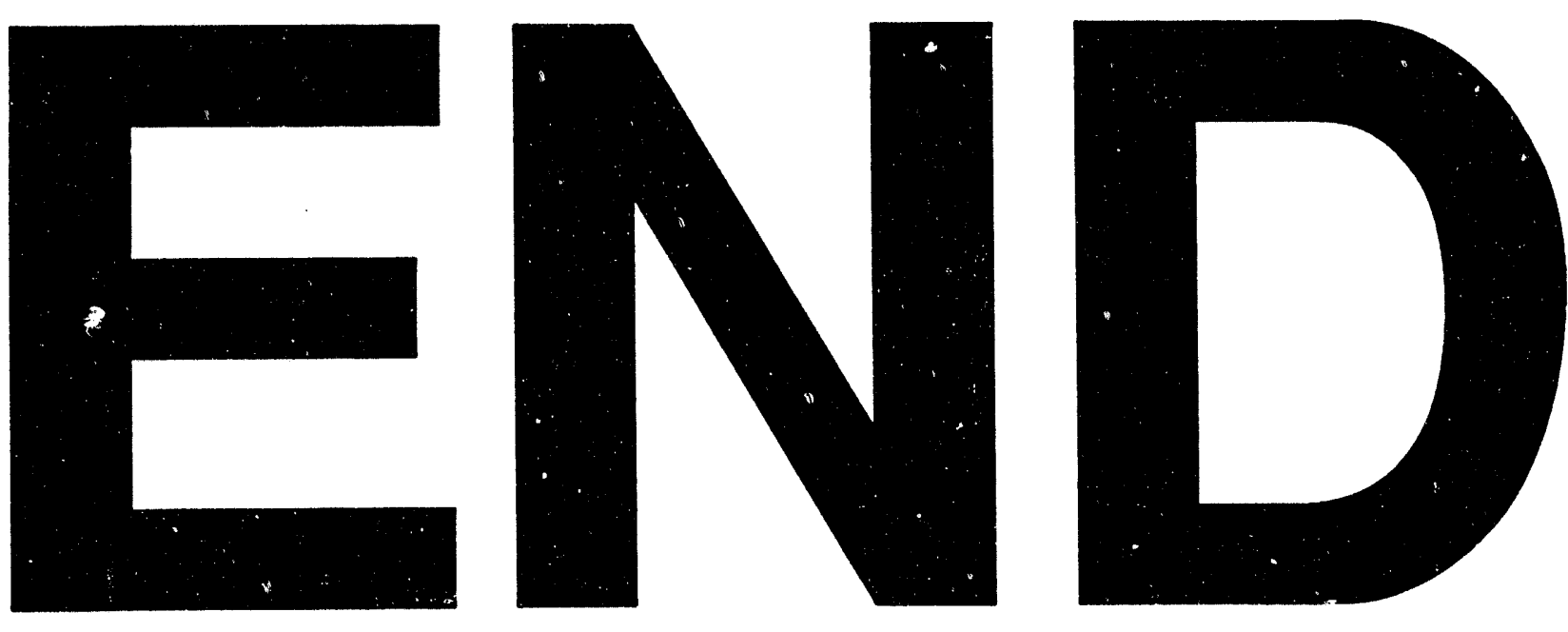
